\title{
SIMULATION OF PROGRESSIVE SHEAR FAILURE IN RAILWAY FOUNDATION
}

\author{
Xu Dong Li
}

A thesis submitted to the examination committee in Partial Fulfillment of the requirements for the degree of

\section{DOCTOR OF PHILOSOPHY IN CIVIL ENGINEERING}

A joint program between Carleton University and University of Ottawa, which is administered by the Ottawa-Carleton Institute for Civil Engineering

Department of Civil Engineering

Faculty of Engineering

University of Ottawa

Ottawa, Ontario, Canada

(C) Xu Dong Li, Ottawa, Canada, 2020 


\begin{abstract}
Railways are one of the largest transportation networks in the world that play an important role in the mass transportation of both the passengers and freight. The speed of trains and as well as the axial load carrying capacity have been increasing significantly during the past few decades to keep in pace with the population and economy growth and to compete with other modes of transportation such as the road, air and water transportation system. Billions of dollars are spent annually for maintenance of rail tracks in the world. The efficient and optimum use of these funds is a challenging task that demands innovative and cutting edge technologies in railway engineering.

The railway subgrade is an important part of railway foundation and should be capable of providing a suitable base supporting the ballast and subballast to accommodate the stresses due to traffic loads without failure or excessive deformation. The progressive shear failure is a wellknown and age old challenging problem for railways over the world for centuries. The subgrade of railway track which typically constitutes of fine-grained material tends to fail through the accumulation of soil movements up- and sideward developing a path for the least resistance along which progressive shear failure occurs under repeated train-induced loads and due to the effects of climate factors. To-date, limited number of studies have addressed failure mechanism associated with the progressive shear failure, especially using the mechanics of unsaturated soils.

In this thesis, a novel and first of its kind, Visual Basic program developed in AutoCAD environment based on Mohr-Coulomb failure criteria and unsaturated soil mechanics theory. This program is capable of taking account of the influence of matric suction and simulate progressive shear failure in the subgrade under moving train. Simulation results suggest several parameters that include stress distribution, matric suction, cohesion, coefficient of lateral earth pressure at rest, and coefficient of residual friction as well as the angle of internal friction have a significant effect on the progressive shear failure and the shape of failure planes in the subgrade. The progressive shear failure in subgrade can be reduced by increasing matric suction, cohesion, coefficient of lateral earth pressure at rest, and coefficient of residual friction as well as the angle of internal friction, and optimizing combination of these parameters.
\end{abstract}


The simulation results suggest the progressive shear failure can be well simulated with the MohrCoulomb failure criteria. Several suggestions are made for railway subgrade construction and maintenance based on the results of this study. 


\section{ACKNOWLEDGMENTS}

Studies presented in this thesis were conducted at the Department of Civil Engineering, University of Ottawa under the supervision of Prof. Sai K. Vanapalli. I am so proud to be Dr. Vanapalli's student and benefit my research from his encouragement, enlightened supervision and insightful suggestions. I sincerely thank Dr. Vanapalli's continuous supports and supervision on my way towards exploring the mysteries of unsaturated soils and broadening my horizon and vision.

The financial supports of Admission Scholarship received from the University of Ottawa are gratefully acknowledged.

My appreciations extend to my colleagues at the University of Ottawa for their friendship, company and support. They are: Mengxi Tan, Shunchao Qi, Mohammed Al-Khazaali, Yunlong Liu, Hongyu Tu, Penghai Yin, Zhong Han and Weilie Zou.

I would like to express my sincere thanks to my wife and three sons for their love and supports that provided me the energy and encouragement to complete this $\mathrm{PhD}$ thesis. 


\section{CONTENTS}

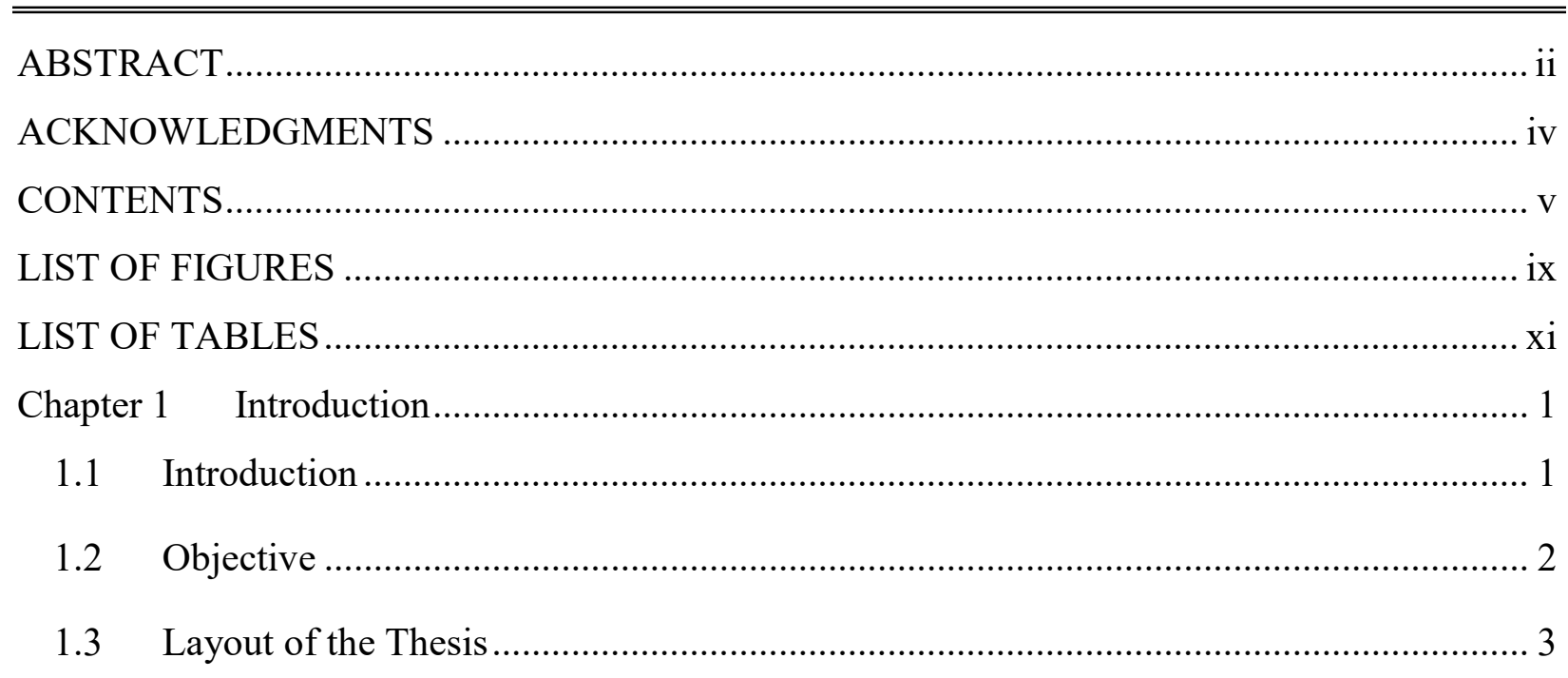

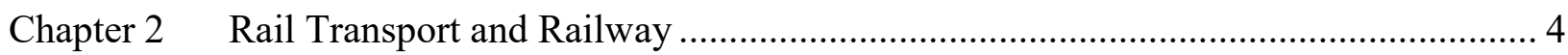

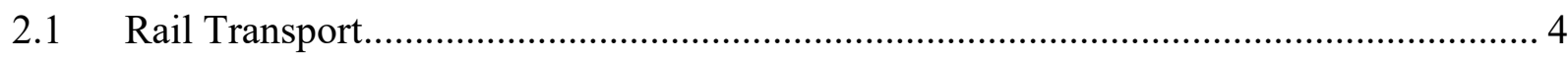

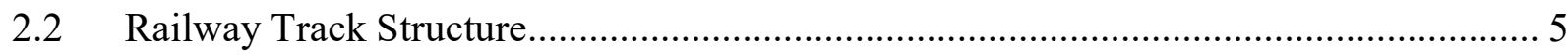

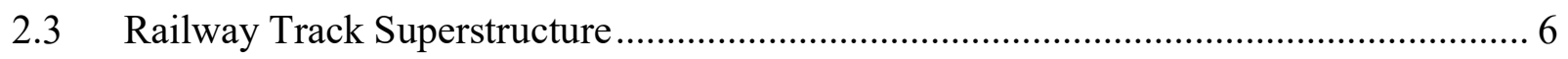

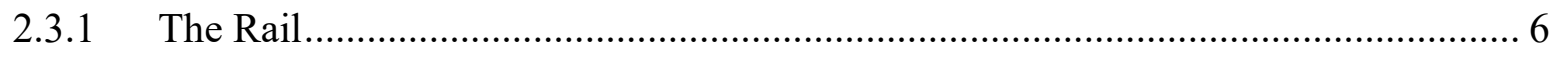

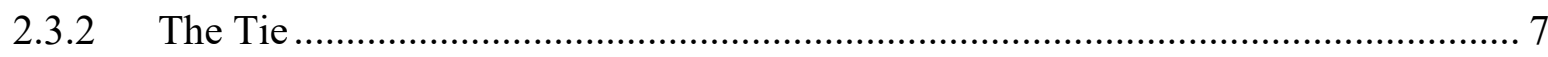

2.3.3 The Fasteners …………………………………....................................... 8

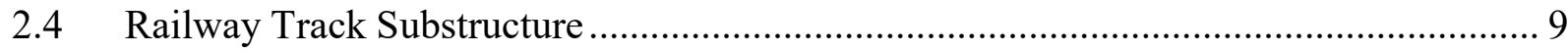

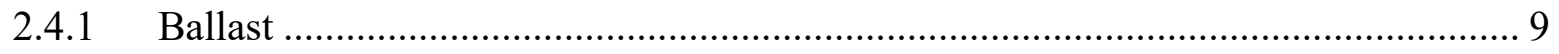

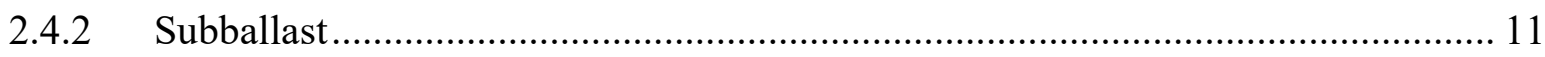

2.4.3 Subgrade (trackbed, formation) …………….................................................. 12

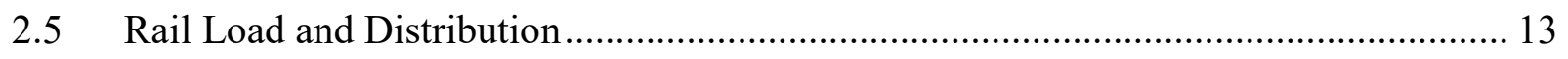

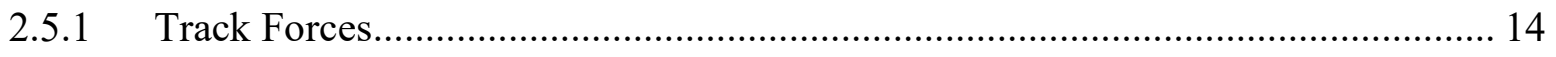

2.5.2 Load Transmission in Track Foundation .............................................................. 18

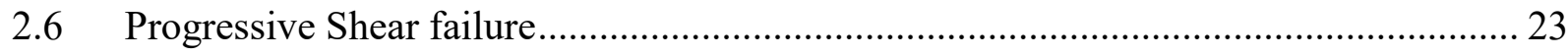

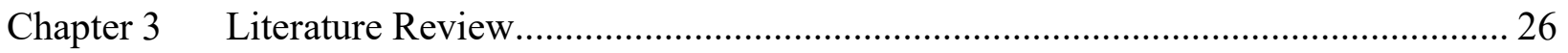




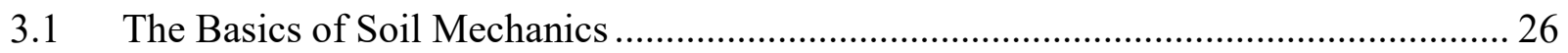

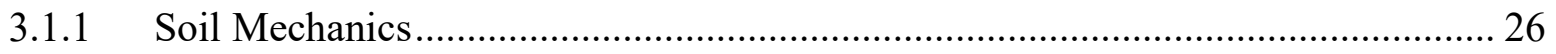

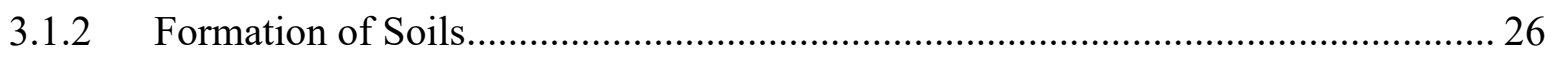

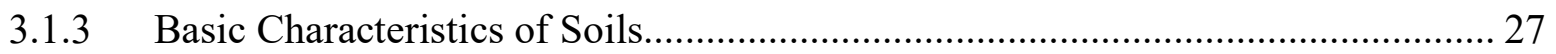

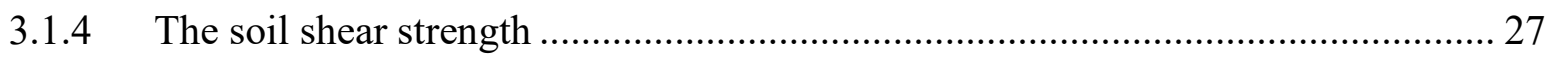

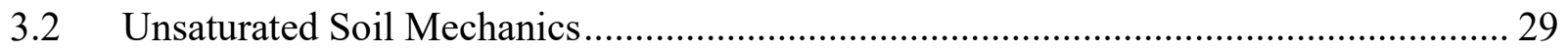

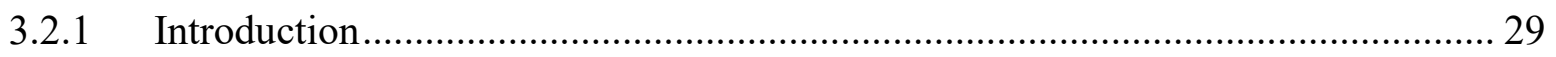

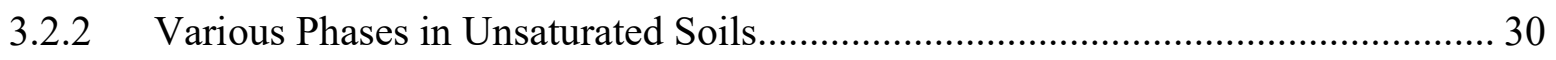

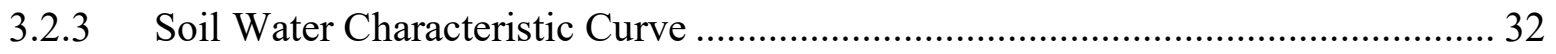

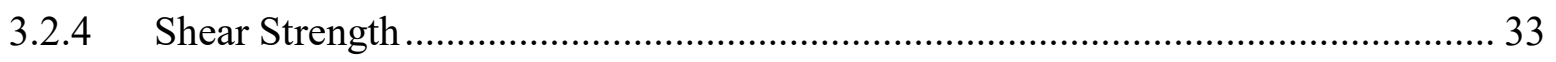

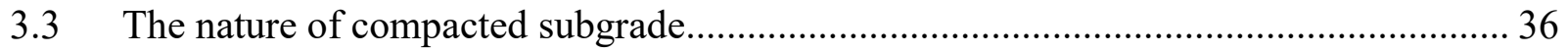

3.4 The Coefficient of Earth Pressure at Rest .................................................................... 40

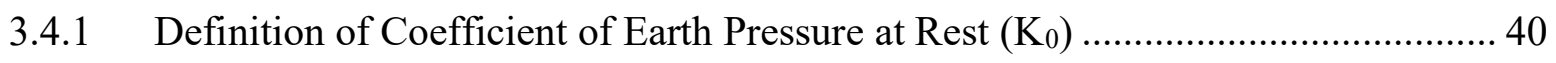

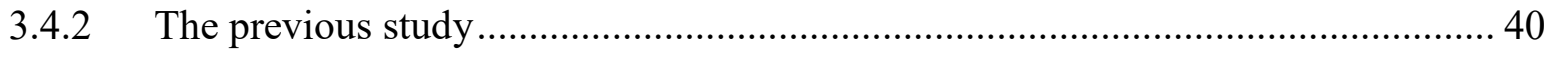

3.4.3 The factors influencing the value of coefficient of earth pressure at rest............... 42

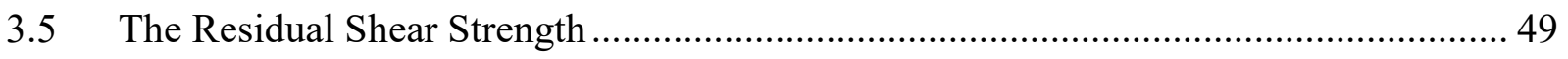

3.5.1 Drained residual strength of cohesive soils ......................................................... 49

3.5.2 Correlation for residual strength .......................................................................... 51

3.5.3 Residual Shear Strength Mobilized in First-Time Slope Failures ........................... 51

3.5.4 Residual shear strength of unsaturated soils via suction-controlled ring shear testing 53

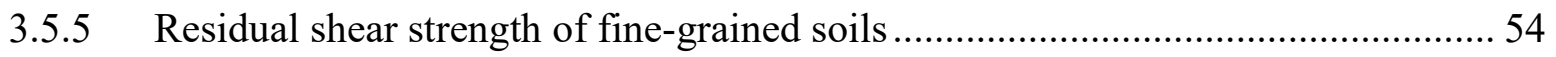

3.5.6 Drained residual shear strength at effective normal stresses relevant to soil slope

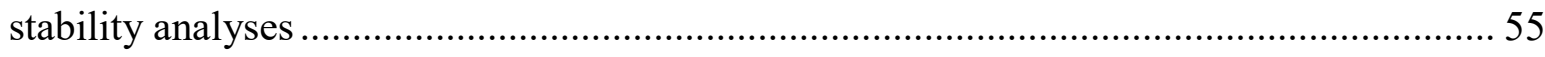

3.5.7 Influence of displacement rate on residual shear strength of clays ......................... 56

3.5.8 Effect of shear rate on the residual shear strength of pre-sheared clays .................. 57 
Chapter 4 Simulation of Progressive Shear Failure in Subgrade ....................................... 58

4.1 Assumptions of progressive shear failure in Subgrade ......................................... 58

4.2 Shear Failure Criterion and Stresses in Subgrade ................................................... 62

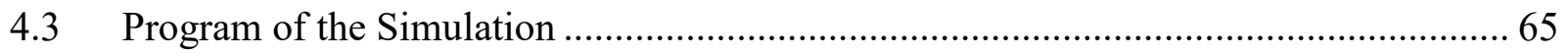

Chapter 5 Simulation results of Progressive shear failure in subgrade ............................... 67

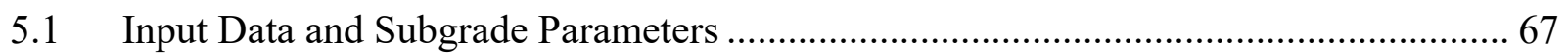

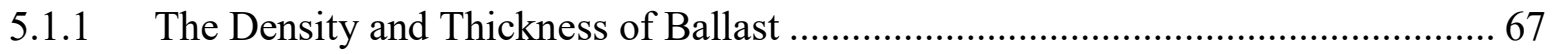

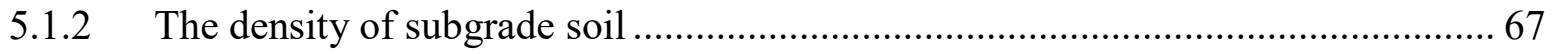

5.1.3 The effective cohesion of subgrade soil and matric suction, $c$.......................... 68

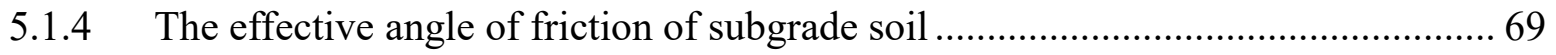

5.1.5 The coefficient of earth pressure at rest ................................................... 71

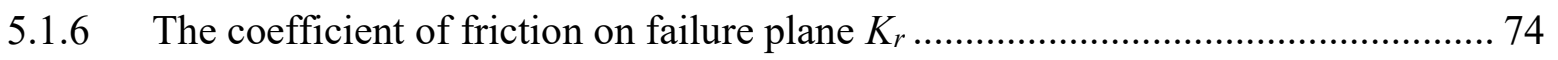

5.1.7 The Stress Distribution in Railway Subgrade .............................................. 79

5.2 Result of Simulation for Point Load ............................................................... 81

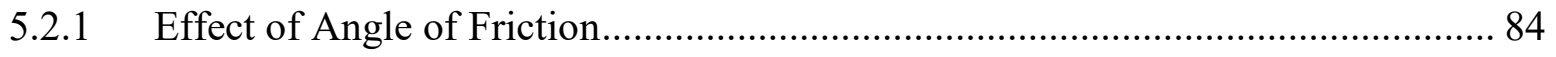

5.2.2 Effect of Subgrade Effective Cohesion..................................................... 85

5.2.3 Effect of Coefficient of Earth Pressure at Rest............................................. 86

5.2.4 Effect of Coefficient of Friction on Failure Plane .......................................... 87

$5.3 \quad$ Result of Simulation for normal spreading load ….......................................... 88

5.3.1 Effect of Stress Distribution to Progressive Shear Failure ................................ 90

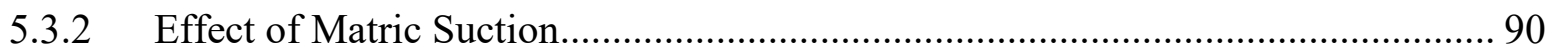

5.3.3 Effect of frication angle, cohesion and coefficient of earth pressure at rest......... 91

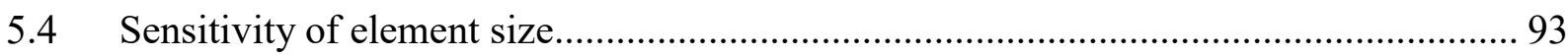

Chapter 6 Conclusions and Suggestions for the Future Research ................................... 95

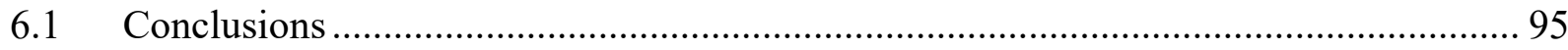

6.2 Recommendations for Subgrade Design and Maintenance ..................................... 96 
6.2.1 Reduce the uneven stress distribution in railway subgrade ............................. 96

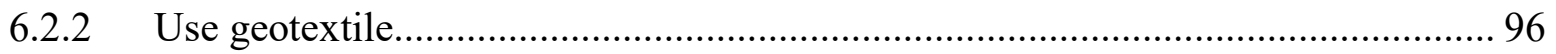

6.2.3 Use high-qualified materials for subgrade ................................................... 96

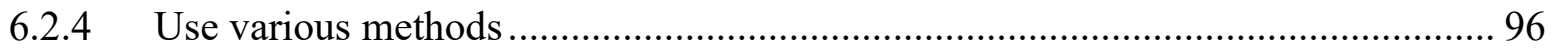

6.3 Suggestion for the Future Research .................................................................. 97

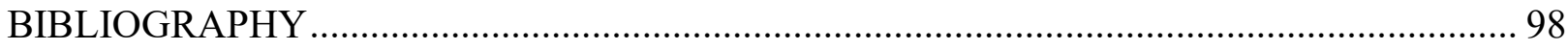

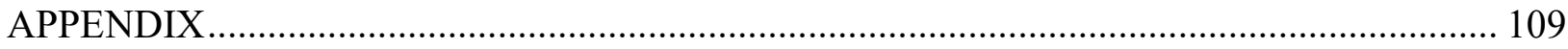

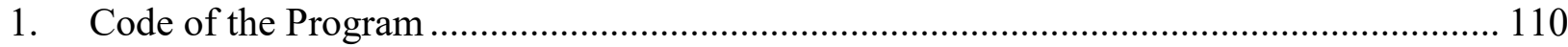

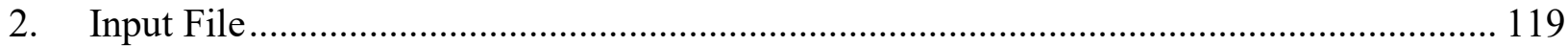

3. Result of Simulation for Point Load .................................................................... 123

4. Result of Simulation for Normal Spreading Load ................................................. 157 


\section{LIST OF FIGURES}

Figure 2-1 Elements of railway infrastructure (from Li et al., 2016) ....................................... 5

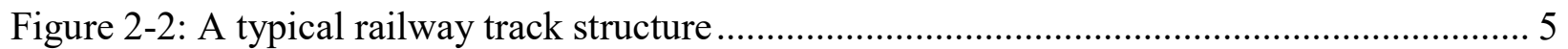

Figure 2-3 Rail (https://www.bemorail.com/portfolio-item/vignola-rail) ................................. 7

Figure 2-4 Railway Ties and fastening systems (https://www.bemorail.com/portfolio-

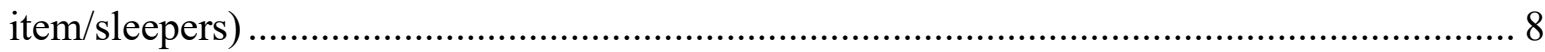

Figure 2-5 Ballast (https://www.123rf.com/photo_93877176\&75780006) .............................. 9

Figure 2-6 Quasi-static vehicle forces on a curve track (from Indraratna et al., 2011) .............. 16

Figure 2-7 Stresses in track foundation ( $\mathrm{Li}$ et al. 2016) ...................................................... 19

Figure 2-8 Load transmission from rail downward along (a) and across (b) concrete and wood

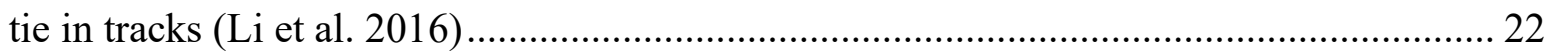

Figure 2-9 Subgrade progressive shear failure (Burrow et al., 2011)................................ 24

Figure 3-1 Mohr Coulomb shear failure criterion with Mohr circle of stress ........................ 28

Figure 3-2 Soil-water characteristic curve and its various zones (modified after Vanapalli et al.

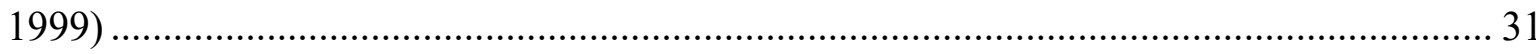

Figure 3-3 Bounding and scanning curves that comprisethe drying and wetting behavior of an

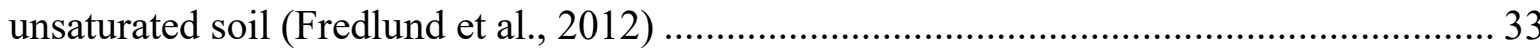

Figure 3-4 Extended Mohr-Coulomb failure surface written as a function of the stress state

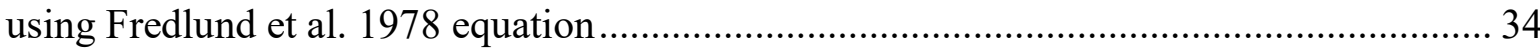

Figure 3-5 Curvature to the shear strength envelope with respect to matric suction (modified

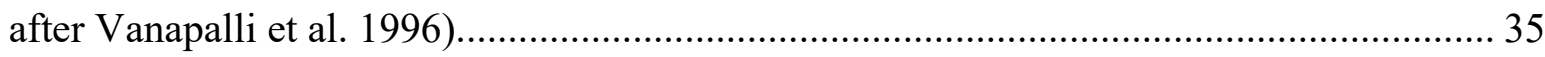

Figure 3-6 SWCC Curve and its relationship with shear strength (modified after Vanapalli et

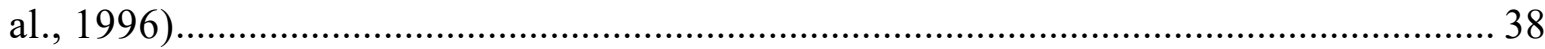

Figure 3-7 $K_{0}$, Relationship of radial versus axial stress for Reid-Bedford sand (Al-Hussaini, 1981)

Figure 3-8 Variation of vertical and horizontal stresses during loading and unloading

(Sivakumar et al. 2002).

Figure 4-1 Subgrade squeeze at end of tie (Li et al., 2016): (a) track cross section with a subgrade squeeze and (b) subgrade squeeze and lime injection hole 
Figure 4-2 Failure elements and plane in Subgrade.

Figure 4-3 Failure element and its stresses: a. Stress status and failure plane in an element. b. New stresses status as the unbalanced shear stress from previous element is transferred in. c. Calculating new major principle stress according to initial principle stresses and unballanced shear stress from previous element.

Figure 5-1 Subgrade stress distribution below geocell-reinforced embankment overlying very soft foundation (2 MPa) (Leshchinsky, 2012).

Figure 5-2 Subgrade stress distribution below geocell-reinforced embankment overlying soft foundation (20 MPa) (Leshchinsky, 2012). 81

Figure 5-3 Failure planes of simulation for point load ................................................. 83

Figure 5-4 Effect of Angle of Friction to progressive shear failure ...................................... 84

Figure 5-5 Effect of Subgrade Effective Cohesion to progressive shear failure ...................... 85

Figure 5-6 Effect of Coefficient of Earth Pressure at Rest to progressive shear failure............ 86

Figure 5-7 Effect of Coefficient of residual Friction on Failure Plane................................. 87

Figure 5-8 Failure planes under normal spreading load ..................................................... 90

Figure 5-9 Effect of Matric Suction to Progressive Shear Failure ........................................ 91

Figure 5-10 The relationship of frication angle $\phi^{\prime}$, cohesion $c^{\prime}$ and coefficient of earth pressure at

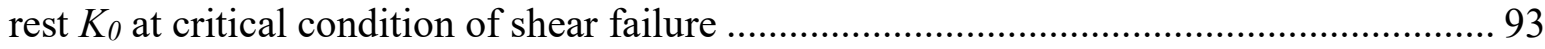

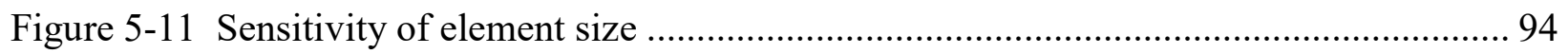




\section{LIST OF TABLES}

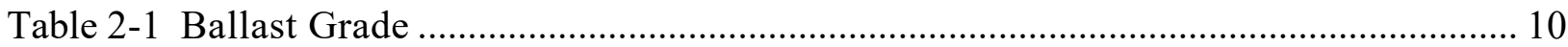

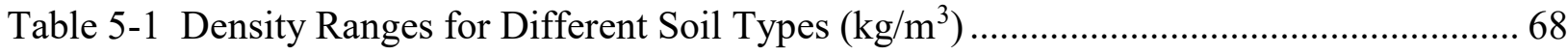

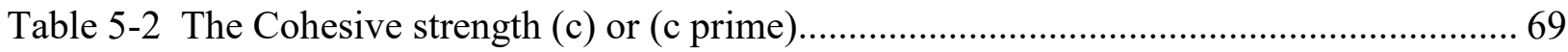

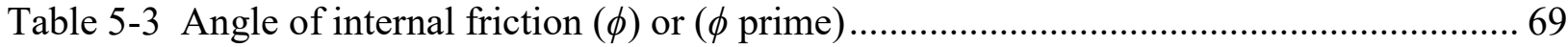

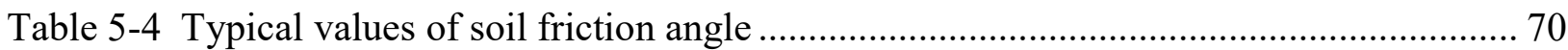

Table 5-5 Values of $K_{0}$ for the sand tested by (Al-Hussaini, 1981) .......................................... 71

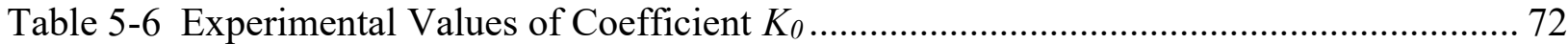

Table 5-7 Index Properties, Mineralogical Composition, and residual friction angle of Natural

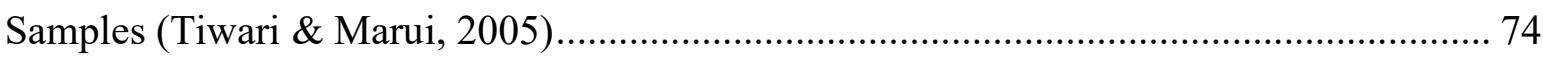

Table 5-8 Reactivated landslides and reported soil residual shear strength correlations (Eid et

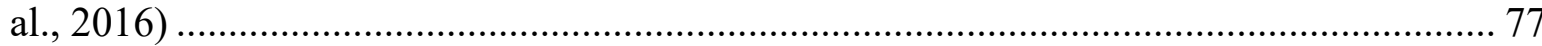

Table 5-9 Model material properties (Leshchinsky \& Ling, 2013) …………………….............. 80

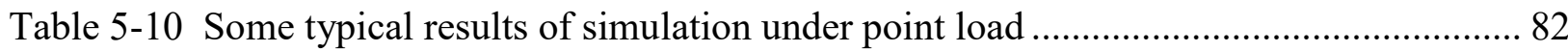

Table 5-11 Some typical results of the simulation under normal spreading load........................ 89

Table 5-12 The relationship of frication angle $\phi^{\prime}$, cohesion $c^{\prime}$ and coefficient of earth pressure at rest $K_{0}$ at critical condition of shear failure .................................................................... 92 


\section{CHAPTER 1}

\section{INTRODUCTION}

\subsection{Introduction}

Rail transport is one of the most commonly used, cost effective and the largest transportation modes in various countries of the world. For the past two centuries, railways served people all over the world by transporting passengers, freight and bulk commodities among major cities, ports, mines and sources of agricultural goods, as well as commuters to contribute to the economic development.

There are 1.1 million kilometers of railway lines in the world, 7 million personnel working in the railway industry, 3.9 trillion passenger-kilometers, and 10.6 trillion ton-kilometers of freight are transported by railway per year, according to data from International Union of Railways (UIC) (Railisa, 2018).

To keep pace with the growth in population and economies and to compete with other modes of transportation such as road, air and water transport with respect to speed and carrying capacity, axial loads must increase and maintenance costs must reduce in order to improve efficiency. Countries such as Canada, China, USA, India and Australia are playing a leading role in the development of heavy haul railway operations that include 3-4 km long trains with axle loads exceeding 35 tons to optimize the efficiency of supply chains in the mining and agricultural sectors (Indraratna, 2016). On one front, this implies continuous needs for upgrading the railway tracks; and, on the other hand, there are challenges for adopting innovative technology to minimize construction and maintenance costs.

Billions of dollars are spent annually for the construction and maintenance of railway tracks in many countries. Euro Rail Consult (Jovanovic, 2016) studied the maintenance costs of railway infrastructure and concluded average $50 €$ costed per meter of railway per year on conventional lines in Western Europe. This translates to approximately $\$ 50$ billion dollars annually for 
maintenance costs worldwide. The efficient and optimum use of these funds is a challenging task which demands innovative and edge-cutting technologies in railway engineering (Indraratna et al., 2011).

\subsection{Objective}

The progressive shear failure is a well-known and age old problem for railways all over the world for centuries. The subgrade of railway track that is typically made of fine-grained materials tends to fail through the cumulative accumulation of plastic strain and reduction of the shear strength associated with repeated train-induced loads and due to the effects of climate factors (Li et al., 2016). Because of repeated cycles of overstressing, surface soil moves up- and sideward developing a path for the least resistance along which progressive shear failure occurs. The progressive shear failure is one of the most common causes for railway subgrade failure (Hendry et al. 2013; Li, 2018; Miller et al. 2000). Several research studies (Boler et al. 2018; Dareeju, 2017; Dey et al. 2010; Loh, 2011; Sánchez et al. 2014) addressed the progressive shear failure in railway subgrade focusing on studying subgrade deformation and stress in ballast and subgrade. The focus of some these studies were directed to propose design solutions to alleviate the occurrence of progressive shear failure. In addition, some of the studies suggested methods for subgrade repair to reduce the progressive shear failure in the existing railway.

To-date, very few studies ( Li \& Selig, 1995) have focused in detail and addressed the process and mechanism of progressive shear failure in railway subgrade. In this thesis, a first of its kind and novel Visual Basic computer program is developed in AutoCAD environment to simulate the process of progressive shear failure. This program is capable to suggest the failure planes based on Mohr-Coulomb failure criteria extending unsaturated soil mechanics. This program facilitates to take into account of the influence of matric suction. In this thesis, 2800 simulations have been conducted to understand mechanics of progressive shear failure and locate failure plane in the subgrade. In this study, the influence of stress distribution under bottom of ballast and other parameters which include matric suction, cohesion, coefficient of lateral earth pressure at rest, and coefficient of residual friction as well as the angle of internal friction are considered to analyze the progressive shear failure conditions. Based on the study results, improved design 
and mitigation methods are suggested that can contribute to prevent or drastically reduce progressive shear failure development and repair failed track foundation.

\subsection{Layout of the Thesis}

This thesis is organized as a "Monograph Thesis". This thesis is summarized six chapters. The main contents of each of these six chapters are briefly described below:

1) Chapter One, entitled "Introduction", presents the introduction, objective, novelty and layout of the thesis.

2) Chapter Two, entitled "Rail Transport and Railway" provides a succinct background of rail transport and railway track structure, and load transmission in track foundation, as well as progressive shear failure in railway subgrade.

3) Chapter Three, entitled "Literature Review" consists of a comprehensive state-of-the-art review on soil mechanics and unsaturated soil mechanics as well as soil properties related to its strength.

4) Chapter Four, entitled "Simulation of Progressive Shear Failure in Subgrade", explain the mechanics of simulating progressive shear failure and its principle equations as well as program.

5) Chapter Five, entitled "Simulation Result of Progressive Shear Failure in Subgrade", consists of detail of the input data selections and discussing the simulation results.

6) Chapter Six, entitled "Conclusion and Suggestions for the Future Research", presents conclusion, recommendation for railway subgrade design and construction, and suggestions for the future research.

In addition, Bibliography summarizes references cited in this thesis and Appendix, containing the code of program, one input data file and two output data tables. 


\section{CHAPTER 2}

\section{RAIL TRANSPORT AND RAILWAY}

This Chapter presents basic knowledge of railway track structures and its foundation, as well as the stress distribution in railway foundations and the mechanism associated with the progressive shear failure.

\subsection{Rail Transport}

Rail transport is also known as train transport (Wikipedia, 2020). It is a means of transport, on which vehicles run on tracks (rails or railroads). It is one of the most important, safe, commonly used and cost effective modes of commuting and goods carriage over long, as well as, short distances. Since this system runs on metal (usually steel) rails and wheels, it has an inherent benefit of lesser frictional resistance which helps attach more load in terms of wagons or carriages. This system is widely known as a train. Usually, trains are powered by an engine locomotive running on electricity or on diesel. Complex signaling systems are utilized if there are multiple route networks. Rail transport is also one of the fastest modes of land transport.

Trains are safe, fast, cost effective and the least affected by usual weather turbulences like rain or fog, compared to other transport mechanisms. Rail transport is better organized than any other modes of transport. It has fixed routes and schedules. Its services are more certain, uniform and regular compared to other modes of transport.

Rail transport however has some constraints and limitations. One of the biggest constraints of rail transport is heavy cost. The cost of building and maintaining a railway and trains as well as its facilities is magnified when a whole rail network is to be built. Also, rail transport cannot provide door-to-door service as it is tied to a particular track. Intermediate loading or unloading involves greater cost, more wear and tear and wastage of time.

The railway system consists railway infrastructure (Figure 2-1) (Li et al., 2016) and Rolling stock. 


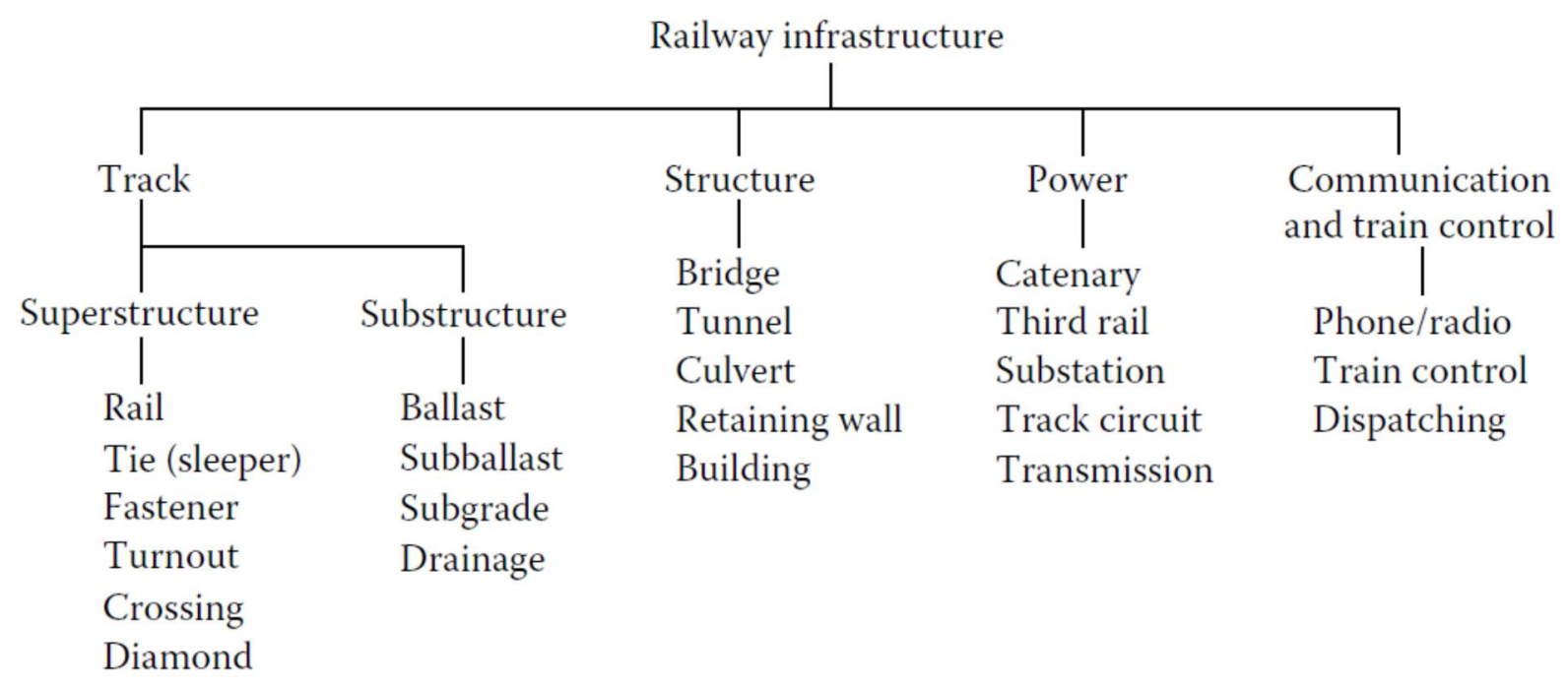

Figure 2-1 Elements of railway infrastructure (from Li et al., 2016)

\subsection{Railway Track Structure}

Track is the most fundamental component of the railway infrastructure, is divided into superstructure and substructure (Figure 2-2). Track supports the rolling stock by distributing wheel loads from the track superstructure to the track substructure. The substructure consists of ballast, subl systems, and concret

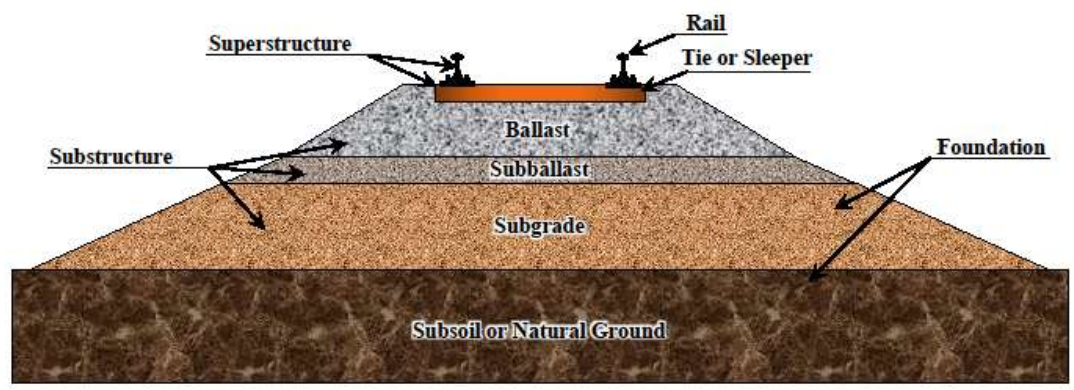

Figure 2-2: A typical railway track structure

The structure of railway track has evolved since its first development more than 150 years ago. The evolution to a strong and durable track structure is the result of overcoming ever-increasing 
challenges associated with moving more, faster, or heavier trains. Safety and cost have always been the primary concerns. The quest for safe and cost effective railway transportation have driven improvements in materials and processes that have provided a track structure with increased reliability and durability (Indraratna et al., 2011; Li et al., 2016).

Modern-day track superstructure and substructure components have changed greatly from the materials used historically. The superstructure of the track has benefitted from many years of research, development, and testing that have resulted in a good understanding of materials, inspection, and maintenance options. Rail steel has become durable, and rail inspection technologies as well as preventive maintenance strategies have advanced significantly. Tie (sleeper) materials have improved both in their strength and durability. Some of these improvements in hardwood tie treatment and use of other materials such as concrete, composite, and steel. The fastening system has evolved from cut spike and tie plate to elastic systems that improve rail restraint from movement relative to the ties.

Railway ballast gradually evolved from the early practice of simply using locally available gravel to the use of coarse and open-graded hard crushed rock. Appreciation for ballast and other components of the track substructure has grown extensively since railway industry started more than 200 years ago.

\subsection{Railway Track Superstructure}

The track superstructure includes the main load-supporting elements of the track that react and transfer train load to the track substructure. The superstructure includes the rail, tie (sleeper), and fastening system that work together to support train loading by reducing the large stresses at the wheel-rail interface to levels that are tolerable for the substructure layers.

The superstructure is required to resist both vertical and lateral loads with only limited elastic and permanent deformation.

\subsubsection{The Rail}

The rail is the most visible element of the track structure that directly supports passing wheels. The rail (Figure 2-3) has changed substantially over the years, from smaller rail cross sections that were installed as individual rail lengths to larger rail cross sections welded into continuous 
strings common in track today. The most recent rails are $39 \mathrm{ft}$ long. The use of high-strength steels and head hardening have resulted in superior rail performance, while the head of the rail has been made larger by proportion to the remainder of the rail section to provide a larger area for wear. Improvements in rail welds can significantly improve track substructure performance if the weld can provide increased yield strength, particularly in the heat-affected zone. Weld rail result in reduced plastic deformation of the rail, less variations in rail profiles, and lower dynamic loading and track deterioration (Li et al., 2016).

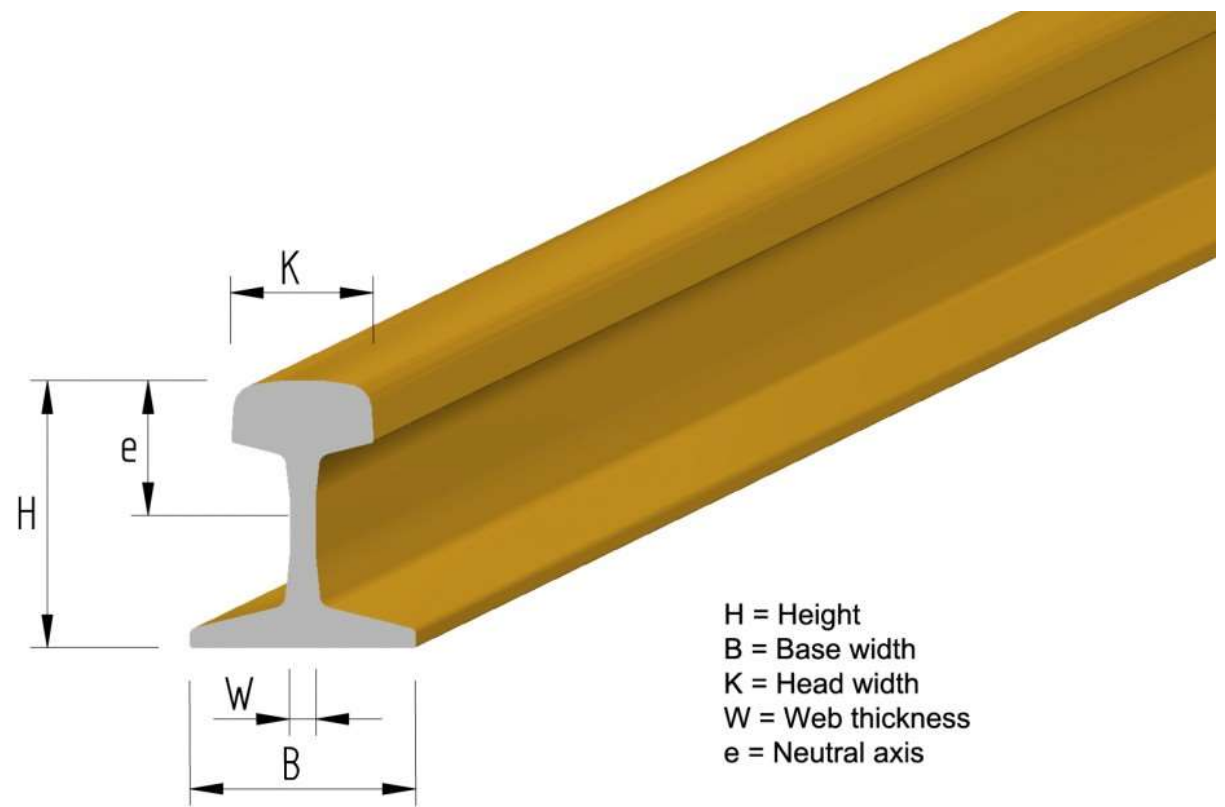

Figure 2-3 Rail (https://www.bemorail.com/portfolio-item/vignola-rail)

Improved rail can enhance track performance and life in well-supported track sections, but heavier and stronger rail do not solve track support problems. Some have assumed that heavier rail can accommodate, or bridge over, track support problem as stronger and stiffer rail will distribute the load over a larger area. However, the effect is minimal, because once the track support has deteriorated, the only choice is to improve the track support.

\subsubsection{The Tie}

Cross-ties (sleepers)(Figure 2-4) are typically wood or concrete elements. Although composite/plastic and steel ties have been developed for specific applications or to obtain desired properties, these types of ties have not yet been widely adopted. Wood ties tend to be most 
common in the United States and Canada not only because of lower cost but also because of the superior resilience of wood towards dynamic track interaction. Both concrete and wood ties are affected by abrasion from the ballast and wear at the rail-tie contact area. Wood ties are more sensitive to drainage problems mainly due to their susceptibility to rot and decay (Li et al., 2016).

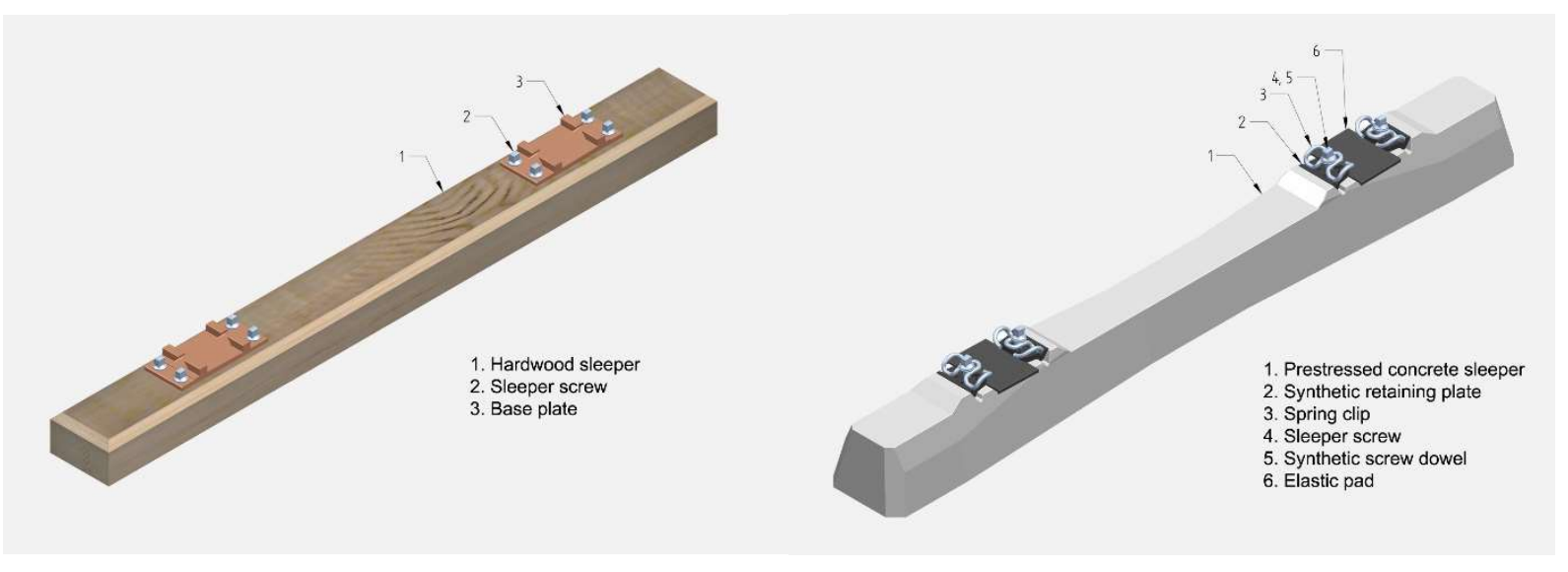

Figure 2-4 Railway Ties and fastening systems (https://www.bemorail.com/portfolioitem/sleepers)

\subsubsection{The Fasteners}

Fastening systems (Figure 2-4) retain the rail in place by restraining lateral, longitudinal, and vertical relative movement between the rail and tie. The rail fastening system, including the rail seat pad (if any), affects track behavior, and pad stiffness influences dynamic load attenuation and vibration transmission, both of which influence track superstructure performance. The plate and cut spike fastener is still the most common fastening system on wood ties, which must be coupled with appropriate rail anchoring to restrain rail longitudinal movement (Li et al., 2016).

Elastic fasteners form the rail-tie fastening system that provide resilient lateral, longitudinal, and vertical rail restraint. The resilience of this fastening system develops with deformation similar to spring stiffness, although not all fasteners provide a linear stiffness variation with deflection. Elastic fasteners are widely used with concrete ties; they are sometimes used on wood tie track. In concrete tie installations, the rail seat pad is an important consideration to control dynamic loads and rail seat abrasion, while ensuring adequate longevity of the pad. In addition, concrete tie track requires insulators to provide electrical insulation of track signals and a degree of 
resilience to the lateral rail-tie interaction. Elastic fasteners and fastening systems have many common elements whether applied to concrete ties or as direct fixation fasteners on slab track.

Under-tie pads have been used successfully on the bottom face of concrete ties. One problem with concrete ties has been the deterioration in the tie-ballast contact zone. The under-tie pad has improved tie-ballast contact, reduced abrasion, as well as added resilience to the stiff concrete tie, all of which contribute to improve ballast life in concrete tie track.

Special trackwork is also part of the track superstructure and includes turnouts, crossing diamonds, insulated joints, and along with grade-crossings and other locations of unique track construction are locations that often experience more rapid degradation. Each of these track features can generate large dynamic loads that are transferred to the substructure.

\subsection{Railway Track Substructure}

Track substructure consists of the foundation layers that support the track superstructure and the drainage arrangements. The foundation layer consists of ballast, subballast, and subgrade. In the case of slab track, the track structure is ballast-less, and the track substructure includes subbase and subgrade.

\subsubsection{Ballast}

Ballast is the granular material placed as the top substructure layer and is the layer that is in direct contact with the ties (sleepers). Ballast is generally large, angular, and uniformly graded (similar size) granular particles (Figure 2-5) derived from crushed hard rock material such as granite and basalt (Li et al., 2016).
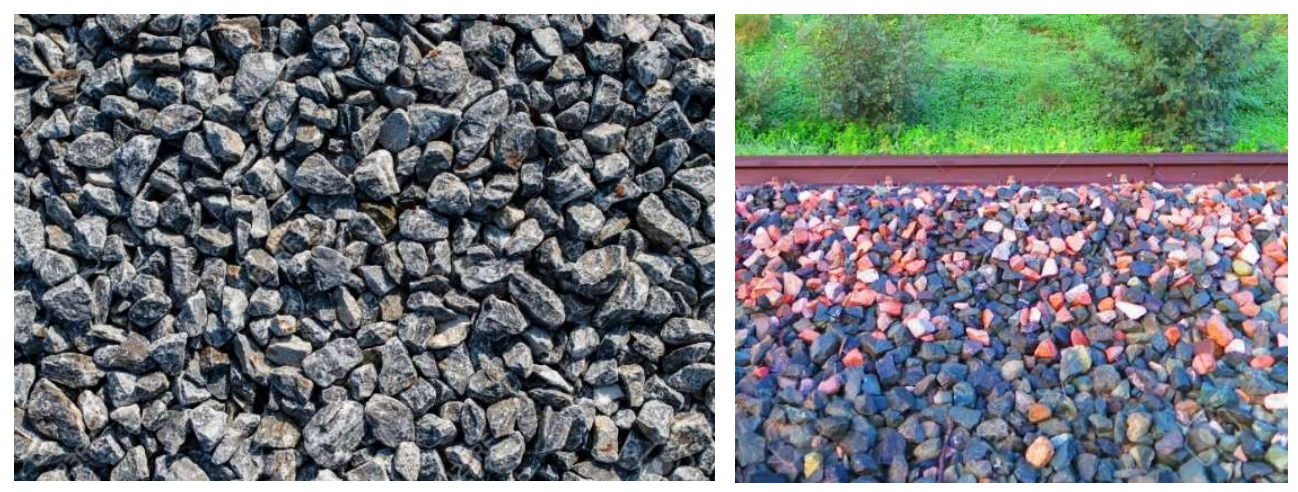

Figure 2-5 Ballast (https://www.123rf.com/photo_93877176\&75780006) 
Ballast has many functions that are requirements for good, well- supported track. The most important are summarized below:

○ Supports the rail-fastener-tie track panel by providing adequate vertical, lateral, and longitudinal resistance.

○ Transmits and reduces wheel/rail forces.

- Facilitates surfacing and lining operations.

○ Provides drainage.

- Provides resilience and damping of dynamic wheel/rail forces.

Ballasted track is not sealed like highway pavement but is designed as an open structure to provide rapid drainage and facilitate maintenance. Ballast-related track maintenance methods include surfacing and lining, stoneblowing, track renewal and superstructure replacement, ballast undercutting to restore drainage and resilience, fouled ballast removal including crib excavation with backhoe or vacuum, and ballast compaction often with a dynamic track stabilizer. Maintenance is required when one of the following problems occurs: excessive vertical or lateral track deformation, excessive ballast degradation (ballast fouling), or drainage is no longer effective (Li et al., 2016).

Table 2-1 Ballast Grade

\begin{tabular}{|l|l|l|}
\hline \multirow{2}{*}{$\begin{array}{l}\text { Sieve } \\
\text { size } \\
(\mathrm{mm})\end{array}$} & \multicolumn{2}{|l|}{ Ballast Grade } \\
\cline { 2 - 3 } & Standard & \multicolumn{2}{|l|}{ Fine } \\
\cline { 2 - 3 } & \multicolumn{2}{|l|}{ Nominal size (mm) } \\
\cline { 2 - 3 } & 60 (graded ballast) & \multicolumn{2}{|l}{50 (graded aggregate) } \\
\cline { 2 - 3 }$\%$ passing by mass \\
\hline 63.0 & 100 & \multicolumn{2}{|l}{} \\
\hline 53.0 & $85-100$ & $70-100$ \\
\hline 37.5 & $50-70$ & - \\
\hline 26.5 & $20-35$ & $40-60$ \\
\hline 19.0 & $10-20$ & $20-30$ \\
\hline 13.2 & $2-10$ & - \\
\hline 9.50 & $0-5$ & \\
\hline
\end{tabular}




\begin{tabular}{|l|l|l|}
\hline 4.75 & $0-2$ & $10-20$ \\
\hline 2.36 & - & $5-10$ \\
\hline
\end{tabular}

To fulfill the ballast functions, there must be adequate ballast layer thickness and proper particle size and gradation. The ballast layer must have a proper gradation to provide a large void space that facilitates both drainage and storage of fouling material. Materials that are smaller in size accumulate in the void spaces within the ballast layer are called fouling material. Fouling material can originate from abraded or broken ballast, material that spills or blows into the track, or material that flows onto the track from water drainage or flooding.

According to ballast specification of RailCorp (ESC 240 BALLAST Version 2.4, 2013), the particle size distribution (grading) of ballast aggregates shall conform to the requirements set out in following Table 2-1.

The thickness of the ballast layer should be specified based on the structural capacity of the track to ensure that it can withstand and distribute the applied train loading at a stress level that will not deform the subgrade over the expected life of the track (Indraratna et al., 2011; Li et al., 2016).

Ballast compaction is essential to provide lateral track resistance. Although ballasted track is normally stable with a considerable lateral strength reserve to resist imposed stresses, when ballast is newly placed or if it has been disturbed by maintenance (tamping or tie replacement), lateral resistance of the track may only be half of its value compared to when it is compacted. Resumed traffic following the maintenance will lead to gradual ballast recompaction and eventual restoration of its lateral strength and track buckling resistance.

\subsubsection{Subballast}

The subballast, or the blanket (another term often used), is the granular layer between the ballast and the subgrade (Figure 2-2). This granular layer often consists of broadly graded gravel and sand. The subballast complements the ballast by further distributing the applied loads and reducing the stresses on the subgrade, and it provides protection from frost action. However, the subballast has some important functions that cannot be fulfilled by ballast: 
- Prevents penetration and mixing of subgrade and ballast.

- Prevents subgrade attrition by ballast, when the top subgrade is composed of clay stone or shale that may be abraded by large ballast stones.

The subballast has a critical role in drainage and has competing requirements to both drain readily and direct water away from the subgrade (Indraratna et al., 2011; Li et al., 2016).

When the groundwater is shallow, the subballast should be capable of providing drainage of water that might be flowing upward from the subgrade. Design of the subballast layer also requires the analyses of layer thickness and gradation. Drainage requirements often conflict with separation and filtration criteria that must also be satisfied to prevent soil migration and piping.

Subballast saturation is a common problem that is often ignored. This results from inadequate drainage of the subballast layer from conditions such as the formation of subgrade settlement depressions that trap water or subballast gradation that makes the subballast inadequately permeable. Under repeated wheel/rail forces, significant deformation and even rapid failure can occur in the subballast layer when drainage is impeded. Not only does the accumulated water soften fine-grained subgrade, it also greatly reduces the stiffness of the subballast along with the ability of the subballast layer to distribute applied loads (Li et al., 2016).

\subsubsection{Subgrade (trackbed, formation)}

Subgrade may consist of either soil or rock and is the platform on which the track structure from the subballast up is built, as shown in Figure 2-2. It can be part of an embankment that is built with fill materials or can be natural ground in cut sections of track where subgrade may consist of the natural soil or placed soil layer(s) (Li et al., 2016).

Trackbed, roadbed, track foundation, and formation are other terms used to describe track substructure. Trackbed is used mainly to refer to the tie/sleeper support layers inclusive of the entire track substructure below the bottom of tie, and this will be the manner in which the term trackbed (roadbed, track foundation) will be used as subgrade in this thesis. Formation is another common term used to refer to the subgrade but includes any placed fill such as the subballast (blanket) layer directly under the ballast.

The primary function of the subgrade is to act as the track foundation by providing uniform and adequate support. In other words, subgrade should be capable of providing a suitable working 
base for the construction of ballast and subballast (or the subbase in the case of slab track), supporting the track structure, and accommodating the stresses due to traffic loads without failure or excessive deformation.

The influence of wheel loads can extend several meters below the bottom of the ties in spite of wheel loads reduce significantly in the subgrade through the load distribution provided by the superstructure, ballast, and subballast. As such, the subgrade over this depth should be strong to resist failure and excessive deformation due to wheel loads as well as the weight of track and substructure. In addition, a stable platform must be maintained over time and should not be excessively affected by environmental conditions (e.g., wet/dry and freeze/thaw cycles). Subgrade should also be designed so that surface water and ground water drain away from the track. A poorly designed and constructed subgrade can cause many track performance problems, so it is imperative that design and construction of subgrade be done according to the best practices available.

Under repeated wheel loads, an overstressed subgrade can experience "cumulative plastic deformation" (ballast pocket) or "progressive shear failure" (subgrade squeezing, shown in Figure 2-9). These are the two most common failure modes for subgrade composed of finegrained cohesive soils. These problems can lead to deterioration of track-geometry conditions, which in turn will increase dynamic wheel loads and accelerate deterioration.

Although soft subgrade failures are more common, problems on hard subgrade also exist. While track stability is not typically a problem on hard subgrade, abrasion of hard subgrade by coarse ballast particles in the presence of water can cause the abraded subgrade fines to infiltrate and foul the ballast, reducing its permeability, which affects track life, performance, and maintenance requirements.

\subsection{Rail Load and Distribution}

A railway track structure not only provides a stable, safe and efficient guided platform for the train wheels to run at various speeds with different axle loadings, but also transfer different types of loading imposed on a track system down to ground. 


\subsubsection{Track Forces}

The loads from standing or running trains (wheel-rail-tie interactions) are a complex combination of 'moving' static loads and dynamic forces. The requirements for the bearing strength and overall quality of the track depend largely on the vertical load per axle, tonnage borne as the sum of the axle loads and the running speed. The static axle load level, to which the dynamic increment is added as a function of speed, determines the required load carrying capacity of the track. The accumulated tonnage determines the deterioration of the track quality and provides an indication of when maintenance and renewal are necessary. The dynamic load component, which depends on speed and horizontal and vertical track geometry, also plays an essential role.

\subsubsection{Vertical forces}

The total vertical wheel load on a rail may be classified into two groups: quasi-static load and dynamic load (Indraratna et al., 2011). The quasi-static load is composed of three components, as given below:

$$
\begin{aligned}
& Q_{\text {total }}=Q_{\text {quasi-static }}+Q_{\text {dyamic }} \\
& Q_{\text {quasi-static }}=Q_{\text {static }}+Q_{\text {centrifugal }}+Q_{\text {wind }}
\end{aligned}
$$

where, $Q_{\text {static }}=$ static wheel load,

$Q_{\text {centrifugal }}=$ increase in wheel load on the outer rail in curves due to non-compensated centrifugal force,

$Q_{\text {wind }}=$ increase in wheel load due to wind,

$Q_{\text {dynamic }}=$ dynamic wheel load component resulting from sprung mass, unsprung mass, corrugations, welds, wheel flats etc.

The static load on each wheel is equal to half of static axle load, thus:

$$
Q_{\text {static }}=\frac{G}{2}
$$

where, $G=$ weight of vehicle per axle.

Considering the limit equilibrium of forces acting on a vehicle, as shown in Figure 2-6 Quasistatic vehicle forces on a curve track, the following expressions are proposed (Indraratna et al., 2011) for the centrifugal and wind forces: 
$Q_{\text {centrifugal }}+Q_{\text {wind }}=G \frac{p_{c} h_{d}}{s^{2}}+H_{w} \frac{p_{w}}{s}$

$h_{d}=\frac{s V^{2}}{g R}-h$

where, $H_{w}=$ cross wind force,

$s=$ track width,

$V=$ speed,

$g=$ acceleration due to gravity,

$R=$ radius of curved track,

$H=$ cant (or superelevation),

$p_{c}=$ distance between center of rails and center of gravity of vehicle, and $p_{w}=$ vertical distance of resultant wind force from center of rails.

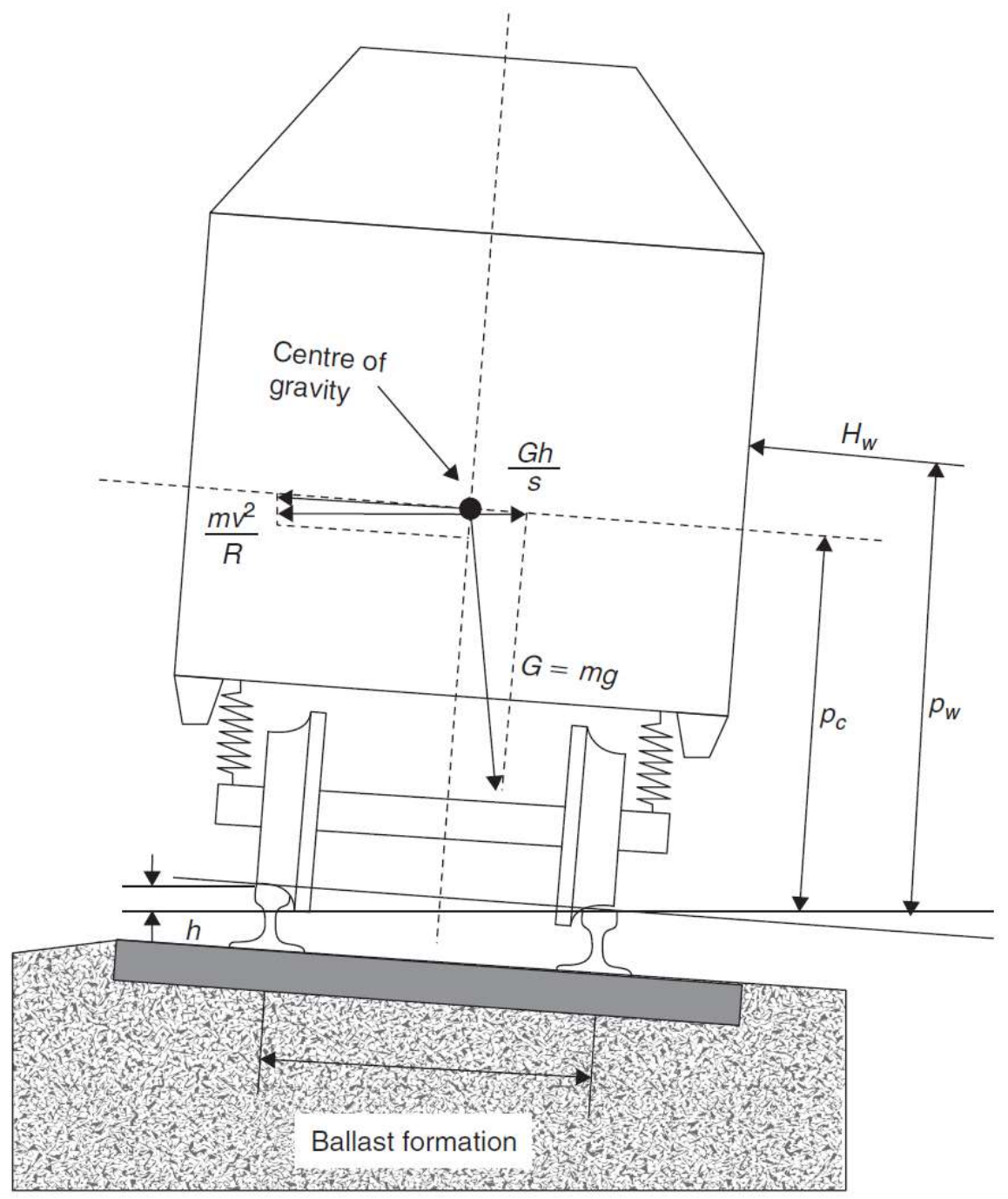


Figure 2-6 Quasi-static vehicle forces on a curve track (from Indraratna et al., 2011) The maximum wheel load usually occurs at the outer rail $\left(h_{d}>0\right)$, thus Equation 2.6 can be obtained combining Equations 2.3 and 2.4, as given below:

$$
Q_{\text {emax }} \approx \frac{G}{2}+G \frac{p_{c} h_{d}}{s^{2}}+H_{w} \frac{p_{w}}{s}
$$

The most uncertain part of the wheel load is the dynamic component, $Q_{\text {dynamic. }}$ In order to obtain an approximate rough estimate of $Q_{\text {dynamic }}$, the static wheel load may be multiplied by a dynamic amplification factor (otherwise known as the impact factor), in lieu of conducting a purely cyclic load analysis. The major factors affecting the magnitude of dynamic load component are:

- Speed of train,

○ Static wheel load and wheel diameter,

- Vehicle unsprung mass and vehicle condition,

○ Track condition (including track joints, track geometry and track modulus), and

- Track construction aspects and properties of ballast and subballast.

A range of empirical formulae has been used by different railway organizations for determining the design vertical wheel load. It is usually expressed empirically as a function of the static wheel load.

American Railway Engineering Association (AREA) recommended the following simple expression for the computation of design wheel load for the purpose of track design (Indraratna et al., 2011):

$$
P_{d}=\varnothing P_{S}
$$

where, $P_{d}=$ design wheel load $(\mathrm{kN})$ incorporating dynamic effects,

$P_{s}=$ static wheel load $(\mathrm{kN})$, and

$\Phi=$ dimensionless impact factor $(>1.0)$ and is given by Equation 2.8.

$$
\emptyset=\left(1+\frac{0.0052 V}{D_{w}}\right)
$$

where, $D_{w}=$ diameter of the wheel (m), and

$V=$ velocity of the train $(\mathrm{km} / \mathrm{h})$. 


\subsubsection{Lateral forces}

Lateral loads in tracks are far more complex than vertical loads. There are two principal sources of lateral loads: (a) lateral wheel force, and (b) buckling reaction force. Lateral wheel forces are initiated by the lateral force component of friction between the wheel and rail, plus the lateral force applied by the wheel flange on the rail. Buckling reaction forces in the lateral direction are developed due to the high compressive stresses caused by high rail temperatures.

Similar to vertical force (Equation 2.1), lateral force exerted by the wheel on outer rail is also equal to the sum of the quasi-static and dynamic loads, thus,

$$
\begin{aligned}
& Y_{\text {total }}=Y_{\text {quasi-static }}+Y_{\text {dyamic }} \\
& Y_{\text {quasi-static }}=Y_{\text {flange }}+Y_{\text {centrifugal }}+Y_{\text {wind }}
\end{aligned}
$$

where, $Y_{\text {flange }}=$ lateral force in curve caused by flanging against the outer rail,

$Y_{\text {centrifugal }}=$ lateral force due to non-compensated centrifugal force,

$Y_{\text {wind }}=$ increase in lateral force due to cross wind,

$Y_{\text {dynamic }}=$ dynamic lateral force component.

Now, if an assumption is made that the centrifugal and wind lateral forces act entirely on the outer rail, then the lateral equilibrium equation obtained from Figure 2-6 will be as follows:

$$
Y_{\text {emax }} \approx G \frac{h_{d}}{s}+H_{w}
$$

Similarly, as in vertical force estimation, to account for dynamic component of lateral force, the static component of the force can be multiplied by the dynamic amplification factor (DAF), thus,

$$
H=D A F\left(G \frac{h_{d}}{s}+H_{w}\right)
$$

The Office of Research and Experiments (ORE) in Netherlands (Indraratna et al., 2011), also found that the lateral track force is dependent only on the radius of curvature, and the following empirical expression was proposed:

$$
H=35+\frac{7400}{R}
$$

where, $H=$ lateral force at curved track $(\mathrm{kN})$, and

$$
R=\text { radius of curve }(\mathrm{m}) \text {. }
$$




\subsubsection{Longitudinal forces}

The longitudinal force imposed on the rail head can be due to any change in length of the released rail occurring as a result of a significant change in temperature. This is insignificant in fixed rails because the resistance is produced by friction forces between rails and ties and between ties and ballast. Other phenomenon causing longitudinal forces include, track creep, accelerating and braking of the vehicle, and shrinkage stresses caused by rail welding.

\subsubsection{Impact forces}

Rail track structures are often subjected to the impact loads due to abnormalities in either a wheel or a rail. The magnitude of these impact loads is high within the short impulse duration (frequency range upto $2000 \mathrm{~Hz}$ ) and usually depends on the nature of wheel or rail irregularities, as well as on the dynamic response of the track.

Impact loads are caused by wheel or rail abnormalities such as wheel-flat, wheelshells, dipped rails, turnouts, crossings, insulated joints, expansion gap between two rail segments, imperfect rail welds and rail corrugations etc.

\subsubsection{Load Transmission in Track Foundation}

Whether it is static, cyclic, or dynamic, loading is transmitted to the track and subgrade, resulting in stresses and strains in the track foundation. This transference of load, stress, and strain to the track foundation depends to a great degree on the strength and stiffness properties of track substructure. With adequate strength and stiffness of track foundation materials, stresses and strains due to various types of loadings should not cause track and subgrade failure or excessive deformation.

\subsubsection{Stresses and strains in track foundation}

Figure 2-7 illustrates the stress state of three different elements in the track foundation under a moving wheel load. Only stresses in the vertical and longitudinal directions are shown. In general, the three-dimensional stress state for an element in the track foundation can be expressed as

$$
\left\{\sigma_{i j}\right\}=\left\{\sigma_{x}, \sigma_{y}, \sigma_{z}, \sigma_{x y}, \sigma_{y z}, \sigma_{z x}\right\}
$$


where: $\sigma_{x}, \sigma_{y}, \sigma_{z}$ are the normal stresses in the longitudinal, lateral, and vertical directions $\sigma_{x y}, \sigma_{y z}, \sigma_{z x}$ are the shear stresses in $x y, y z$, and $z x$ planes.

Figure 2-7 shows the normal and shear stresses in the $z x$ plane, as such $\sigma_{z x}=\tau$.

A normal stress is called a principal stress when the shear stress is equal to zero. As shown in Figure 2-7, for the element directly under the wheel load, both vertical and lateral normal stresses are principal stresses. The larger principal stress is referred to as the major principal stress and is denoted as $\sigma_{l}$. The smaller principal stress is referred to as the minor principal stress and is denoted as $\sigma_{3}$.

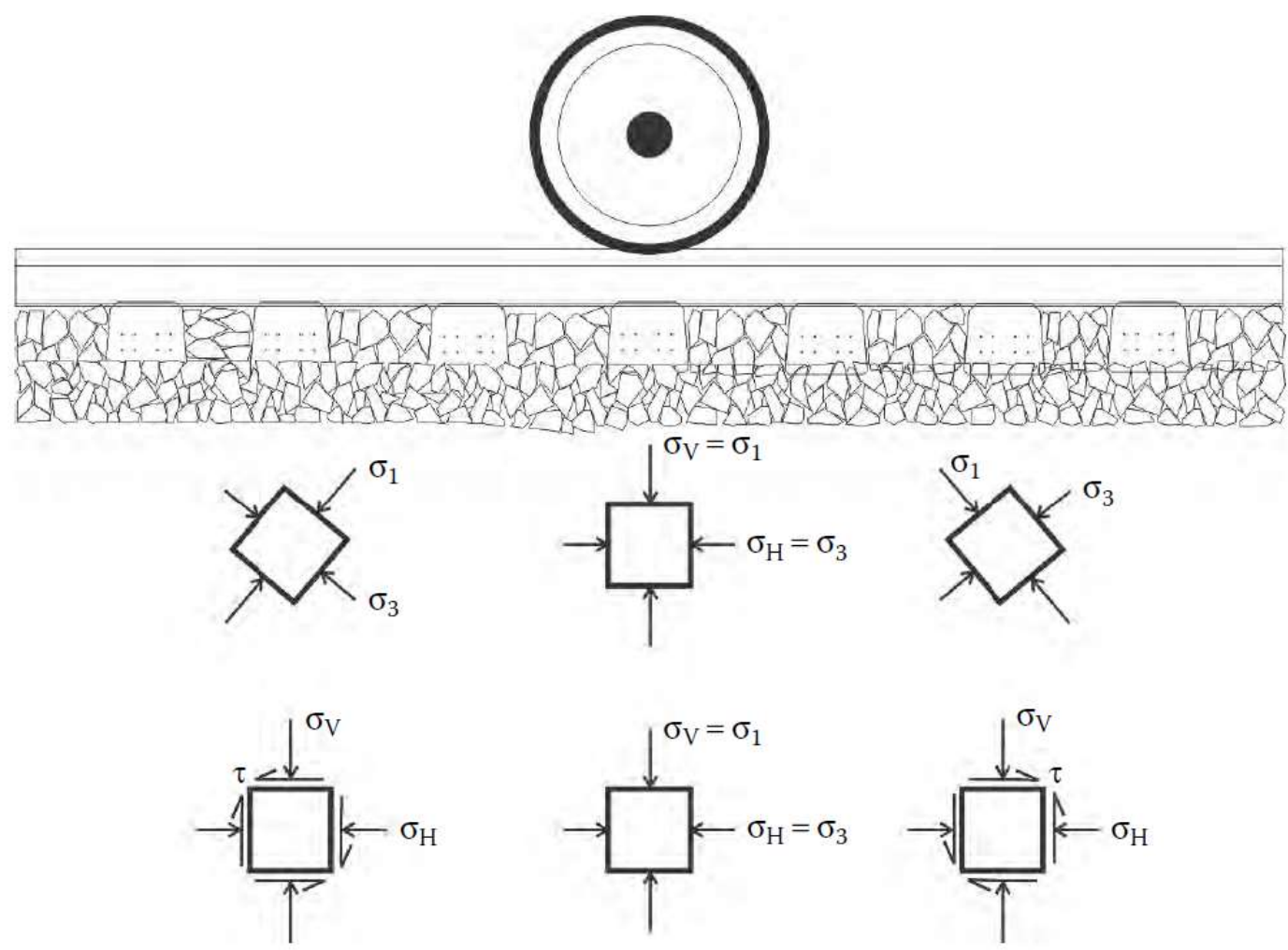

Figure 2-7 Stresses in track foundation (Li et al. 2016)

Bulk stress, as defined in Equation 2.15, is a stress parameter generally used for the granular layer (ballast and subballast) analysis, while deviator stress, as defined in Equation 2.16, is a stress parameter generally used for the analysis of subgrade consisting of cohesive soils.

$$
\theta=\sigma_{1}+\sigma_{2}+\sigma_{3}
$$




$$
\sigma_{d}=\sigma_{1}-\sigma_{3}
$$

where: $\theta$ is the bulk stress

$\sigma_{d}$ is the deviator stress

The ratio of horizontal to vertical stress is expressed by a factor called the coefficient of lateral stress or lateral stress ratio and is often denoted by the symbol $K$ :

$$
K=\frac{\sigma_{H}}{\sigma_{V}}
$$

Where there is no lateral strain, this ratio is called the coefficient of lateral stress at rest or lateral stress ratio at rest and is often denoted using the symbol $K_{0}$. Typically, lateral stress ratio at rest is between 0.4 and 0.5 , although it is possible that the horizontal stress exceeds the vertical stress, and in that case, this coefficient is greater than 1.0. This is especially true when residual stress in the ballast is high and resulting lateral stress ratio can be significantly higher than 1.0 (Li et al., 2016).

After stresses are determined, strains can be obtained by

$$
\begin{aligned}
& \varepsilon_{x}=\frac{1}{E}\left[\sigma_{x}-v\left(\sigma_{y}+\sigma_{z}\right)\right] \\
& \varepsilon_{y}=\frac{1}{E}\left[\sigma_{y}-v\left(\sigma_{x}+\sigma_{z}\right)\right] \\
& \varepsilon_{z}=\frac{1}{E}\left[\sigma_{z}-v\left(\sigma_{x}+\sigma_{y}\right)\right] \\
& \gamma_{x y}=\frac{\tau_{x y}}{G} \\
& \gamma_{y z}=\frac{\tau_{y z}}{G} \\
& \gamma_{z x}=\frac{\tau_{z x}}{G}
\end{aligned}
$$

where: $\varepsilon_{x}, \varepsilon_{y}, \varepsilon_{z}$ is the normal elastic strain in the longitudinal, lateral, and vertical directions $\gamma_{x y}, \gamma_{y z}, \gamma_{z x}$ is the elastic shear strain in $x y, y z$, and $z x$ planes

$E$ is the elastic modulus

$v$ is the Poisson ratio

$G$ is the shear modulus

The relationship between $E, v$, and $G$ is defined by

$$
G=\frac{E}{2(1+v)}
$$


Under repeated wheel load applications, however, cumulative plastic strain may become a deformation parameter that is more critical than elastic strain. Elastic modulus, when defined in terms of resilient deformation and deviator stress, is referred to as resilient modulus. Resilient modulus and plastic deformation are two main parameters critical to the vertical strain, analysis and design of track foundation subjected to repeated wheel load applications.

\subsubsection{Load transmission in track}

Depending on the spectrum of frequency components, some of higher frequency force components will dissipate quickly when they are transmitted from the wheel-rail interface downward to the track substructure layer. Static or dynamic wheel loads of lower frequencies, however, are spread to the underling track substructure layers over larger area with increasing depth.

This spreading of load over larger area at greater depth, to a large degree, depends on the stiffness characteristic of each layer of the track structure, including the rail, ties, ballast, and subgrade.

GEOTRACK is a software for track structure analysis under vertical quasi-dynamic loads. It uses a three dimensional, multilayer elastic model for determining track and subgrade responses. However, the GEOTRACK software is not presently because is being reprogramed and updated.

Using GEOTRACK (old version), two examples are summarized from Li et al. 2016 to illustrate how a static wheel load is transmitted from the wheel-rail interface to the rail-tie interface, to the tie-ballast interface, and to various depths in the ballast and subgrade layers.

One example is for a typical concrete tie track, and the other is for a typical wood tie track, as shown in Figure 2-8. In these two examples, a single 40-kip (276 MPa) wheel load is applied on the rail directly above a tie, and this figure shows how this load is transmitted downward to different depths both along and across the track (Li et al., 2016).

Figure 2-8a show the results at various depths under the rail along the track longitudinally. The left sideplot of Figure 2-8b highlights the concrete tie track and the right side plot provides details of the wood tie track. As illustrated, for a 40-kip single wheel load on the concrete tie track, 12.4 kips ( $85 \mathrm{MPa}, 31 \%$ ) is transmitted to the rail-tie interface directly under the load, and 9 kips ( $62 \mathrm{mPa}, 23 \%)$ is transmitted to the two adjacent concrete ties. The entire wheel load is 
spread only to the fourth tie, because the rail-tie force is essentially zero on the fifth tie. On the other hand, for the wood tie track, 16.6 kips $(114 \mathrm{MPa}, 42 \%)$ is transmitted to the rail-tie interface directly under the 40-kip wheel load, which is spread over a shorter distance along the track, roughly to the third tie, as the plot on the top right shows.
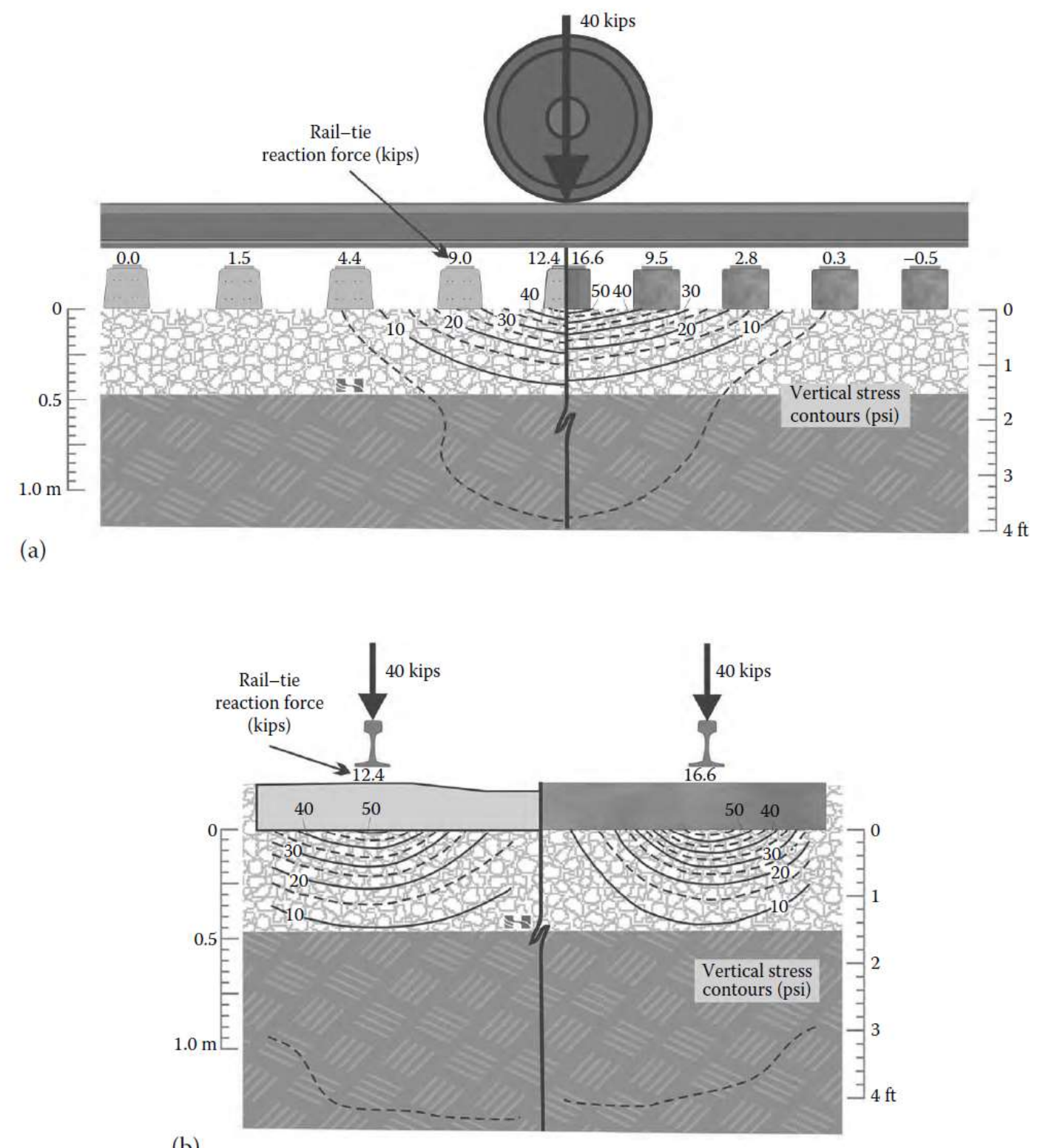

(b)

Figure 2-8 Load transmission from rail downward along

(a) and across (b) concrete and wood tie in tracks (Li et al. 2016)

At the ballast surface, maximum vertical stress is generated directly under the wheel load, although the wood tie track has higher maximum vertical stress than the concrete tie track, 
because the former does not spread the load over a distance along the track as much as the latter does. The stress contours illustrate how vertical stress is distributed at various depths along the track. As shown, directly under the wheel load, stress is still somewhat significant 5 psi (e.g., 34 $\mathrm{kPa}$ ) at a depth of approximately $4 \mathrm{ft}(1.2 \mathrm{~m}$ ) in the subgrade (from bottom of the tie), but this stress reduces quickly and becomes insignificant further away from the wheel load.

Figure 2-8 show how the 40-kip single wheel load is transmitted downward across half the track with respect to the center of the track, for both the concrete and wood tie tracks. Again, higher vertical stress over $50 \mathrm{psi}(345 \mathrm{kPa})$ is generated directly under the rail for the wood tie track compared to the concrete tie track. Distribution of vertical stress across the track at various depths in the ballast and subgrade can be seen to be more uniform for the concrete track than for the wood tie track. It is also worth noting that toward the end of tie, the concrete tie generates higher vertical stress on the ballast surface than the wood tie does.

Note that the load transmission patterns, as shown in Figure 2-8, are based on an assumption of a typical concrete and wood tie track with a nominal ballast layer thickness of 18 in $(457 \mathrm{~mm})$. with modulus of 60,000 psi (414 MPa) and a subgrade modulus of 8,000 psi (55 MPa).

\subsection{Progressive Shear failure}

Conventional ballasted railway track (Figure 2-2) deteriorates progressively over time due to the combined effects of traffic and climate. Appropriate maintenance treatments are periodically applied to reduce the effects of this deterioration but an important and often neglected part of the track structure is the subgrade which, unlike the ballast, does not lend itself to be maintained easily (Burrow et al., 2011).

Subgrades of fine-grained material without adequate protection from repeated train induced loads and the effects of climate, may fail primarily by attrition from the ballast, progressive shear failure or excessive rate of settlement through the accumulation of plastic strain and massive shear failure (Burrow et al., 2011)(Figure 2-9). Due to the repeat overstressing wheel loads, surface soil moves upwards and side wards, following the least resistance path to form "cumulative plastic deformation" (ballast pocket) or "progressive shear failure". Burrow et al 
(2011) suggested that progressive shear failure occurs where train induced cyclic stress levels are sufficiently high to cause the soil to be sheared and remoulded (Figure 2-9) but at stress levels below those causing massive shear. Loh \& Nikraz (2012) also found that subgrade soil beneath railway tracks experiences stress of cyclic nature with the passing of train axles/wheels that can result in progressive shear failure at a stress level lower than its monotonic strength. The progressive shear failure can lead to deterioration of track-geometry conditions (i.e. track defects, which in turn will increase dynamic wheel loads because track defects increase rail and wheel contacting impact and accelerate deterioration). Heave of soil due to progressive failure at the subgrade-subballast interface also cause the water ponding in subgrade and escalate the subgrade progressive shear failure.
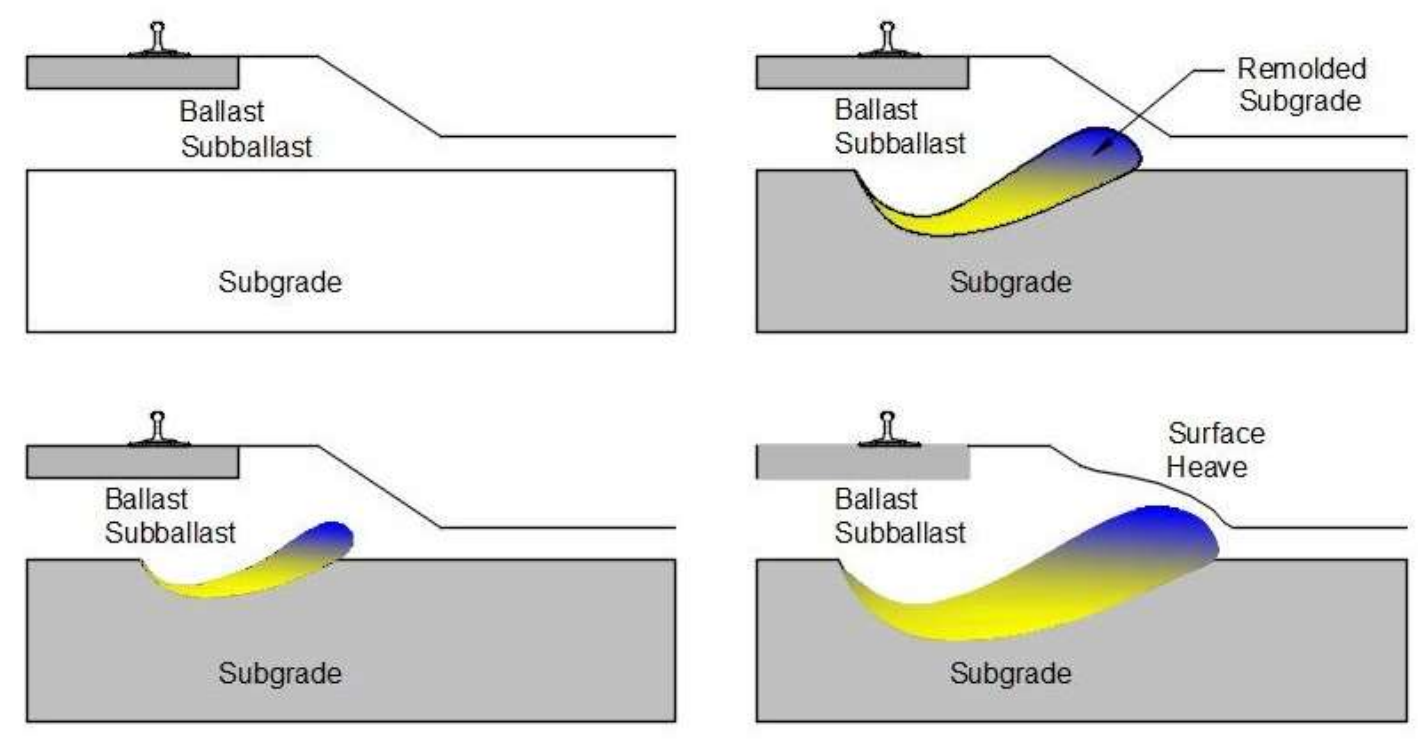

Figure 2-9 Subgrade progressive shear failure (Burrow et al., 2011)

Factors contributing to subgrade failures can be categorized into three groups: load factors, soil factors, and environmental factors (soil moisture and temperature) (Li \& Selig, 1995). These three factors contribute progressive shear failure too.

The load factor is an external factor, which is a function of self-weight of rail structure and cyclic train loads. The self-weight of the structure can be considered to be key triggering factor that can be associated with massive shear failures for a high embankment and consolidation settlement of a rail track. However, the load factor of greatest concern is from repeated traffic loading. The subgrade behaves quite differently under a single static loading than under repeated traffic 
loading, even though the magnitudes of individual axle loads may be the same. For example, the subgrade, particularly subgrades of fine-grained soils such as silt and clay, will exhibit lower strengths under repeated loadings than under a single loading. The subgrade settlement accumulated under smaller magnitudes of wheel loads with large numbers of repeated applications may be significantly larger than that generated under a single application of a larger dynamic wheel loading (Li \& Selig, 1995).

The influence of soil type on the subgrade performance is strongly related to fine-grained soils (silt and clay) because of its lower strength and permeability, since the fine-grained soils that do not typically drain well are most susceptible to decrease in shear strength and stiffness with an increasing water content.

Almost every subgrade problem can be attributed to the high moisture content in the fine-grained soil subgrade. The presence of water in the subgrade can reduce the strength and stiffness of subgrade soils dramatically. A subgrade may become wet or saturated by the infiltration of water from the surface or from groundwater. The duration of water contact with a subgrade soil has significant influence on the resulting shear strength of the soil. A clay sub grade exposed to the air with occasional rain showers and dry periods may stay strong, whereas a subgrade covered by ballast and subballast (which cuts off evaporation) may get weak. The ballast and subballast allow water to penetrate, but they do not allow it to evaporate. As a result a subgrade that is not free-draining invariably can be saturated (Li \& Selig, 1995).

Soil temperature is also of concern particularly during freezing and thawing cycles. Under certain combinations of temperature, soil suction, soil permeability, and availability of water, ice lenses will form when the soil freezes, causing ground heave. When the soil thaws again excess water from the ice lens will cause weakening of the soil.

The huge costs associated with the rail substructure maintenance can be significantly reduced if the PROGRESSIVE SHEAR FAILURE and its influence on the physical and mechanical characteristics of the railway foundation are well understood. 


\section{CHAPTER 3 \\ LITERATURE REVIEW}

This chapter provides a brief review about the mechanics of saturated and unsaturated soils that is relevant to the research topic.

\subsection{The Basics of Soil Mechanics}

\subsubsection{Soil Mechanics}

Soil mechanics is a discipline of civil engineering that can be used as a tool in interpreting the soil performance characteristics utilizing the engineering techniques of statics, dynamics, fluid mechanics, and other technologies. The soil composition, shear strength, compaction, hydraulic conductivity and consolidation are some of the key properties that are addressed for explaining soil sediments and other deposits behavior using soil mechanics. The field of soil mechanics is regarded as one of the major sciences for resolving problems related to geotechnical engineering, geology and geophysical engineering. These studies are important for civil engineers because several civil infrastructures are designed and constructed based on using the soil mechanics as a tool. The type of construction, type of equipment to be used, type of foundation, support material, and many other aspects of construction works are largely affected by the soil mechanics studies (Vandevelde \& Basudhar, 2020).

\subsubsection{Formation of Soils}

Soil is a combination of minerals and organic elements that are in solid, gaseous, and aqueous form. Soil consists of particle layers that are different from the original materials in their physical, mineralogical, and chemical properties because of the interactions between the atmosphere and hydrosphere and other reasons. The particles of the soil are created from broken rocks that have been changed due to the chemical and environmental effects, including weather and erosion. Particles of soil are filled loosely, creating a soil formation that consists of pore spaces. Studying soil formation modes is important because it helps in determining properties of soil. Several such as the cohesion, adhesion, friction, acidity, and other related soil characteristics factors can easily be determined from various tests. However, we cannot draw any concrete 
conclusions merely by conducting soil studies but we surely can narrow our research parameters by studying the basic characteristics of soil like color, texture, and nature of soil (Vandevelde $\&$ Basudhar, 2020).

\subsubsection{Basic Characteristics of Soils}

Soil consists of different phases of solid, liquid, and gas and its characteristics depend on the interacting behavior of these phases, and on the stress applied. The solid phase includes clay, non-clay minerals, and organic matter. They are categorized as clay, sand, and gravel based on their size. The liquid phase is primarily composed of water; however, it can contain organic compounds available from chemical spills, and wastes, while the gas phase is normally air. The size, form, chemical properties, compressibility, and load carrying capability of the soil particles are determined by soil mineralogy, which is a science related with the chemistry, structure, and physical properties of minerals. The structure of a soil depends upon the arrangement of particles, particle groups, pore spaces, and the composition. These basic characteristics determine the type of structure to be built and what external support measures, if any, has to be taken to make the structure last long and bear the effects of earthquake, water seepage, and other external factors (Vandevelde \& Basudhar, 2020).

Soil mechanics studies are used to determine lateral earth pressure, bearing capacity of soil, and conduct slope stability analysis. These studies always help a civil engineer to design and construct better structures and indirectly these studies help in risk mitigation too because if we know beforehand how the soil mass is going to behave, we can take precautionary measures at the time of construction.

\subsubsection{The soil shear strength}

The shear strength of a soil mass is the internal resistance per unit area that the soil mass can offer to resist failure and sliding along any plane inside it. A geotechnical engineer must understand the nature of shearing resistance in order to analyze soil stability problems such as bearing capacity, slope stability, and lateral pressure on earth retaining structures (Das, 2001). Mohr (1900) presented a theory for rupture in materials and concluded that a material fails because of a critical combination of normal stress and shearing stress, and not from either maximum normal or shear stress alone. Thus, the functional relationship between normal stress 
and shear stress on a failure plane can be expressed by a curved line. For most soil mechanics problems, it is sufficient to approximate the shear stress on the failure plane as a linear function of the normal stress (Coulomb, 1776). This linear function can be written as

$$
\tau_{f}=c+\sigma \tan \varnothing
$$

where, $c=$ cohesion

$$
\begin{aligned}
& \phi=\text { angle of internal friction } \\
& \sigma=\text { normal stress on the failure plane } \\
& \tau_{f}=\text { shear strength }
\end{aligned}
$$

The preceding equation is called the Mohr-Coulomb failure criterion.

In saturated soil, the total normal stress at a point is the sum of the effective stress $\left(\sigma^{\prime}\right)$ and pore water pressure (u), or $\sigma=\sigma^{\prime}+u$. The effective stress $\sigma^{\prime}$ is carried by the soil solids. The MohrCoulomb failure criterion, expressed in terms of effective stress as below:

$$
\tau_{f}=c^{\prime}+\sigma^{\prime} \tan \emptyset^{\prime}
$$

where, $c^{\prime}=$ effective cohesion, and

$$
\phi^{\prime}=\text { angle of internal friction, based on effective stress. }
$$
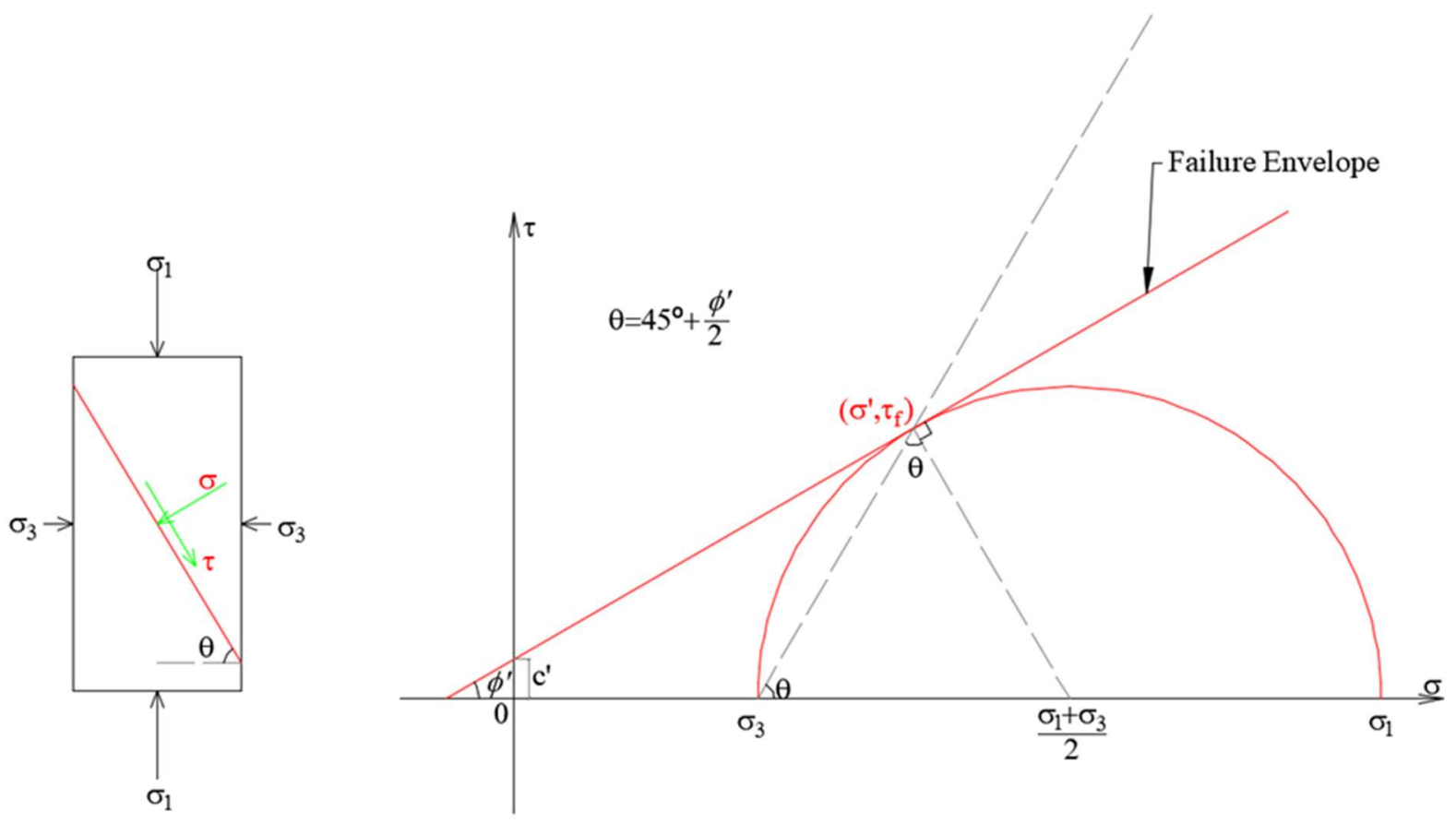

Figure 3-1 Mohr Coulomb shear failure criterion with Mohr circle of stress 
Thus, Equation 3.1 and 3.2 are expressions of shear strength based on total stress and effective stress. The value of effective cohesion, $c^{\prime}$ for sand and inorganic silt is zero. For normally consolidated clays, effective cohesion $c^{\prime}$ can be approximated as zero. However, overconsolidated clays have values of effective cohesion $c^{\prime}$ that are greater than zero. The angle of friction, $\phi^{\prime}$, is sometimes referred to as the drained angle of friction.

The significance of Equation 3.2 can be explained by referring to Figure 3-1, which shows stress on a soil mass and the plot of the failure envelope. If the magnitudes of $\sigma^{\prime}$ and $\tau$ on failure plane are plotted as a point on Figure 3-1 and if falls below the failure envelope, shear failure will not occur along the plane. If the effective normal stress and the shear stress on plane falls on the failure envelope, shear failure will occur along that plane. A state of stress on a plane represented by a point above the failure envelope cannot exist, because shear failure in a soil would have occurred already (Das, 2001).

\subsection{Unsaturated Soil Mechanics}

\subsubsection{Introduction}

Unsaturated soils contain both air and water phases in their pores. They can be either naturally occurring soils, such as those found in arid and tropical zones, or artificially created (man-made) soils such as those that are formed by compaction.

Fundamental principles pivotal to understanding the engineering behavior of saturated soils emerged with the concept of effective stress in the 1930s (Terzaghi, 1943). However, there was considerable interest in understanding the behavior of unsaturated soils along with saturated soils. This is documented through the research papers published in the First International Conference on Soil Mechanics and Foundation Engineering in 1936.

Theoretically based framework of stress state variables for interpreting the engineering behavior of an unsaturated soil was proposed 40 years later within the context of multiphase continuum mechanics (Fredlund \& Morgenstern, 1977). Two stress state variables, namely; net normal stress, $\left(\sigma_{n}-u_{a}\right)$ and matric suction, $\left(u_{a}-u_{w}\right)$ which is the difference between the pore-air pressure, $u_{a}$ and pore-water pressure $u_{w}$ are used for explaining the behavior of unsaturated soils. 
The behavior of unsaturated soils could be viewed as a natural extension of saturated soil behavior (Fredlund \& Morgenstern, 1976).

The seven international conferences held in Paris, France (1995), Beijing, China (1998), Recife, Brazil (2002), Carefree, U.S.A (2006), Barcelona, Spain (2010), Sydney, Australia (2014), and Hong Kong, China (2018) have been fruitful to exchange the latest developments in the research and application of unsaturated soil mechanics. In recent years, there is an increased interest in the application of the mechanics of unsaturated soil into engineering practice.

\subsubsection{Various Phases in Unsaturated Soils}

Unsaturated soils contain both air and fluid phases in their pores. Soil in a state of saturated condition is commonly referred to as a two-phase mixture (i.e., solids and water), but an unsaturated soil includes two other independent phases (i.e., air and the contractile skin or the air-water interface) (Fredlund et al., 2012). The contractile skin acts like a thin membrane interwoven throughout the voids of the soil, acting as a partition between the air and water phases. It is the interaction of the contractile skin with the soil structure that causes an unsaturated soil to have a significant influence on its mechanical behavior (i.e., volume change and shear strength properties). The unsaturated soil properties change in response to the position of the contractile skin. It is important to view an unsaturated soil as a four-phase mixture for purposes of stress analysis, within the context of multiphase continuum mechanics (Fredlund \& Morgenstern, 1976).

The contractile skin can be considered as part of the water phase with regard to changes in volume-mass soil properties but must be considered as an independent phase when describing the stress state and phenomenological behavior of an unsaturated soil (Fredlund et al., 2012). Numerous research studies on the nature of the contractile skin point toward its independent role in the mechanics of unsaturated soils. A surface tension of approximately $75 \mathrm{MN} / \mathrm{m}$ translates into a unit stress in the order of $140,000 \mathrm{kPa}$.

The soil suction is defined in terms of the free energy or the relative vapor pressure (relative humidity) of the soil moisture. A meniscus forms at the soil-air interface, due to the surface tension, resulting in reduced vapor pressure in the water. The vapor pressure decreases, becomes more negative, and the matric suction pressure increases as the radius of curvature of the 
meniscus decreases. The size of the soil pores decreases with a decrease in soil particle size which then affects the size of the radius of curvature and consequently the matric suction pressure. The vapor pressure decreases as the degree of saturation decreases (Han et al., 2017).

Soil suction is a key factor that controls effective shear stress of unsaturated soils and is influenced by particle size distribution (PSD), soil type, fine particle percentage, soil fabric orientation, and drainage boundary conditions (Bishop, 1959). Rajeev et al. (2012) suggested that soil suction is highly sensitive to climate changes. In addition to soil suction, soil temperature has a significant influence on the track foundation failures in cold regions, as soil freezing and thawing can control permeability, stiffness, and strength (Wang et al. 2007).

The suction in the unsaturated soils can range from zero at the water table to a maximum tension of approximately $1,000,000 \mathrm{kPa}$ under dry soil conditions (Fredlund et al. 2012). For the same range of suction, degree of saturation of the soil varies from $100 \%$ to zero. The suction in soils varies from zero to $1,000,000 \mathrm{kPa}$ irrespective of the type of soil. The changes in soil suction result in distinct zones of saturation. The zones of saturation can be been defined in situ as well as in the laboratory through the use of soil-water characteristic curve as shown Figure 3-2 (Vanapalli et al. 1999).

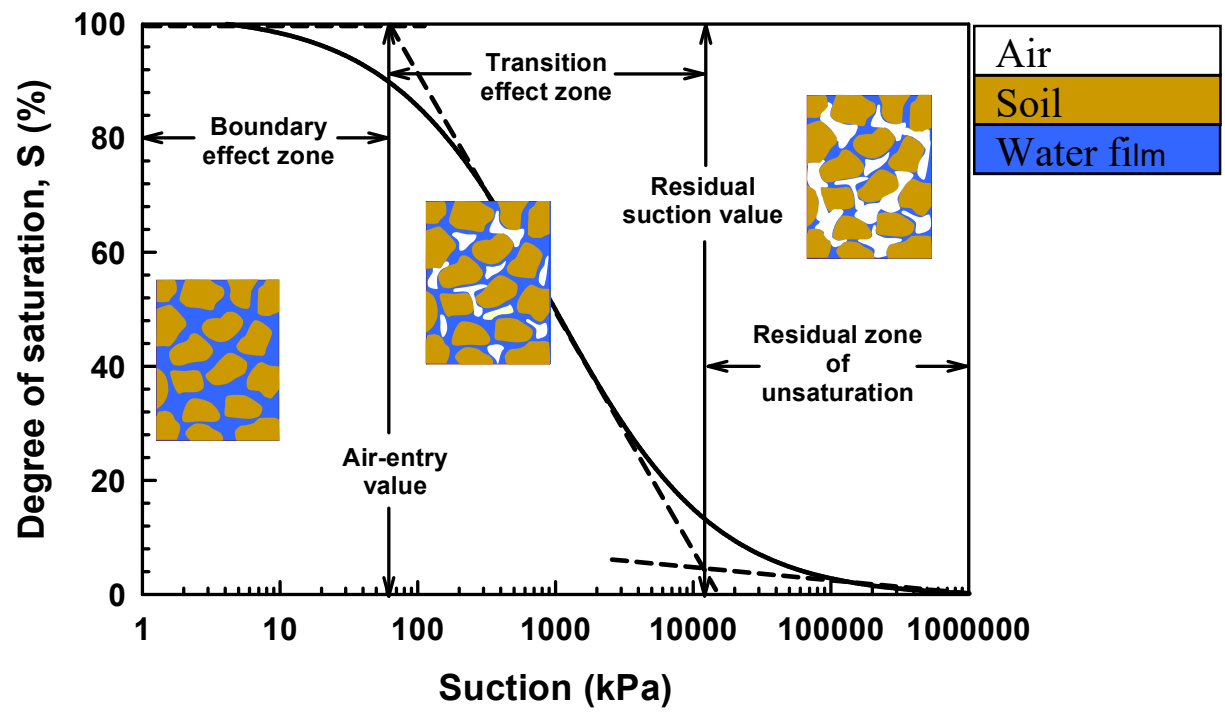

Figure 3-2 Soil-water characteristic curve and its various zones (modified after Vanapalli et al. 1999) 


\subsubsection{Soil Water Characteristic Curve}

The Soil Water Characteristic Curve (SWCC) (Fredlund et al., 2012) defines the amount of water in a soil versus soil suction (Figure 3-2). The amount of water in the soil is commonly defined in more than one way and it is difficult to restrict the definition to a single variable. Three common variables used to define the amount of water in the soil are: gravimetric water content, w, volumetric water content, $\theta$, and degree of saturation, $\mathrm{S}$. This relationship is referred in the literature using different terms which include Soil Water Retention Curve (SWRC) or Soil Moisture Curve (SMC) or Soil-Water Characteristic Curve (SWCC) as used in this thesis.

The SWCC can be divided into three zones; namely, boundary effect, transition and residual zones (Vanapalli et al., 1999). Within the boundary effect zone, soil pores are saturated with capillary water under suction. It is likely there may be some air in the form of occluded bubbles, which is not continuous. As suction exceeds the air-entry suction, air starts to enter the largest soil pores and subsequently drain the capillary water out of the soil. In this stage of desaturation, both air phase and water phase are continuous; however, liquid phase flow and capillary effect tends to decrease with increasing suction. When suction exceeds the residual suction, the amount of capillary water and the contribution of capillary effect and suction towards the skeleton constitutive stress become negligible. Water transports in the soil pores only in the form of vapor as the water phase retreats to the micro-pores and becomes discontinuous in the residual zone of desaturation. In this stage, the rate of the desaturation of water becomes remarkably slower regardless of the large suction increase. This characteristic can be recognized from the flattened part of the SWCC at large suction values.

There is no unique SWCC but rather, there is an infinite number of scanning curves contained within a drying (desorption) boundary curve and an adsorption (wetting) boundary curve (Figure 3-3) (Fredlund et al., 2012). It is the primary drying and wetting curves that are of greatest relevance to unsaturated soil mechanics. The drying curve is easier to measure and is therefore the curve is generally measured in the laboratory. Most of the research studies published in the literature use the drying SWCC (Vanapalli et al., 2008). The scanning curves define the pathways between the boundary curves. However, for many geotechnical practical applications, a drying SWCC may be sufficient. Several models are available in the literature that takes into account of hysteresis. Several investigators have used SWCC as a tool in the prediction of 
engineering properties of unsaturated soils such as the coefficient of permeability and the shear strength.

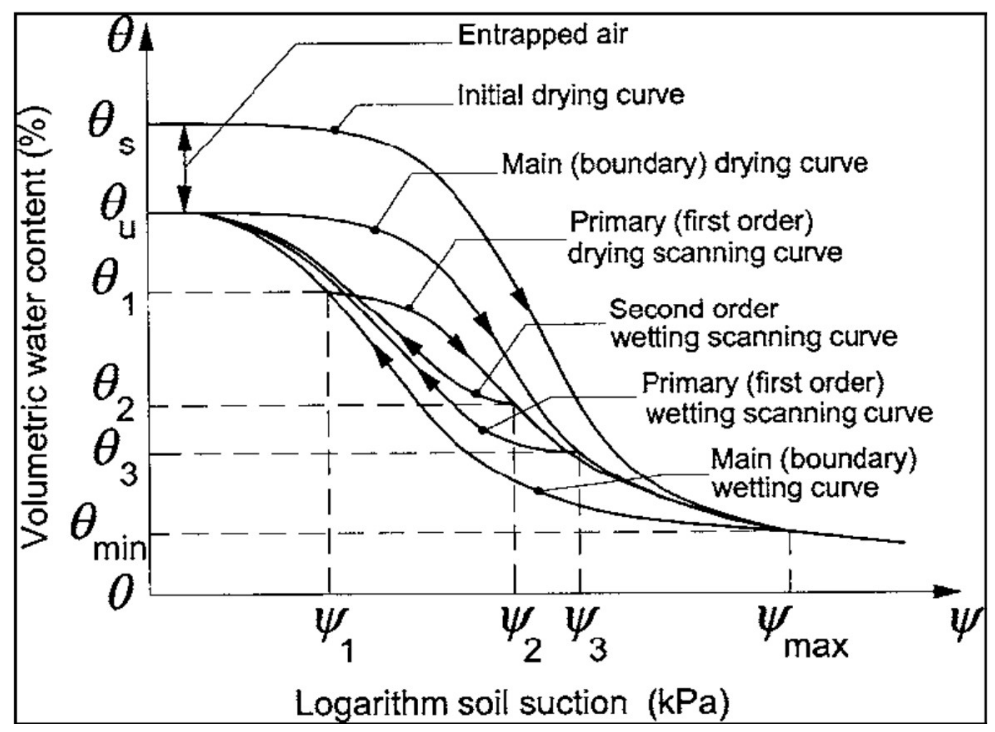

Figure 3-3 Bounding and scanning curves that comprisethe drying and wetting behavior of an unsaturated soil (Fredlund et al., 2012)

\subsubsection{Shear Strength}

Several investigators made an attempt to explain the unsaturated soils behavior using a single stress state variable. These equations proposed in the literature relate different stresses into a single stress variable through the inclusion of other soil properties. The best known single-valued relationship to describe effective stress in unsaturated soils is Bishop's equation (Bishop, 1959):

$$
\sigma^{\prime}=\left(\sigma-u_{a}\right)+\chi\left(u_{a}-u_{w}\right)
$$

where, $\sigma^{\prime}=$ effective stress and

$$
\chi=\text { soil parameter related to degree of saturation, } \mathrm{S} \text { which ranges from } 0 \text { to } 1 .
$$

The shear strength constitutive relationship provides a mathematical equation relating the normal and shear components of the stress tensor. Any one of several shear strength failure criteria could be extended from saturated soil conditions to unsaturated soil conditions. The Mohr-Coulomb failure criterion was extended to embrace unsaturated soils by (Fredlund et al. 1978). In a general form, the shear strength equation can be written as follows:

$$
\tau=c^{\prime}+\left(\sigma_{n}-u_{a}\right) \tan \emptyset^{\prime}+\left(u_{a}-u_{w}\right) f_{1}
$$


where, $\tau=$ shear strength;

$c^{\prime}=$ effective cohesion intercept;

$\sigma_{n}=$ total normal stress on the failure plane at failure;

$\phi^{\prime}=$ effective angle of internal friction;

$f_{1}=$ soil property function defining the relationship between shear strength and soil suction; the derivative of which [i.e., $d f_{1} / d\left(u_{a}-u_{w}\right)$ ], gives the instantaneous rate of change in shear strength.

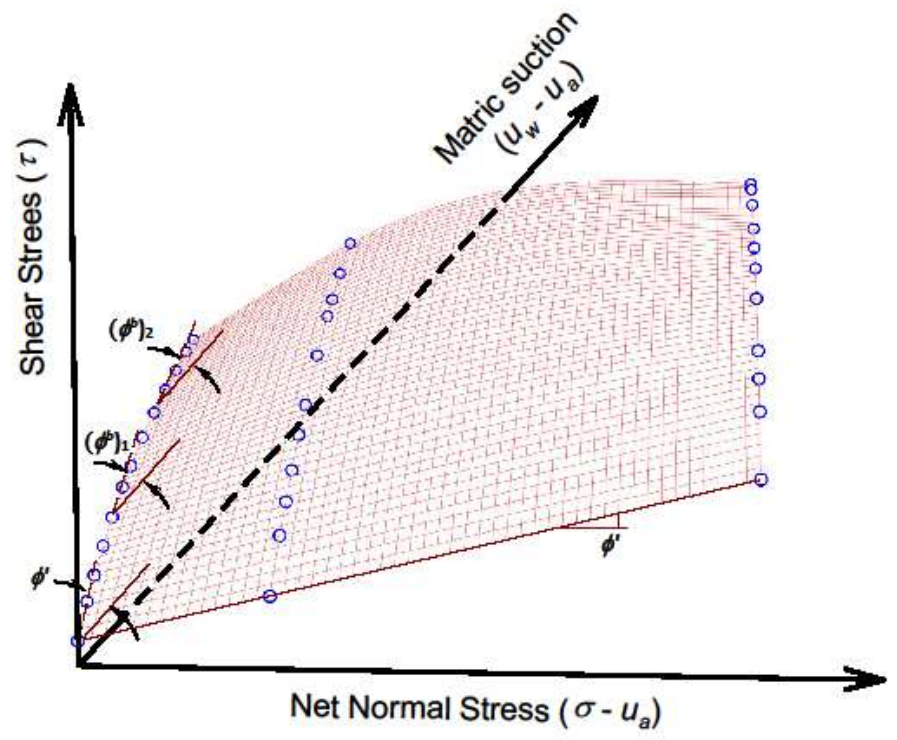

Figure 3-4 Extended Mohr-Coulomb failure surface written as a function of the stress state using Fredlund et al. 1978 equation

Figure 3-4 shows a three-dimensional constitutive surface with matric suction plotted perpendicular to the conventional two-dimensional Mohr-Coulomb plot. The shear strength parameters $c^{\prime}$, and $\phi^{\prime}$ are presented as saturated soil constants; however, the soil property function, $f_{l}$, varies in response to the amount of water filling the voids of the soil (i.e., it is a function of matric suction) (Gan et al., 2006).

There is a relationship between the SWCC and the shear strength (Vanapalli et al., 1996) as shown in Figure 3-5. 


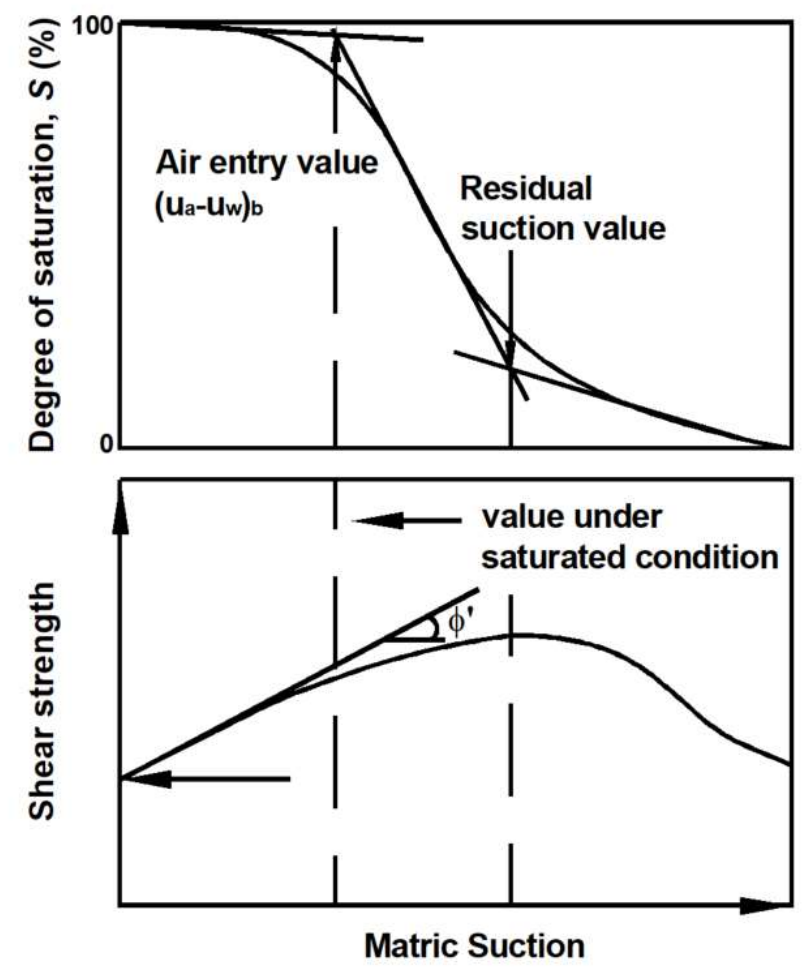

Figure 3-5 Curvature to the shear strength envelope with respect to matric suction (modified after Vanapalli et al. 1996)

The peak shear strength of an unsaturated soil bears a relationship to key points along the SWCC. Under low suction conditions (i.e., less than the air entry value of the soil), the derivative of $f_{l}$, tends to equal the tangent of the effective angle of internal friction of the saturated soil (i.e., $\tan \phi^{\prime}$ ) (Vanapalli et al., 1996). At high suction conditions (i.e., greater than residual soil suction), the derivative of $f_{l}$, has been shown to tend toward zero for several soils with varying silt and clay contents. Sandy soils have shown that the slope may even become negative at suctions greater than the residual value (Vanapalli et al., 1996).

A linear form of the general shear strength equation [i.e., 3.5] was published by Fredlund et al. 1978):

$$
\tau=c^{\prime}+\left(\sigma_{n}-u_{a}\right) \tan \emptyset^{\prime}+\left(u_{a}-u_{w}\right) \tan \emptyset^{b}
$$

The linear form is more appropriate for limited ranges of matric suction, particularly for finegrained soils. Some of the earlier unsaturated soils shear strength data sets (Bishop et al. 1960) 
show a close fit to the linear equation (Fredlund et al., 2012). The linear form is also more convenient to use for shear strength solutions.

Vanapalli et al (1996) proposed a semi-empirical procedure based on the equation proposed by (Fredlund et al., 1978) to predict the variation of shear strength with respect to matric suction using the saturated shear strength parameters and the SWCC as given below.

$$
\tau=c^{\prime}+\left(\sigma_{n}-u_{a}\right) \tan \emptyset^{\prime}+\left(u_{a}-u_{w}\right)\left(S^{K}\right) \tan \emptyset^{\prime}
$$

where, $S=$ the degree of saturation and

$$
\kappa=\text { is fitting parameter. }
$$

Several other empirical or semi-empirical procedures are available in the literature to predict or estimate the shear strength of unsaturated soils.

Most of data on shear strength of unsaturated soils appear to have been undertaken on soils that were initially compacted to an initial water content and density and then wetted such that the initial suction was allowed to come toward a zero value (Gan et al., 2006; Vanapalli et al., 1996). The soil specimens are then subjected to a series of increasing matric suctions along the desorption branch of the SWCC. Since there is hysteresis between the drying and wetting curve it would be anticipated that soils may exhibit a different shear strength envelope if first subjected to high matric suction conditions and then reduced to a series of suction values along the wetting curve.

Melinda et al. 2004 reported the shear strength results on a residual soil from Singapore tested along both the drying curve and the wetting curve. The results showed that the measured shear strengths along the drying curve are higher than those measured along the wetting curve. These results can be explained on the basis of the hysteresis of the SWCC that shows the matric suction having a greater cross-sectional area over which to act along the drying curve, for a specific suction. The difference in shear strength between drying and wetting conditions appears to be related to the magnitude of the drying and wetting hysteresis loop.

\subsection{The nature of compacted subgrade}

The soil shear strength and stiffness are two key properties that significantly influence the performance of subgrade. An increase in subgrade water content contributes to a decrease in 
strength and stiffness of fine-grained soil, resulting in higher plastic deformation under cyclic train loads, consolidation settlement or massive shear failures.

The compacted subgrade soil is a typical example of an unsaturated soil with its moisture and suction influenced by the environmental factors. Moisture content of compacted pavement materials during their service life can fluctuate seasonally due to environmental factors such as surface infiltration and evaporation, freeze-thaw cycles, and variation of the ground water table (Han et al. 2017). As compacted soils are initially in an unsaturated state, their hydraulic and mechanical behavior should be interpreted within the framework of the mechanics of unsaturated soils using suction (s) as the primary stress-state variable (Fredlund et al. 2012; Sheng, 2011).

The stiffness - suction and shear strength - suction relationships for unsaturated soils are nonlinear and sensitive to various factors such as the external stress, moisture regime, soil type, hydraulic hysteresis, soil structure, aging and testing technique. The soil-water characteristic curve (SWCC), which represents the moisture regime - suction relationship, is frequently used in the interpretation and prediction of the stiffness - suction and shear strength - suction relationships (Alonso et al. 1990; Fredlund \& Rahardjo, 1993; Alonso et al., 2013; Gallipoli et al. 2003; Gens, 2010; Sawangsuriya et al. 2009; Thu et al. 2007).

Figure 3-6(a) and Figure 3-6(b) show an example, for a glacial till from Saskatchewan, Canada (liquid limit $w_{L}=35.5 \%$, plastic index $I_{p}=18.7 \%$, optimum moisture content $w_{\text {opt }}=16.3 \%$ ), the SWCC and the peak shear strength $\left(\tau_{p}\right)$ - suction (s) relationship obtained from suction-controlled multistage direct shear tests under a net normal stress of $25 \mathrm{kPa}$ (data from Vanapalli et al. 1996). The relationship between the SWCC and the $\tau_{p}$ shown in Figure 3-6(a) and Figure 3-6(b) is corroborated by the testing data of other soils from the literature on the relationships between the SWCC and the stiffness and shear strength properties. 

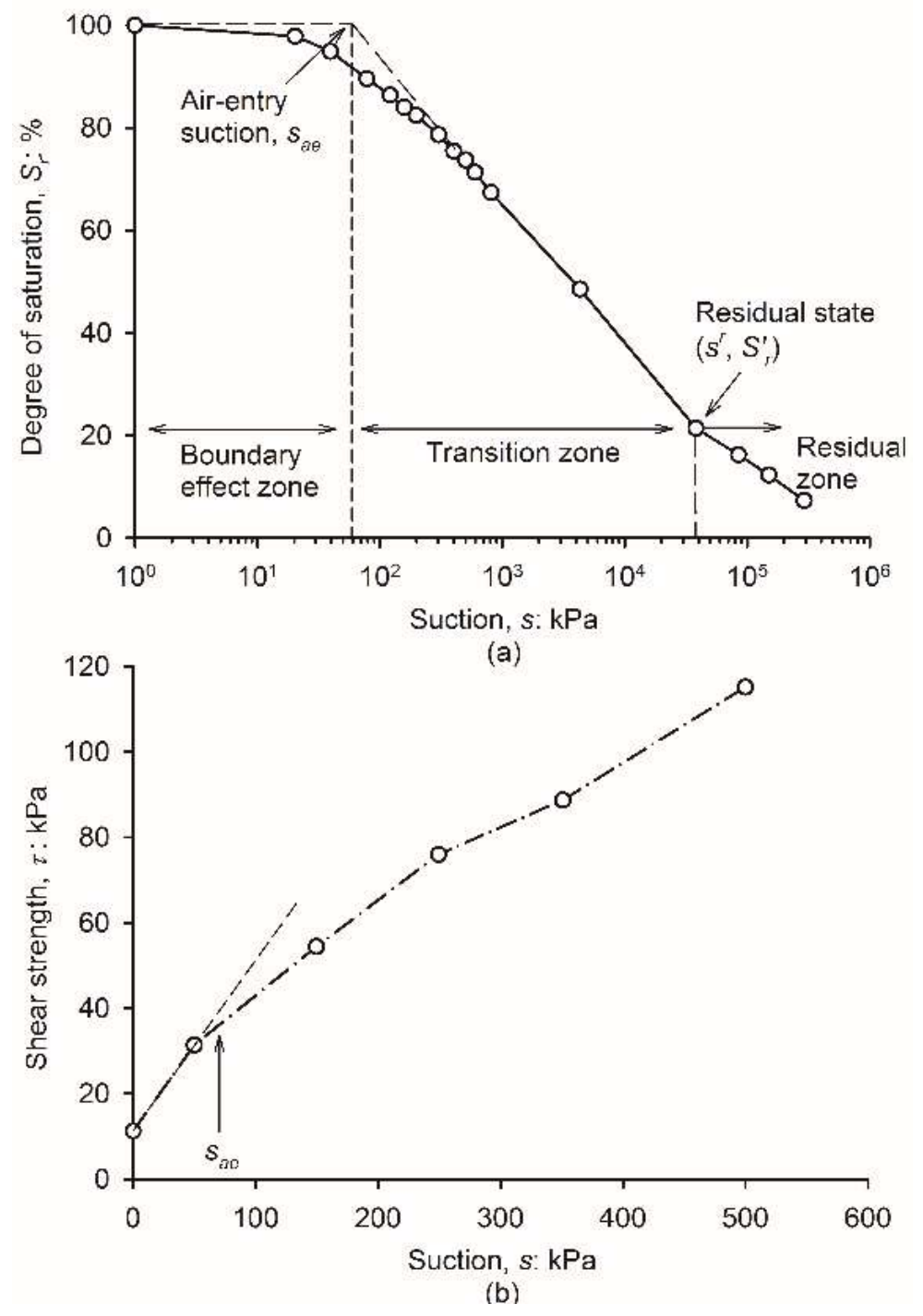

Figure 3-6 SWCC Curve and its relationship with shear strength (modified after Vanapalli et al., 1996)

It is well recognized from experimental investigations that the stiffness and shear strength properties exhibit non-linear evolution with suction and water degree of saturation (see Figure 3-6(b)) and also in (Cunningham et al. 2003; Escario \& Saez, 1986; Jotisankasa et al. 2009; Lu \& Kaya, 2014; Ng \& Yung, 2008; Ng \& Zhou, 2014; Oh et al., 2009; Sivakumar et al. 2013; Wheeler \& Sivakumar, 1995). Such a behaviour can be related to the variation of the capillary water and its associated capillary effect and suction, which contributes to the changes in the skeleton constitutive stress and therefore, the stiffness and shear strength properties (Alonso et al. 2010; Baker \& Frydman, 2009; Lu \& Likos, 2006). Within the boundary effect zone, the soil 
system stays in a stage of capillary saturation and can be treated as a continuum medium. The increasing suction fully contributes to the constitutive stress of the soil skeleton, resulting in a significant increase in the stiffness and shear strength properties. The contribution of suction becomes less efficient with further suction increase and the corresponding drainage of the capillary water in the transition zone, which results in a less significant increase in the stiffness and shear strength properties.

It should be noted that, apart from the suction, the physicochemical inter-particle forces such as the van der Waals and cementation forces also influence the mechanical properties (Baker \& Frydman, 2009; Lu \& Likos, 2006). The physicochemical inter-particle forces are different for different soil types. Their influence on the soil mechanical behaviour for natural soils may be secondary compared with that of suction within the lower suction range. At higher suction range, the influence of suction decreases with decreasing capillary water and the physicochemical interparticle forces start to dominate. For example, the stiffness and shear strength for cohesionless soils such as gravels and sands usually decrease in the residual zone of desaturation due to the decrease in the contribution of the suction and the weak physicochemical inter-particle forces (Escario et al. 1989; Ghayoomi \& McCartney, 2011; Oh et al. 2009; Wu et al. 1984). However, for cohesive soils, stiffness and shear strength behaviour in the high suction range varies for different soil types. Decreasing, constant or increasing trends of stiffness and shear strength behaviour are respectively reported for various soils (Cunningham et al. 2003; Escario et al. 1989; Geiser et al. 2006). It would be rather difficult to clearly determine or distinguish the boundary suction value or moisture regime where the influence of the physicochemical forces outweigh that of the suction. However, it is reasonable to assume, for natural soils, that the capillary effect and suction govern i) the mechanical behaviour of cohesionless soils over the whole suction range, and ii) the mechanical behaviour of cohesive soils in the lower suction range where liquid flow is typically predominant, especially the in-situ suction range which is typically between $0 \mathrm{kPa}$ and $600 \mathrm{kPa}$ (Cui \& Delage, 1996; Khalili \& Khabbaz, 1998; Vanapalli et al. 1996). Within higher suction range, physicochemical inter-particle forces should be taken into account, in addition to suction, for the reasonable interpretation of the mechanical behaviour of cohesive soils. 


\subsection{The Coefficient of Earth Pressure at Rest}

\subsubsection{Definition of Coefficient of Earth Pressure at Rest $\left(\mathrm{K}_{0}\right)$}

The coefficient of earth pressure at rest is a relationship between the in situ horizontal and vertical stress and usually expressed as a factor (Sivakumar et al. 2002). The relationship factor was first proposed by Donath in his 1891-paper for total stresses (Brooker \& Ireland, 1965; Hamouche et al. 1995) as Equation 3.7

$$
K_{0}=\frac{\sigma_{h}}{\sigma_{v}}
$$

where, $K_{0}$ is the coefficient of earth pressure at rest,

$\sigma_{v}$ is vertical earth stress, and

$\sigma_{h}$ is horizontal earth stress.

Considering the pore pressure, the horizontal and vertical effective stresses are used to express Ko', as seen in Equation 3.8 (Mesri \& Castro, 1987; Mesri \& Hayat, 1993; Schmertmann, 1983), and it will be used in this report as the coefficient of earth pressure at rest.

$$
K_{0}^{\prime}=\frac{\sigma_{h}^{\prime}}{\sigma_{v}^{\prime}}
$$

where, $K^{\prime}{ }_{0}$ is the Coefficient of Earth Pressure at Rest,

$\sigma_{v}^{\prime}$ is vertical effective stress, and

$\sigma_{h}^{\prime}$ is horizontal effective stress.

The above Equation 3.8 has a conditions of no lateral deformation under vertical loading (Mesri \& Hayat, 1993).

\subsubsection{The previous study}

Jaky (1944) presented a theoretical relationship between the $K_{0}$ value and the angle of internal friction $\phi^{\prime}$ by analyzing a talus of a granular soil mass. In this study, the angle of repose of the talus was equal to the angle of internal friction of the granular soil, and the lateral pressure acting on a plane passing through the apex of the talus and perpendicular to the base was the lateral earth pressure at rest. He divided a talus of granular soil mass into two zones including the outer zone and the inner zone. In the outer zone, sliding planes were developed and stresses on the 
planes were determined by the Rankine theory. In the inner zone, shear stress distribution on any horizontal plane was assumed to be a parabolic shape and decreased to zero at the center vertical plane of talus.

The relationship coefficient of earth pressure at rest as provided by Jaky (1944) is

$$
K_{0}=\left(1+\frac{2}{3} \sin \phi^{\prime}\right) \frac{1-\sin \phi^{\prime}}{1+\sin \phi^{\prime}}
$$

Mesri \& Hayat, (1993) pointed out that a granular soil mass forming a talus was loose, normally consolidated and young, and therefore, Jaky's analysis corresponds to loose normally consolidated young granular soils that have not been densified.

Jaky (1948) dropped out the $\left(1+\frac{2}{3} \sin \phi^{\prime}\right) /\left(1+\sin \phi^{\prime}\right)$ in Eq.3.9, and the coefficient of earth pressure at rest of normally consolidated loose granular soils, generally used in engineering practice, becomes

$$
K_{0}=1-\sin \phi^{\prime}
$$

Nevertheless, Mayne \& Kulhawy $(1982 ; 1983)$ provide a summary of the effects of stress history on $K_{0}$, including data compiled from over 170 different soils tested and reported by many researchers. They conducted a statistical analysis of this data and determined relationships between at rest earth pressure and soil stress history. Based on these results, Jaky's formula Eq. 3.10 was found to have close agreement with the data for normally consolidated soil and deviated significantly for overconsolidated soil. Mayne \& Kulhawy (1982; 1983) provided a relationship between $K_{0}$ and the overconsolidation ratio (OCR) that builds on Jaky's simplified formula as follows:

$$
K_{0}=\left(1-\sin \phi^{\prime}\right) O C R^{\sin \phi^{\prime}}
$$

Moreover, Feda (1984) objected that the same equation claims the dependence of $K_{0}$ on the strength parameter, although $K_{0}$ is a deformation parameter.

Cherubini et al (1990) found that values of $K_{0}$, calculated using Eq. 3.11, are 3.5\% less than the average measured values, which is practically acceptable. Hanna \& Al-Romhein (2008) compared the theoretical values predicted by Mayne \& Kulhawy (1982; 1983) with experimental results conducted on well-graded dry silica sand. The comparison indicated that Mayne and Kulhawy's formula provided good agreement with the experimental results of the coefficient of 
earth pressure at rest $K_{0}$ up to $\mathrm{OCR}=3.0$, whereas the theoretical values underestimated $K_{0}$ thereafter.

Despite its practical significance and attractive simplicity, Jaky's formula and its derivative (i.e., Eq. 3.9 and 3.11) claim the dependence of $K_{0}$ only on the soil internal friction angle, $\phi^{\prime}$. However, Feda (1984) proved theoretically that $K_{0}$ depends on soil deformation. The ignorance of soil deformation in calculating $K_{0}$ using Jaky's formula is considered a major deficiency, as stated by (Feda, 1984).

Massarsch (1986) proposed an empirical formula to estimate the $K_{0}$ of normal consolidated finegrained soils:

$$
K_{0}=0.44+0.42 P I
$$

where, $P I$ is the plasticity index.

Guo (2010) found that the coefficient of earth pressure at rest $K_{0}$ of granular materials is not a unique function of neither the critical friction angle $\phi_{c v}^{\prime}$ or the peak friction angle $\phi_{p}^{\prime}$. Instead, the effect of density and stress level on $K_{0}$ should not be neglected.

Zhao et al. (2010) conducted consecutive consolidated isotropically drained triaxial tests and concluded that the coefficient of the earth pressure at rest is not constant at high pressure, but shows an increasing trend as the consolidation stress increases. The methods of predicting $K_{0}$ values from the Jaky and Roscoe equations are not applicable for soils without cohesion with bilinear strength variations. The nonlinear characteristics of $K_{0}$ are related to the variation in the void ratio during compression. Zhao et al. (2010) also proposed linear functions for the calculation of $K_{0}$ values based on test results in order to interpret the rules of nonlinear variation for the coefficient of earth pressure at rest.

\subsubsection{The factors influencing the value of coefficient of earth pressure at rest}

The research of field and laboratory investigations of coefficient of earth pressure at rest, has made it clear that the value of coefficient of earth pressure at rest is affected by both the material properties of the soil and the stress history (Shin \& Santamarina, 2009). 


\subsubsection{Effect of Stress History (Unloading and Reloading)}

The horizontal stress is affected by the loading history of the deposit investigated according to (Hamouche et al. 1995; Shin \& Santamarina, 2009; Sivakumar et al. 2002).

The relationship between the radial and axial stress for Reid-Bedford sand under repeated load and unload cycles is shown in Figure 3-7 (Al-Hussaini, 1981).

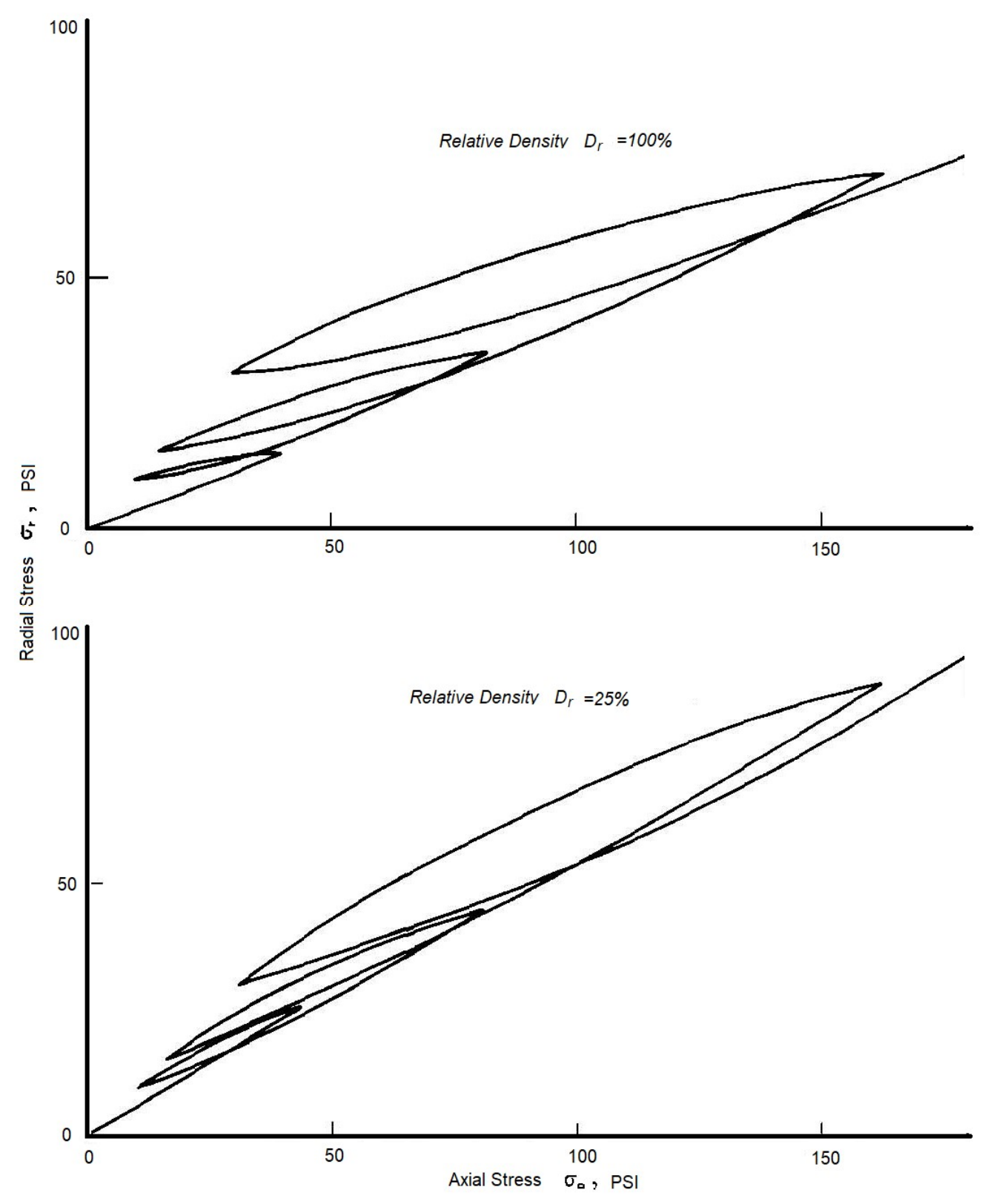


Figure 3-7 $K_{0}$, Relationship of radial versus axial stress for Reid-Bedford sand (Al-Hussaini, 1981)

The relationship for the first loading cycle may be approximated by a straight line. However, upon unloading, the relationship becomes nonlinear with a flatter curvature at the higher stress level, which then becomes concave downward with increasing slope as unloading continues. The relationship during first reloading is also nonlinear but concave upward with slope much flatter than the first loading cycle. This trend was similar for the dense specimen that exhibited a flatter slope than the loose specimen for any particular loading or unloading cycle. These results also indicate that the value of coefficient of earth pressure at rest is always lower on loading than unloading. It also indicates that the secant value of coefficient of earth pressure at rest increases with increasing number of cycles, which implies that coefficient of earth pressure at rest is dependent on stress history (Al-Hussaini, 1981).

Normally consolidated clay is often referred to a soil which only experienced primary loading, while overconsolidated clays have experienced preconsolidation pressures which are higher than the present overburden pressures due to unloading (Sivakumar et al. 2002). Many researchers consider overconsolidated clays has soils that have preconsolidation pressure higher than the present overburden pressure, regardless of what has caused the preconsolidation pressure. Sivakumar et al $(2002,2009)$ stated that the value of coefficient of earth pressure at rest is a constant during first loading that is horizontal stress and increases proportionally with vertical loading. However, during unloading process, the horizontal stress is no longer proportional and decreases with the vertical stress. The horizontal stress reduces at a slower rate than vertical stress, because the interparticle locking contributes a higher horizontal stress than the vertical stress.

The difference of coefficient of earth pressure at rest between loading and unloading is illustrated in Figure 3-8 (Sivakumar et al., 2002). For soil deposits with high overconsolidation values, with much higher preconsolidation pressure than the current loading, the horizontal stress is likely to be greater than the vertical stress. Hence, the value of coefficient of earth pressure at rest tend to increase with the overconsolidation ratio, OCR (Sivakumar et al. 2009). This has also been confirmed experimental studies by Hamouche et al. (1995). 


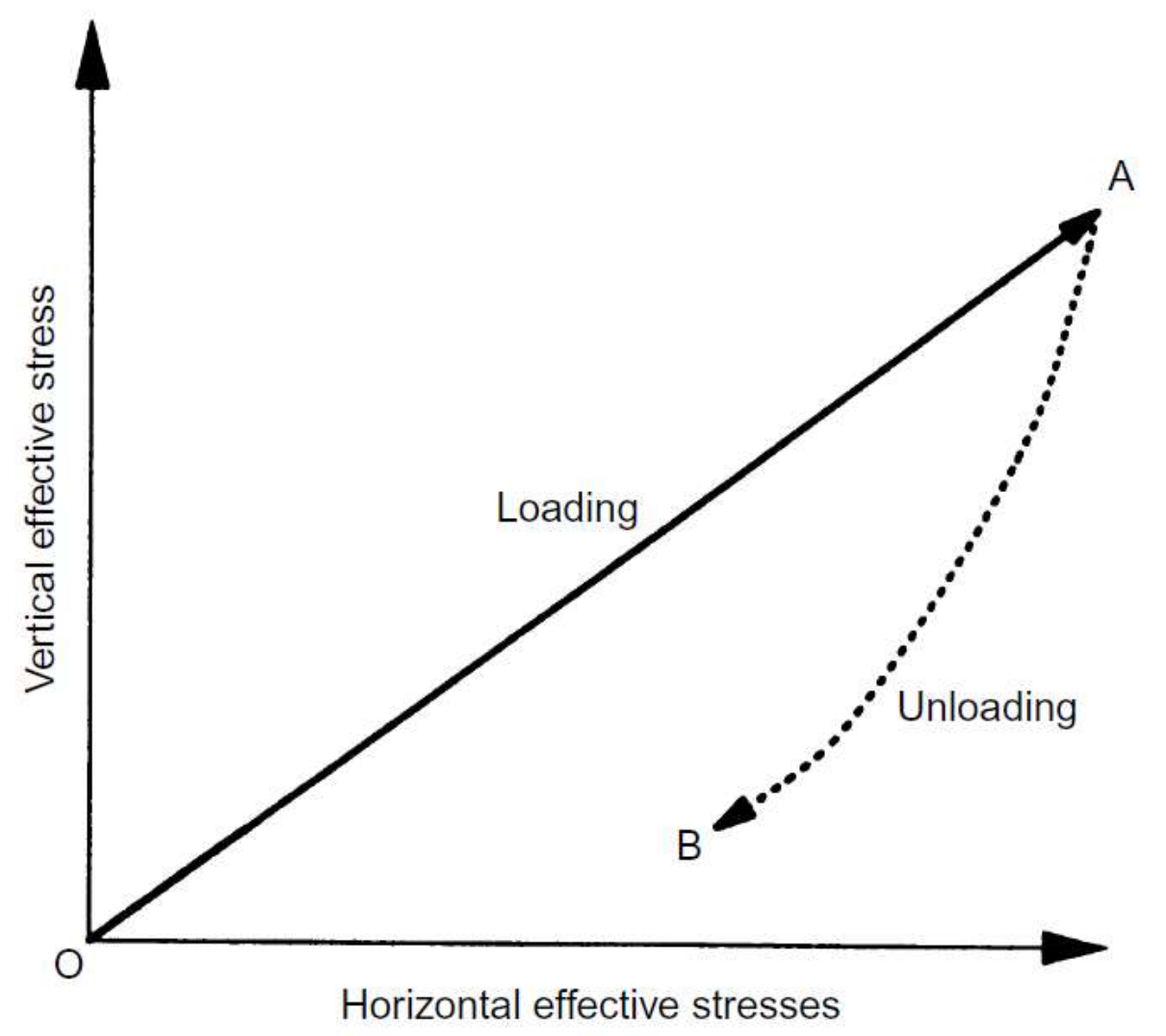

Figure 3-8 Variation of vertical and horizontal stresses during loading and unloading (Sivakumar et al. 2002)

OCR is defined in Equation 3.13 (Mayne \& Kulhawy, 1982; 1983).

$$
O C R=\frac{p^{\prime}{ }_{c}}{\sigma^{\prime}{ }_{v 0}}
$$

where, $p_{c}^{\prime}$ is the effective vertical preconsolidation pressure, and $\sigma_{v 0}^{\prime}$ is the current effective overburden pressure.

There is a clear link between coefficient of earth pressure at rest and OCR from several research studies (Keskin et al., 2004; Mayne \& Kulhawy, 1982; 1983; Sivakumar et al., 2009). As over consolidation ratio increases, the coefficient of earth pressure at rest also increases.

One straightforward example of such overconsolidated materials are clays deposited towards the end of the last ice age in Norway (Gylland et al. 2013). As the ice melted (unloading) and the ground rebound, the clays deposited in the seabed were brought up to become continent. 
Subsequent erosion resulted in further unloading of the overburden pressure and finally form overconsolidated clay materials.

\subsubsection{Time Effects}

As per the discussions summarized in earlier sections, the consolidation and overconsolidation characteristics influence the coefficient of earth pressure at rest. El-Emam (2011) suggested overconsolidation ratio of sandy soil is an important factor that affects the at-rest lateral earth force. However, consolidation characteristics are related to the time, due to this reason, time also has an effect on the coefficient of earth pressure at rest.

Several researchers concluded that significant aging effects occur in virtually all types of soils, including dry sands (Schmertmann, 1991; Tomás et al., 2007). These investigators found many examples that demonstrate soil aging over engineering times can cause a general 50 to $100 \%$ improvement effect in many key soil properties. These evidences indicate that most engineeringtime age-strengthening effects are drove by in situ effective stresses and result from increased basic soil friction, including dilatancy effects, but not from increased cohesion. These effects include grain slippage, soil-structure dispersion, increased interlocking, and a postulated internal arching of stresses. These investigators differentiated between chemical time effects that include thixotrophy and mechanical time effects that include secondary compression and other effects. Schmertmann (1991) argued that both types of time effects resulted in an increased strength of the material and that both involve the flocculation and dispersion of particles. On the other hand, thixotrophy is most likely to occur during very low effective stresses whilst mechanical time effects will dominate under higher stresses. Hence, the mechanical time effects will be much more pronounced from an engineering practice point of view.

\subsubsection{Chemical Changes}

Mesri \& Castro, (1987) confirmed that chemical changes can contribute to an increase in interparticle resistance, including cation exchange and the bonding of the soil fabric by components such as oxides, carbonates, silicates, and organic molecules. The increased resistance can be relatively small or strong that contribute to brittle links at particle contacts. Bjerrum (1967) stated exchange of cations and cementation are the most important chemical bonding effects in the relatively young Norwegian clays. Exchange of cations is a direct 
consequence of rainwater entering the clay. The basic factor governing the chemical stability of minerals in clay is the $p H$ value of the pore water; any change reducing the $p H$ value of the pore water will increase the rate of disintegration of the minerals, and vice-versa.

The geological and topographic conditions in Norway are such that as soon as a clay deposit rises above seawater level it will in almost all cases be subjected to a slow exchange of the original pore water by percolating rainwater. This will lead to a gradual removal of the $\mathrm{Na}^{+}$ions. This in itself has no great effect on the $\mathrm{pH}$ value, but rainwater contains dissolved $\mathrm{O}_{2}$, and $\mathrm{CO}_{2}$. $\mathrm{CO}_{2}$, lowers the $\mathrm{pH}$ of the pore water and the $\mathrm{O}_{2}$ coming into contact with organic matter forms humic acids which also reduce the $p H$-value. If this slow but persistent process advances to such an extent that the $\mathrm{pH}$ is reduced to a sufficiently low value, then a disintegration of feldspar, mica and chlorite will commence. The disintegration results in liberation of cations of higher order than $\mathrm{Na}^{+}$which collect on the surface of the clay particles. The effect of this base-exchange is to raise the plasticity of the clay and additional strength is developed. The disintegration also causes the liberation of other chemical compounds which tend to increase the $p H$ and thereby prevent the process. The development of structural strength by exchange of $\mathrm{Na}^{+}$ions by ions of higher order thus requires a continuous supply of $p H$-reducing agents to the clay (Bjerrum, 1967).

The $K^{+}$ions are liberated from the mineral lattice of feldspar and mica, two minerals which exist in all Norwegian clays. The $\mathrm{K}^{+}$ions are believed to be the dominant ones in the early phase of this process and govern the development of additional structural strength in the relatively young Norwegian clays (Bjerrum, 1967).

Fischer et al. (1978) investigated the process of cementation, in which sediments eventually develop from soils into rock under high pressure, also known as lithification. In clays exposed to this process, there exists additional chemical bonding in addition to the friction and cohesion found in uncemented clays. In addition, Fischer et al. (1978) also investigated the possibility of developing cementation in two normally consolidated samples of Drammen clay. The authors found that the strength of a normally consolidated clay increased with about $35-40 \%$ as a consequence of the cementation process. For a stiff clay the change in engineering properties was essentially the same regardless of whether the preconsolidation originated from mechanical overconsolidation or cementation. 
Thixotropy is a strength increasing process due to reversible changes in viscosity (Fioravante et al. 1998; Schmertmann, 1991). Thixotropic behaviour are able to stiffen with a great increase in strength over a short period of time and thereafter loose most of its strength and become a viscous fluid when exposed to some mechanical disturbance. Schmertmann (1991) argued that the process is the result of a dispersion-flocculation process occurring for instance during the deposition of sediments. Even when exposed to almost no effective stresses, particles will tend to accumulate due to attractive forces. Because of the low stress level, it takes almost no disturbance for the particles to break apart.

The interparticle force and soil structure of bentonite were notably affected by the salinity, whereas for kaolin and marine clay, the soil structure appeared insensitive to the pore fluid salinity (Yan \& Chang, 2015). The $K_{0}$ coefficient and friction angle of kaolin and marine clay were barely affected by the pore fluid salinity. However, as the salt content increased, the $K_{0}$ coefficient of bentonite decreased significantly and the friction angle increased noticeably (Yan $\&$ Chang, 2015). The mineral type may play an important role in the relationship between the salt content and $K_{0}$ coefficient. Due to the difference in the material structure, different minerals have different sensitivities to the ion concentration. For soils that mainly consist of sensitive minerals (bentonite), the effect of the salt content on the $K_{0}$ coefficient and friction angle was significant (Yan \& Chang, 2015). Ko predicted using Jaky's formula was close to the measurement for kaolin regardless of its salt content. The prediction became less promising in marine clay, for which consistently underestimation was seen, and the prediction error appeared to increase with the increase in salt content. Jaky's formula gave a reasonable prediction of $K_{0}$ for bentonite at higher salinity. Prediction using the Atterberg limits failed in all cases, particularly for bentonite at low salinity (Yan \& Chang, 2015).

\subsubsection{Moisture change}

Water table changes associated rainfall infiltration, evaporation or freezing can significantly influence the preconsolidation pressure (Tomás et al., 2007). When a material experiences drying, the loss of pore water will generate suction (Shin \& Santamarina, 2009). During repeated wet and dry cycles, very fine soils may experience high effective stresses due to the suction. The effect of moisture is likely to mainly affect the first few meters of a soil deposit, where the existing preconsolidation due to overburden load is quite small (Tomás et al., 2007). 
The laboratory tests performed by Abrantes \& Pereira de Campos (2019) suggest the coefficient of earth pressure at rest $\left(K_{0}\right)$ of the colluvium soil under saturated condition was equal to $K_{0}$ of 0.36 . This value is higher than the average value of $K_{0}$ of 0.26 , obtained under a suction of 10 $\mathrm{kPa}$, following a loading path. This is in agreement with other studies in the literature that suggest the $K_{0}$ value decreases with an increase of suction or decrease of the degree of saturation. Mahar \& O'Neill (1983) investigated the geotechnical properties of dried clays and suggested that the suction process may generate cracks in the material. These cracks will lead to variable suction force, resulting in high variability in both preconsolidation pressure and undrained shear strength.

\subsection{The Residual Shear Strength}

The residual shear strength is the minimum strength that a soil can offer to large shear displacements under given effective normal stresses. It is the available shear strength of landslides which underwent large displacements on a slip surfaces (Scaringi \& Di Maio, 2016). There is extensive research available in the literature during the past three decades for rational interpretation of the residual shear strength behavior (Mesri \& Shahien, 2003). The residual shear strength parameters depend on the composition of both the solid skeleton and the pore fluid (Scaringi \& Di Maio, 2016). In addition, several results reported in the technical literature, also suggest a dependence on the displacement rate, showing that the residual shear strength may increase, decrease or remain constant with the displacement rate.

\subsubsection{Drained residual strength of cohesive soils}

Lupini et al (1981) studied drained residual strength of cohesive soils and recognized three modes of residual shear behavior; namely, a turbulent mode, a transitional mode and a sliding mode. The mode depends on the dominant particle shape and the coefficient of interparticle friction.

The turbulent mode occurs when behaviour is dominated by rotund particles, or, possibly, in by platy particles in soils, when the coefficient of interparticle friction between these particles is high. Residual strength is typically high when no preferred particle orientation occurs and brittleness is due to dilatant behaviour only. The residual friction angle depends primarily on the 
shape and packing of the rotund particles and not on the coefficient of interparticle friction. A shear zone, once formed, is a zone of different porosity only and it is considerably modified by subsequent stress history.

The sliding mode occurs when behaviour is dominated by platy, low-friction particles. A low strength shear surface of strongly orientated platy particles then develops. The residual friction angle depends primarily on mineralogy, pore water chemistry and on the coefficient of interparticle friction. A shear surface, once formed, is not significantly affected by subsequent stress history. Brittleness during first shearing is due primarily to preferred particle orientation. The transitional mode occurs when there is no dominant particle shape, and involves turbulent and sliding behaviour in different parts of a shear zone. The properties of the soil in residual shear change progressively across the transitional range from those of turbulent shear to those typical of sliding shear. In this mode the residual friction angle is sensitive to small changes in grading of the soil, and the changes in grading required to cross this range entirely are typically small.

A soil which will fail internally in turbulent shear may fail at least partly in sliding if it is sheared against a smooth, hard interface.

The type of shearing mode can be determined by examining brittleness with a special sequence of loading and by examining the post-failure structure of the soil. The residual friction angle depends on the normal effective stress and this dependence is typically greatest for the sliding mode of behaviour.

The type of shearing mode to a much lesser extent and the magnitude of the residual strength correlate best with the granular void ratio of the soil defined as the ratio of the volume of platy particles plus voids to the volume of rotund particles. This correlation is not effective for the sliding mode and, if high friction platy particles are present, these may behave as rotund particles. The shape of clay mineral particles present is of great importance. The correlations of change in shearing mode with the granular void ratio depend on the relative size of the platy and rotund particles and on the grading of the rotund particles.

There are no unique correlations between residual strength and gradation or soil index properties. However, such correlations are valuable in studying the residual strength provided they are 
investigated properly reflect changes in the more fundamental properties of particle shape, grading, mineralogy, pore water chemistry, etc.

\subsubsection{Correlation for residual strength}

Collotta et al. (1989) proposed correlation for residual strength evaluation in form of Eq. 3.14.

$$
\sigma_{R}^{\prime}=c_{R}^{\prime}+\sigma_{v c}^{\prime} \tan \phi_{R}^{\prime}
$$

where, $\sigma_{R}^{\prime}$ is the residual shear strength,

$c_{R}^{\prime}$ is residual apparent cohesion intercept,

$\phi_{R}^{\prime}$ is residual friction angle, and

$\sigma_{V C}^{\prime}$ is vertical stress.

The suggested correlation confirms that the residual friction angle is influenced by both the clay fraction (CF) and the mineralogical composition of the clay. The mineralogy factor is indirectly reflected in the liquid limit (LL), and plasticity index (PI). So the proposed correlation relates residual friction angle to a parameter that combines CF, LL and PI.

\subsubsection{Residual Shear Strength Mobilized in First-Time Slope Failures}

Mesri \& Shahien (2003) reviewed the long-term stability of stiff clay and clay shale slopes by reanalyzing 99 slope failures in 36 soft clays to stiff clays and clay shales. Some key conclusions from this study are summarized below.

1) Most stiff clays and clay shales are not homogeneous. They are usually stratified and may include hard to soft or permeable to impermeable layer interfaces, bedding planes and separations, laminations, or thin weak continuous seams.

2) Erosion and unloading, including removal of lateral support, lead to swelling, fissuring, and softening. The end result of softening is the fully softened condition with a shear strength equal to that of the normally consolidated mineralogical composition of the stiff clay or clay shale. Any state of stiff clay or clay shale before the fully softened condition is reached is said to be an "intact" condition. The intact condition is quite variable, because different degrees of fissuring and softening are possible. Stiff clay and shale masses may include sheared zones in which plate shaped clay mineral particles are parallel-oriented to the maximum extent possible in the direction of shearing. This is the residual condition. 
3) The relationships between shear strength and effective normal stress for all conditions of stiff clays and shales - intact, fully softened, and residual - are curved, and there is no shear strength at zero effective normal stress. A convenient method for describing the nonlinear intact, fully softened, and residual shear strength envelopes is to employ secant friction angles, respectively, that are functions of the effective normal stress. There are some reliable empirical information based on secant fully softened and secant residual friction angles of stiff clays and clay-shale mineralogical compositions characterized by Atterberg's plasticity index in a practical range of effective normal stresses. However, caution should be exercised in the use of empirical correlations for friction angles because for certain stiff clay, shale, and mudstone compositions, sample preparation may have a significant effect on Atterberg limits. Also, the plasticity index of weak seams may be different from that of the scarp cutting across the laminations.

4) On reactivated slip surfaces of landslides in stiff clays and clay shales the residual condition has been reached, and the mobilized shear strength is equal to the residual shear strength from laboratory reversal direct shear or ring shear tests, independent of time after initial failure.

5) In first-time slope failures in unstratified stiff clays of low plasticity, the mobilized strength is equal to the intact strength from laboratory specimens because there is little post peak reduction in strength.

6) The fully softened shear strength is the lower bound for mobilized strength in first-time slope failures in homogeneous soft to stiff clay slopes and on the part of the slip surface cutting across bedding planes and laminations in stiff fissured clays and shales.

7) Part of the slip surface for first-time slope failures may be at the residual condition. In stiff clays and shales either the residual condition already exists along bedding planes and laminations before a cut is made or it develops by progressive deformation. Sufficient strain energy to reach the residual condition is available along nearly horizontal surfaces, including bedding planes and laminations. When shearing strain is localized in thin weak bands, and clay particles are already substantially oriented parallel to the direction of shearing, rather small displacements will cause the clay to reach the residual condition.

8) Delayed first-time failure of slopes in stiff clays and clay shales is caused by (i) timedependent rise of pore water pressure toward the steady seepage condition, swelling, 
decrease in effective stress and shear strength, (ii) fissuring and softening, and (iii) development and propagation of the residual condition into the slope on nearly horizontal surfaces, including layer boundaries, bedding planes and partings, laminations, or weak seams.

9) Selection of potential slip surfaces for stability analyses of natural and excavated slopes should be based on a knowledge of geology. Special attention should be directed toward structural features such as presheared surfaces produced by old landslides, tectonic or glacial deformation, or downslope creep, as well as to lithological details such as horizontal or subhorizontal bedding planes, laminations, and weak seams that are likely to drop to the residual condition after relatively small shear displacements, measured in millimeters or centimeters as opposed to meters as commonly assumed for homogeneous clays or across laminations. For existing slopes, locating the position and shape of the critical slip surface by trial and error may be aided by observations of movements. In the absence of well-defined weak surfaces, including pre-existing shear surfaces, the planar basal portion of the critical slip surface in stiff clays and shales should be selected parallel to the bedding and at the level of the base of the slope.

\subsubsection{Residual shear strength of unsaturated soils via suction-controlled ring shear testing}

Results from a comprehensive series of suction-controlled ring shear (RS) tests on statically compacted specimens of silty clayey sand (SC-SM) and silty sand (SM) soils were presented by (Hoyos et al. 2014). The experiments were conducted in a newly developed servo/suctioncontrolled RS apparatus that is suitable for testing unsaturated soils under large deformations via axis translation technique. The results reflect the important role played by matric suction on residual shear strength properties of unsaturated soils. For the range of net normal stresses and suction states investigated, the increase in residual shear strength with increasing suction was found to be virtually linear for SM soil, but significantly nonlinear for SC-SM soil. Multi-stage test results also appear to confirm that the residual shear strength of compacted soils is independent of both the pre-shearing and the suction histories undergone by the soil. Results, in general, suggest that a conceptual residual shear strength framework for unsaturated soils, similar to that postulated for peak shear strength, could eventually be devised as more experimental evidence of this kind is made available. Further investigations, including Environmental 
Scanning Electron Microscopy (ESEM) technology, are necessary to correlate and further substantiate the observed phenomena with changes in soil particle gradation, aggregation and plasticity as the soil is subjected to suction controlled ring shearing.

\subsubsection{Residual shear strength of fine-grained soils}

The following conclusions are drawn by (Eid et al., 2015) based on the results of soil and interface shear testing at low effective normal stresses (between 3 and $6.7 \mathrm{kPa}$ ) using a modified torsional ring shear apparatus and the macroscale interface direct shear test device.

1) The secant residual friction angle of soil decreases with increasing liquid limit and clay-size fraction. These soil parameters have a similar effect on the measured interface residual friction angles that are also lower for smoother surfaces. The change in effective normal stresses within the range utilized in this study did not show a considerable effect on the measured residual friction angles of soils and interfaces;

2) For low effective normal stresses, the clay-size fraction, as an indication of particle size and shearing mode, has less influence on the measured residual friction angle than the influence of the liquid limit that indicates the clay mineralogy and particle shape;

3) Correlations were developed to help in estimating residual shear strength at low effective normal stresses for soil types similar to those utilized in the current study. These describe the secant residual friction angle as a function of soil liquid limit and clay-size fraction as well as plasticity index. Since the residual shear strength envelope of most fine-grained soils is known to be nonlinear especially at low effective stress ranges, the newly developed correlations can assist in avoiding significant underestimation of residual shear strength angles that would occur when using current correlations that are developed for high effective normal stress ranges. These also avoid overestimating the drained residual friction angles of such soil types when using residual strength expressions, the development of which is influenced by testing soils of distinct contents (i.e., foraminifera, faecal pellets, carbonates, allophane, or halloysite) at low effective normal stresses and consequently do not consider the effect of soil plasticity; 
4) A correlation and a simple equation have been suggested for estimating the interface residual friction between fine grained soils and solid surfaces sheared at low effective normal stresses as a function of the surface average roughness of the solid surface and the soil residual friction angles. The residual interface efficiencies (i.e., the ratio between soil and interface friction angles) determined using the introduced correlation and equation compare well with those reported in the literature for high effective normal stresses, provided that the soil and interface residual shear strengths that are estimated at the same effective normal stress range are used for efficiency calculations;

5) Using the normalized roughness seems to be ineffective in developing a better correlation to estimate the residual interface efficiency for fine-grained soils. It is advocated that the surface roughness alone may not adequately characterize a given surface. Parameters such as hardness, yield strength, stress-strain behavior of solid material, and compatibility between soil particle size and interface surface roughness are likely to impact the overall interface frictional response observed at soil-solid interfaces. Further studies are warranted to explore these aspects.

\subsubsection{Drained residual shear strength at effective normal stresses relevant to soil slope stability analyses}

Eid et al. 2016 have undertaken to evaluate the results from a comprehensive torsional ring shear test program conducted to measure the drained residual shear strengths of clays, silts, mudstones, and shales at the wide range of effective normal stresses relevant to slope stability analyses. It was found that nonlinearity of the residual shear strength envelopes is most pronounced for effective normal stresses lower than $50 \mathrm{kPa}$. For effective stresses equal or higher than $200 \mathrm{kPa}$ that are occasionally mobilized in slope failures, these envelopes can be approximated as straight lines. The influence of clay-size fraction, which is the governing factor in developing different shearing behaviors, on the measured residual friction angle decreased with decreasing the effective normal stress level.

The work led to the development of new residual shear strength correlations for sedimentary soils as a function of soil index parameters and a wide range of effective normal stress levels (i.e., $10 \mathrm{kPa}$ to $400 \mathrm{kPa}$ ). This is a significant advancement since the currently available 
correlations do not cover the residual strength at effective normal stresses lower than $50 \mathrm{kPa}$, and also between $100 \mathrm{kPa}$ and $400 \mathrm{kPa}$. The new correlations are suitable for fine-grained materials with mostly plate-like clay particles. It is noted that, they would underestimate the drained residual friction angles of soils with distinct contents - such as carbonate soils, and soils that contain allophan, halloysite, or foraminifera - that are unlikely to have particle rearrangement towards some preferred orientation.

For shales, mudstones, and heavily over consolidated clays, the liquid limit and clay-size fraction used in developing the presented correlations were derived from a modified sample preparation procedure that involves ball-milling to disaggregate the particles of such indurated materials. To facilitate the use of the empirical shear strength correlations introduced herein, a set of new equations were developed - using previously published data - to convert the index parameters derived from the commonly used standard procedures to result in indices equivalent to those derived from the ball-milled sample preparation procedure.

The suitability of the new correlations in predicting the residual strength was verified through comparisons with back-calculated shear strength data reported in the literature as well as results yielded from similar existing correlations. It was revealed that accounting for the effect of normal stress is an important consideration in arriving at better predictions using such empirical correlations. New simple formula was generated to express the residual shear strength correlations developed in this study. The formula should facilitate incorporating the nonlinearity of the residual shear strength envelopes in slope stability software.

\subsubsection{Influence of displacement rate on residual shear strength of clays}

Shear tests under controlled displacement rates were carried out by (Scaringi \& Di Maio, 2016) on a kaolin, a bentonite, on their mixtures with sand at various percentages, and on the clayey soil of the Costa della Gaveta earthflow. The range $10^{-4}-10^{2} \mathrm{~mm} / \mathrm{min}$ of displacement rate was investigated. The results relative to the material mixed with distilled water show that the mixtures clay-sand with clay fraction $\geqslant 50 \%$ exhibit positive rate effects which increase with the clay fraction content. The rate effect becomes significant for displacement rate in the order of $\mathrm{mm} / \mathrm{min}$, with slight differences dependent on the used experimental shear apparatus. Results consistent with those of artificial mixtures are found on the Costa della Gaveta soil, the clay fraction of which is about $50 \%$. 
The results relative to the material mixed with $\mathrm{NaCl}$ solutions at various concentrations show that the rate effect increases with the pore solution concentration. Since the increase in salt concentration also makes the material void ratio decrease greatly, the observed strength improvement could be reasonably attributed to the increasing number of solid-solid contacts that probably endeavours the turbulent shearing mechanism.

The independence of residual shear strength on the displacement rate in the range $10^{-6}-10^{-1}$ has been confirmed by the results of shear tests performed under controlled shear stress conditions. This latter procedure can be promisingly improved for the evaluation of rate effects in a wider rate range.

\subsubsection{Effect of shear rate on the residual shear strength of pre-sheared clays}

Habibbeygi \& Nikraz (2018) investigation the shear strength behaviour of a pre-sheared clay to examine the effect of shear rate on the residual shear strength. Based on the results of the ring shear tests, the following conclusions have been derived:

1) There is an immediate increase of residual strength in comparison with the slow residual strength when the shear rates increase. In fact, there is a positive rate effect on the residual strength at a small displacement.

2) The fast residual strength of pre-sheared clays increases with an increasing applied normal stress.

3) The peak residual strengths of the pre-sheared clay in the fast shear steps are dependent on the rates of shear displacement. The fast residual strengths increase the slow residual strength when the rates increase. Moreover, the maximum peak residual strength of the fast steps occurs at the displacement rates of 50 and $200 \mathrm{~mm} / \mathrm{min}$.

4) There is a drop in the fast residual strength on top of the increase in the displacement for all various shear rates and the applied normal stresses.

5) There is a positive and negative effect of displacement rate on the residual strength for the rates greater than $50 \mathrm{kPa}$, which requires more research on the shear behaviour of presheared clayey soils at fast shearing conditions. 


\section{CHAPTER 4 \\ SIMULATION OF PROGRESSIVE SHEAR FAILURE IN SUBGRADE}

This chapter includes assumptions, equations, and programming for simulating the progressive shear failure and finding out shear failure plane.

\subsection{Assumptions of progressive shear failure in Subgrade}

Progressive shear failure is the plastic flow of the soil caused by overstressing at the subgrade surface under repeated loading. The subgrade soil gradually squeezes out from under the tie and then upward at the tie end, following the path of least resistance as shown in Figure 4-1 (Li et al., 2016). This is primarily a problem with fine-grained soils, particularly those with high clay content. The addition of more ballast above the subgrade squeeze zone results in an increase in ballast depth and a corresponding tendency for a reduction in stress at the subgrade level, which might improve subgrade stability. However, the depression in the subgrade surface will trap water that can further soften the subgrade. 

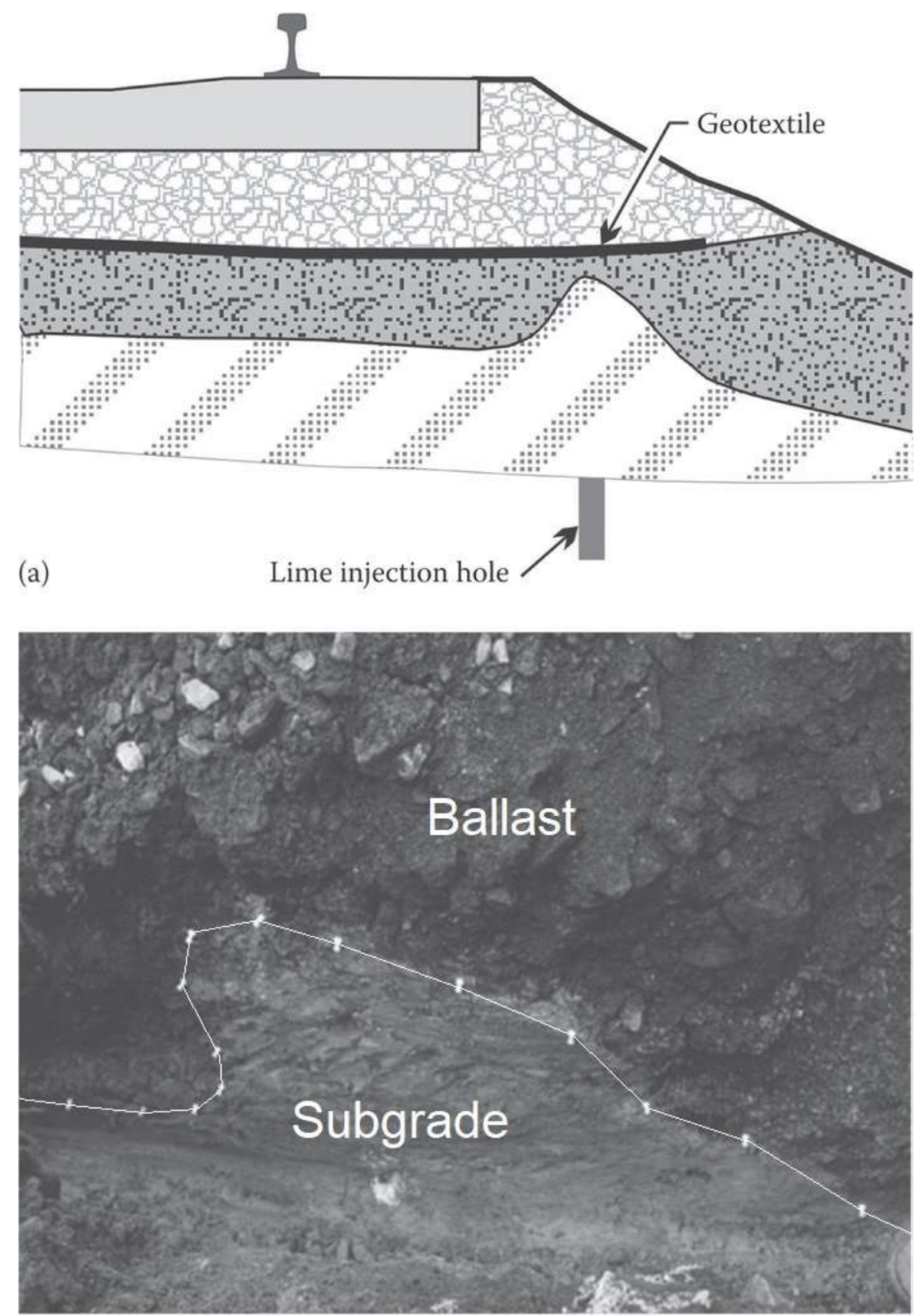

(b)

Figure 4-1 Subgrade squeeze at end of tie (Li et al., 2016):

(a) track cross section with a subgrade squeeze and (b) subgrade squeeze and lime injection hole

The above descripted progression of progressive shear failure could be broken down and simulated with following steps. 
1) The progressive shear failure typically initiates within a weak zone of the subgrade. Figure 4-2 shows series of elements on a typical shear failure plane within a railway subgrade. The elements 0 through 6 are zoomed-in and highlighted along a simulated failure plane. The stresses within these elements typically increase in the foundation due to an approaching train on the track, and the stresses decrease in the foundation when the train is leaving away on the track.

2) As the train approaches and contributes to a significant increase in the foundation stress, the (shear) stress within an element of the weak zone increases too. When stress exceeds the shear strength of the element, i.e. the shear stress in the element is above the Mohr Coulomb shear failure envelope (see Figure 3-1), the element will fail. We name this first failed element as primary element (i.e. element 0 shown in Figure 4-2). Figure 4-3a shows the shearing stress on the failed element.

3) In spite of the shear failure in the primary element, there is still some limited strength in the form of residual shear strength (see Figure 4-3a and Eq. 4.11 in Section 4.2) on failure plane. For this condition, there is an unbalanced shear stress (see Figure 4-3b and Eq. 4.13 in Section 4.2) which equals shear stress generated by train load minus the residual shear strength. This unbalanced shear stress will be transferred to the neighboring elements (or zones) -- the first element, i.e. the element 1 in Figure 4-2.

4) The first element, under the additional stress (i.e., unbalanced stress) from the primary element, has a new stress state (see Figure 4-3b \& c).

5) As the train comes, the stress within the first element continues increase and may exceeds the shear strength of the soil (see Figure 3-1). Under such a scenario, the first element fails too under shear loading (see Figure 4-3a).

6) After first element fails, similar to the primary element, the unbalanced shear stress transfer to its neighboring secondary elements (i.e. see, the element 2 in Figure 4-2).

7) The shear stress within the elements typically increase with the train approaches closer. Due to this reason, the failure may extend to the second, third and fourth elements (i.e. element 2, 3, and 4 in Figure 4-2) as the stress increase. These increasing loads may contribute to the failure plane finally reaching the surface of Subgrade (see Figure 4-2). 
8) The stresses in the elements decrease after the first pair of wheels of the train passes these elements (or weak zone), and the progressive shear failure plane will cease extension if the failure plan has not reached the surface of subgrade.

9) The stresses in the subgrade increase with the approach of the next pair of wheel loads. The above mentioned progressive shear failure continues with the repeated loads of passing train.

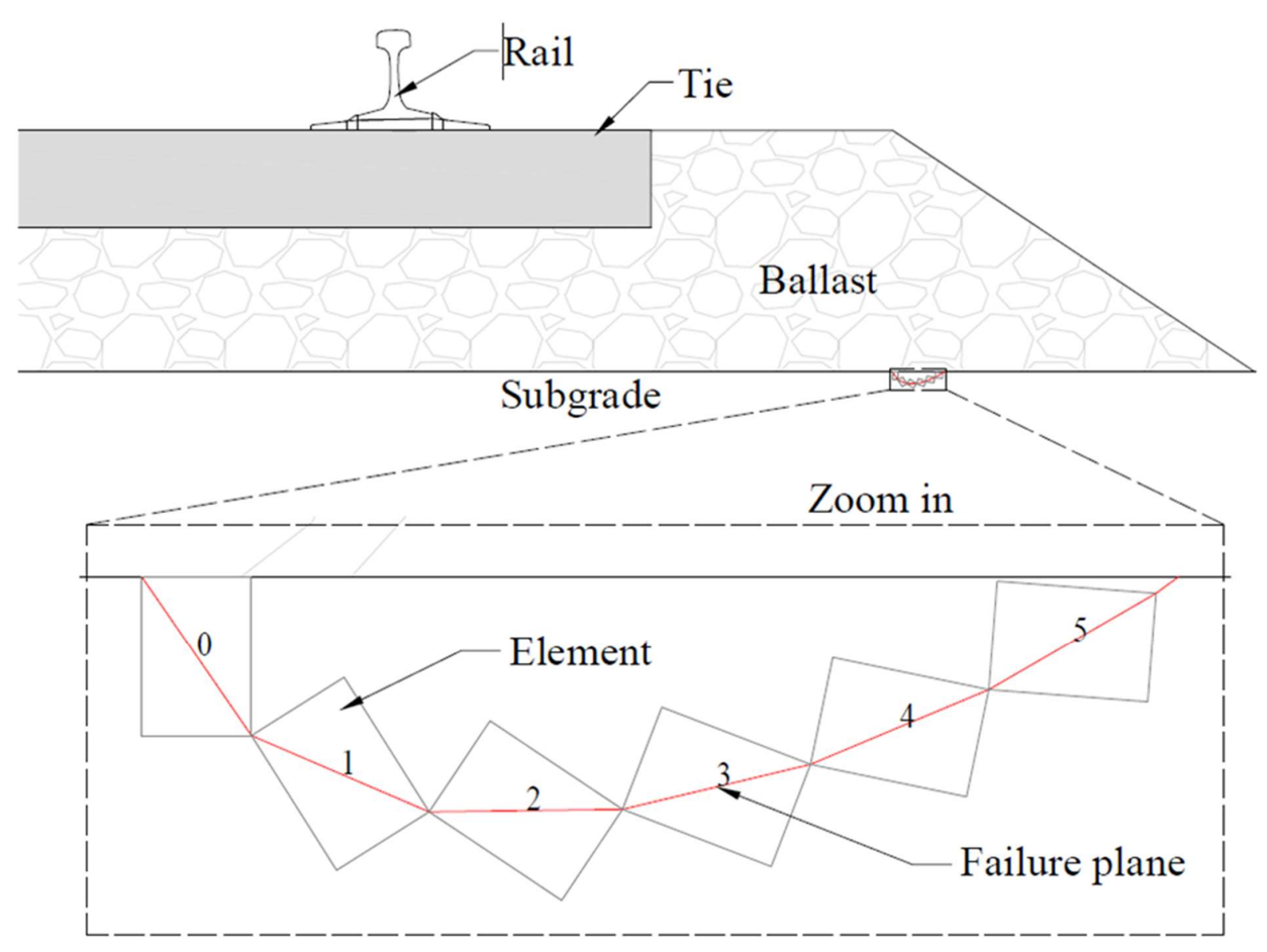

Figure 4-2 Failure elements and plane in Subgrade 

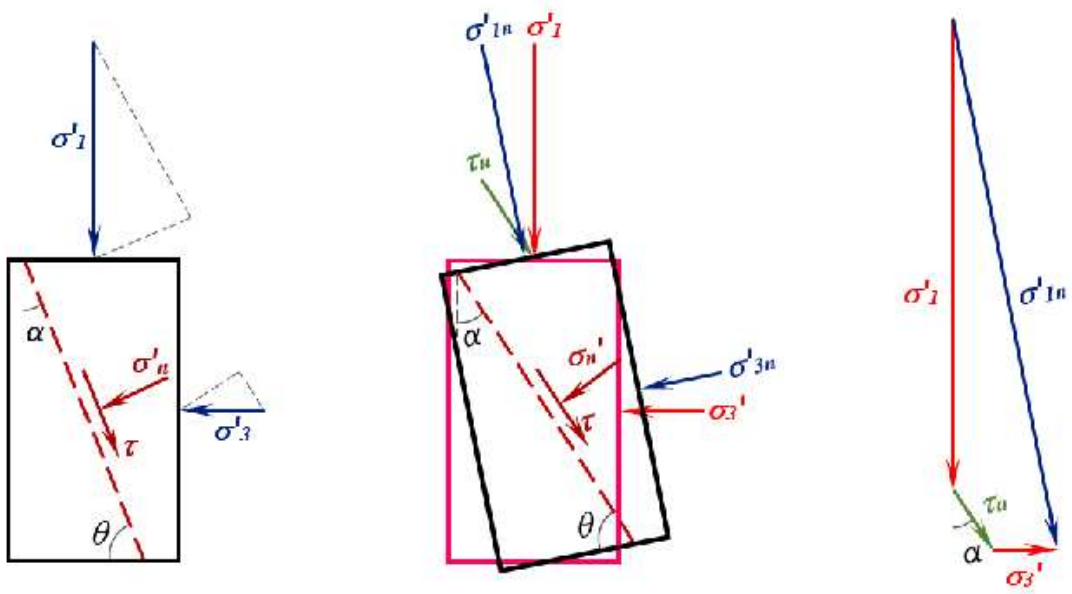

Figure 4-3 Failure element and its stresses:

a. Stress status and failure plane in an element.

b. New stresses status as the unbalanced shear stress from previous element is transferred in.

c. Calculating new major principle stress according to initial principle stresses and unballanced shear stress from previous element

\subsection{Shear Failure Criterion and Stresses in Subgrade}

During above described progression of progressive shear failure, element shear failure and stress transfer are calculate and simulated with the following equations summarized in this section.

1) Mohr-Coulomb failure criteria in terms of effective shear strength parameters (Figure 3-1):

$$
\tau_{f}=c^{\prime}+\sigma_{f}^{\prime} \tan \phi^{\prime}
$$

where $\tau_{f}$ is shear strength at failure, $c^{\prime}$ is effective cohesion, $\sigma_{f}^{\prime}$ is effective stress at failure, and $\phi^{\prime}$ is the effective stress friction angle.

This is a principle equation to identify the element failure.

2) Extension of Mohr-Coulomb failure criteria in unsaturated soil mechanics by (Vanapalli et al., 1996):

$$
\tau=c^{\prime}+\left(\sigma_{n}-u_{a}\right) \tan \phi^{\prime}+\left(\sigma_{a}-u_{w}\right) \Theta^{k} \tan \phi^{\prime}
$$


where $\tau$ is shear strength, $\left(\sigma_{n}-u_{a}\right)$ is the net normal stress, $\sigma_{n}$ is the total net normal stress, $u_{a}$ is the pore-air pressure, $\left(u_{a}-u_{w}\right)$ is the matric suction, $u_{w}$ is the pore-water pressure, $\Theta$ is the degree of saturation and $\kappa$ is fitting parameter.

The progressive shear failure can be considered mainly a subgrade surface failure ( $\mathrm{Li}$ et al., 2016), so the variation of matric suction $\left(u_{a}-u_{w}\right)$ is small. To simplify the calculation of shear strength, we can ignore the variation of shear strength $\left(u_{a}-u_{w}\right) \Theta^{K} \tan \phi^{\prime}$ contributed by matric suction and assume it is a constant in the progressive shear failure zone, so we consider it is part of apparent cohesion, $c$. i.e.

$$
c=c^{\prime}+\left(u_{a}-u_{w}\right) \Theta^{K} \tan \emptyset^{\prime}
$$

Then, the Mohr-Coulomb failure equation (4.1) can be used to instead of equation (4.2) to study the progressive shear failure under unsaturated condition.

3) The normal and shear stresses at failure expressed with principal stresses:

Based on Mohr-Coulomb failure equation (3.2 or 4.1) and Figure 3-1, equation (4.4) and (4.5) could be derived on failure envelope. The normal and shear stressed at failure on failure plane can also be calculated with major and minor principal stresses.

$$
\begin{aligned}
\tau_{f} & =\frac{\sigma_{1}^{\prime}-\sigma_{3}^{\prime}}{2} \sin 2 \theta \\
\sigma_{f}{ }^{\prime} & =\frac{\sigma_{1}^{\prime}+\sigma_{3}^{\prime}}{2}+\frac{\sigma_{1}^{\prime}-\sigma_{3}^{\prime}}{2} \cos 2 \theta=\sigma^{\prime}{ }_{1} \cos ^{2} \theta+\sigma^{\prime}{ }_{3} \sin ^{2} \theta
\end{aligned}
$$

where $\sigma_{l}^{\prime}$ is the major principal stress, $\sigma_{3}^{\prime}$ is the minor principal stress, $\theta$ is angle between direction of minor principal stress and shear failure plane (see Figure 3-1).

$$
\theta=45^{\circ}+\frac{\phi^{\prime}}{2}
$$

4) Mohr-Coulomb failure envelope (criteria) expressed with principal stresses:

Mohr-Coulomb failure envelope (criteria) can also be expressed with major \& minor principal stresses by substituting shear strength, $\tau_{f}$, in Equation 4.1 with Equation 4.4 and substitute effective normal stress, $\sigma_{f}^{\prime}$, in Equation 4.1 with Equation 4.5, to get the relationship Equation 4.7.

$$
\sigma_{f 1}^{\prime}=\sigma_{f 3}^{\prime} \tan ^{2} \theta+2 c^{\prime} \tan \theta
$$


In other words, Equation 4.7 represents the relationship between major and minor principle stresses at failure.

5) The initial principal stresses on element:

The initial major principle stress (see Figure 4-2 and Figure 4-3a) can be calculated according to track load and weight of subgrade with following formula.

$$
\sigma_{1}^{\prime}=p(d)+\rho g d
$$

where, $p(d)$ is vertical stress (or load of track) transferred to element in subgrade, $\rho$ is density of subgrade material, $g$ is standard gravity, $d$ is depth of element to the top surface of subgrade.

The minor principal stress (see Figure 4-3) can be calculated with major principal stress according to following formula.

$$
\sigma_{3}^{\prime}=K_{0} \sigma_{1}^{\prime}
$$

where, $K_{0}$ is the Coefficient of earth pressure at rest.

6) The effective normal stress on the shear plane after failure:

The normal stress on failure plane can be calculated with major and minor principal stresses by following formula. See Figure 4-3a.

$$
\sigma_{n}{ }^{\prime}=\sigma_{1}^{\prime} \cos \theta+\sigma_{3}^{\prime} \sin \theta
$$

7) The residual shear strength after failure:

$$
\tau_{r}=K_{r} \sigma_{n}^{\prime}=\sigma_{n}^{\prime} \tan \phi_{r}^{\prime}
$$

where, $K_{r}$ is coefficient of residual friction,

$\phi^{\prime}{ }_{r}$ is residual effective friction angle,

$\phi_{r}^{\prime}=34^{\circ} e^{-0,114 I_{P}}$ (Eid et al., 2015),

$I_{P}$ is plastic index.

8) Shear stress (see Figure 4-3a) along the shear plane after failure:

$$
\tau=\sigma^{\prime}{ }_{1} \sin \theta-\sigma^{\prime}{ }_{3} \cos \theta
$$

9) Unbalanced shear stress (see Figure 4-3b) along the shear plane after failure: 


$$
\tau_{u}=\tau-\tau_{r}
$$

10) New stresses status in element after previous element failed:

In the railway foundation, the major principal stress is not in the vertical direction (Li et al., 2016) (see Figure 2-8), but there are no experimental data to reveal the accurate direction of

principal stresses. To simplify the calculation, assume the major principal stress is in the vertical direction in this thesis.

After previous element failed, the unbalanced shear stress transfer to its next element, so the stress status in next element is changed. The new major and minor principal stresses are:

$$
\begin{aligned}
& \sigma_{1 n}^{\prime}=\sigma_{1}^{\prime} \cos \beta+\tau_{u} \cos (\alpha-\beta)+\sigma_{3}^{\prime} \sin \beta \\
& \sigma_{3 n}^{\prime}=\sigma_{1}^{\prime} \sin \beta+\tau_{u} \sin (\alpha-\beta)+\sigma_{3}^{\prime} \cos \beta
\end{aligned}
$$

where $\sigma_{1 n}^{\prime}$ is the new major principal stress,

$\beta$ is the angle between initial major principal stress $\sigma_{l}^{\prime}$ and new major principal stress $\sigma_{l n}^{\prime}$, $\alpha$ is the angle between initial major principal stress $\sigma_{l}^{\prime}$ and unbalanced shear stress $\tau_{u}^{\prime}$.

The $\alpha$ can be calculated with $\theta$, the angle between direction of major principal stress and failure plane. The $\alpha$ of the primary element can be calculated with following equation:

$$
\alpha=90^{\circ}-\theta
$$

$\beta$ can be calculated with following equation:

$$
\beta=\tan ^{-1} \frac{\sigma_{3}+\tau \sin \alpha}{\sigma_{1}+\tau \cos \alpha}
$$

\subsection{Program of the Simulation}

The computer program of progressive shear failure simulation is a Visual Basic program developed in the environment of AutoCAD based on above assumption in Section 4.1 and equations in Section 4.2. The full Code of the Program has around 500 lines.

The program facilitates an Input file which can feed the data for the program. An output file is generated to gather all the simulation results. In addition, the program is also capable of displaying the progressive shear failure planes in AutoCAD drawing. 
The Code of the Program, An input file and two output files are provided in the Appendix and will be used in later sections to detail the program simulation. The input file is named as "Data.txt" for user to input the data required for the program running. Each inputted data is followed by a note or explanation. The output file "Output.txt" records the number of failed elements along failure plane during each simulation and final load or stress in the subgrade at end of each simulation. 


\section{CHAPTER 5 \\ SIMULATION RESULTS OF PROGRESSIVE SHEAR \\ FAILURE IN SUBGRADE}

This chapter provides details of the required input data along with the other information for performing numerical simulations. The numerical simulation results are also analyzed and discussed.

\subsection{Input Data and Subgrade Parameters}

The input file provides source data for the simulation, including size of the element, geometry data of track, property parameters of ballast and subgrade, as well as stress distribution at bottom of the ballast. Appendix provides more details of a sample input file. The key data and parameters are discussed in this section.

\subsubsection{The Density and Thickness of Ballast}

According to specification of RailCorp and Australian Rail Track Corporation (Wilson, 2013), the particle density of ballast material shall not be less than $2500 \mathrm{~kg} / \mathrm{m}^{3}$, and the compacted bulk density of ballast material shall not be less than $1,400 \mathrm{~kg} / \mathrm{m}^{3}$. In addition, most railway specifications require the thickness of the ballast should not be less than 12 " $(300 \mathrm{~mm})$ from bottom of the tie, and the top width of ballast is $3.5 \mathrm{~m}$.

In this study, to simplify the calculations, track weight (including rail, plate, fastener, tie and ballast) is considered as ballast weight. A constant width, thickness and density of ballast are respectively taken $3.5 \mathrm{~m}, 0.5 \mathrm{~m}$, and $2000 \mathrm{~kg} / \mathrm{m}^{3}$.

\subsubsection{The density of subgrade soil}

Structural Engineering Resources (StructX, 2019) suggests following density ranges for different soil types (see Table 5-1). 
Table 5-1 Density Ranges for Different Soil Types $\left(\mathrm{kg} / \mathrm{m}^{3}\right)$

\begin{tabular}{|l|l|l|l|l|}
\hline & \multicolumn{3}{|c|}{ Dry Density } & \multicolumn{2}{l|}{ Submerged Density } \\
\hline & Min. & Max. & Min. & Max. \\
\hline Sand; clean / uniform / fine or medium & 1346 & 2179 & 833 & 1169 \\
\hline Silt; uniform / inorganic & 1297 & 2179 & 817 & 1169 \\
\hline Silty Sand & 1410 & 2275 & 865 & 1265 \\
\hline Sand; Well-graded & 1378 & 2371 & 849 & 1378 \\
\hline Silty Sand and Gravel & 1442 & 2483 & 897 & 1474 \\
\hline Sandy or Silty Clay & 1602 & 2355 & 609 & 1362 \\
\hline Silty Clay with Gravel; uniform & 1842 & 2419 & 849 & 1426 \\
\hline Well-graded Gravel / Sand / Silt and Clay & 2002 & 2499 & 993 & 1506 \\
\hline Clay & 1506 & 2130 & 497 & 1137 \\
\hline Colloidal Clay & 1137 & 2050 & 128 & 1057 \\
\hline Organic Silt & 1394 & 2098 & 400 & 1105 \\
\hline Organic Clay & 1297 & 2002 & 288 & 993 \\
\hline
\end{tabular}

Progressive shear failure typically occurs in a subgrade constructed with fine grained soils that is nearly saturated. From the information of density values in the Table 5.1, a value of $1560 \mathrm{~kg} / \mathrm{m}^{3}$ was used as subgrade density in this thesis.

\subsubsection{The effective cohesion of subgrade soil and matric suction, $c$}

The cohesion is the non-frictional part of the soil shear strength which is independent of the normal stress.

Table 5-2 summarizes typical cohesive strength values from GEOL 615 course notes of Pennsylvania State University. 
Table 5-2 The Cohesive strength (c) or (c prime)

\begin{tabular}{|l|l|}
\hline Rock & $10,000 \mathrm{kPa}$ \\
\hline Silt & $75 \mathrm{kPa}$ \\
\hline Clay & $10-20 \mathrm{kPa}$ \\
\hline Very soft clay & $0-48 \mathrm{kPa}$ \\
\hline Soft clay & $48-96 \mathrm{kPa}$ \\
\hline Medium clay & $96-192 \mathrm{kPa}$ \\
\hline Stiff clay & $192-384 \mathrm{kPa}$ \\
\hline Very stiff clay & $384-766 \mathrm{kPa}$ \\
\hline Hard clay & $>766 \mathrm{kPa}$ \\
\hline
\end{tabular}

In this thesis, the apparent cohesion includes effective cohesion along with the shear resistance arising from the contribution of matric suction (Equation 4.3). Since increasing effective cohesion or matric suction, increases the total shear strength of the soil, relatively small values of cohesion, $c$ between $0-10 \mathrm{kPa}$ are used.

\subsubsection{The effective angle of friction of subgrade soil}

In GEOL 615 course notes of Pennsylvania State University, following angle of internal friction has been used (Table 5-3).

Table 5-3 Angle of internal friction $(\phi)$ or ( $\phi$ prime)

\begin{tabular}{|l|l|}
\hline Rock & $30^{\circ}$ \\
\hline Sand & $30-40^{\circ}$ \\
\hline Gravel & $35^{\circ}$ \\
\hline Silt & $34^{\circ}$ \\
\hline Clay & $20^{\circ}$ \\
\hline Loose sand & $30-35^{\circ}$ \\
\hline Medium sand & $40^{\circ}$ \\
\hline Dense sand & $35-45^{\circ}$ \\
\hline Gravel with some sand & $34-48^{\circ}$ \\
\hline Silt & $26-35^{\circ}$ \\
\hline
\end{tabular}


Geotechdata.info web (Geotechdata.info, 2013) lists typical values of angle of friction for different USCS (Unified Soil Classification System) soil types.

Table 5-4 Typical values of soil friction angle

\begin{tabular}{|c|c|c|c|c|}
\hline \multirow[b]{2}{*}{ Soil Description } & \multirow[b]{2}{*}{ USCS } & \multicolumn{3}{|c|}{ Friction angle $\left({ }^{\circ}\right)$} \\
\hline & & & $\max$ & $\begin{array}{l}\text { Specific } \\
\text { value }\end{array}$ \\
\hline $\begin{array}{l}\text { Well graded gravel, sandy gravel, with little or no } \\
\text { fines }\end{array}$ & GW & 33 & 40 & \\
\hline $\begin{array}{l}\text { Poorly graded gravel, sandy gravel, with little or no } \\
\text { fines }\end{array}$ & GP & 32 & 44 & \\
\hline Sandy gravels - Loose & $(\mathrm{GW}, \mathrm{GP})$ & & & 35 \\
\hline Sandy gravels - Dense & $(\mathrm{GW}, \mathrm{GP})$ & & & 50 \\
\hline Silty gravels, silty sandy gravels & GM & 30 & 40 & \\
\hline Clayey gravels, clayey sandy gravels & $\mathrm{GC}$ & 28 & 35 & \\
\hline $\begin{array}{l}\text { Well graded sands, gravelly sands, with little or no } \\
\text { fines }\end{array}$ & SW & 33 & 43 & \\
\hline Well-graded clean sand, gravelly sands - Compacted & SW & - & - & 38 \\
\hline Well-graded sand, angular grains - Loose & $(\mathrm{SW})$ & & & 33 \\
\hline Well-graded sand, angular grains - Dense & (SW) & & & 45 \\
\hline $\begin{array}{l}\text { Poorly graded sands, gravelly sands, with little or no } \\
\text { fines }\end{array}$ & SP & 30 & 39 & \\
\hline Poorly-garded clean sand - Compacted & SP & - & - & 37 \\
\hline Uniform sand, round grains - Loose & (SP) & & & 27 \\
\hline Uniform sand, round grains - Dense & (SP) & & & 34 \\
\hline Sand & SW, SP & 37 & 38 & \\
\hline Loose sand & $(\mathrm{SW}, \mathrm{SP})$ & 29 & 30 & \\
\hline Medium sand & $(\mathrm{SW}, \mathrm{SP})$ & 30 & 36 & \\
\hline Dense sand & $(\mathrm{SW}, \mathrm{SP})$ & 36 & 41 & \\
\hline Silty sands & SM & 32 & 35 & \\
\hline Silty clays, sand-silt mix - Compacted & SM & - & - & 34 \\
\hline Silty sand - Loose & SM & 27 & 33 & \\
\hline Silty sand - Dense & SM & 30 & 34 & \\
\hline Clayey sands & SC & 30 & 40 & \\
\hline Calyey sands, sandy-clay mix - compacted & $\mathrm{SC}$ & & & 31 \\
\hline Loamy sand, sandy clay Loam & $\mathrm{SM}, \mathrm{SC}$ & 31 & 34 & \\
\hline $\begin{array}{l}\text { Inorganic silts, silty or clayey fine sands, with slight } \\
\text { plasticity }\end{array}$ & ML & 27 & 41 & \\
\hline Inorganic silt - Loose & ML & 27 & 30 & \\
\hline Inorganic silt - Dense & ML & 30 & 35 & \\
\hline
\end{tabular}




\begin{tabular}{|l|c|c|c|c|}
\hline $\begin{array}{l}\text { Inorganic clays, silty clays, sandy clays of low } \\
\text { plasticity }\end{array}$ & CL & 27 & 35 & \\
\hline Clays of low plasticity - compacted & CL & & & 28 \\
\hline Organic silts and organic silty clays of low plasticity & OL & 22 & 32 & \\
\hline Inorganic silts of high plasticity & MH & 23 & 33 & \\
\hline Clayey silts - compacted & MH & & & 25 \\
\hline Silts and clayey silts - compacted & ML & & & 32 \\
\hline Inorganic clays of high plasticity & CH & 17 & 31 & \\
\hline Clays of high plasticity - compacted & CH & & & 19 \\
\hline Organic clays of high plasticity & OH & 17 & 35 & \\
\hline Loam & ML, OL, MH, OH & 28 & 32 & \\
\hline Silt Loam & ML, OL, MH, OH & 25 & 32 & \\
\hline Clay Loam, Silty Clay Loam & ML, OL, CL, MH, OH, & 18 & 32 & \\
\hline Silty clay & CH & & & \\
\hline Clay & OL, CL, OH, CH & 18 & 32 & \\
\hline Peat and other highly organic soils & CL, CH, OH, OL & 18 & 28 & \\
\hline
\end{tabular}

The minimum angle of friction of soil in Table 5-4 is $17^{\circ}$ and the maximum angle of friction is $44^{\circ}$. In this research, following these guidelines, the relatively smaller values of angle of friction $17-25^{\circ}$ are used.

\subsubsection{The coefficient of earth pressure at rest}

Al-Hussaini (1981) tested values of $K_{0}$ for the sand using the LVDT clamp, swinging arms, the $K_{0}$-belt with strain gages, and the burette method are presented in terms of initial relative densities in Table 5-5. The $K_{0}$ value are from 0.39 to 0.55 .

Table 5-5 Values of $K_{0}$ for the sand tested by (Al-Hussaini, 1981)

\begin{tabular}{|c|c|c|c|c|c|c|c|}
\hline \multicolumn{2}{|c|}{ LVDT Clamps } & \multicolumn{2}{|c|}{ Swinging-Arms } & \multicolumn{2}{c|}{$K_{0}$-Belt } & \multicolumn{2}{c|}{ Burette Method } \\
\hline$D_{r}, \%$ & $K_{0}$ & $D_{r}, \%$ & $K_{0}$ & $D_{r}, \%$ & $K_{0}$ & $D_{r}, \%$ & $K_{0}$ \\
\hline 30.9 & 0.53 & 25.6 & 0.51 & 26.9 & 0.55 & 36.0 & 0.52 \\
\hline 75.1 & 0.45 & 72.1 & 0.42 & 72.9 & 0.48 & 69.3 & 0.44 \\
\hline 94.0 & 0.39 & 99.5 & 0.39 & 96.5 & 0.42 & 96.8 & 0.39 \\
\hline
\end{tabular}

Note: $D_{r}$, Relative Density, $\%$. 
Wang et al (2018) used materials which are mixtures of mixed artificially by crushed sandstone and mudstone particles. The test materials are classified as well-graded sand (SW). The test results of $K_{0}$ values are listed in Table 5-6 with coefficient of determination $\mathrm{R}^{2}$, which are calculated from the experimental data. The $K_{0}$ value ranges from 0.242 to 0.381 , with a mean value of 0.300 . And the $\mathrm{R}^{2}$ value ranges from 0.976 to 0.999 , with a mean value of 0.989 .

Table 5-6 Experimental Values of Coefficient $K_{0}$

\begin{tabular}{|c|c|c|c|c|}
\hline No. & $\begin{array}{l}\text { Mudstone } \\
\text { particle } \\
\text { content } \\
\text { by weight of } \\
\text { test material } \\
(\%)\end{array}$ & $\begin{array}{l}\text { Initial dry } \\
\text { bulk density } \\
\text { of test } \\
\text { specimen } \rho_{d} \\
\left(\mathrm{~g} / \mathrm{cm}^{3}\right)\end{array}$ & $\begin{array}{l}\text { Coefficient of } \\
\text { earth pressure } \\
\text { at rest } \\
K_{0}\end{array}$ & $\begin{array}{l}\mathrm{R}^{2} \text { of } \\
\text { fitting } \\
\text { straight } \\
\text { line }\end{array}$ \\
\hline 1 & 80 & 1.7 & 0.365 & 0.996 \\
\hline 2 & 80 & 1.7 & 0.375 & 0.991 \\
\hline 3 & 80 & 1.7 & 0.378 & 0.998 \\
\hline 4 & 80 & 1.7 & 0.381 & 0.989 \\
\hline 5 & 80 & 1.8 & 0.313 & 0.988 \\
\hline 6 & 80 & 1.8 & 0.320 & 0.991 \\
\hline 7 & 80 & 1.8 & 0.323 & 0.986 \\
\hline 8 & 80 & 1.8 & 0.329 & 0.993 \\
\hline 9 & 80 & 1.9 & 0.264 & 0.994 \\
\hline 10 & 80 & 1.9 & 0.274 & 0.997 \\
\hline 11 & 80 & 1.9 & 0.277 & 0.988 \\
\hline 12 & 80 & 1.9 & 0.281 & 0.999 \\
\hline 13 & 80 & 2.0 & 0.242 & 0.993 \\
\hline 14 & 80 & 2.0 & 0.244 & 0.991 \\
\hline 15 & 80 & 2.0 & 0.252 & 0.997 \\
\hline 16 & 80 & 2.0 & 0.254 & 0.986 \\
\hline 17 & 80 & 1.8 & 0.253 & 0.998 \\
\hline 18 & 80 & 1.8 & 0.262 & 0.977 \\
\hline 19 & 80 & 1.8 & 0.256 & 0.985 \\
\hline 20 & 80 & 1.8 & 0.269 & 0.991 \\
\hline
\end{tabular}




\begin{tabular}{|c|c|c|c|c|}
\hline 21 & 80 & 1.8 & 0.271 & 0.997 \\
\hline 22 & 80 & 1.8 & 0.281 & 0.991 \\
\hline 23 & 80 & 1.8 & 0.285 & 0.985 \\
\hline 24 & 80 & 1.8 & 0.292 & 0.976 \\
\hline 25 & 80 & 1.8 & 0.358 & 0.992 \\
\hline 26 & 80 & 1.8 & 0.367 & 0.985 \\
\hline 27 & 80 & 1.8 & 0.372 & 0.976 \\
\hline 28 & 80 & 1.8 & 0.381 & 0.988 \\
\hline 29 & 80 & 1.8 & 0.319 & 0.991 \\
\hline 30 & 80 & 1.8 & 0.326 & 0.996 \\
\hline 31 & 80 & 1.8 & 0.331 & 0.985 \\
\hline 32 & 80 & 1.8 & 0.346 & 0.979 \\
\hline 33 & 0 & 1.8 & 0.281 & 0.993 \\
\hline 34 & 0 & 1.8 & 0.299 & 0.991 \\
\hline 35 & 0 & 1.8 & 0.289 & 0.987 \\
\hline 36 & 0 & 1.8 & 0.287 & 0.998 \\
\hline 37 & 20 & 1.8 & 0.252 & 0.990 \\
\hline 38 & 20 & 1.8 & 0.269 & 0.978 \\
\hline 39 & 20 & 1.8 & 0.259 & 0.986 \\
\hline 40 & 20 & 1.8 & 0.264 & 0.997 \\
\hline 41 & 40 & 1.8 & 0.265 & 0.988 \\
\hline 42 & 40 & 1.8 & 0.281 & 0.991 \\
\hline 43 & 40 & 1.8 & 0.271 & 0.976 \\
\hline 44 & 40 & 1.8 & 0.275 & 0.995 \\
\hline 45 & 60 & 1.8 & 0.315 & 0.989 \\
\hline 46 & 60 & 1.8 & 0.297 & 0.982 \\
\hline 47 & 60 & 1.8 & 0.307 & 0.986 \\
\hline 48 & 60 & 1.8 & 0.310 & 0.994 \\
\hline 49 & 100 & 1.8 & 0.298 & 0.989 \\
\hline 50 & 100 & 1.8 & 0.316 & 0.991 \\
\hline
\end{tabular}




\begin{tabular}{|c|c|c|c|c|}
\hline 51 & 100 & 1.8 & 0.304 & 0.982 \\
\hline 52 & 100 & 1.8 & 0.306 & 0.988 \\
\hline Mean & & & 0.300 & 0.989 \\
\hline
\end{tabular}

The subgrade which experienced progressive failure are mostly saturated fine grained soil, so $K_{0}$ values $0.25 \sim 0.4$ are used in the present study.

\subsubsection{The coefficient of friction on failure plane $K_{r}$}

Tiwari \& Marui (2005) collected 82 soil samples from existing landslide areas, slope failure areas, debris flow areas, and the volcanic eruption areas to investigate the influence of the mineralogical composition of the soil in various disaster areas. These details are summarized in Table 5-7.

Table 5-7 Index Properties, Mineralogical Composition, and residual friction angle of Natural Samples (Tiwari \& Marui, 2005)

\begin{tabular}{|l|l|l|l|l|l|l|l|l|l|l|}
\hline Sampling site & No & LL & PI & CF & $\begin{array}{l}\text { Massive } \\
\text { minerals }\end{array}$ & Kaolinite & Mica & Smectite & $\phi_{R}^{\prime}$ \\
\hline Landslide area & \multicolumn{7}{|l|}{} \\
\hline Okimi & 1 & 75.0 & 38.0 & 30.2 & 81.0 & 3.9 & 0.1 & 15.0 & 15.0 \\
\hline Okimi & 2 & 82.0 & 39.1 & 32.2 & 82.0 & 2.8 & 0.2 & 15.0 & 16.0 \\
\hline Okimi & 3 & 78.0 & 38.0 & 30.1 & 81.0 & 3.9 & 0.1 & 15.0 & 16.0 \\
\hline Okimi & 4 & 66.7 & 21.9 & 17.5 & 84.0 & 1.9 & 0.1 & 14.0 & 22.0 \\
\hline Okimi & 5 & 71.0 & 35.0 & 30.2 & 79.0 & 4.9 & 0.1 & 16.0 & 14.0 \\
\hline Okimi & 6 & 72.3 & 37.1 & 31.1 & 79.0 & 4.8 & 0.2 & 16.0 & 14.0 \\
\hline Okimi & 7 & 76.0 & 36.0 & 30.8 & 82.0 & 2.9 & 0.1 & 15.0 & 16.0 \\
\hline Okimi & 8 & 68.1 & 34.6 & 28.8 & 78.0 & 5.9 & 0.1 & 16.0 & 12.0 \\
\hline Okimi & 9 & 84.0 & 52.9 & 45.2 & 75.0 & 2.9 & 0.1 & 22.0 & 11.0 \\
\hline Okimi & 10 & 69.2 & 31.0 & 26.3 & 78.0 & 6.9 & 0.1 & 15.0 & 12.0 \\
\hline Okimi & 11 & 81.4 & 43.9 & 37.5 & 77.0 & 2.9 & 0.1 & 20.0 & 11.0 \\
\hline Okimi & 12 & 78.2 & 25.8 & 20.5 & 76.0 & 9.0 & 0.1 & 15.0 & 12.0 \\
\hline Okimi & 13 & 75.5 & 25.6 & 21.5 & 77.0 & 7.9 & 0.1 & 15.0 & 12.0 \\
\hline Okimi & 14 & 77.2 & 49.5 & 38.2 & 77.0 & 4.9 & 0.1 & 18.0 & 10.0 \\
\hline Okimi & 15 & 66.0 & 31.0 & 27.7 & 79.4 & 4.5 & 0.6 & 15.5 & 12.5 \\
\hline
\end{tabular}




\begin{tabular}{|l|c|c|c|c|c|c|c|c|c|}
\hline Okimi & 16 & 55.0 & 18.0 & 19.5 & 85.3 & 3.5 & 1.0 & 10.2 & 18.8 \\
\hline Yosio & 1 & 86.3 & 47.1 & 28.2 & 77.0 & 5.0 & 0.0 & 18.0 & 10.0 \\
\hline Yosio & 2 & 89.0 & 41.9 & 37.5 & 73.0 & 8.0 & 0.0 & 19.0 & 10.0 \\
\hline Yosio & 3 & 73.0 & 35.3 & 22.1 & 74.9 & 7.7 & 1.6 & 15.8 & 10.1 \\
\hline Yosio & 4 & 64.0 & 34.1 & 19.2 & 74.2 & 6.9 & 1.2 & 17.7 & 12.7 \\
\hline Yosio & 5 & 68.0 & 38.2 & 28.2 & 75.6 & 5.4 & 0.4 & 18.6 & 9.8 \\
\hline Yosio & 6 & 69.0 & 40.0 & 27.2 & 76.4 & 7.0 & 0.7 & 15.9 & 9.8 \\
\hline Yosio & 7 & 51.0 & 19.0 & 21.8 & 80.0 & 6.1 & 0.2 & 13.7 & 10.7 \\
\hline Mukohidehara & 1 & 71.5 & 36.4 & 21.2 & 84.0 & 7.0 & 0.0 & 9.0 & 19.0 \\
\hline Mukohidehara & 2 & 55.8 & 32.6 & 20.5 & 85.0 & 6.0 & 0.0 & 9.0 & 18.0 \\
\hline Mukohidehara & 3 & 70.0 & 38.0 & 24.0 & 72.6 & 11.2 & 0.9 & 15.3 & 8.9 \\
\hline Mukohidehara & 4 & 65.0 & 34.0 & 22.0 & 72.3 & 7.3 & 0.8 & 19.6 & 10.7 \\
\hline Mukohidehara & 5 & 61.0 & 15.0 & 20.0 & 84.6 & 2.8 & 0.5 & 12.1 & 16.2 \\
\hline Mukohidehara & 6 & 53.0 & 26.0 & 14.0 & 85.7 & 2.0 & 1.9 & 10.4 & 19.3 \\
\hline Engyoji & 1 & 91.3 & 50.5 & 32.8 & 73.0 & 10.0 & 0.0 & 17.0 & 10.0 \\
\hline Engyoji & 2 & 94.6 & 62.4 & 33.2 & 74.0 & 8.0 & 0.0 & 18.0 & 10.0 \\
\hline Engyoji & 3 & 69.0 & 38.0 & 27.5 & 75.0 & 4.5 & 2.5 & 18.0 & 9.8 \\
\hline Engyoji & 4 & 62.0 & 29.0 & 19.9 & 78.8 & 5.2 & 2.6 & 13.4 & 12.8 \\
\hline Engyoji & 5 & 59.0 & 19.0 & 20.0 & 85.1 & 3.5 & 1.4 & 10.0 & 17.6 \\
\hline Iwagami & 1 & 96.2 & 48.0 & 32.2 & 78.0 & 6.0 & 1.0 & 15.0 & 12.0 \\
\hline Iwagami & 2 & 94.7 & 59.2 & 33.5 & 78.0 & 6.0 & 0.0 & 16.0 & 12.0 \\
\hline Iwagami & 3 & 63.0 & 32.0 & 24.8 & 75.9 & 14.5 & 1.9 & 7.7 & 17.1 \\
\hline Iwagami & 4 & 71.0 & 38.0 & 26.2 & 77.8 & 10.8 & 0.3 & 11.1 & 11.2 \\
\hline Iwagami & 5 & 64.0 & 21.0 & 23.0 & 70.5 & 3.9 & 1.7 & 23.8 & 11.1 \\
\hline Tsuboyama & 1 & 79.8 & 36.3 & 40.2 & 75.0 & 8.0 & 0.0 & 17.0 & 10.0 \\
\hline Tsuboyama & 2 & 100.0 & 68.3 & 42.8 & 76.0 & 6.0 & 0.0 & 18.0 & 10.0 \\
\hline Tsuboyama & 3 & 120.0 & 65.5 & 42.0 & 73.7 & 3.9 & 1.7 & 20.7 & 10.9 \\
\hline Tsuboyama & 4 & 108.0 & 66.2 & 41.2 & 73.6 & 8.7 & 2.2 & 14.4 & 14.7 \\
\hline Tsuboyama & 5 & 58.0 & 29.2 & 21.3 & 86.5 & 3.8 & 0.4 & 9.3 & 19.2 \\
\hline Landslide area & & & & & & & & & \\
\hline
\end{tabular}




\begin{tabular}{|l|c|c|c|c|c|c|c|c|c|}
\hline Hirayama & 1 & 57.0 & 17.0 & 10.0 & 76.9 & 3.1 & 1.8 & 18.1 & 12.7 \\
\hline Hirayama & 2 & 57.0 & 23.0 & 2.8 & 75.0 & 4.4 & 1.8 & 17.7 & 10.4 \\
\hline Takao & 1 & 61.0 & 24.0 & 18.0 & 85.4 & 3.2 & 1.4 & 10.0 & 18.1 \\
\hline Takao & 2 & 55.0 & 27.0 & 6.5 & 84.0 & 4.1 & 0.9 & 11.0 & 17.6 \\
\hline Hotenji & 1 & 82.0 & 51.0 & 31.0 & 82.0 & 6.0 & 2.2 & 9.8 & 15.2 \\
\hline Hotenji & 2 & 84.0 & 31.0 & 22.0 & 84.8 & 3.2 & 1.7 & 10.3 & 14.0 \\
\hline Heito & 1 & 54.0 & 19.0 & 10.0 & 74.6 & 6.9 & 1.8 & 16.5 & 12.9 \\
\hline Heito & 2 & 56.0 & 28.0 & 5.4 & 80.7 & 11.7 & 1.0 & 6.6 & 25.7 \\
\hline Utsunomata & 1 & 49.0 & 9.0 & 5.0 & 80.9 & 6.7 & 5.6 & 6.8 & 26.7 \\
\hline Utsunomata & 2 & 41.0 & 6.0 & 2.9 & 83.7 & 0.0 & 11.7 & 4.6 & 28.9 \\
\hline Utsunomata & 3 & 83.0 & 54.0 & 51.0 & 76.4 & 7.0 & 1.4 & 15.2 & 11.0 \\
\hline Utsunomata & 4 & 41.2 & 29.9 & 10.0 & 83.6 & 5.1 & 7.3 & 4.0 & 28.7 \\
\hline Utsunomata & 5 & 46.8 & 30.3 & 10.0 & 80.8 & 4.8 & 8.1 & 6.3 & 23.1 \\
\hline Utsunomata & 6 & 67.7 & 27.5 & 17.0 & 79.3 & 3.5 & 0.2 & 17.0 & 14.4 \\
\hline Utsunomata & 7 & 72.3 & 29.9 & 17.0 & 81.5 & 4.1 & 0.3 & 14.1 & 17.2 \\
\hline Utsunomata & 8 & 55.6 & 38.6 & 12.0 & 72.1 & 6.2 & 0.5 & 21.2 & 8.3 \\
\hline Utsunomata & 9 & 56.8 & 34.3 & 16.0 & 70.2 & 7.0 & 0.4 & 22.4 & 7.8 \\
\hline Tunnel & 1 & 36.0 & 10.0 & 10.0 & 92.0 & 5.2 & 0.7 & 1.4 & 29.0 \\
\hline Tunnel & 2 & 35.0 & 8.0 & 6.0 & 93.9 & 1.6 & 0.0 & 1.6 & 29.0 \\
\hline Tukuche & & 26.0 & 8.0 & 5.0 & 94.0 & 0.0 & 3.0 & 0.0 & 31.0 \\
\hline Slope failure area & & & & & & & & \\
\hline Karamatsu & 1 & 77.2 & 20.7 & 16.2 & 84.0 & 14.0 & 0.0 & 2.0 & 25.6 \\
\hline Karamatsu & 2 & 57.0 & 17.3 & 15.2 & 84.0 & 14.0 & 0.0 & 2.0 & 25.8 \\
\hline Heito & & 57.3 & 12.7 & 11.2 & 89.0 & 5.0 & 0.0 & 6.0 & 23.4 \\
\hline Tsukidate & 1 & 36.0 & 5.0 & 9.0 & 90.6 & 3.0 & 0.2 & 6.2 & 23.3 \\
\hline Tsukidate & 2 & 45.0 & 19.0 & 13.0 & 89.2 & 3.1 & 1.6 & 5.5 & 25.5 \\
\hline Tsukidate & 3 & 47.0 & 9.0 & 6.5 & 92.3 & 2.6 & 1.4 & 3.7 & 28.0 \\
\hline Debris flow area & & & & & & & & \\
\hline Urakawa & 1 & 36.4 & 9.6 & 0.4 & 91.8 & 3.0 & 0.0 & 5.2 & 28.4 \\
\hline Urakawa & 2 & 31.1 & 11.1 & 1.0 & 88.0 & 4.0 & 0.0 & 8.0 & 24.9 \\
\hline
\end{tabular}




\begin{tabular}{|c|c|c|c|c|c|c|c|c|c|}
\hline Urakawa & 3 & 54.0 & 23.5 & 2.4 & 89.0 & 3.0 & 0.0 & 8.0 & 24.4 \\
\hline Urakawa & 4 & 48.6 & 16.6 & 4.3 & 91.0 & 3.0 & 0.0 & 5.0 & 30.1 \\
\hline Urakawa & 5 & 42.7 & 16.1 & 4.2 & 91.5 & 3.2 & 0.0 & 5.3 & 29.0 \\
\hline Urakawa & 6 & 32.0 & 4.5 & 1.8 & 89.5 & 3.0 & 0.0 & 7.5 & 23.6 \\
\hline Urakawa & 7 & 35.0 & 6.0 & 2.3 & 88.0 & 4.0 & 0.0 & 8.0 & 21.1 \\
\hline Urakawa & 8 & 36.0 & 5.5 & 3.9 & 87.9 & 3.9 & 0.0 & 8.2 & 21.4 \\
\hline \multicolumn{10}{|c|}{ Volcanic area } \\
\hline Usu & 1 & 65.8 & 42.6 & 6.7 & 85.0 & 3.0 & 0.0 & 12.0 & 21.3 \\
\hline Usu & 2 & 44.6 & 20.7 & 10.9 & 87.0 & 3.0 & 0.0 & 10.0 & 23.2 \\
\hline Usu & 3 & 37.9 & 15.4 & 7.0 & 87.0 & 4.0 & 0.0 & 9.0 & 23.7 \\
\hline Usu & 4 & 47.8 & 21.9 & 8.9 & 82.0 & 0.0 & 0.0 & 18.0 & 17.8 \\
\hline Average & & 63.8 & 29.8 & 19.8 & 81.2 & 5.3 & 1.0 & 12.4 & 17.1 \\
\hline
\end{tabular}

Note: All units except $\phi_{R}^{\prime}$ are in $\%$ and $\phi_{R}^{\prime}$ is in degrees; LL=liquid limit; PI=plasticity index; $\mathrm{CF}=$ clay fraction.

The residual friction angles of Natural Samples (Tiwari \& Marui, 2005) vary from $7.8^{\circ}$ to $31^{\circ}$, average $17.1^{\circ}$.

Fifty four landslides through sedimentary fine-grained materials (i.e., clays, marls, mudstones, and shales) were chosen by (Eid et al., 2016) from the large number of reactivated landslides reported in the literature as case histories (Table 5-8).

Table 5-8 Reactivated landslides and reported soil residual shear strength correlations (Eid et al., 2016)

\begin{tabular}{|c|l|l|c|}
\hline No. & \multicolumn{1}{|c|}{ Site } & \multicolumn{1}{|c|}{ Stratum } & $\phi^{\prime}\left(^{\circ}\right)$ \\
\hline $1-5$ & Chiusi della Verna (5 slides), Tuscany, Italy & Clay shale & $\begin{array}{c}11.7-15.6 \\
(\text { av.=13.2) }\end{array}$ \\
\hline 6 & River Beas Valley, India & Siwalik rock & $18-20$ \\
\hline 7 & Jackfield, Shropshire, UK & Carboniferous mudstone & 17.1 \\
\hline 8 & St. Martino Valley, Italy & Weathered marl & 17 \\
\hline 9 & Weirton,West Virginia, USA & Colluviume & 16 \\
\hline 10 & St. Cristoforo, Italy & Lugagnano clay & 11.5 \\
\hline 11 & Mam Tor, Berbyshire, UK & Edale shale & 14 \\
\hline
\end{tabular}




\begin{tabular}{|c|l|l|c|}
\hline $12-19$ & Seattle Freeway (8 slides), Seattle, USA & Lawton clay & $\begin{array}{c}13.6-16.5 \\
\text { (av.=15.3) }\end{array}$ \\
\hline 20 & Walton's Wood, Staffordshire, UK & Carboniferous mudstone & $13.5-15.5$ \\
\hline 21 & Lyme Regis, UK & Lower Lias clay & 11.2 \\
\hline 22 & Bury Hill, Staffordshire, UK & Etruria marl & 12 \\
\hline 23 & Burderop Wood, Swindon, UK & Gault clay & 13.3 \\
\hline 24 & Hodson, Swindon, UK & Gault clay & 14 \\
\hline 25 & Folkestone Warren, slip W4, Kent, UK & Gault clay & $7.7-9.4$ \\
\hline 26 & Barnsdale, Leicestershire, UK & Upper Lias clay & 10.4 \\
\hline 27 & Hambleton, Leicestershire, UK & Upper Lias clay & 10.3 \\
\hline 28 & Uppingham, Leicestershire, UK & Upper Lias clay & 16.2 \\
\hline 29 & Gretton, Northamptonshire, UK & Upper Lias clay & 13.5 \\
\hline 30 & Daventry, Northamptonshire, UK & Upper Lias clay & 13 \\
\hline 31 & Rockingham, Northamptonshire, UK & Upper Lias clay & 13.9 \\
\hline 32 & Weedon, Northamptonshire, UK & Upper Lias clay & 14.2 \\
\hline 33 & Wansford, Cambs, UK & Upper Lias clay & 9.8 \\
\hline 34 & Wardley, Leicestershire,UK & Upper Lias clay & 14.9 \\
\hline 35 & Endcombe, UK & Atherfield clay & 13.7 \\
\hline 36 & Patney-Chirton, UK & Gault clay & 11.9 \\
\hline 37 & Petrofka, Saskatchewan, Canada & Bedrock clay & 5.7 \\
\hline 38 & Spinney Hill, Saskatchewan, Canada & Clay shale & 8.7 \\
\hline 39 & Denholm, Saskatchewan, Canada & Bedrock clay & 6.7 \\
\hline 40 & Hadleigh, (slip surf. 2\&3), Essex, UK & Brown London clay & 13.2 \\
\hline 41 & Hadleigh, (slip surf. 5), Essex, UK & Brown London clay & 13.3 \\
\hline 42 & Hadleigh, (slip surf. 8), Essex, UK & Brown London clay & 13.5 \\
\hline 43 & Hadleigh, (slip surf. 12), Essex, UK & Brown London clay & 13.2 \\
\hline 44 & Guildford, Surrey, UK & Brown London clay & 10.9 \\
\hline 45 & Beacon Hill, Herne Bay, Kent, UK & $\begin{array}{l}\text { Brown and Blue London } \\
\text { clay }\end{array}$ & $14.1-14.8$ \\
clay & $12.3-12.5$ \\
\hline 477 & Kent, UK & arown and Blue London & \\
\hline
\end{tabular}




\begin{tabular}{|c|l|l|c|}
\hline $48-51$ & $\begin{array}{l}\text { Miramar, }(1953,1956,1966,1970), \text { Hern } \\
\text { Bay, Kent, UK }\end{array}$ & $\begin{array}{l}\text { Brown and Blue London } \\
\text { clay }\end{array}$ & $10.8-12.3$ \\
\hline 52 & San Diego, California, USA & Santiago claystone & 7.5 \\
\hline 53 & Portuguese Bend, California, USA & Altamira bentonitic tuff & 6.5 \\
\hline 54 & Gardiner Dam, Saskatchewan, Canada & Bearpaw Shale & 9.8 \\
\hline
\end{tabular}

For each considered case history (Eid et al., 2016) investigated the soils summarized in Table 5-8 for slope stability analyses and suggested the residual friction angles vary from $5.7^{\circ}$ to $20^{\circ}$, with an average value of $13.7^{\circ}$.

In this thesis, residual friction angles $5^{\circ} \sim 20^{\circ}$ were used use for angle of internal friction on failure plane and $K_{r}$ values from $0.05 \sim 0.35$ were used.

\subsubsection{The Stress Distribution in Railway Subgrade}

The stress distribution variation under ballast is typically "W" shape (see Figure 5-1 and Figure 5-2), which is referred to as normal spreading load. In some scenarios, under the action of cyclic wheel loads and vibration, a few large ballast particles may punch into subgrade as a point load and contribute to the progressive shear failure. For this reason, in the study, two different types of load, namely, point load and normal spreading are considered.

The point load is that stress concentrated on one or a few of particles of ballast in a small area and stress is typically small in the surrounding domain of the stress concentrated area.

The normal spreading load is the stress that distribute normally in subgrade without major stress concentration. This is typically to Figure 2-8, Figure 5-1and Figure 5-2.

Leshchinsky (2012) and Leshchinsky \& Ling (2013) have investigated the effects of geocell confinement on ballasted embankments when encountering a soft subgrade, weaker ballast, or varying reinforcement stiffness values.

A series of 6 large-scale model tests of ballasted railroad embankments were conducted by (Leshchinsky, 2012; Leshchinsky \& Ling, 2013) in the laboratory. The material properties used in the analysis are summarized in Table 5-9. 
Table 5-9 Model material properties (Leshchinsky \& Ling, 2013)

\begin{tabular}{|l|c|c|c|c|c|c|}
\hline Properties & Ballast & Subballast & Subgrade & Geocell & Tie plates & Ties \\
\hline Mass Density, $\gamma\left(\mathrm{kg} / \mathrm{m}^{3}\right)$ & 1520 & 1520 & 1700 & 1500 & 2000 & 2000 \\
\hline Elastic modulus, $E(\mathrm{MPa})$ & 2 & 2 & 20 & 2070 & 200,000 & 30,000 \\
\hline Poisson's Ratio, $v$ & 0.35 & 0.35 & 0.35 & 0.35 & 0.3 & 0.25 \\
\hline Internal Angle of Friction, $\phi\left(^{\circ}\right)$ & 45 & 45 & - & - & - & - \\
\hline Angle of Dilation, $\psi\left(^{\circ}\right)$ & 15 & 15 & - & - & - & - \\
\hline
\end{tabular}

The wheel load chosen for the analysis in the present study conservative in order to demonstrate track behavior under the worst conditions possible (Leshchinsky \& Ling, 2013). This load corresponds to two wheels, each having a wheel load of $22.4 \mathrm{kN}(50,000 \mathrm{lbs}$ or 25 tons, USACE Railroad Design Manual).

A series of simulations were performed by on displacements, stresses and strains in railway subgrade in order to determine the effects of geocell stiffness, ballast strength, and foundation compressibility. 6 types of Geocell Stiffness (MPa) were used in the study, which are 100, 500, 1000, 2070, 100000, 200000 MPa. Similar values are suggested by Leshchinsky \& Ling, 2013

The Figure 5-1 is Subgrade stress distribution below geocell-reinforced embankment overlying very soft foundation $(2 \mathrm{MPa})$.

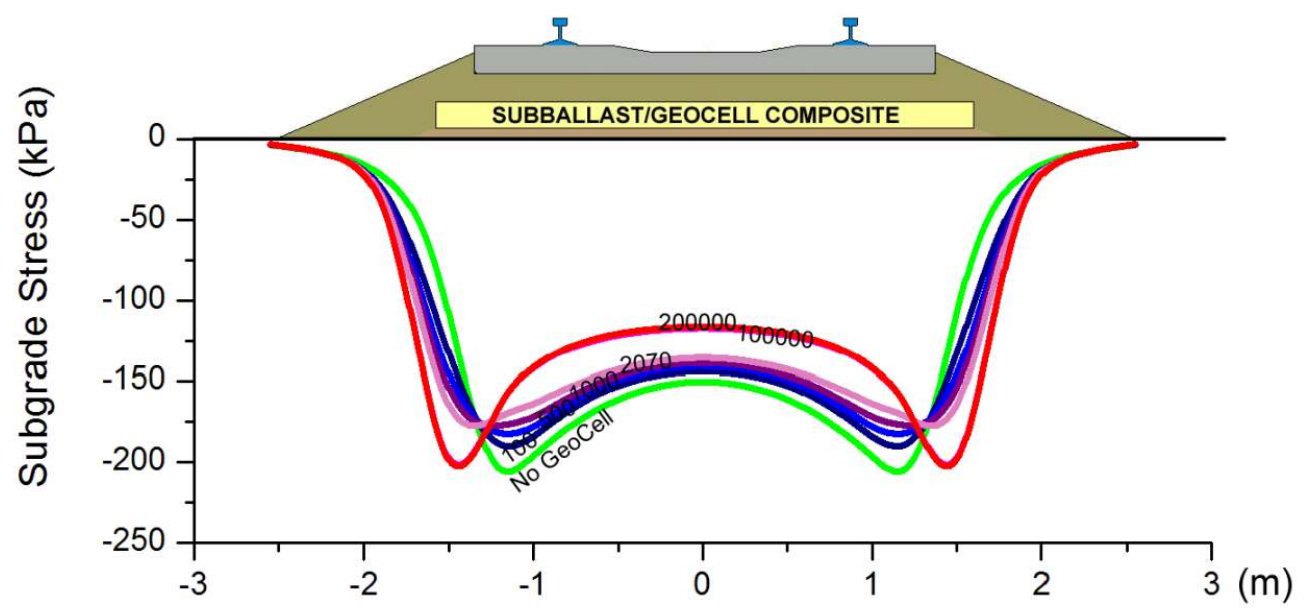

Figure 5-1 Subgrade stress distribution below geocell-reinforced embankment overlying very soft foundation (2 MPa) (Leshchinsky, 2012). 
The Figure 5-2 is Subgrade stress distribution below geocell-reinforced embankment overlying soft foundation (20 MPa).

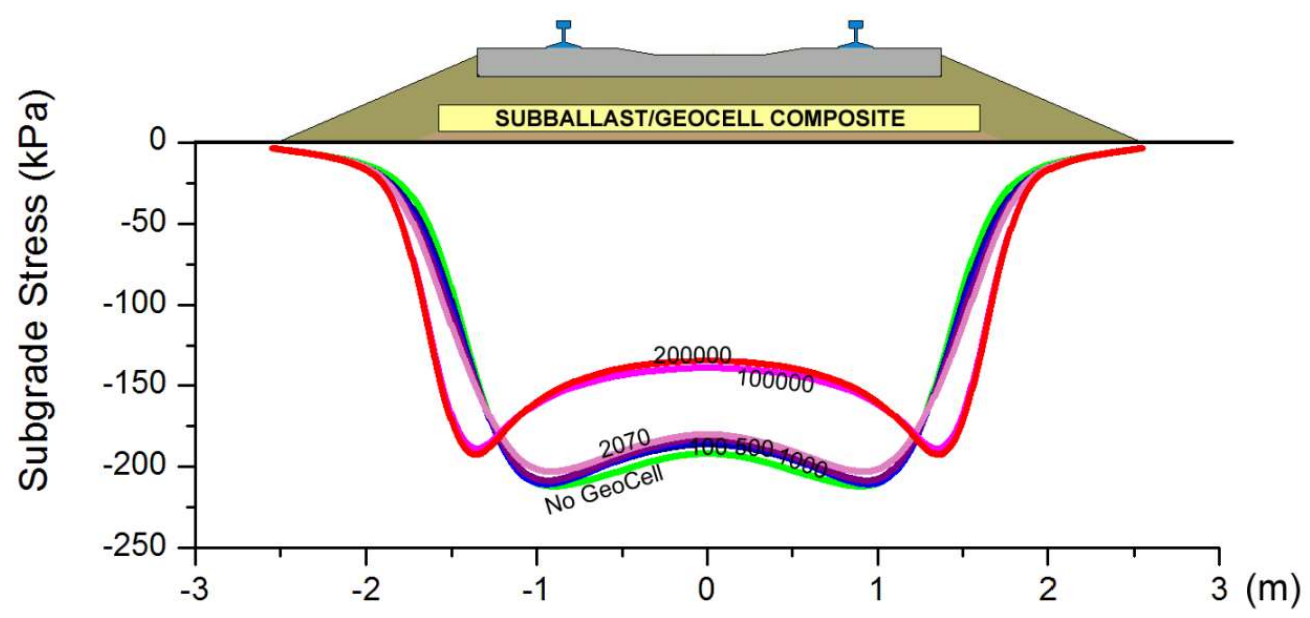

Figure 5-2 Subgrade stress distribution below geocell-reinforced embankment overlying soft foundation (20 MPa) (Leshchinsky, 2012).

Although the stress distribution in subgrade presented in Figure 2-8 is more rational, but it is difficult to accurately digitalize it. For this reason, in this thesis, the $\mathrm{N}$ Geocell values and pattern of stress distribution in subgrade of soft soils shown in Figure 5-1 is used for representing the normal spreading load.

To the best of the knowledge of the author, there are no experimental studies results in the literature to provide guidance on the likely maximum point load (or stress) that arises in railway tracks. This value is difficult or measure or estimate. For this reason, a value of $420 \mathrm{kPa}$, is considered as stress associated with a point load with a safety factor of 2 as shown Figure 5-1.

\subsection{Result of Simulation for Point Load}

Based on selected input data of four key soil properties, which include the effective angle of friction, effective cohesion, coefficient of earth pressure at rest, and the coefficient of residual friction on failure plane, 1400 simulations have been conducted. In these simulations, the effective angle of friction of subgrade soils was varied from $17^{\circ}$ to $25^{\circ}$ with increments of $2^{\circ}$ (i.e., $\phi^{\prime}=17^{\circ}, 19^{\circ}, 21^{\circ}, 23^{\circ}, 25^{\circ}$ ), the effective cohesion values was varied from $1 \mathrm{kPa}$ to $10 \mathrm{kPa}$ 
with increments of $1 \mathrm{kPa}$ (i.e., $c^{\prime}=1,2,3,4,5,6,7,8,9,10 \mathrm{kPa}$ ), the coefficient of earth pressure at rest was varied from 0.25 to 0.4 with increments of 0.05 (i.e., $K_{o}=0.25,0.3,0.35$, 0.4 ), and the coefficient of residual friction on failure plane was varied from 0.05 to 0.35 with increments of 0.05 (i.e., $K_{r}=0.05,0.1,0.15,0.2,0.25,0.3,0.35$ ) (i.e., total $5 \times 10 \times 4 \times 7=1400$ simulations). Some typical results of the simulations under point load are summarized in the Table 5-10 (see detail results in Appendix).

Table 5-10 Some typical results of simulation under point load

\begin{tabular}{|c|c|c|c|c|c|c|}
\hline $\begin{array}{c}\text { No of } \\
\text { simulation }\end{array}$ & $\begin{array}{l}\text { Angle } \\
\text { of } \\
\text { friction }\end{array}$ & Cohesion & $\begin{array}{c}\text { Coefficient } \\
\text { of earth } \\
\text { pressure } \\
\text { at rest }\end{array}$ & $\begin{array}{l}\text { Coefficient } \\
\text { of residual } \\
\text { friction }\end{array}$ & $\begin{array}{l}\text { Number } \\
\text { of } \\
\text { elements }\end{array}$ & $\begin{array}{l}\text { Final } \\
\text { Load }\end{array}$ \\
\hline & $\phi^{\prime}$ & $c^{\prime}$ & $K_{0}$ & $K_{r}$ & No. & $P$ \\
\hline & o & $\mathrm{kPa}$ & & & & $\%$ \\
\hline 75 & 25 & 5 & 0.3 & 0.05 & 7 & 18 \\
\hline 255 & 25 & 1 & 0.3 & 0.1 & 200 & 20 \\
\hline 260 & 25 & 2 & 0.3 & 0.1 & 47 & 48 \\
\hline 265 & 25 & 3 & 0.3 & 0.1 & 23 & 41 \\
\hline 270 & 25 & 4 & 0.3 & 0.1 & 11 & 27 \\
\hline 275 & 25 & 5 & 0.3 & 0.1 & 8 & 25 \\
\hline 280 & 25 & 6 & 0.3 & 0.1 & 6 & 21 \\
\hline 285 & 25 & 7 & 0.3 & 0.1 & 6 & 25 \\
\hline 290 & 25 & 8 & 0.3 & 0.1 & 5 & 23 \\
\hline 295 & 25 & 9 & 0.3 & 0.1 & 5 & 26 \\
\hline 300 & 25 & 10 & 0.3 & 0.1 & 5 & 29 \\
\hline 475 & 25 & 5 & 0.3 & 0.15 & 8 & 29 \\
\hline 521 & 17 & 5 & 0.35 & 0.15 & 8 & 35 \\
\hline 522 & 19 & 5 & 0.35 & 0.15 & 8 & 35 \\
\hline 523 & 21 & 5 & 0.35 & 0.15 & 8 & 35 \\
\hline 524 & 23 & 5 & 0.35 & 0.15 & 7 & 32 \\
\hline 525 & 25 & 5 & 0.35 & 0.15 & 6 & 31 \\
\hline 625 & 25 & 5 & 0.25 & 0.2 & 10 & 35 \\
\hline
\end{tabular}




\begin{tabular}{|c|c|c|c|c|c|c|}
\hline 675 & 25 & 5 & 0.3 & 0.2 & 9 & 40 \\
\hline 725 & 25 & 5 & 0.35 & 0.2 & 7 & 43 \\
\hline 775 & 25 & 5 & 0.4 & 0.2 & 1 & 256 \\
\hline 875 & 25 & 5 & 0.3 & 0.25 & 9 & 48 \\
\hline 1075 & 25 & 5 & 0.3 & 0.3 & 9 & 58 \\
\hline 1275 & 25 & 5 & 0.3 & 0.35 & 10 & 82 \\
\hline
\end{tabular}

In the program, three conditions are set to end the each simulation of progressive shear failure.

(i) The limit number of elements for one progressive shear failure is 200 .

(ii) The maximum stress (final load) in an element is limited to $200 \%$ of input stress (load).

(iii) The failure plane reaches the surface of subgrade. Therefore, in table 1, there are many simulations which its number of elements is 200 or its final load is $200 \%$.

In Table 5-10, the number of elements is the number of failed elements along failure plane during each simulation. The final load is the percentage of maximum load or stress in the subgrade at end of each simulation.

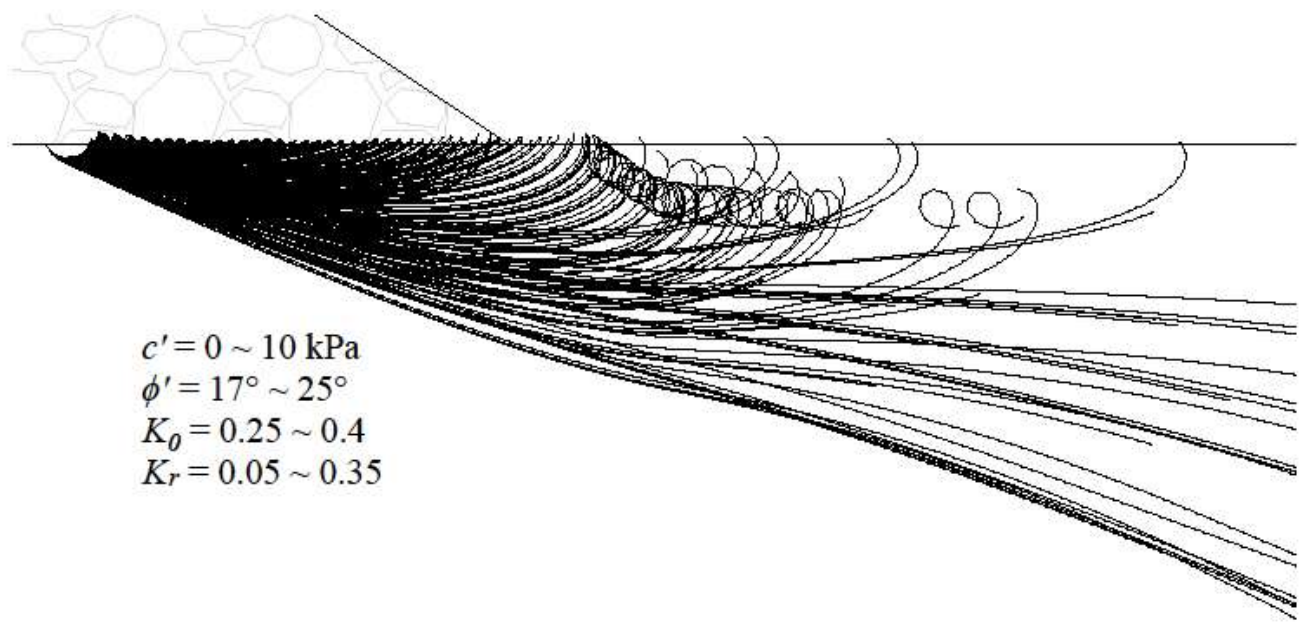

Figure 5-3 Failure planes of simulation for point load

Among the 1400 results of simulation for the point load, there are 77 simulations its number of element is 0 ; that represent the subgrade material is so weak and fail under self-weight according to Mohr-coulomb criteria, so these cases do not exist in the reality. There are 21 simulations its 
number of element is 200; that represent the subgrade material is weak and failure plane extends inside subgrade, so it is not progressive shear failure but displacement or settlement. There are 88 simulations its final load is $200 \%$; that represent the subgrade material is weak and failure plane extends inside subgrade until the load reaches $200 \%$ input load. There are 49 simulations its final load is greater than $200 \%$; that represent the subgrade material is strong and failure does not occur under input load. The other 1165 simulations are progressive shear failure.

The simulation results show a few failure planes that are curled at end of failure plane. Such a behavior may be associated with some limitations in simulation program. This is most likely due to not considering the principle stresses rotation in the element under wheel load and displacements after element fails associated with the stress changes.

\subsubsection{Effect of Angle of Friction}

The Figure 5-4 shows the five failure planes for angle of friction, $\phi^{\prime}$ from $17^{\circ}$ to $25^{\circ}$ while the effective cohesion, $c^{\prime}$ of subgrade is $5 \mathrm{kPa}$, the coefficient of earth pressure at rest, $K_{0}$ is 0.35 , and the coefficient of residual friction, $K_{r}$ is 0.15 .

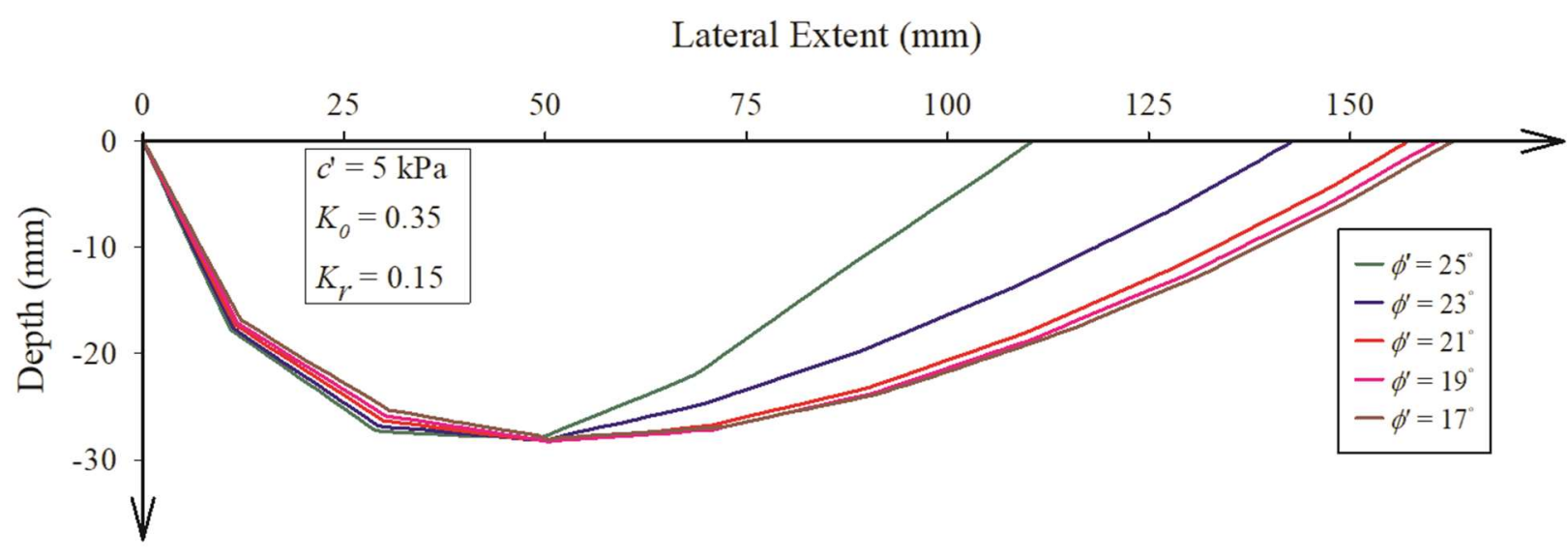

Figure 5-4 Effect of Angle of Friction to progressive shear failure

From this figure and the results summarized in Table 5-10, it can be observed that the failure planes progress rapidly and reach the surface of subgrade (i.e. lesser number of failed elements) with an increase in the angle of friction. The final (failure) load or stress increases slightly with an increase in the angle of friction, $\phi^{\prime}$ value used for the subgrade. As expected, the possibility of 
progressive shear failure reduces by using a subgrade soil with a higher angle of friction, $\phi^{\prime}$ value.

\subsubsection{Effect of Subgrade Effective Cohesion}

The Figure 5-5 shows ten failure planes for the subgrade with effective cohesion, $c$ ' values varying from $1 \mathrm{kPa}$ to $10 \mathrm{kPa}$ for a soil with an angle of friction $\phi^{\prime}$ value of $25^{\circ}$, the coefficient of earth pressure at rest, $K_{0}$ value of 0.3 , and the coefficient of residual friction $K_{0}$ value of 0.1 .

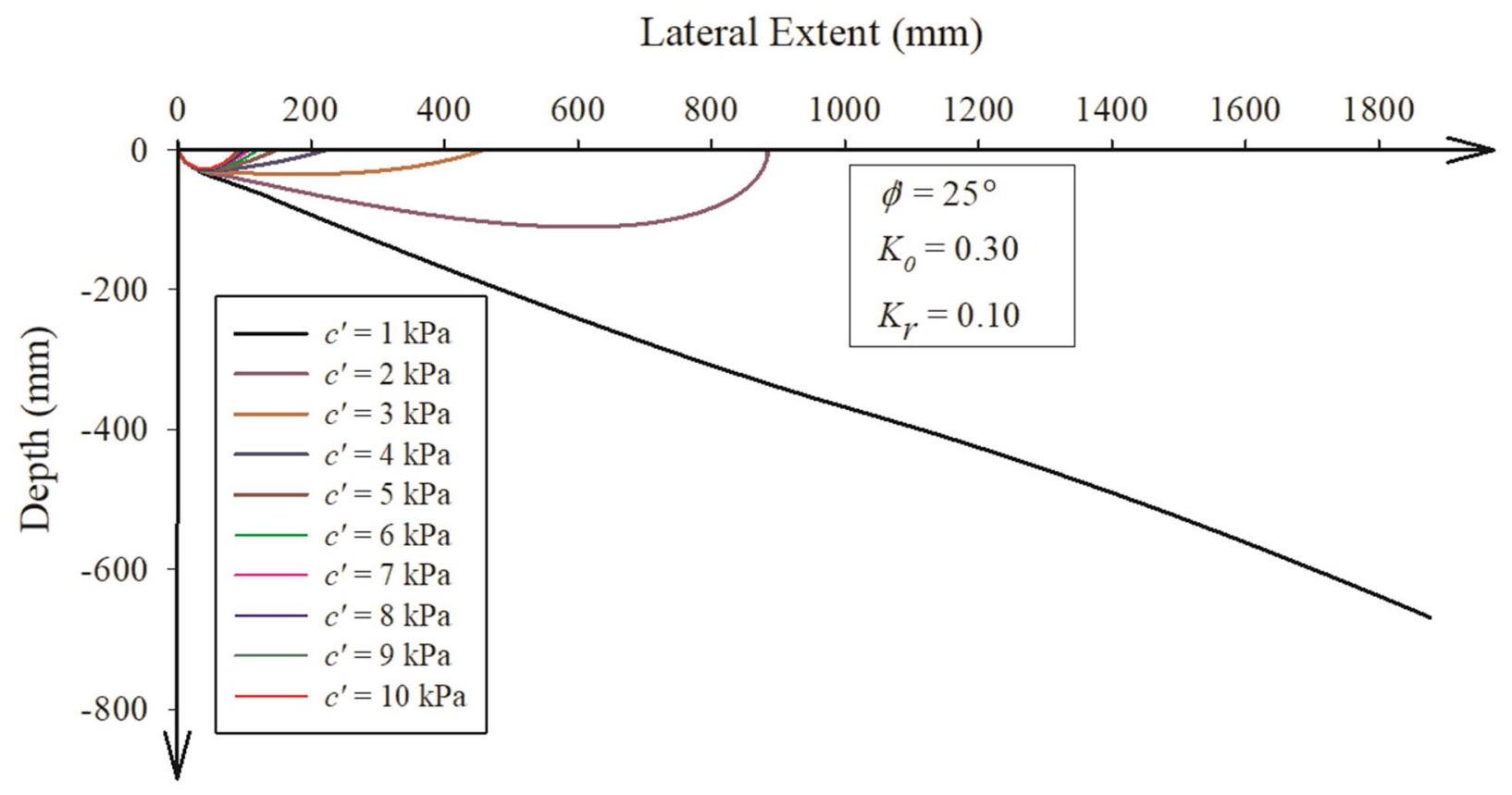

Figure 5-5 Effect of Subgrade Effective Cohesion to progressive shear failure

From Figure 5-5 and Table 5-10, we can see when the effective cohesion, $c$ ' of subgrade is 1 $\mathrm{kPa}$, the failure plane goes out and down into subgrade with an around $20^{\circ}$ angle to the horizontal direction, and does not return up to the surface of subgrade. For effective cohesion, $c$ ' value of subgrade is $2 \mathrm{kPa}$, the failure plane goes down initially, then slowly turns up, and finally it reaches the surface of subgrade where is out of ballast area after 47 failed elements. When the cohesion of subgrade is $3 \mathrm{kPa}$ the failure plane turns up quicker than when the effective cohesion $c^{\prime}$ of $2 \mathrm{kPa}$, and reaches the surface of subgrade after 23 failed elements. When the cohesion of subgrade is $4 \mathrm{kPa}$ the failure plane turns up even quicker and reach the surface of subgrade after 
11 failed elements. Similarly, for the cohesion of subgrade from $5 \mathrm{kPa}$ to $10 \mathrm{kPa}$, the failure plane reaches the surface of subgrade earlier and closer to primary failure element with lesser failed elements, as the cohesion increases.

The final (failure) load or stress increase and the number of failed elements decrease as the cohesion increase. In other words, increasing the effective cohesion of subgrade can reduce the risk of progressive shear failure in subgrade.

\subsubsection{Effect of Coefficient of Earth Pressure at Rest}

Figure 5-6 shows four failure planes for the coefficient of earth pressure at rest, $K_{0}$ value varying from 0.25 to 0.4 while the effective cohesion $c^{\prime}$ of subgrade is $5 \mathrm{kPa}$, the angle of friction $\phi^{\prime}$ value is $25^{\circ}$, and the coefficient of residual friction, $K_{r}$ is 0.2 .

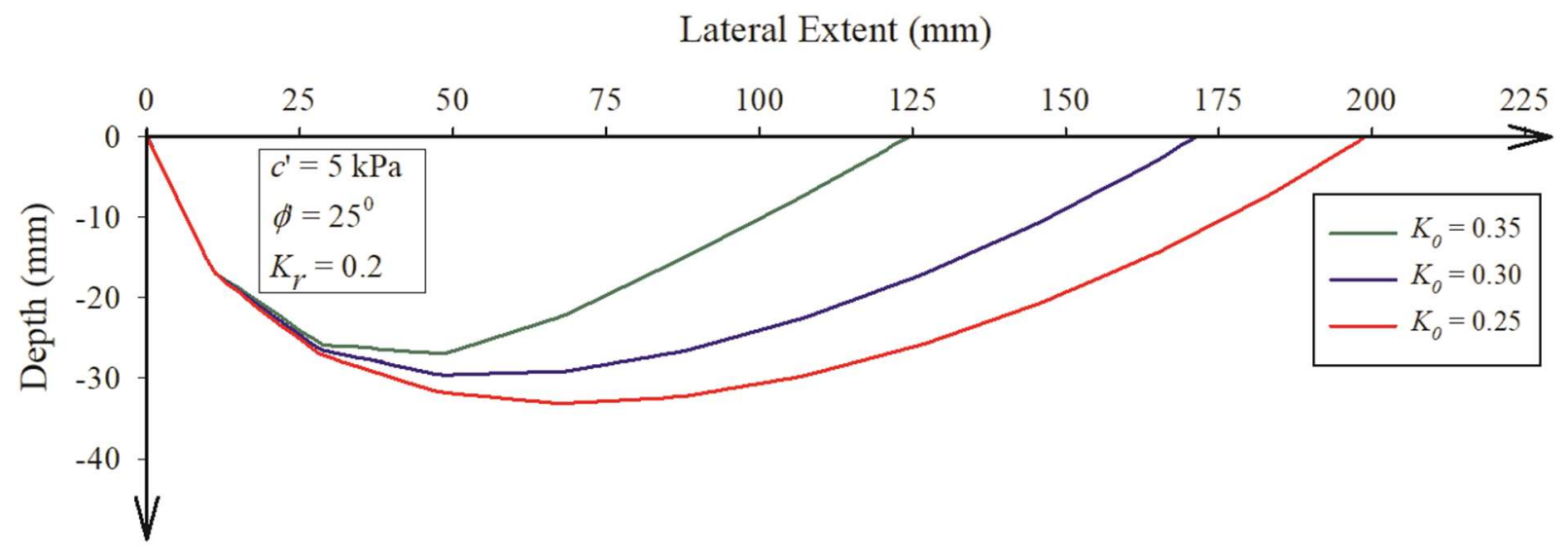

Figure 5-6 Effect of Coefficient of Earth Pressure at Rest to progressive shear failure From Figure 5-6 and Table 5-10, we can see when the coefficient of earth pressure at rest, $K_{0}$ is 0.25 the failure plane extends down initially, then turns up, and finally reaches the surface of subgrade after 10 failed elements. When the coefficient of earth pressure at rest, $K_{0}$ is 0.3 , the failure plane extends shorter than the coefficient of earth pressure at rest, $K_{0}$ is 0.25 , and reaches the surface of subgrade after 9 failed elements. Similarly, when the coefficient of earth pressure at rest $K_{0}$ is 0.35 , the failure plane goes up quicker than the coefficient of earth pressure at rest $K_{0}$ is 0.3 , and reaches the surface of subgrade after 7 failed elements. However, when the coefficient of earth pressure at rest, $K_{0}$ is 0.4 , the primary element does not fail until the load (or stress) is 2.56 times over the applied point load (or stress) in subgrade. This simulation result suggests the 
failure would not occur normally when the coefficient of earth pressure at rest $K_{0}$ is greater than 0.4. This is because at higher values of $K_{0}$ there is more confinement which offers more resistance in the development of failure plane. Therefore, increasing the coefficient of earth pressure at rest $K_{0}$ value can reduce the risk of progressive shear failure in the subgrade.

\subsubsection{Effect of Coefficient of Friction on Failure Plane}

The Figure 5-7 shows seven failure planes for the coefficient of residual friction, $K_{r}$ values varying from 0.05 to 0.35 on failure plane for a soil with an effective cohesion, $c$ ' value of subgrade is $5 \mathrm{kPa}$, and the angle of internal friction is $25^{\circ}$, and the coefficient of earth pressure at rest $K_{0}$ value is 0.3 .

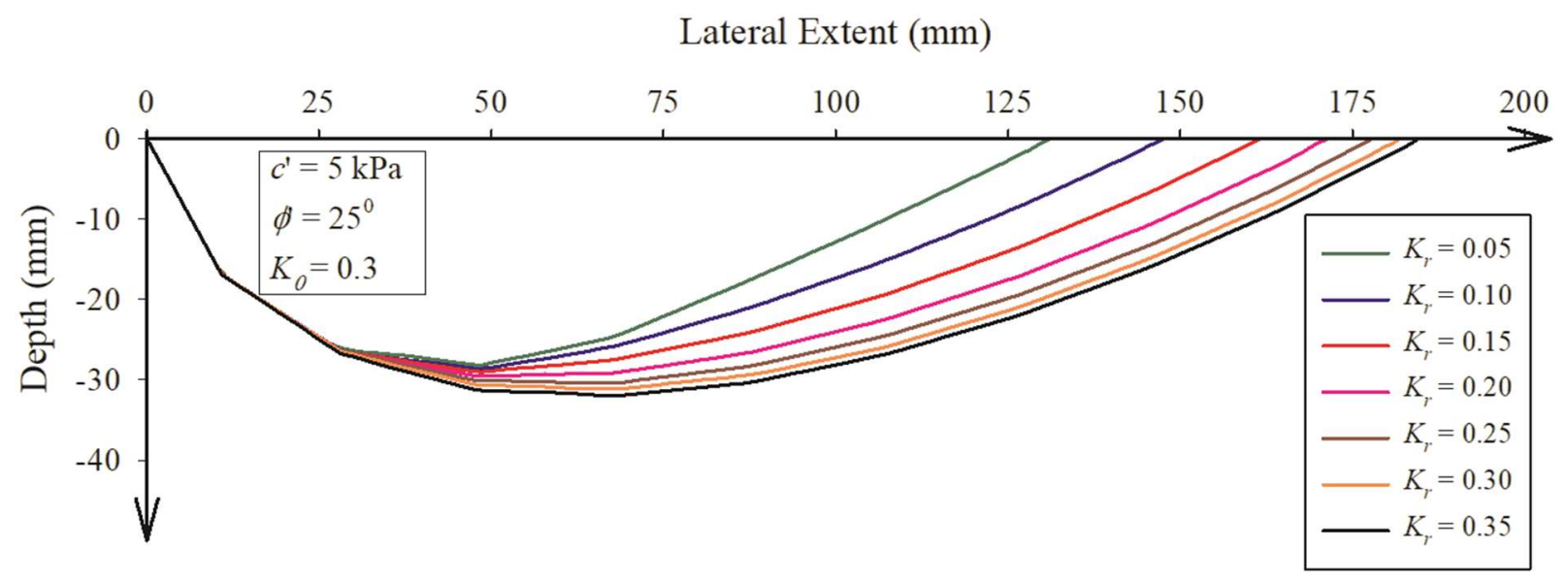

Figure 5-7 Effect of Coefficient of residual Friction on Failure Plane

From Figure 5-7 and Table 5-10, similar to analyses of results summarized earlier, all failure planes extend down initially, then turns up, and finally reaches the surface of subgrade after 7 to 10 failed elements. These simulation results suggest as the coefficient of residual friction, $K_{r}$ on failure plane increase from 0.05 to 0.35 , along the shear failure plane, the number of failed elements increase from 7 to 10 , and the final load factor increase from $18 \%$ to $82 \%$. These simulation results are consistent with the expected behavior which suggest that an increase in the coefficient of residual friction, $K_{r}$ value on failure plane can reduce the risk of progressive shear failure in the subgrade. 


\subsection{Result of Simulation for normal spreading load}

The typical load or stress on surface of subgrade, which is referred to as normal spreading load can be assumed as shown in Figure 5-1 and Figure 2-8. Based on selected input data which were summarized in earlier sections, 1400 simulation were conducted. Some typical results of these simulations are summarized in Table 5-11 (see detailed results in Appendix). In addition, Figure 5-8 summarizes the various failure planes.

From Figure 5-8 and Table 5-11, it can be observed, under normal spreading load, almost all the failure planes go down and then spread out in subgrade with an angle of $12^{\circ} \sim 32^{\circ}$ to the horizontal direction after the first several elements. They never turn up to the surface of subgrade, except when the cohesion or suction stress are $3 \sim 5 \mathrm{kPa}$. Some failure planes that turn up towards the surface of subgrade under the toe of ballast however do not reach the surface of subgrade. 
Table 5-11 Some typical results of the simulation under normal spreading load

\begin{tabular}{|c|c|c|c|c|c|c|}
\hline $\begin{array}{c}\text { No of } \\
\text { simulation }\end{array}$ & $\begin{array}{l}\text { Angle } \\
\text { of } \\
\text { friction }\end{array}$ & Cohesion & $\begin{array}{c}\text { Coefficient } \\
\text { of earth } \\
\text { pressure } \\
\text { at rest }\end{array}$ & $\begin{array}{l}\text { Coefficient } \\
\text { of residual } \\
\text { friction }\end{array}$ & $\begin{array}{l}\text { Number } \\
\text { of } \\
\text { elements }\end{array}$ & $\begin{array}{l}\text { Final } \\
\text { Load }\end{array}$ \\
\hline & $\phi^{\prime}$ & $C$ & $K_{0}$ & $K_{r}$ & No. & $\mathrm{P}$ \\
\hline & $\circ$ & $\mathrm{kPa}$ & & & & $\%$ \\
\hline 5 & 25 & 1 & 0.25 & 0.05 & 0 & 0 \\
\hline 10 & 25 & 2 & 0.25 & 0.05 & 200 & 7 \\
\hline 11 & 17 & 3 & 0.25 & 0.05 & 200 & 101 \\
\hline 12 & 19 & 3 & 0.25 & 0.05 & 168 & 200 \\
\hline 13 & 21 & 3 & 0.25 & 0.05 & 143 & 200 \\
\hline 14 & 23 & 3 & 0.25 & 0.05 & 132 & 200 \\
\hline 15 & 25 & 3 & 0.25 & 0.05 & 126 & 200 \\
\hline 20 & 25 & 4 & 0.25 & 0.05 & 93 & 200 \\
\hline 25 & 25 & 5 & 0.25 & 0.05 & 80 & 200 \\
\hline 30 & 25 & 6 & 0.25 & 0.05 & 67 & 200 \\
\hline 35 & 25 & 7 & 0.25 & 0.05 & 60 & 200 \\
\hline 40 & 25 & 8 & 0.25 & 0.05 & 54 & 200 \\
\hline 45 & 25 & 9 & 0.25 & 0.05 & 50 & 200 \\
\hline 50 & 25 & 10 & 0.25 & 0.05 & 47 & 200 \\
\hline 65 & 25 & 3 & 0.3 & 0.05 & 92 & 200 \\
\hline 115 & 25 & 3 & 0.35 & 0.05 & 40 & 200 \\
\hline 165 & 25 & 3 & 0.4 & 0.05 & 1 & 310 \\
\hline 215 & 25 & 3 & 0.25 & 0.1 & 146 & 200 \\
\hline 415 & 25 & 3 & 0.25 & 0.15 & 135 & 200 \\
\hline 615 & 25 & 3 & 0.25 & 0.2 & 109 & 200 \\
\hline 815 & 25 & 3 & 0.25 & 0.25 & 90 & 200 \\
\hline 1015 & 25 & 3 & 0.25 & 0.3 & 70 & 200 \\
\hline 1215 & 25 & 3 & 0.25 & 0.35 & 54 & 200 \\
\hline
\end{tabular}




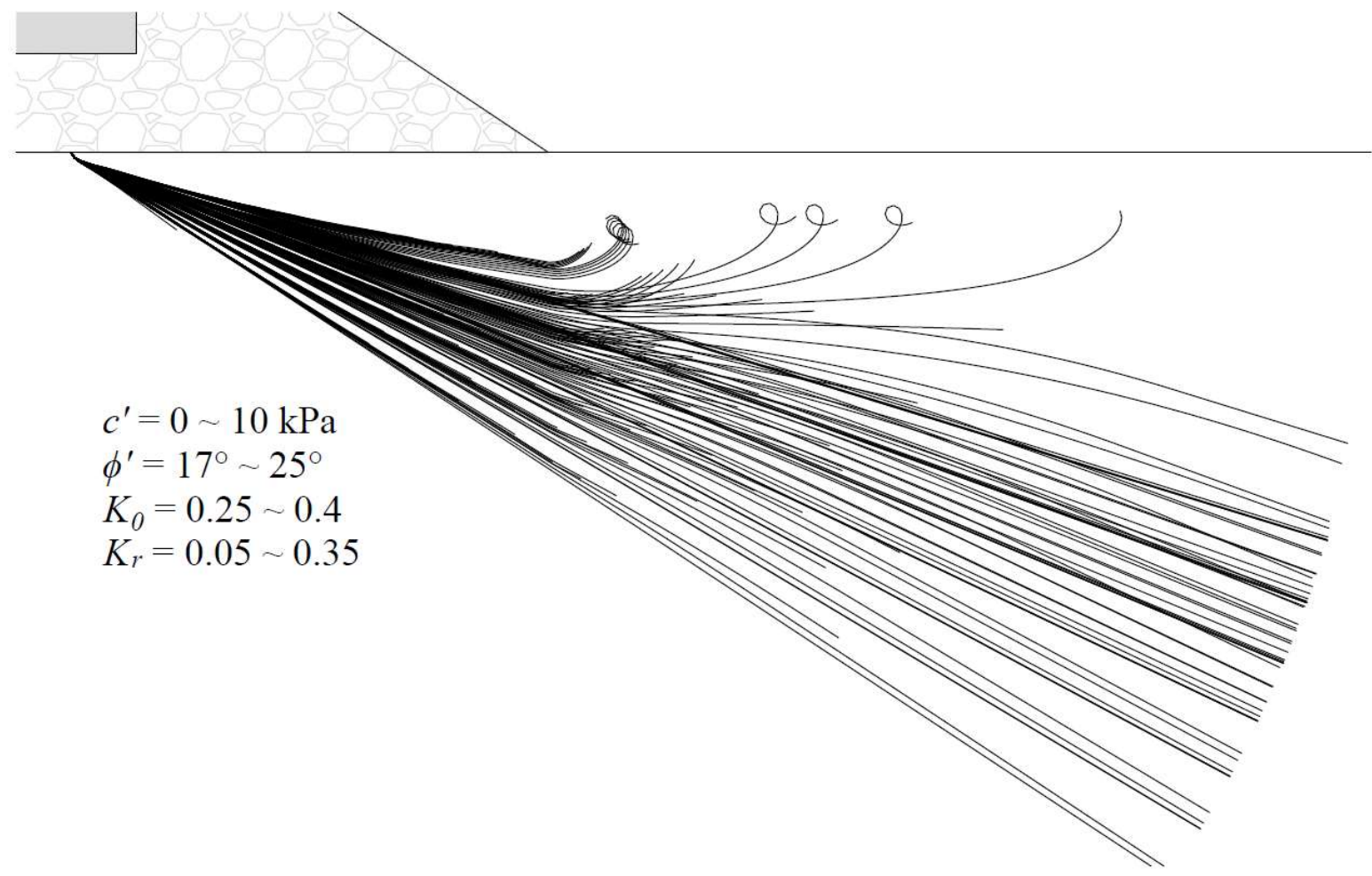

Figure 5-8 Failure planes under normal spreading load

\subsubsection{Effect of Stress Distribution to Progressive Shear Failure}

Comparing to the Figure 5-3 and the Figure 5-8, no failure plane finally reaches the surface of subgrade under normal spreading load although some failure planes turn up toward the surface of subgrade while many failure planes reach the surface of subgrade under point load. In other words, under the normal spreading load distribution, the progressive shear failure would not occur although many elements have failed but failure planes have not reached the surface of subgrade. However, under the point load, the progressive shear failure would occur when the failure planes reach the surface of subgrade.

\subsubsection{Effect of Matric Suction}

As per discussions summarized in Section 4.2 2) and Equation 4.3, for the cohesionless soil, the effective cohesion $c^{\prime}=0$, so $c$ directly involves as the effect of matric suction.

The Figure 5-9 shows ten failure planes for the subgrade with effective cohesion, $c$ ' values varying from $1 \mathrm{kPa}$ to $10 \mathrm{kPa}$ for a soil with an angle of friction $\phi^{\prime}$ value of $25^{\circ}$, the coefficient of earth pressure at rest, $K_{0}$ value of 0.25 , and the coefficient of residual friction $K_{0}$ value of 0.05 . 


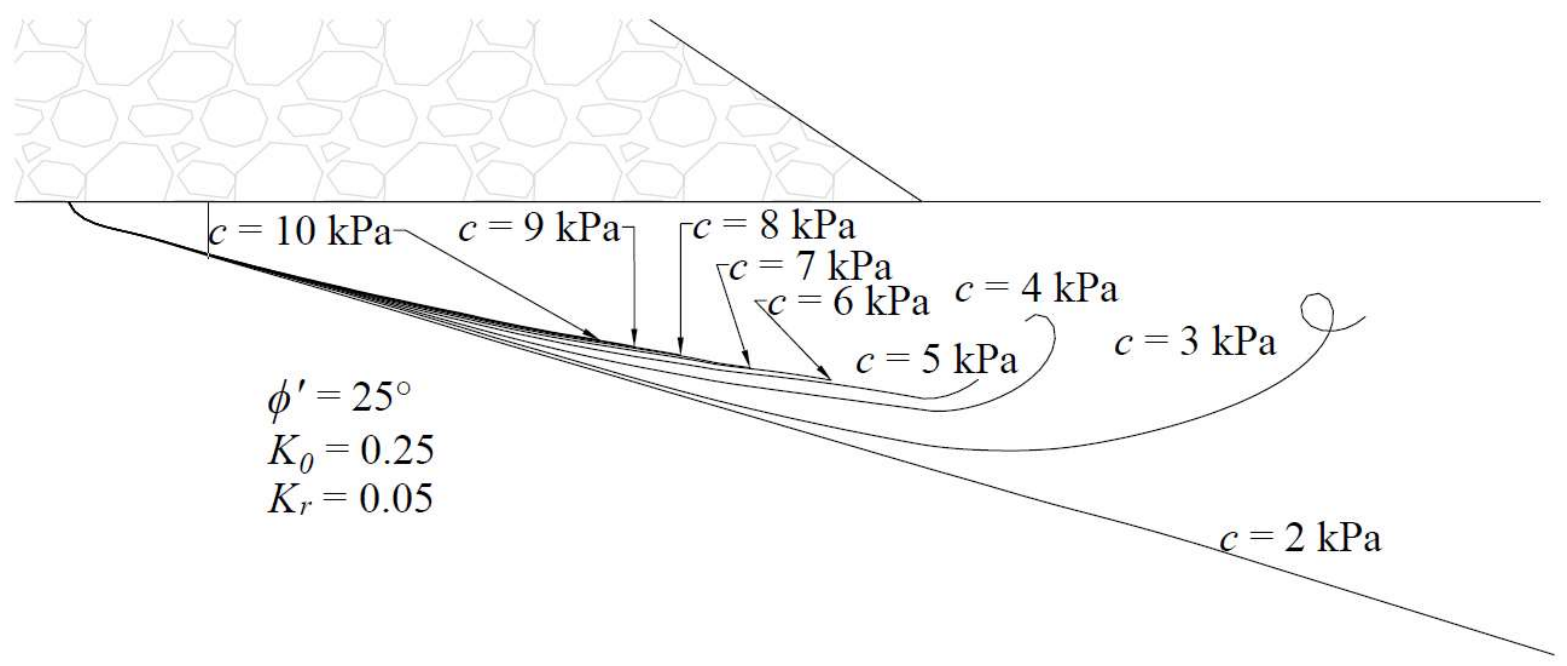

Figure 5-9 Effect of Matric Suction to Progressive Shear Failure

From Figure 5-9 and Table 5-11, we can see, all the failure plane goes down and out in subgrade with an angle of around $15^{\circ}$ to the horizontal direction. As the suction increases, the angle of failure plane to the horizontal direction become smaller, and the number of failed elements become smaller too. So, increasing the cohesion or suction of subgrade can reduce the risk of progressive shear failure in subgrade.

\subsubsection{Effect of frication angle, cohesion and coefficient of earth pressure at rest}

According to Eq. 3.7 and 4.7, in this study, $\sigma_{3}^{\prime}=K_{0} \sigma_{1}^{\prime}$. If ${\sigma^{\prime}}_{1}>{\sigma^{\prime}}_{3} \tan ^{2} \theta+2 c^{\prime} \tan \theta$, the element will fail. Or if $K_{0}>\frac{\sigma_{1}-2 c^{\prime} \tan \theta}{\sigma_{\prime} \tan ^{2} \theta}$, the element will not fail. For cohesionless soil, the $c^{\prime}=$ 0 , then if $K_{0}>\frac{1}{\tan ^{2} \theta}$, the progressive shear fail will not occur.

According to Leshchinsky \& Ling (2013) and Leshchinsky (2012) (as summarized in Figure $5-1$ ), the maximum stress under bottom of ballast is $210 \mathrm{kPa}$. Considering the safety factor of 2 as for point load, we use $420 \mathrm{kPa}$ as vertical (major principal) stress $\sigma_{1}$ '. Therefore, we can calculate the relationship of friction angle $\phi^{\prime}$, cohesion $c^{\prime}$ and coefficient of earth pressure at rest $K_{0}$ at critical condition of shear failure as in Table 5-12 and Figure 5-10. 
Table 5-12 The relationship of frication angle $\phi^{\prime}$, cohesion $c^{\prime}$ and coefficient of earth pressure at rest $K_{0}$ at critical condition of shear failure

\begin{tabular}{|c|c|c|c|c|c|c|c|c|c|c|c|c|c|c|c|}
\hline$\phi^{\prime}\left({ }^{\circ}\right)$ & 11 & 12 & 13 & 14 & 15 & 16 & 17 & 18 & 19 & 20 & 21 & 22 & 23 & 24 & 25 \\
\hline$c^{\prime}(\mathrm{kPa})$ & 0.98 & 0.99 & 1.01 & 1.03 & 1.05 & 1.06 & 1.08 & 1.10 & 1.12 & 1.13 & 1.15 & 1.17 & 1.19 & 1.20 & 1.22 \\
\hline 0 & 0.45 & 0.42 & 0.39 & 0.36 & 0.33 & 0.31 & 0.28 & 0.26 & 0.24 & 0.22 & 0.20 & 0.18 & 0.16 & 0.15 & 0.13 \\
\hline 1 & 0.45 & 0.42 & 0.39 & 0.36 & 0.33 & 0.30 & 0.28 & 0.26 & 0.24 & 0.22 & 0.20 & 0.18 & 0.16 & 0.15 & 0.13 \\
\hline 2 & 0.45 & 0.42 & 0.38 & 0.36 & 0.33 & 0.30 & 0.28 & 0.25 & 0.23 & 0.21 & 0.19 & 0.18 & 0.16 & 0.14 & 0.13 \\
\hline 3 & 0.45 & 0.41 & 0.38 & 0.35 & 0.33 & 0.30 & 0.28 & 0.25 & 0.23 & 0.21 & 0.19 & 0.17 & 0.16 & 0.14 & 0.13 \\
\hline 4 & 0.44 & 0.41 & 0.38 & 0.35 & 0.32 & 0.30 & 0.27 & 0.25 & 0.23 & 0.21 & 0.19 & 0.17 & 0.16 & 0.14 & 0.13 \\
\hline 5 & 0.44 & 0.41 & 0.38 & 0.35 & 0.32 & 0.29 & 0.27 & 0.25 & 0.23 & 0.21 & 0.19 & 0.17 & 0.15 & 0.14 & 0.12 \\
\hline 6 & 0.44 & 0.40 & 0.37 & 0.34 & 0.32 & 0.29 & 0.27 & 0.25 & 0.22 & 0.20 & 0.19 & 0.17 & 0.15 & 0.14 & 0.12 \\
\hline 7 & 0.43 & 0.40 & 0.37 & 0.34 & 0.31 & 0.29 & 0.26 & 0.24 & 0.22 & 0.20 & 0.18 & 0.17 & 0.15 & 0.13 & 0.12 \\
\hline 8 & 0.43 & 0.40 & 0.37 & 0.34 & 0.31 & 0.29 & 0.26 & 0.24 & 0.22 & 0.20 & 0.18 & 0.16 & 0.15 & 0.13 & 0.12 \\
\hline 9 & 0.43 & 0.39 & 0.36 & 0.34 & 0.31 & 0.28 & 0.26 & 0.24 & 0.22 & 0.20 & 0.18 & 0.16 & 0.15 & 0.13 & 0.12 \\
\hline 10 & 0.42 & 0.39 & 0.36 & 0.33 & 0.31 & 0.28 & 0.26 & 0.24 & 0.21 & 0.20 & 0.18 & 0.16 & 0.14 & 0.13 & 0.12 \\
\hline 11 & 0.42 & 0.39 & 0.36 & 0.33 & 0.30 & 0.28 & 0.25 & 0.23 & 0.21 & 0.19 & 0.17 & 0.16 & 0.14 & 0.13 & 0.11 \\
\hline 12 & 0.42 & 0.38 & 0.35 & 0.33 & 0.30 & 0.28 & 0.25 & 0.23 & 0.21 & 0.19 & 0.17 & 0.16 & 0.14 & 0.13 & 0.11 \\
\hline 13 & 0.41 & 0.38 & 0.35 & 0.32 & 0.30 & 0.27 & 0.25 & 0.23 & 0.21 & 0.19 & 0.17 & 0.15 & 0.14 & 0.12 & 0.11 \\
\hline 14 & 0.41 & 0.38 & 0.35 & 0.32 & 0.29 & 0.27 & 0.25 & 0.23 & 0.21 & 0.19 & 0.17 & 0.15 & 0.14 & 0.12 & 0.11 \\
\hline 15 & 0.41 & 0.38 & 0.35 & 0.32 & 0.29 & 0.27 & 0.24 & 0.22 & 0.20 & 0.18 & 0.17 & 0.15 & 0.13 & 0.12 & 0.11 \\
\hline 16 & 0.40 & 0.37 & 0.34 & 0.32 & 0.29 & 0.27 & 0.24 & 0.22 & 0.20 & 0.18 & 0.16 & 0.15 & 0.13 & 0.12 & 0.10 \\
\hline 17 & 0.40 & 0.37 & 0.34 & 0.31 & 0.29 & 0.26 & 0.24 & 0.22 & 0.20 & 0.18 & 0.16 & 0.15 & 0.13 & 0.12 & 0.10 \\
\hline 18 & 0.40 & 0.37 & 0.34 & 0.31 & 0.28 & 0.26 & 0.24 & 0.22 & 0.20 & 0.18 & 0.16 & 0.14 & 0.13 & 0.11 & 0.10 \\
\hline 19 & 0.39 & 0.36 & 0.33 & 0.31 & 0.28 & 0.26 & 0.23 & 0.21 & 0.19 & 0.18 & 0.16 & 0.14 & 0.13 & 0.11 & 0.10 \\
\hline 20 & 0.39 & 0.36 & 0.33 & 0.30 & 0.28 & 0.25 & 0.23 & 0.21 & 0.19 & 0.17 & 0.16 & 0.14 & 0.12 & 0.11 & 0.10 \\
\hline
\end{tabular}

Note: Row 1 are the values of friction angle $\phi^{\prime}$ in degree

Row 2 are the value of angle of shear failure plane $\theta$ in radian

Colon 1 are the value of cohesion $c^{\prime}$ in $\mathrm{kPa}$, including suction

All the other cell are value of coefficient of earth pressure at rest $K_{0}$ 


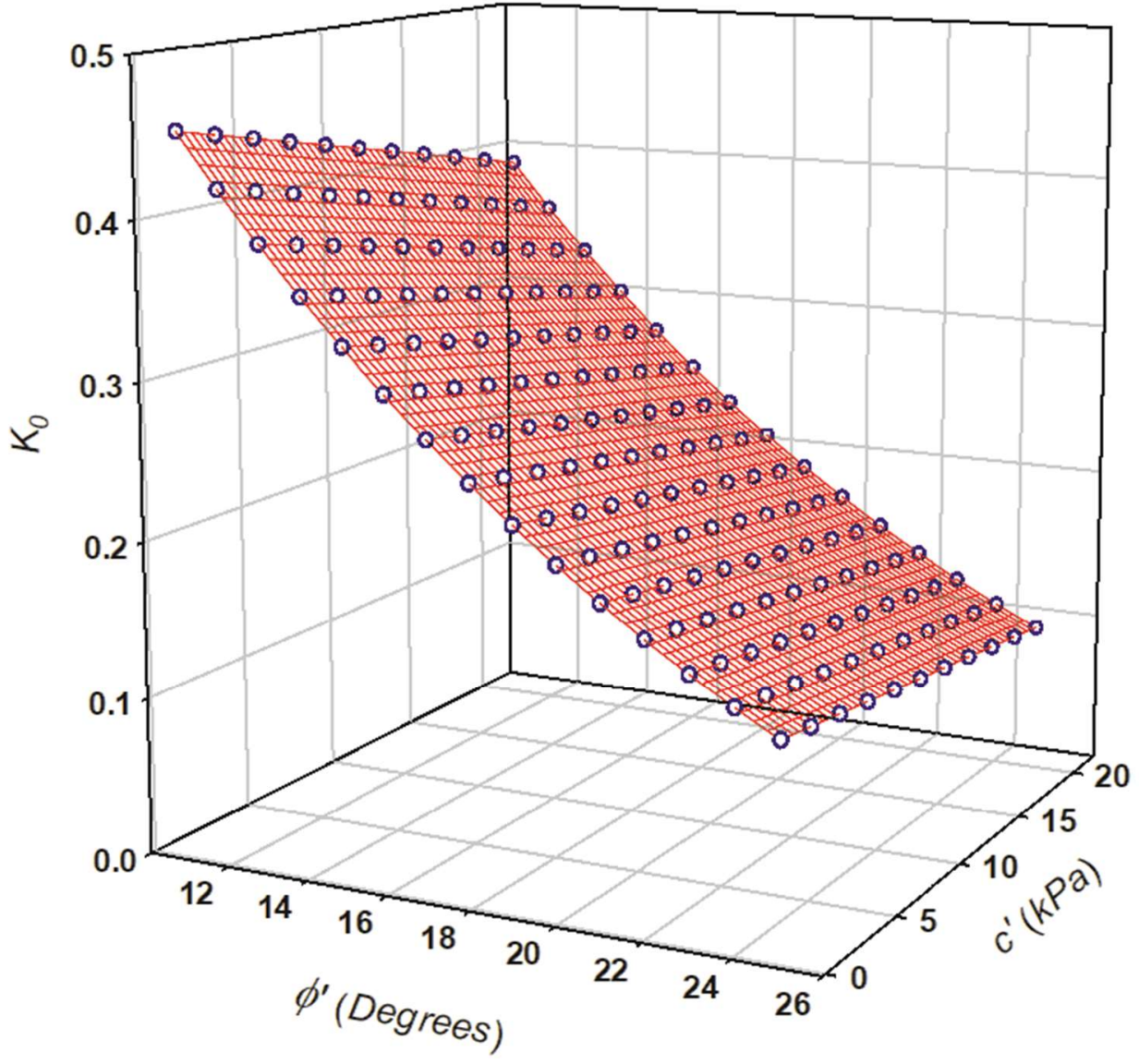

Figure 5-10 The relationship of frication angle $\phi^{\prime}$, cohesion $c^{\prime}$ and coefficient of earth pressure at rest $K_{0}$ at critical condition of shear failure

In the Figure 5-10, if the relationship of friction angle $\phi^{\prime}$, cohesion $c^{\prime}$ and coefficient of earth pressure at rest $K_{0}$ is above the critical surface, the shear failure would not occur; if the relationship is beneath the critical surface, the shear failure would occur, and it may develop into the progressive shear failure.

\subsection{Sensitivity of element size}

Figure 5-11 shows nine failure planes for the element is $0.02 \mathrm{~m}, 0.05 \mathrm{~m}$ and $0.1 \mathrm{~m}$, and the angle of friction is $17^{\circ}, 21^{\circ}$ and $25^{\circ}$ while the effective cohesion, $c^{\prime}$ of subgrade is $2 \mathrm{kPa}$, the coefficient of earth pressure at rest, $K_{0}$ is 0.35 , and the coefficient of residual friction, $K_{r}$ is 0.1 . 


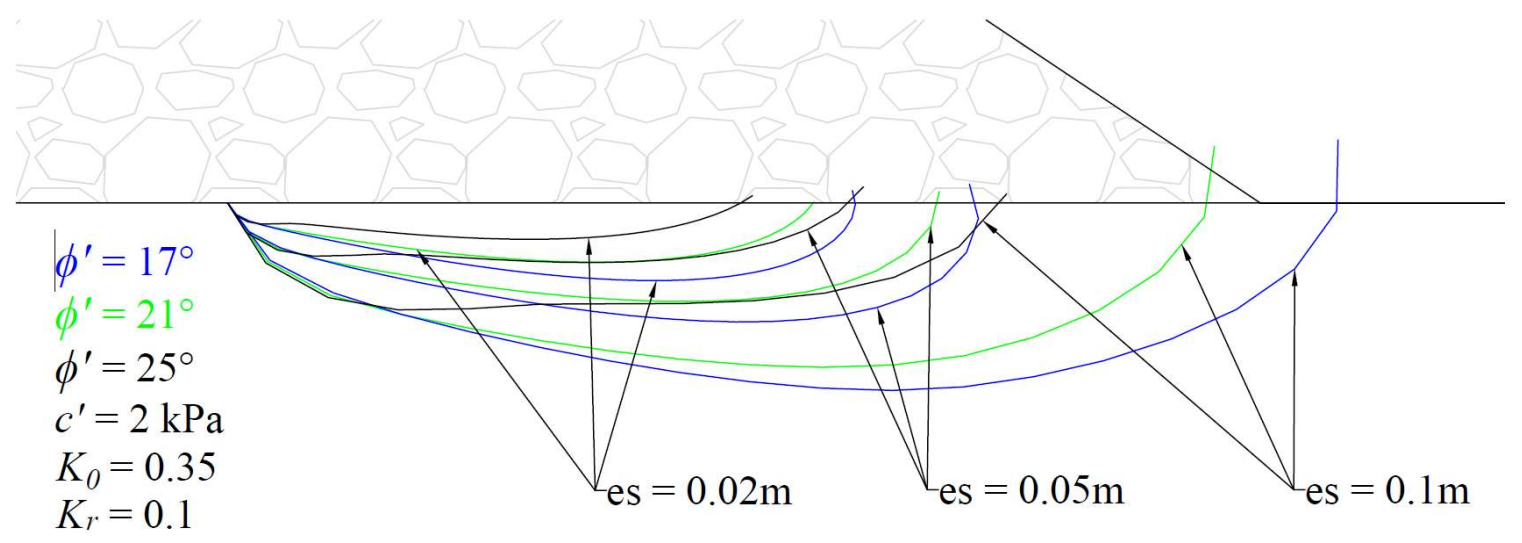

Figure 5-11 Sensitivity of element size

From Figure 5-11, we can see, as the element size increases, the failure plane goes down into subgrade deeper and extends longer, but the change of failure plane shape is not proportional to the increase of element size. Although the element size increases 2.5 times from $0.02 \mathrm{~m}$ to $0.05 \mathrm{~m}$, the length of failure plane only increases $20 \%$. When the element size increases 2 times from $0.05 \mathrm{~m}$ to $0.1 \mathrm{~m}$, the length of failure plane increases $38 \%$. So the element size does have an effect on simulation of progressive shear failure and shape of failure plane. 


\section{CHAPTER 6 \\ CONCLUSIONS AND SUGGESTIONS \\ FOR THE FUTURE RESEARCH}

This chapter summarizes conclusions from the present study; in addition, recommendations for railway subgrade design and construction and suggestions for the future research are provided.

\subsection{Conclusions}

1) A first of its kind and novel numerical simulations of progressive shear failure in railway subgrade is undertaken in this study extending Mohr-Coulomb failure criteria considering the effect of matric suction within the framework of unsaturated soil mechanics. This is a rational approach to investigate progressive shear failure in the railway foundation subgrade taking account of the influence of soil suction in the railway subgrade.

2) Load (or stress) distribution has significant effects to progressive shear failure. The risk of progressive shear failure is low under the normal spreading load distribution.

However, the ballast is constituted of uniformly large size granular material without any cohesion; under cyclic wheel load and vibration, the stress distribution under bottom of ballast has a high possibility to spread unevenly over surface of subgrade and form stress concentration, and have high risk of progressive shear failure.

3) The angle of internal friction, cohesion or suction, coefficient of earth pressure at rest, and coefficient of residual friction on failure plane have significant effects to progressive shear failure. Increasing the angle of friction of subgrade, increasing the cohesion (or matric suction) of subgrade, increasing the coefficient of earth pressure at rest, and increasing the coefficient of friction on failure plane, all can reduce the risk of progressive shear failure in subgrade.

4) There is a relationship among frication angle, cohesion or suction, and coefficient of earth pressure at rest. If $K_{0}>\frac{\sigma_{1}-2 c^{\prime} \tan \theta}{\sigma_{1} \tan ^{2} \theta}$, both the shear failure and progressive shear 
failure would not occur. This is a valuable guideline that can be followed in the design of railway tracks to alleviate railway subgrade failure.

\subsection{Recommendations for Subgrade Design and Maintenance}

\subsubsection{Reduce the uneven stress distribution in railway subgrade}

Leshchinsky (2012) suggested use of geocell to constrain lateral movement of ballast to achieve a more even distribution of stress on the surface of subgrade. Increasing thickness of ballast and adding subballast layer (Sayeed \& Shahin, 2018), as well as well-tamping and maintenance of ballast, can also contribute to even stress distribution over top of subgrade.

\subsubsection{Use geotextile}

Burrow et al. (2011) recommended placing a layer of geotextile between subgrade and ballast (or subballast). Geotextile can separate ballast (or subballast) from subgrade materials and prevent the ballast particles sinking into subgrade. Geotextile can serve as effective filters to keep fine soil in subgrade in place but drain the water away. Geotextile can also serve as lateral reinforce to reduce lateral movement of ballast and subgrade materials.

\subsubsection{Use high-qualified materials for subgrade}

Use materials for subgrade with high friction angle, high cohesion (or matric suction), high coefficient of earth pressure at rest, and high coefficient of residual friction, or with optimum combination of friction angle, cohesion (or matric suction), coefficient of earth pressure at rest, and coefficient of residual friction to ensure the shear failure would not occur in subgrade.

\subsubsection{Use various methods}

Use various methods (Dong et al. 2018; Esmaeili \& Khajehei, 2016; Milne et al., 2018) to increase the angle of friction, cohesion (or matric suction), coefficient of earth pressure at rest, and coefficient of residual friction of subgrade during railway construction and maintenance. The results of this study also consistent with the suggestions of these researchers. 


\subsection{Suggestion for the Future Research}

The program developed for this research for simulating progressive shear failure had consumed a significant amount of time. Due to this reason, it was not possible to undertaken experimental studies in a laboratory environment and provide validations with numerical simulations of progressive shear failure in railway subgrade. It is important to undertake experimental studies in a laboratory environment along with field studies to validate the program developed through the present study.

The improvement of the simulations of progressive shear failure with Mohr-Coulomb failure criteria and finite element method (FEM) by considering the soil displacement and stress changes would be valuable.

In the present study, Mohr-Coulomb failure criteria is used. The simulations of progressive shear failure should also be compared with other soil failure theories to understand the strengths and limitations of the proposed approach presented in this thesis. 


\section{BIBLIOGRAPHY}

Abrantes, L. G., \& Pereira de Campos, T. M. (2019). Evaluation of the coefficient of earth pressure at rest (K0) of a saturated-unsaturated colluvium soil. E3S Web of Conferences, 92, 1-6. https://doi.org/10.1051/e3sconf/20199207006

Al-Hussaini, M. (1981). Comparison of Various Methods for Determining Ko. American Society for Testing and Materials, 78-93.

Alonso, E. E., Gens, A., \& Josa, A. (1990). A constitutive model for partially saturated soils. Geotechnique, 40(3), 405-430. https://doi.org/10.1680/geot.1991.41.2.273

Alonso, E. E., Pereira, J. M., Vaunat, J., \& Olivella, S. (2010). A microstructurally based effective stress for unsaturated soils. Geotechnique, 60(12), 913-925. https://doi.org/10.1680/geot.8.P.002

Alonso, E. E., Pinyol, N. M., \& Gens, A. (2013). Compacted soil behaviour: Initial state, structure and constitutive modelling. Geotechnique, 63(6), 463-478. https://doi.org/10.1680/geot.11.P.134

Baker, R., \& Frydman, S. (2009). Unsaturated soil mechanics. Critical review of physical foundations. Engineering Geology, 106(1-2), 26-39. https://doi.org/10.1016/j.enggeo.2009.02.010

Bishop, A. W. (1959). The principle of effective stress. Teknisk Ukeblad, 106, 859-863.

Bjerrum, L. (1967). Engineering geology of norwegian normally-consolidated marine clays as related to settlements of buildings. Geotechnique, 17(2), 83-118. https://doi.org/10.1680/geot.1967.17.2.83

Boler, H., Mishra, D., Hou, W., \& Tutumluer, E. (2018). Understanding track substructure behavior: Field instrumentation data analysis and development of numerical models. Transportation Geotechnics, 17(July), 109-121. https://doi.org/10.1016/j.trgeo.2018.10.001

Brooker, E. W., \& Ireland, H. O. (1965). Earth Pressures at Rest Related to Stress History. Canadian Geotechnical Journal, II(I), 1-15. https://doi.org/DOI: 10.1139/t65-001 
Burrow, M. P. N., Ghataora, G. S., \& Evdorides, H. (2011). Railway Foundation Design Principles. Journal of Civil Engineering and Architecture, 5(3), 224-232.

Cherubini, C., Giasi, C. I., \& Guadagno, F. M. (1990). Coefficient of pressure at rest in Subapenninc blue clays in Matera (Southern Italy). Proc 6th International Congress International Association of Engineering Geology, 2, 1163-1169.

Collotta, T., Cantoni, R., Pavesi, U., Ruberl, E., \& Moretti, P. C. (1989). A correlation between residual friction angle, gradation and the index properties of cohesive soils. Geotechnique, 39(2), 343-346. https://doi.org/10.1680/geot.1989.39.2.343

Cui, Y. J., \& Delage, P. (1996). Yielding and plastic behaviour of an unsaturated compacted silt. Geotechnique, 46(2), 291-311. https://doi.org/10.1680/geot.1996.46.2.291

Cunningham, M. R., Ridley, A. M., Dineen, K., \& Burland, J. B. (2003). The mechanical behaviour of a reconstituted unsaturated silty clay. Geotechnique, 53(2), 183-194. https://doi.org/10.1680/geot.2003.53.2.183

Dareeju, B. S. S. S. (2017). Performance Evaluation of Unsaturated Rail Track Foundations Under Cyclic Moving Wheel Load. Queensland University of Technology (QUT).

Das, B. M. (2001). Shear strength of soils. In M. Vezilich (Ed.), Advanced Soil Mechanics (5th ed.). BilL Stenqttist. https://doi.org/10.1201/9781351215183-9

Dey, A., Valsa, S., \& Nainegali, L. S. (2010). Reinforced Earth Design of Embankments and Cuts in Railways Department of Civil Engineering Indian Institute of Technology Kanpur (Issue August).

Dong, K., Connolly, D. P., Laghrouche, O., Woodward, P. K., \& Alves Costa, P. (2018). The stiffening of soft soils on railway lines. Transportation Geotechnics, 17(August), 178-191. https://doi.org/10.1016/j.trgeo.2018.09.004

Eid, H. T., Amarasinghe, R. S., Rabie, K. H., \& Wijewickreme, D. (2015). Residual shear strength of fine-grained soils and soil-solid interfaces at low effective normal stresses. Canadian Geotechnical Journal, 52(2), 198-210. https://doi.org/10.1139/cgj-2014-0019

Eid, H. T., Rabie, K. H., \& Wijewickreme, D. (2016). Drained residual shear strength at effective 
normal stresses relevant to soil slope stability analyses. Engineering Geology, 204, 94-107. https://doi.org/10.1016/j.enggeo.2016.02.003

El-Emam, M. (2011). Experimental and numerical study of at-rest lateral earth pressure of overconsolidated sand. Advances in Civil Engineering, 2011. https://doi.org/10.1155/2011/524568

Escario, V., Juca, J. F. T., \& Coppe, M. S. (1989). Strength and deformation of partly saturated soils. Proc 12th International Conference on Soil Mechanics and Foundation Engincering, $13,43-46$.

Escario, V., \& Suez, J. (1986). The shear strength of partly saturated soils. Geotechnique, 36(3), 453-456. https://doi.org/10.1680/geot.1987.37.4.523

Esmaeili, M., \& Khajehei, H. (2016). Mechanical behavior of embankments overlying on loose subgrade stabilized by deep mixed columns. Journal of Rock Mechanics and Geotechnical Engineering, 8(5), 651-659. https://doi.org/10.1016/j.jrmge.2016.02.006

Feda, J. (1984). Ko-coeflicient of sand in triaxial apparatus. Technical note. $J$ Geotech Engng Div ASCE, 110(NGT4), 519-524.

Fioravante, V., Jamiolkowski, M., Lo Presti, D. C. F., Manfredini, G., \& Pedroni, S. (1998). Assessment of the coefficient of the earth pressure at rest from shear wave velocity measurements. Geotechnique, 48(5), 657-666. https://doi.org/10.1680/geot.1998.48.5.657

Fischer, K. P., Andersen, K. H., \& Moum, J. (1978). Properties of an Artificially Cemented Clay. Canadian Geotechnical Journal, 15(3), 322-331. https://doi.org/10.1139/t78-030

Fredlund, D. G., \& Morgenstern, N. R. (1976). Constitutive Relations for Volume Change in Unsaturated Soils. Canadian Geotechnical Journal, 13(3), 261-276. https://doi.org/10.1139/t76-029

Fredlund, D. G., \& Morgenstern, N. R. (1977). Stress state variables for unsaturated soils. $J$ Geotech Engng Div ASCE, 103(NGT5), 447-466. https://doi.org/10.1016/B978-0-44498950-5.50008-3

Fredlund, D. G., Morgenstern, N. R., \& R. A. WIDGE. (1978). The shear strength of unsaturated 
soils. Canadian Geotechnical Journal, 15, 313-321.

Fredlund, D. G., \& Rahardjo, H. (1993). Soil mechanics for unsaturated soils. In John Wiley \& Sons, Inc. https://doi.org/10.1016/0267-7261(93)90011-f

Fredlund, Delwyn G., Rahardjo, H., \& Fredlund, M. D. (2012). Unsaturated Soil Mechanics in Engineering Practice. In JOHN WILEY \& SONS, INC. https://doi.org/10.1002/9781118280492

Gallage, C., Dareeju, B., Dhanasekar, M., \& Ishikawa, T. (2016). Effects of Principal Stress Axis Rotation on Unsaturated Rail Track Foundation Deterioration. Procedia Engineering, 143(Ictg), 252-259. https://doi.org/10.1016/j.proeng.2016.06.032

Gallipoli, D., Gens, A., Sharma, R., \& Vaunat, J. (2003). An elasto-plastic model for unsaturated soil incorporating the effects of suction and degree of saturation on mechanical behaviour. Geotechnique, 53(1), 123-135. https://doi.org/10.1680/geot.2003.53.1.123

Gan, J. K. M., Feuerharmel, C., \& Rahardo, H. (2006). Determination of the shear strength parameters of two unsaturated colluvium soils using the direct shear test. Geotechnical Special Publication, 147, 1181-1190. https://doi.org/10.1061/40802(189)96

Geiser, F., Laloui, L., \& Vulliet, L. (2006). Elasto-Plasticity of Unsaturated Soils: Laboratory Test Results on a Remoulded Silt. Soils and Foundations, 46(5), 545-556. http://www.mendeley.com/research/geology-volcanic-history-eruptive-style-yakedakevolcano-group-central-japan/

Gens, A. (2010). Soil-environment interactions in geotechnical engineering. Geotechnique, 60(1), 3-74. https://doi.org/10.1680/geot.9.P.109

Geotechdata.info. (2013). Soil friction angle. Geotechdata.Info. http://www.geotechdata.info/parameter/angle-of-friction.html

Ghayoomi, M., \& McCartney, J. S. (2011). Measurement of small-strain shear moduli of partially saturated sand during infiltration in a geotechnical centrifuge. Geotechnical Testing Journal, 34(5), 503-513. https://doi.org/10.1520/GTJ103608

Guo, P. (2010). Effect of density and compressibility on K0 of cohesionless soils. Acta 
Geotechnica, 5(4), 225-238. https://doi.org/10.1007/s11440-010-0125-0

Gylland, A., Long, M., Emdal, A., \& Sandven, R. (2013). Characterisation and engineering properties of Tiller clay. Engineering Geology, 164, 86-100.

https://doi.org/10.1016/j.enggeo.2013.06.008

Habibbeygi, F., \& Nikraz, H. (2018). Effect of shear rate on the residual shear strength of presheared clays. Cogent Geoscience, 4(1), 1-9.

https://doi.org/10.1080/23312041.2018.1453989

Hamouche, K. K., Leroueil, S., Roy, M., \& Lutenegger, A. J. (1995). In situ evaluation of K0 in eastern Canada clays. Canadian Geotechnical Journal, 32(4), 677-688. https://doi.org/10.1139/t95-067

Han, Z., Vanapalli, S. K., \& Zou, W. L. (2017). Integrated approaches for predicting soil-water characteristic curve and resilient modulus of compacted fine-grained subgrade soils. Canadian Geotechnical Journal, 54(5), 646-663. https://doi.org/10.1139/cgj-2016-0349

Hanna, A., \& Al-Romhein, R. (2008). At-Rest Earth Pressure of Overconsolidated Cohesionless Soil. Journal of Geotechnical and Geoenvironmental Engineering, 134(3), 408-412. https://doi.org/10.1061/(ASCE)1090-0241(2008)134

Hendry, M. T., Martin, C. D., \& Barbour, S. L. (2013). Measurement of cyclic response of railway embankments and underlying soft peat foundations to heavy axle loads. Canadian Geotechnical Journal, 50(5), 467-480. https://doi.org/10.1139/cgj-2012-0118

Hoyos, L. R., Velosa, C. L., \& Puppala, A. J. (2014). Residual shear strength of unsaturated soils via suction-controlled ring shear testing. Engineering Geology, 172, 1-11. https://doi.org/10.1016/j.enggeo.2014.01.001

Indraratna, B. (2016). 1st Ralph Proctor Lecture of ISSMGE. Railroad performance with special reference to ballast and substructure characteristics. Transportation Geotechnics, 7, 74-114. https://doi.org/10.1016/j.trgeo.2016.05.002

Indraratna, B., Salim, W., \& Rujikiatkamjorn, C. (2011). Advanced rail geotechnology Ballasted track. In Advanced Rail Geotechnology - Ballasted Track. https://doi.org/10.1201/b10861 
Jotisankasa, A., Coop, M., \& Ridley, A. (2009). The mechanical behaviour of an unsaturated compacted silty clay. Geotechnique, 59(5), 415-428.

https://doi.org/10.1680/geot.2007.00060

Jovanovic, S. (2016). Maintenance - the key driver of railway infrastructure costs. SEETO Transport Infrastructure Forum, Transport: A Driver of Growth., 43.

http://www.seetoint.org/wp-content/uploads/downloads/2016/03/Maintenance-the-keydriver-of-railway-infrastructure-costs-Mr.-Stasha-Jovanovic1.pdf

Keskin, S. N., Tekinsoy, M. A., \& Uzundurukan, S. (2004). The Effects of Over Consolidation Radio and Effective Stresses on the Earth Pressure Coefficient at Rest of Clayey Soils. Digest, 947-961.

Khalili, N., \& Khabbaz, M. H. (1998). A unique relationship for $\chi$ for the determination of the shear strength of unsaturated soils. Geotechnique, 48(5), 681-687. https://doi.org/10.1680/geot.1998.48.5.681

Leshchinsky, B. A. (2012). Enhancing Ballast Performance using Geocell Confinement. Columbia University.

Leshchinsky, B. A., \& Ling, H. I. (2013). Numerical modeling of behavior of railway ballasted structure with geocell confinement. Geotextiles and Geomembranes, 36, 33-43. https://doi.org/10.1016/j.geotexmem.2012.10.006

Li, D. (2018). 25 years of heavy axle load railway subgrade research at the Facility for Accelerated Service Testing (FAST). Transportation Geotechnics, 17(August), 51-60. https://doi.org/10.1016/j.trgeo.2018.09.003

Li, D., Hyslip, J., Sussmann, T., \& Chrismer, S. (2016). Railway Geotechnics. In Taylor \& Francis Group, LLC. CRC Press.

Li, D., \& Selig, E. T. (1995). Evaluation of railway subgrade problems. Transportation Research Record, 1489, 17-25.

Loh, H. (2011). Behaviour of Railway Track Subgrade under Cyclic Loading (Issue November). Curtin University November. 
Loh, R. B. H., \& Nikraz, H. R. (2012). Effective stress method on threshold stress of clay under high rate cyclic loading. 5th Asia-Pacific Conference on Unsaturated Soils 2012, 2, 511515.

Lu, N., \& Kaya, M. (2014). Power law for elastic moduli of unsaturated soil. Journal of Geotechnical and Geoenvironmental Engineering, 140(1), 46-56.

https://doi.org/10.1061/(ASCE)GT.1943-5606.0000990

Lu, N., \& Likos, W. J. (2006). Suction Stress Characteristic Curve for Unsaturated Soil. Journal of Geotechnical and Geoenvironmental Engineering, 132(2), 131-142. https://doi.org/10.1061/(ASCE)1090-0241(2006)132

Lupini, J. F., Skinner, A. E., \& Vaughan, P. R. (1981). The drained residual strength of cohesive soils. Geddmique, 31(2), 181-213.

Massarsch, K. R. (1986). Lateral earth pressure at rest in clay. Proc 4th International Geotechnical Semtuar, Field Instrumentation and In-Situ Measurements, Singapore, 203209.

Mayne, P. W., \& Kulhawy, F. H. (1983). Closure to "Ko-OCR Relationships in Soils." Journal of Geotechnical Engineering, 109(6), 867-869.

Melinda, F., Rahardjo, H., Han, K. K., \& Leong, E. C. (2004). Shear Strength of Compacted Soil under Infiltration Condition. Journal of Geotechnical and Geoenvironmental Engineering, 130(8), 807-817. https://doi.org/10.1061/(ASCE)1090-0241(2004)130

Mesri, G., \& Castro, A. (1987). Ca/Cc concept and K0 during secondary compression. Journal of Geotechnical Engineering, 113(3), 230-247.

Mesri, G., \& Hayat, T. M. (1993). The coefficient of earth pressure at rest. Canadian Geotechnical Journal, 30(4), 647-666. https://doi.org/10.1139/t93-056

Mesri, G., \& Shahien, M. (2003). Residual shear strength mobilized in first-time slope failures. Journal of Geotechnical and Geoenvironmental Engineering, 129(1), 12-31. https://doi.org/10.1061/(ASCE)1090-0241(2003)129:1(12)

Miller, G. A., Teh, S. Y., Li, D., \& Zaman, M. M. (2000). Cyclic Shear Strength of Soft Railroad 
Subgrade. J. Geotech. Geoenviron. Eng., 126(1090-0241/00/0002-0139-0147), 139-147.

Milne, D., Le Pen, L., Watson, G., Thompson, D., Powrie, W., Hayward, M., \& Morley, S. (2018). Monitoring and repair of isolated trackbed defects on a ballasted railway. Transportation Geotechnics, 17(August), 61-68. https://doi.org/10.1016/j.trgeo.2018.09.002

Ng, C. W. W., \& Yung, S. Y. (2008). Determination of the anisotropic shear stiffness of an unsaturated decomposed soil. Geotechnique, 58(1), 23-35. https://doi.org/10.1680/geot.2008.58.1.23

Ng, C. W. W., \& Zhou, C. (2014). Cyclic behaviour of an unsaturated silt at various suctions and temperatures. Geotechnique, 64(9), 709-720. https://doi.org/10.1680/geot.14.P.015

Oh, W. T., Vanapalli, S. K., \& Puppala, A. J. (2009). Semi-empirical model for the prediction of modulus of elasticity for unsaturated soils. Canadian Geotechnical Journal, 46(8), 903914. https://doi.org/10.1139/T09-030

Railisa. (2018). RAIL TRANSPORT IN THE WORLD. Union Internationale Des Chemins de Fer (UIC). https://uic.org/support-activities/statistics/

Rajeev, P., Chan, D., \& Kodikara, J. (2012). Ground-atmosphere interaction modelling for longterm prediction of soil moisture and temperature. Canadian Geotechnical Journal, 49(9), 1059-1073. https://doi.org/10.1139/T2012-068

Sánchez, M., Wang, D., Briaud, J. L., \& Douglas, C. (2014). Typical geomechanical problems associated with railroads on shrink-swell soils. Transportation Geotechnics, 1(4), 257-274. https://doi.org/10.1016/j.trgeo.2014.07.002

Sawangsuriya, A., Edil, T. B., \& Bosscher, P. J. (2009). Modulus-suction-moisture relationship for compacted soils in postcompaction state. Journal of Geotechnical and Geoenvironmental Engineering, 135(10), 1390-1403. https://doi.org/10.1061/(ASCE)GT.1943-5606.0000108

Sayeed, M. A., \& Shahin, M. A. (2018). Design of ballasted railway track foundations using numerical modelling. Part I: Development1. Canadian Geotechnical Journal, 55(3), 353368. https://doi.org/10.1139/cgj-2016-0633 
Scaringi, G., \& Di Maio, C. (2016). Influence of Displacement Rate on Residual Shear Strength of Clays. Procedia Earth and Planetary Science, 16, 137-145. https://doi.org/10.1016/j.proeps.2016.10.015

Schmertmann, J. H. (1983). A Simple Question About Consolidation. Ournal of Geotechnical Engineering, 109(1), 119-122.

Schmertmann, J. H. (1991). The mechanical aging of soils. Journal of Geotechnical Engineering, $117(9), 1288-1330$.

Sheng, D. (2011). Review of fundamental principles in modelling unsaturated soil behaviour. Computers and Geotechnics, 38(6), 757-776. https://doi.org/10.1016/j.compgeo.2011.05.002

Shin, H., \& Santamarina, J. C. (2009). Mineral dissolution and the evolution of k0. Journal of Geotechnical and Geoenvironmental Engineering, 135(8), 1141-1147. https://doi.org/10.1061/(ASCE)GT.1943-5606.0000053

Sivakumar, V., Doran, I. G., Graham, J., \& Navaneethan, T. (2002). Relationship between K0 and overconsolidation ratio: A theoretical approach. Geotechnique, 52(3), 225-230. https://doi.org/10.1680/geot.2002.52.3.225

Sivakumar, V., Kodikara, J., O’Hagan, R., Hughes, D., Cairns, P., \& McKinley, J. D. (2013). Effects of confining pressure and water content on performance of unsaturated compacted clay under repeated loading. Geotechnique, 63(8), 628-640. https://doi.org/10.1680/geot.10.P.103

Sivakumar, V., Navaneethanf, T., Hughes, D., \& Gallagher, G. (2009). An assessment of the earth pressure coefficient in overconsolidated clays. Geotechnique, 59(10), 825-838. https://doi.org/10.1680/geot.8.P.033

StructX. (2019). Density Ranges for Different Soil Types. https://structx.com/Soil_Properties_002.html

Terzaghi, K. (1943). Theoretical Soil Mechanics. In John Wiler and Sons Inc (Eighth). John Wiler and Sons Inc. 
Thu, T. M., Rahardjo, H., \& Leong, E. C. (2007). Elastoplastic model for unsaturated soil with incorporation of the soil-water characteristic curve. Canadian Geotechnical Journal, 44(1), 67-77. https://doi.org/10.1139/T06-091

Tiwari, B., \& Marui, H. (2005). A new method for the correlation of residual shear strength of the soil with mineralogical composition. Journal of Geotechnical and Geoenvironmental Engineering, 131(9), 1139-1150. https://doi.org/10.1061/(ASCE)10900241(2005)131:9(1139)

Tomás, R., Domenech, C., Mira, A., Cuenca, A., \& Delgado, J. (2007). Preconsolidation stress in the Vega Baja and Media areas of the River Segura (SE Spain): Causes and relationship with piezometric level changes. Engineering Geology, 91(2-4), 135-151. https://doi.org/10.1016/j.enggeo.2007.01.006

Vanapalli, S. K., \& Fredlund, D. G. (1999). Empirical procedures to predict the shear strength of unsaturated soils. 11 Asian Regional Conference on Soil Mechnics and Geotechnical Engineering, 93-96.

Vanapalli, S. K., Fredlund, D. G., Pufahl, D. E., \& Clifton, A. W. (1996). Model for the prediction of shear strength with respect to soil suction. In Canadian Geotechnical Journal (Vol. 33, Issue 3, pp. 379-392). https://doi.org/10.1139/t96-060

Vanapalli, S. K., Nicotera, M. V., \& Sharma, R. S. (2008). Axis translation and negative water column techniques for suction control. Geotechnical and Geological Engineering, 26(6), 645-660. https://doi.org/10.1007/s10706-008-9206-3

Vandevelde, J., \& Basudhar, P. K. (2020). The Basics of Soil Mechanics in Civil Engineering. Bright Hub Engineering.

Wang, D. yan, Ma, W., Niu, Y. hong, Chang, X. xiao, \& Wen, Z. (2007). Effects of cyclic freezing and thawing on mechanical properties of Qinghai-Tibet clay. Cold Regions Science and Technology, 48(1), 34-43. https://doi.org/10.1016/j.coldregions.2006.09.008

Wang, J., Yang, Y., Bai, J., Hao, J. Y., \& Zhao, T. L. (2018). Coefficient of Earth Pressure at Rest of a Saturated Artificially Mixed Soil from Oedometer Tests. KSCE Journal of Civil Engineering, 22(5), 1691-1699. https://doi.org/10.1007/s12205-017-1811-3 
Wheeler, S. J., \& Sivakumar, V. (1995). An elasto-plastic critical state framework for unsaturated soil. Geotechnique, 45(1), 35-53. https://doi.org/10.1680/geot.1995.45.1.35

Wikipedia. (2020). Rail transport. Wikipedia, the Free Encyclopedia. https://en.wikipedia.org/wiki/Rail_transport

ESC 240 BALLAST Version 2.4, Railcorp Transport 11 (2013).

Wu, S., Gray, D. H., \& Richart, F. E. (1984). Capillary effects on dynamic modulus of sands and silts. Journal of Geotechnical Engineering, 110(9), 1188-1203. https://doi.org/10.1061/(ASCE)0733-9410(1987)113:7(793)

Yan, W. M., \& Chang, J. (2015). Effect of pore water salinity on the coefficient of earth pressure at rest and friction angle of three selected fine-grained materials. Engineering Geology, 193, 153-157. https://doi.org/10.1016/j.enggeo.2015.04.025

Zhao, X., Zhou, G., Tian, Q., \& Kuang, L. (2010). Coefficient of earth pressure at rest for normal, consolidated soils. Mining Science and Technology, 20(3), 406-410. https://doi.org/10.1016/S1674-5264(09)60216-7 


\section{APPENDIX}

for

The thesis of

SIMULATION OF PROGRESSIVE SHEAR FAILURE IN RAILWAY FOUNDATION 


\title{
1. CODE OF THE PROGRAM
}

\author{
Const g As Double $=9.81 \quad$ 'Gravity \\ Dim nlp As Integer 'the number of stress points \\ Dim $\operatorname{lp}(50,1)$ As Double 'Stress location (horizontal distance to track center)and Stress \\ Dim rb As Double 'the density of Ballast including track \\ Dim wb As Double 'the width of top of Ballast \\ Dim hb As Double 'the thickness of Ballast \\ Dim mlp As Integer 'the max stress point \\ Dim se As Double 'the size of element \\ Dim rd As Double 'the density of subgrade soil \\ Dim c As Double 'the effective cohesion of subgrade soil \\ Dim phi As Double 'the effective angle of friction of soil in Degree \\ Dim theta As Double the angle of failure plane to Major priciple stress in Radiant \\ Dim K0 As Double 'the lateral earth pressure at rest \\ Dim Kr As Double 'the coefficient of friction on failure plane \\ Dim LayerName As String 'the name of layer
}

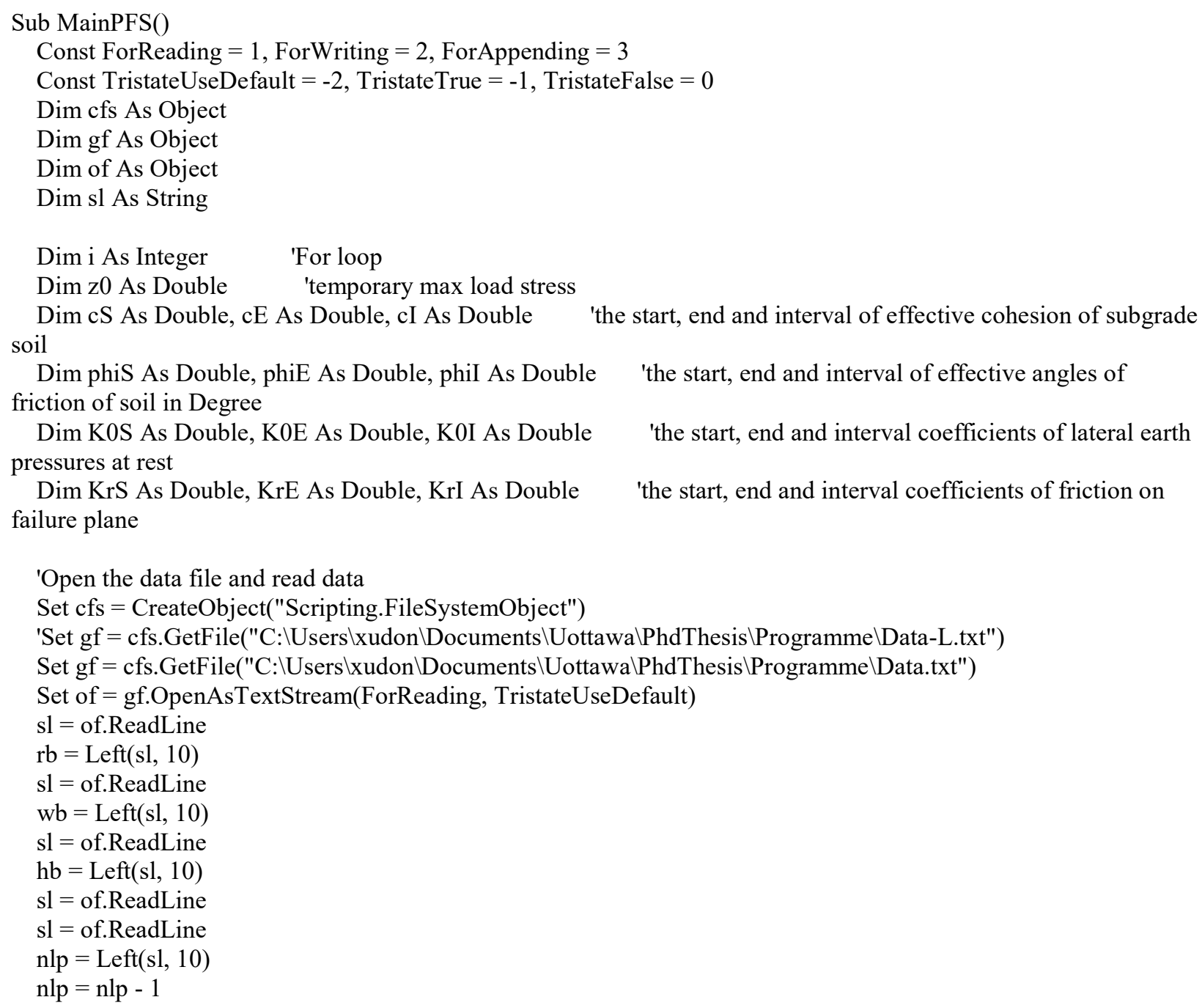




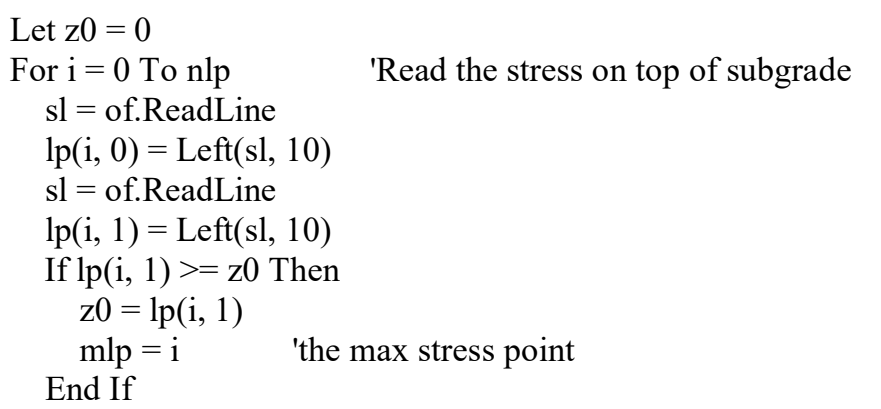

\section{Next i}

'MsgBox mlp \& "-" \& lp(mlp, 0) \& "-" \& lp(mlp, 1) 'For watching.

$\mathrm{sl}=$ of.ReadLine $\quad$ 'Space line

$\mathrm{sl}=$ of.ReadLine

$\mathrm{se}=\operatorname{Left}(\mathrm{sl}, 10)$

$\mathrm{sl}=$ of.ReadLine

$\mathrm{rd}=\operatorname{Left}(\mathrm{sl}, 10)$

$\mathrm{sl}=$ of.ReadLine

$\mathrm{cS}=\operatorname{Left}(\mathrm{sl}, 10)$

$\mathrm{sl}=$ of.ReadLine

$\mathrm{cE}=\operatorname{Left}(\mathrm{sl}, 10)$

$\mathrm{sl}=$ of.ReadLine

$\mathrm{cI}=\operatorname{Left}(\mathrm{sl}, 10)$

$\mathrm{sl}=$ of.ReadLine

phiS $=\operatorname{Left}(\mathrm{sl}, 10)$

$\mathrm{sl}=$ of.ReadLine

phiE $=\operatorname{Left}(\mathrm{sl}, 10)$

$\mathrm{sl}=$ of.ReadLine

phiI $=\operatorname{Left}(\mathrm{sl}, 10)$

$\mathrm{sl}=$ of.ReadLine

$\mathrm{K} 0 \mathrm{~S}=\operatorname{Left}(\mathrm{sl}, 10)$

$\mathrm{sl}=$ of.ReadLine

$\mathrm{K} 0 \mathrm{E}=\operatorname{Left}(\mathrm{sl}, 10)$

$\mathrm{sl}=$ of.ReadLine

$\mathrm{K} 0 \mathrm{I}=\operatorname{Left}(\mathrm{sl}, 10)$

$\mathrm{sl}=$ of.ReadLine

$\mathrm{KrS}=\operatorname{Left}(\mathrm{sl}, 10)$

$\mathrm{sl}=$ of.ReadLine

$\mathrm{KrE}=\operatorname{Left}(\mathrm{sl}, 10)$

$\mathrm{sl}=$ of.ReadLine

$\mathrm{KrI}=\operatorname{Left}(\mathrm{sl}, 10)$

of.Close

'Open the output file and write the result

'Set $\mathrm{gf}=$ cfs.CreateTextFile("Output.txt", True)

Set $\mathrm{gf}=\mathrm{cfs}$. CreateTextFile("C: $\backslash$ Users $\backslash$ xudon $\backslash$ Documents $\backslash$ Uottawa $\backslash$ PhdThesis $\backslash$ Programme $\backslash$ Output.txt", True)

'Simulation

'Loop for a range of coefficients of friction on failure plane

$\mathrm{Kr}=\mathrm{KrS}$

Do

'Loop for a range of the coefficients of lateral earth pressures at rest 


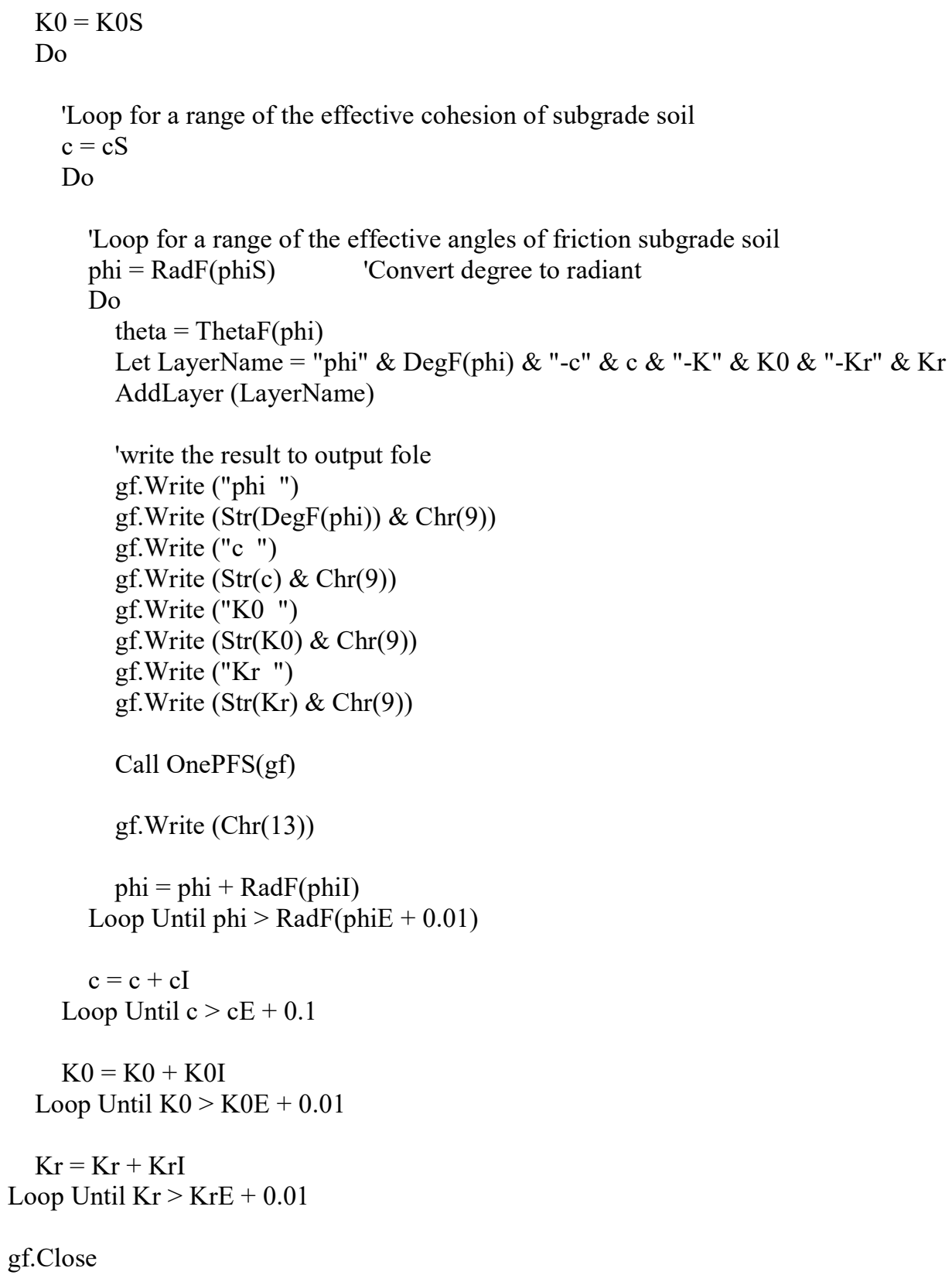

End Sub

Public Sub OnePFS(gf As Object)

Dim i, j As Integer 'For loop

$\operatorname{Dim} x z a(200,2)$ As Double 'location (x,z) and angle of failure plane of the element Dim lpsr As Double 'the ratio of start failure load to max load (or stress)

Dim x0 As Double, z0 As Double 'temporary distances on x \& z

Dim svs As Double, svd As Double 'the vertical static and dynamic stresses in the original element

Dim so1 As Double, so3 As Double 'the priciple stresses in the original element

Dim sn1 As Double, sn3 As Double 'the priciple stresses in the new element at failure

Dim tau As Double, sn As Double 'the normal stress and shear stress on failure plane 
Dim s1f As Double 'the major principle stress at failure

Dim rtau As Double 'the unbalanced shear stress after failure plane

Dim alpha As Double 'the new major principal stress direction of the element in Radiant

Dim beta As Double

'the turning angle of two adjient failure planes in Radiant

'Calculate the location $(\mathrm{x}, \mathrm{z})$ and angle of first failure plane or element

'The first element

$\operatorname{xza}(0,0)=\operatorname{lp}(\mathrm{mlp}, 0)$

$\operatorname{xza}(0,1)=0$

$\mathrm{xza}(0,2)=2 * \operatorname{Atn}(1)-$ theta

'The second element

$\mathrm{xza}(1,0)=\mathrm{xza}(0,0)+\mathrm{se} * \operatorname{Sin}(\mathrm{xza}(0,2))$

$\mathrm{xza}(1,1)=\mathrm{xza}(0,1)+\mathrm{se} * \operatorname{Cos}(\mathrm{xza}(0,2))$

Call DrawPline(xza(0, 0), xza(0, 1), xza(1, 0), xza(1, 1), "0")

$\operatorname{svs}=\operatorname{SigmavF}(\operatorname{xza}(0,0), \operatorname{xza}(0,1))$

'so3 = SigmahF(svs) '!!! not consider dynamic load yet.

so $1=2 * \mathrm{c} *$ Tan (theta) $/\left(1-\mathrm{K} 0 *(\operatorname{Tan}(\text { theta }))^{\wedge} 2\right)$

so $3=\mathrm{K} 0 *$ so 1

svd $=$ so $1-$ svs

If $\operatorname{svd}<0$ Then

'MsgBox "Warning!!! The first element fails at static load"

lpsr $=0$

$\mathrm{i}=0$

GoTo 100

'Exit Sub

Else

lpsr $=\mathrm{svd} / \operatorname{lp}(\mathrm{mlp}, 1)$

End If

For $\mathrm{i}=1$ To $199 \quad$ 'Calculate each faied element

Do lpsr $=$ lpsr $+0.0001 \quad$ 'Load increase or Train approach

For $\mathrm{j}=0$ To $\mathrm{i}-1$

'Calculate the initial (original) principal stress in element svd $=\operatorname{lpsr} * \operatorname{SigmadF}(x z a(j, 0))$

$\operatorname{svs}=\operatorname{SigmavF}(x z a(j, 0), x z a(j, 1))$

so $1=$ svd + svs

'so3 = SigmahF(svs) !!!! not consider dynamic load yet.

so3 $=$ SigmahF(so1)

'Calculate the normal and shear stress on failure plane

If $\mathrm{j}<1$ Then

beta $=0$

$\mathrm{rtau}=0$

Else

beta $=x z a(j, 2)-x z a(j-1,2)$

End If 


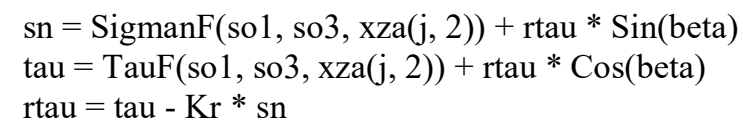

Next $j$

'Calculate the initial (original) principal stress in element

svd $=1$ psr * $\operatorname{SigmadF}(x z a(i, 0))$

svs $=\operatorname{SigmavF}(x z a(i, 0), x z a(i, 1))$

so1 $=$ svd + svs

'so3 = SigmahF(svs) !!! not consider dynamic load yet.

so3 $=$ SigmahF(so1)

'Calculate the new principal stress in element

$\mathrm{x} 0=\mathrm{so} 3+\mathrm{rtau} * \operatorname{Sin}(\mathrm{xza}(\mathrm{i}-1,2))$

$\mathrm{z} 0=\mathrm{so} 1+\mathrm{rtau} * \operatorname{Cos}(\mathrm{xza}(\mathrm{i}-1,2))$

$\mathrm{sn} 1=\operatorname{Sqr}\left(\mathrm{z} 0^{\wedge} 2+\mathrm{x} 0 \wedge 2\right)$

'Calculate the new major principal stress direction of the element

alpha $=\operatorname{Atn}(\mathrm{x} 0 / \mathrm{z} 0)$

If $\mathrm{z} 0<0$ Then

alpha $=$ alpha $+4 * \operatorname{Atn}(1)$

End If

sn $3=$ so $1 * \operatorname{Sin}($ alpha $)+$ so $3 * \operatorname{Cos}($ alpha $)-$ rtau $* \operatorname{Sin}(x z a(i-1,2)-$ alpha $)$

'sn $3=$ so $1 * \operatorname{Sin}($ alpha $)+$ so $3 * \operatorname{Cos}($ alpha $)$

'Calculate the new major principal stress at failure

$\mathrm{s} 1 \mathrm{f}=\operatorname{Sigma} 1 \mathrm{~F}(\mathrm{sn} 3)$

If lpsr $>2 \#$ Then

Exit For

End If

Loop Until sn1 > s1f

'MsgBox $\operatorname{Str}(\mathrm{i}) \& \operatorname{Chr}(13) \& \operatorname{Chr}(10) \& \operatorname{Str}(\mathrm{lpsr}) \quad$ 'For watching.

$\mathrm{xza}(\mathrm{i}, 2)=\mathrm{alpha}+2 * \mathrm{Atn}(1)$ - theta

$\mathrm{xza}(\mathrm{i}+1,0)=\mathrm{xza}(\mathrm{i}, 0)+\mathrm{se} * \operatorname{Sin}(\mathrm{xza}(\mathrm{i}, 2))$

$x z a(i+1,1)=x z a(i, 1)+$ se $^{*} \operatorname{Cos}(x z a(i, 2))$

Call DrawPline(xza(i, 0), xza(i, 1), xza(i $+1,0), x z a(i+1,1), \operatorname{CStr}(i))$

If $x z a(i+1,1)<=0$ Then

Exit For

End If

Next i

'MsgBox "Elements " \& i 'For watching.

'MsgBox "Final Load " \& Int(lpsr * 100) \& Chr(37) 'For watching.

100 'write the result to output fole

gf.Write ("No ")

gf.Write ( $\operatorname{Str}(\mathrm{i}) \& \operatorname{Chr}(9))$

gf.Write ("Load ")

gf.Write $(\operatorname{Str}(\operatorname{Int}(1 \mathrm{psr} * 100)) \& \operatorname{Chr}(37))$ 
End Sub

'Convert degree to radiant

Function RadF(deg As Double) As Double

$\operatorname{RadF}=\operatorname{Atn}(1) * \operatorname{deg} / 45$

End Function

'Convert radiant to degree

Function DegF(rad As Double) As Double

$\operatorname{DegF}=45 * \operatorname{rad} / \operatorname{Atn}(1)$

End Function

'Calculate the angle of failure plane

Function ThetaF(phi As Double) As Double

ThetaF $=\operatorname{Atn}(1)+$ phi $/ 2$

End Function

'Calculate the major principal stress with minor principal stress at failure

Function Sigma1F(Sigma3 As Double) As Double

$\operatorname{Sigma} 1 \mathrm{~F}=\operatorname{Sigma} 3 *(\operatorname{Tan}(\text { theta }))^{\wedge} 2+2 * \mathrm{c} * \operatorname{Tan}($ theta $)$

End Function

'Calculate the shear stress on failure plane with major and minor principal stresses

Function TauF(Sigma1 As Double, Sigma3 As Double, alpha As Double) As Double

$\mathrm{TauF}=$ Sigma $1 * \operatorname{Cos}($ alpha $)-\operatorname{Sigma} 3 * \operatorname{Sin}($ alpha $)$

End Function

'Calculate the normal stress on failure plane with major and minor principal stresses

Function SigmanF(Sigma1 As Double, Sigma3 As Double, alpha As Double) As Double

$\operatorname{SigmanF}=\operatorname{Sigma} 1 * \operatorname{Sin}($ alpha $)+\operatorname{Sigma} 3 * \operatorname{Cos}($ alpha $)$

End Function

'Calculate the vertical load stress on Subgrade

Function SigmadF(x As Double) As Double

If $\mathrm{x}<=\operatorname{lp}(0,0)$ Then

'MsgBox "Warning!!! The load location out of range"

SigmadF $=\operatorname{lp}(0,1)$

Exit Function

End If

If $x>=\operatorname{lp}(n l p, 0)$ Then

'MsgBox "Warning!!! The load location out of range"

SigmadF $=\operatorname{lp}(\mathrm{nlp}, 1)$

Exit Function

End If

For $\mathrm{i}=1$ To nlp 


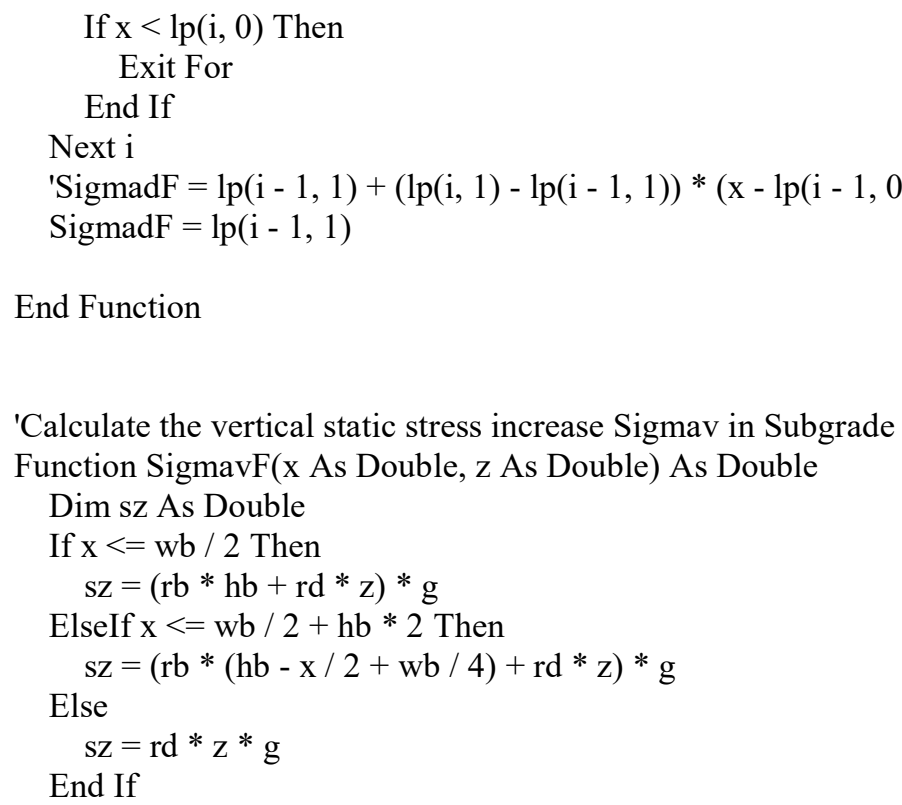

End Function

'Calculate the vertical static stress increase Sigmav in Subgrade

Function SigmavF(x As Double, z As Double) As Double

Dim sz As Double

If $\mathrm{x}<=\mathrm{wb} / 2$ Then

$\mathrm{sz}=(\mathrm{rb} * \mathrm{hb}+\mathrm{rd} * \mathrm{z}) * \mathrm{~g}$

ElseIf $\mathrm{x}<=\mathrm{wb} / 2+\mathrm{hb} * 2$ Then

SigmavF $=\mathrm{sz} / 1000$

End Function

'Calculate the lateral stress Sigma3 in Subgrade

Function SigmahF(sz As Double) As Double

$\operatorname{SigmahF}=\mathrm{sz} * \mathrm{~K} 0$

End Function

Public Sub AddLayer(strLayerName As String)

Dim objLayer As AcadLayer

If "" = strLayerName Then

Exit Sub ' exit if no name entered

End If

On Error Resume Next ' handle exceptions inline

'check to see if layer already exists

Set objLayer $=$ ThisDrawing.Layers $($ strLayerName $)$

If objLayer Is Nothing Then

Set objLayer $=$ ThisDrawing.Layers.Add(strLayerName $)$

If objLayer Is Nothing Then ' check if obj has been set 'MsgBox "Unable to Add "' \& strLayerName \& "'"

Else

'MsgBox "Added Layer "' \& objLayer.Name \& "'" End If

Else

'MsgBox "Layer already existed"

End If 
On Error GoTo $0 \quad$ 'Disables any error handler

End Sub

Public Sub DrawPline(xs As Double, ys As Double, xe As Double, ye As Double, noe As String)

Dim pline As AcadPolyline

Dim Points(0 To 5) As Double

'Define the 2D polyline points

Points $(0)=\mathrm{xs}$

Points $(1)=-y s$

Points $(2)=0$

Points $(3)=x e$

Points (4) $=-$ ye

Points $(5)=0$

'Create a line in model space

Set pline $=$ ThisDrawing.ModelSpace.AddPolyline(Points)

pline.Layer $=$ LayerName

Call DrawElement(xs, ys, xe, ye, noe)

End Sub

Public Sub DrawElement(xs As Double, ys As Double, xe As Double, ye As Double, noe As String) Dim line As AcadLine

Dim text As AcadText

Dim StartPoint(0 To 2) As Double

Dim EndPoint(0 To 2) As Double

Dim x1, y1, x2, y2, aa, bb, cc, dd, bc As Double

'Calculate the other two corner coordinates of the Element with quadratic equation of one unknown $\mathrm{dd}=\mathrm{xs}^{\wedge} 2-\mathrm{xe}^{\wedge} 2+\mathrm{ys}^{\wedge} 2-\mathrm{ye}^{\wedge} 2+\mathrm{se}^{\wedge} 2 *\left((\operatorname{Cos}(\text { theta }))^{\wedge} 2-(\operatorname{Sin}(\text { theta }))^{\wedge} 2\right)$

$\mathrm{aa}=(\mathrm{xs}-\mathrm{xe})^{\wedge} 2+(\mathrm{ys}-\mathrm{ye})^{\wedge} 2$

$\mathrm{bb}=2 *(\mathrm{ys}-\mathrm{ye}) *(\mathrm{xe} * \mathrm{ys}-\mathrm{xs} * \mathrm{ye})+\mathrm{dd} *(\mathrm{xs}-\mathrm{xe})$

$\mathrm{cc}=\left(\mathrm{xs}^{\wedge} 2+\mathrm{ys}^{\wedge} 2-\mathrm{se}^{\wedge} 2 *(\operatorname{Sin}(\text { theta }))^{\wedge} 2\right) *(\mathrm{ys}-\mathrm{ye})^{\wedge} 2-\mathrm{dd}^{*} \mathrm{ys} *(\mathrm{ys}-\mathrm{ye})+\mathrm{dd}^{\wedge} 2 / 4$

$\mathrm{bc}=\mathrm{bb}^{\wedge} 2-4 * \mathrm{aa} * \mathrm{cc}$

If $b c<0$ Then

'MsgBox "Error with quadratic equation"

Exit Sub

End If

'Calculate the third corner coordinates of the Element

If ys $>$ ye Then

$\mathrm{x} 1=(\mathrm{bb}+\operatorname{Sqr}(\mathrm{bc})) / \mathrm{aa} / 2$

Else

$\mathrm{x} 1=(\mathrm{bb}-\operatorname{Sqr}(\mathrm{bc})) / \mathrm{aa} / 2$

End If

$\mathrm{y} 1=(\mathrm{dd} / 2-(\mathrm{xs}-\mathrm{xe}) * \mathrm{x} 1) /(\mathrm{ys}-\mathrm{ye})$

'Calculate the fourth corner coordinates of the Element 
$\mathrm{x} 2=\mathrm{xs}+\mathrm{xe}-\mathrm{x} 1$

$\mathrm{y} 2=\mathrm{ys}+\mathrm{ye}-\mathrm{y} 1$

'Create the first line of element in model space

StartPoint $(0)=\mathrm{xs}$

StartPoint $(1)=-y s$

StartPoint (2) $=0$

EndPoint $(0)=\mathrm{x} 1$

EndPoint $(1)=-y 1$

EndPoint $(2)=0$

Set line $=$ ThisDrawing.ModelSpace.AddLine(StartPoint, EndPoint)

line.Layer $=$ LayerName

'Create the second line of element in model space

StartPoint $(0)=x e$

StartPoint $(1)=-$ ye

StartPoint $(2)=0$

Set line $=$ ThisDrawing.ModelSpace.AddLine(StartPoint, EndPoint)

line.Layer $=$ LayerName

'Create the third line of element in model space

EndPoint $(0)=x 2$

EndPoint $(1)=-y 2$

EndPoint $(2)=0$

Set line $=$ ThisDrawing.ModelSpace.AddLine(StartPoint, EndPoint)

line.Layer $=$ LayerName

'Create the fourth line of element in model space

StartPoint $(0)=x s$

StartPoint $(1)=-y s$

StartPoint $(2)=0$

Set line $=$ ThisDrawing.ModelSpace.AddLine(StartPoint, EndPoint)

line.Layer $=$ LayerName

'Insert the No of element in model space

$\operatorname{StartPoint}(0)=(\mathrm{xs}+\mathrm{xe}) / 2$

StartPoint $(1)=-(\mathrm{ys}+\mathrm{ye}) / 2$

StartPoint $(2)=0$

Set text $=$ ThisDrawing.ModelSpace.AddText(noe, StartPoint, 0.002)

text.Layer $=$ LayerName

End Sub 


\section{INPUT FILE}

2000 'the density of Ballast including track, $\mathrm{kg} / \mathrm{m} 3$

3.5 'the width of top of Ballast, $m$

0.5 'the thickness of Ballast, $\mathrm{m}$

40 'the number of stress points

$0 \quad$ 'Stress location (horizontal distance to track center), $\mathrm{m}$

151 'Stress, $\mathrm{kPa}$

0.08 'Stress location (horizontal distance to track center)

$151 \quad$ 'Stress

0.15 'Stress location (horizontal distance to track center)

$152 \quad$ 'Stress

0.23 'Stress location (horizontal distance to track center)

154 'Stress

0.3 'Stress location (horizontal distance to track center)

156 'Stress

0.36 'Stress location (horizontal distance to track center)

$158 \quad$ 'Stress

0.41 'Stress location (horizontal distance to track center)

160 'Stress

0.47 'Stress location (horizontal distance to track center)

163 'Stress

0.54 'Stress location (horizontal distance to track center)

167 'Stress

0.63 'Stress location (horizontal distance to track center)

173 'Stress

0.72 'Stress location (horizontal distance to track center)

$180 \quad$ 'Stress

0.81 'Stress location (horizontal distance to track center)

$188 \quad$ 'Stress

0.89 'Stress location (horizontal distance to track center) 
196 'Stress

0.95 'Stress location (horizontal distance to track center)

202 'Stress

0.99 'Stress location (horizontal distance to track center)

205 'Stress

1.03 'Stress location (horizontal distance to track center)

207 'Stress

1.05 'Stress location (horizontal distance to track center)

207 'Stress

1.08 'Stress location (horizontal distance to track center)

206 'Stress

1.11 'Stress location (horizontal distance to track center)

202 'Stress

1.14 'Stress location (horizontal distance to track center)

197 'Stress

1.17 'Stress location (horizontal distance to track center)

$190 \quad$ 'Stress

1.2 'Stress location (horizontal distance to track center)

$181 \quad$ 'Stress

1.24 'Stress location (horizontal distance to track center)

168 'Stress

1.28 'Stress location (horizontal distance to track center)

$151 \quad$ 'Stress

1.31 'Stress location (horizontal distance to track center)

134 'Stress

1.35 'Stress location (horizontal distance to track center)

115 'Stress

1.39 'Stress location (horizontal distance to track center)

$97 \quad$ 'Stress

1.44 'Stress location (horizontal distance to track center)

79 'Stress 
1.48 'Stress location (horizontal distance to track center)

$65 \quad$ 'Stress

1.53 'Stress location (horizontal distance to track center)

51 'Stress

1.57 'Stress location (horizontal distance to track center)

$42 \quad$ 'Stress

1.62 'Stress location (horizontal distance to track center)

34 'Stress

1.67 'Stress location (horizontal distance to track center)

28 'Stress

1.75 'Stress location (horizontal distance to track center)

$21 \quad$ 'Stress

1.8 'Stress location (horizontal distance to track center)

17 'Stress

1.87 'Stress location (horizontal distance to track center)

13 'Stress

1.93 'Stress location (horizontal distance to track center)

11 'Stress

2.0 'Stress location (horizontal distance to track center)

$9 \quad$ 'Stress

2.13 'Stress location (horizontal distance to track center)

$6 \quad$ 'Stress

2.5 'Stress location (horizontal distance to track center)

$0 \quad$ 'Stress

0.02 'the size of element, $\mathrm{m}$

1560 'the density of subgrade soil, $\mathrm{kg} / \mathrm{m} 3$

1 '1 the start effective cohesion of subgrade soil, $\mathrm{kPa}$

10 '10 the end effective cohesion of subgrade soil, $\mathrm{kPa}$

1 '1 the interval of effective cohesion of subgrade soil, $\mathrm{kPa}$

17 '17 the start effective angle of friction of soil in Degree 
2525 the end effective angle of friction of soil in Degree

22 the interval of effective angle of friction of soil in Degree

$0.25 \quad 0.25$ the start Coefficient of earth pressure at rest

$0.4 \quad 0.4$ the end Coefficient of earth pressure at rest

0.05 ' 0.05 the interval of Coefficient of earth pressure at rest

0.05 ' 0.05 the start coefficient of friction on failure plane

0.35 ' 0.35 the end coefficient of friction on failure plane

0.05 ' 0.05 the interval of coefficient of friction on failure plane 


\section{RESULT OF SIMULATION FOR POINT LOAD}

\begin{tabular}{|c|c|c|c|c|c|c|}
\hline $\begin{array}{c}\text { No of } \\
\text { simulation }\end{array}$ & $\begin{array}{l}\text { Angle } \\
\text { of } \\
\text { friction }\end{array}$ & Cohesion & $\begin{array}{c}\text { Coefficient } \\
\text { of earth } \\
\text { pressure } \\
\text { at rest }\end{array}$ & $\begin{array}{l}\text { Coefficient } \\
\text { of residual } \\
\text { friction }\end{array}$ & $\begin{array}{l}\text { Number } \\
\text { of } \\
\text { elements }\end{array}$ & $\begin{array}{l}\text { Final } \\
\text { Load }\end{array}$ \\
\hline & $\phi^{\prime}$ & $c^{\prime}$ & $K_{0}$ & $K_{r}$ & No. & $\mathrm{P}$ \\
\hline & 0 & $\mathrm{kPa}$ & & & & $\%$ \\
\hline 1 & 17 & 1 & 0.25 & 0.05 & 0 & 0 \\
\hline 2 & 19 & 1 & 0.25 & 0.05 & 0 & 0 \\
\hline 3 & 21 & 1 & 0.25 & 0.05 & 0 & 0 \\
\hline 4 & 23 & 1 & 0.25 & 0.05 & 0 & 0 \\
\hline 5 & 25 & 1 & 0.25 & 0.05 & 0 & 0 \\
\hline 6 & 17 & 2 & 0.25 & 0.05 & 85 & 200 \\
\hline 7 & 19 & 2 & 0.25 & 0.05 & 83 & 200 \\
\hline 8 & 21 & 2 & 0.25 & 0.05 & 81 & 200 \\
\hline 9 & 23 & 2 & 0.25 & 0.05 & 79 & 200 \\
\hline 10 & 25 & 2 & 0.25 & 0.05 & 78 & 200 \\
\hline 11 & 17 & 3 & 0.25 & 0.05 & 36 & 30 \\
\hline 12 & 19 & 3 & 0.25 & 0.05 & 34 & 29 \\
\hline 13 & 21 & 3 & 0.25 & 0.05 & 33 & 30 \\
\hline 14 & 23 & 3 & 0.25 & 0.05 & 31 & 29 \\
\hline 15 & 25 & 3 & 0.25 & 0.05 & 29 & 28 \\
\hline 16 & 17 & 4 & 0.25 & 0.05 & 17 & 23 \\
\hline 17 & 19 & 4 & 0.25 & 0.05 & 17 & 24 \\
\hline 18 & 21 & 4 & 0.25 & 0.05 & 16 & 23 \\
\hline 19 & 23 & 4 & 0.25 & 0.05 & 15 & 22 \\
\hline 20 & 25 & 4 & 0.25 & 0.05 & 14 & 21 \\
\hline 21 & 17 & 5 & 0.25 & 0.05 & 10 & 18 \\
\hline 22 & 19 & 5 & 0.25 & 0.05 & 10 & 19 \\
\hline 23 & 21 & 5 & 0.25 & 0.05 & 9 & 17 \\
\hline 24 & 23 & 5 & 0.25 & 0.05 & 9 & 17 \\
\hline 25 & 25 & 5 & 0.25 & 0.05 & 9 & 18 \\
\hline 26 & 17 & 6 & 0.25 & 0.05 & 7 & 16 \\
\hline 27 & 19 & 6 & 0.25 & 0.05 & 7 & 16 \\
\hline 28 & 21 & 6 & 0.25 & 0.05 & 7 & 16 \\
\hline 29 & 23 & 6 & 0.25 & 0.05 & 7 & 16 \\
\hline 30 & 25 & 6 & 0.25 & 0.05 & 7 & 17 \\
\hline 31 & 17 & 7 & 0.25 & 0.05 & 6 & 16 \\
\hline 32 & 19 & 7 & 0.25 & 0.05 & 6 & 16 \\
\hline 33 & 21 & 7 & 0.25 & 0.05 & 6 & 16 \\
\hline
\end{tabular}




\begin{tabular}{|c|c|c|c|c|c|c|}
\hline 34 & 23 & 7 & 0.25 & 0.05 & 6 & 16 \\
\hline 35 & 25 & 7 & 0.25 & 0.05 & 6 & 17 \\
\hline 36 & 17 & 8 & 0.25 & 0.05 & 6 & 20 \\
\hline 37 & 19 & 8 & 0.25 & 0.05 & 6 & 20 \\
\hline 38 & 21 & 8 & 0.25 & 0.05 & 6 & 19 \\
\hline 39 & 23 & 8 & 0.25 & 0.05 & 6 & 20 \\
\hline 40 & 25 & 8 & 0.25 & 0.05 & 6 & 20 \\
\hline 41 & 17 & 9 & 0.25 & 0.05 & 5 & 18 \\
\hline 42 & 19 & 9 & 0.25 & 0.05 & 5 & 18 \\
\hline 43 & 21 & 9 & 0.25 & 0.05 & 5 & 18 \\
\hline 44 & 23 & 9 & 0.25 & 0.05 & 5 & 18 \\
\hline 45 & 25 & 9 & 0.25 & 0.05 & 5 & 18 \\
\hline 46 & 17 & 10 & 0.25 & 0.05 & 5 & 21 \\
\hline 47 & 19 & 10 & 0.25 & 0.05 & 5 & 21 \\
\hline 48 & 21 & 10 & 0.25 & 0.05 & 5 & 20 \\
\hline 49 & 23 & 10 & 0.25 & 0.05 & 5 & 20 \\
\hline 50 & 25 & 10 & 0.25 & 0.05 & 5 & 21 \\
\hline 51 & 17 & 1 & 0.3 & 0.05 & 0 & 0 \\
\hline 52 & 19 & 1 & 0.3 & 0.05 & 0 & 0 \\
\hline 53 & 21 & 1 & 0.3 & 0.05 & 0 & 0 \\
\hline 54 & 23 & 1 & 0.3 & 0.05 & 0 & 0 \\
\hline 55 & 25 & 1 & 0.3 & 0.05 & 200 & 8 \\
\hline 56 & 17 & 2 & 0.3 & 0.05 & 72 & 200 \\
\hline 57 & 19 & 2 & 0.3 & 0.05 & 70 & 200 \\
\hline 58 & 21 & 2 & 0.3 & 0.05 & 62 & 83 \\
\hline 59 & 23 & 2 & 0.3 & 0.05 & 49 & 36 \\
\hline 60 & 25 & 2 & 0.3 & 0.05 & 46 & 37 \\
\hline 61 & 17 & 3 & 0.3 & 0.05 & 29 & 36 \\
\hline 62 & 19 & 3 & 0.3 & 0.05 & 28 & 36 \\
\hline 63 & 21 & 3 & 0.3 & 0.05 & 26 & 34 \\
\hline 64 & 23 & 3 & 0.3 & 0.05 & 24 & 33 \\
\hline 65 & 25 & 3 & 0.3 & 0.05 & 22 & 32 \\
\hline 66 & 17 & 4 & 0.3 & 0.05 & 14 & 25 \\
\hline 67 & 19 & 4 & 0.3 & 0.05 & 13 & 24 \\
\hline 68 & 21 & 4 & 0.3 & 0.05 & 13 & 25 \\
\hline 69 & 23 & 4 & 0.3 & 0.05 & 12 & 24 \\
\hline 70 & 25 & 4 & 0.3 & 0.05 & 10 & 21 \\
\hline 71 & 17 & 5 & 0.3 & 0.05 & 9 & 21 \\
\hline 72 & 19 & 5 & 0.3 & 0.05 & 9 & 21 \\
\hline 73 & 21 & 5 & 0.3 & 0.05 & 8 & 19 \\
\hline 74 & 23 & 5 & 0.3 & 0.05 & 8 & 20 \\
\hline 75 & 25 & 5 & 0.3 & 0.05 & 7 & 18 \\
\hline
\end{tabular}




\begin{tabular}{|c|c|c|c|c|c|c|}
\hline 76 & 17 & 6 & 0.3 & 0.05 & 7 & 20 \\
\hline 77 & 19 & 6 & 0.3 & 0.05 & 7 & 20 \\
\hline 78 & 21 & 6 & 0.3 & 0.05 & 7 & 20 \\
\hline 79 & 23 & 6 & 0.3 & 0.05 & 6 & 17 \\
\hline 80 & 25 & 6 & 0.3 & 0.05 & 6 & 19 \\
\hline 81 & 17 & 7 & 0.3 & 0.05 & 6 & 20 \\
\hline 82 & 19 & 7 & 0.3 & 0.05 & 6 & 19 \\
\hline 83 & 21 & 7 & 0.3 & 0.05 & 6 & 20 \\
\hline 84 & 23 & 7 & 0.3 & 0.05 & 6 & 21 \\
\hline 85 & 25 & 7 & 0.3 & 0.05 & 5 & 17 \\
\hline 86 & 17 & 8 & 0.3 & 0.05 & 5 & 18 \\
\hline 87 & 19 & 8 & 0.3 & 0.05 & 5 & 18 \\
\hline 88 & 21 & 8 & 0.3 & 0.05 & 5 & 18 \\
\hline 89 & 23 & 8 & 0.3 & 0.05 & 5 & 19 \\
\hline 90 & 25 & 8 & 0.3 & 0.05 & 5 & 20 \\
\hline 91 & 17 & 9 & 0.3 & 0.05 & 5 & 21 \\
\hline 92 & 19 & 9 & 0.3 & 0.05 & 5 & 21 \\
\hline 93 & 21 & 9 & 0.3 & 0.05 & 5 & 21 \\
\hline 94 & 23 & 9 & 0.3 & 0.05 & 5 & 22 \\
\hline 95 & 25 & 9 & 0.3 & 0.05 & 5 & 23 \\
\hline 96 & 17 & 10 & 0.3 & 0.05 & 5 & 24 \\
\hline 97 & 19 & 10 & 0.3 & 0.05 & 5 & 24 \\
\hline 98 & 21 & 10 & 0.3 & 0.05 & 5 & 24 \\
\hline 99 & 23 & 10 & 0.3 & 0.05 & 5 & 24 \\
\hline 100 & 25 & 10 & 0.3 & 0.05 & 5 & 26 \\
\hline 101 & 17 & 1 & 0.35 & 0.05 & 0 & 0 \\
\hline 102 & 19 & 1 & 0.35 & 0.05 & 0 & 0 \\
\hline 103 & 21 & 1 & 0.35 & 0.05 & 200 & 67 \\
\hline 104 & 23 & 1 & 0.35 & 0.05 & 200 & 95 \\
\hline 105 & 25 & 1 & 0.35 & 0.05 & 200 & 121 \\
\hline 106 & 17 & 2 & 0.35 & 0.05 & 46 & 48 \\
\hline 107 & 19 & 2 & 0.35 & 0.05 & 44 & 48 \\
\hline 108 & 21 & 2 & 0.35 & 0.05 & 42 & 47 \\
\hline 109 & 23 & 2 & 0.35 & 0.05 & 39 & 47 \\
\hline 110 & 25 & 2 & 0.35 & 0.05 & 35 & 48 \\
\hline 111 & 17 & 3 & 0.35 & 0.05 & 23 & 40 \\
\hline 112 & 19 & 3 & 0.35 & 0.05 & 22 & 39 \\
\hline 113 & 21 & 3 & 0.35 & 0.05 & 20 & 37 \\
\hline 114 & 23 & 3 & 0.35 & 0.05 & 16 & 32 \\
\hline 115 & 25 & 3 & 0.35 & 0.05 & 8 & 21 \\
\hline 116 & 17 & 4 & 0.35 & 0.05 & 12 & 28 \\
\hline 117 & 19 & 4 & 0.35 & 0.05 & 11 & 26 \\
\hline
\end{tabular}




\begin{tabular}{|l|l|l|l|l|l|l|}
\hline 118 & 21 & 4 & 0.35 & 0.05 & 10 & 25 \\
\hline 119 & 23 & 4 & 0.35 & 0.05 & 8 & 22 \\
\hline 120 & 25 & 4 & 0.35 & 0.05 & 5 & 19 \\
\hline 121 & 17 & 5 & 0.35 & 0.05 & 8 & 23 \\
\hline 122 & 19 & 5 & 0.35 & 0.05 & 7 & 20 \\
\hline 123 & 21 & 5 & 0.35 & 0.05 & 7 & 21 \\
\hline 124 & 23 & 5 & 0.35 & 0.05 & 6 & 20 \\
\hline 125 & 25 & 5 & 0.35 & 0.05 & 5 & 24 \\
\hline 126 & 17 & 6 & 0.35 & 0.05 & 6 & 20 \\
\hline 127 & 19 & 6 & 0.35 & 0.05 & 6 & 20 \\
\hline 128 & 21 & 6 & 0.35 & 0.05 & 6 & 21 \\
\hline 129 & 23 & 6 & 0.35 & 0.05 & 5 & 19 \\
\hline 130 & 25 & 6 & 0.35 & 0.05 & 5 & 30 \\
\hline 131 & 17 & 7 & 0.35 & 0.05 & 6 & 23 \\
\hline 132 & 19 & 7 & 0.35 & 0.05 & 5 & 19 \\
\hline 133 & 21 & 7 & 0.35 & 0.05 & 5 & 20 \\
\hline 134 & 23 & 7 & 0.35 & 0.05 & 5 & 22 \\
\hline 135 & 25 & 7 & 0.35 & 0.05 & 5 & 35 \\
\hline 136 & 17 & 8 & 0.35 & 0.05 & 5 & 21 \\
\hline 137 & 19 & 8 & 0.35 & 0.05 & 5 & 22 \\
\hline 138 & 21 & 8 & 0.35 & 0.05 & 5 & 23 \\
\hline 139 & 23 & 8 & 0.35 & 0.05 & 5 & 26 \\
\hline 140 & 25 & 8 & 0.35 & 0.05 & 5 & 41 \\
\hline 141 & 17 & 9 & 0.35 & 0.05 & 5 & 24 \\
\hline 142 & 19 & 9 & 0.35 & 0.05 & 5 & 25 \\
\hline 143 & 21 & 9 & 0.35 & 0.05 & 5 & 26 \\
\hline 144 & 23 & 9 & 0.35 & 0.05 & 5 & 29 \\
\hline 145 & 25 & 9 & 0.35 & 0.05 & 4 & 46 \\
\hline 146 & 17 & 10 & 0.35 & 0.05 & 5 & 27 \\
\hline 147 & 19 & 10 & 0.35 & 0.05 & 5 & 28 \\
\hline 148 & 21 & 10 & 0.35 & 0.05 & 5 & 28 \\
\hline 149 & 23 & 10 & 0.35 & 0.05 & 4 & 33 \\
\hline 150 & 25 & 10 & 0.35 & 0.05 & 4 & 52 \\
\hline 151 & 17 & 1 & 0.4 & 0.05 & 200 & 165 \\
\hline 152 & 19 & 1 & 0.4 & 0.05 & 96 & 77 \\
\hline 153 & 21 & 1 & 0.4 & 0.05 & 73 & 62 \\
\hline 154 & 23 & 1 & 0.4 & 0.05 & 61 & 58 \\
\hline 155 & 25 & 1 & 0.4 & 0.05 & 4 & 49 \\
\hline 156 & 17 & 2 & 0.4 & 0.05 & 38 & 59 \\
\hline 157 & 19 & 2 & 0.4 & 0.05 & 36 & 58 \\
\hline 158 & 21 & 2 & 0.4 & 0.05 & 33 & 57 \\
\hline 159 & 23 & 2 & 0.4 & 0.05 & 24 & 52 \\
\hline & & & & & & \\
\hline
\end{tabular}




\begin{tabular}{|c|c|c|c|c|c|c|}
\hline 160 & 25 & 2 & 0.4 & 0.05 & 4 & 101 \\
\hline 161 & 17 & 3 & 0.4 & 0.05 & 18 & 42 \\
\hline 162 & 19 & 3 & 0.4 & 0.05 & 16 & 39 \\
\hline 163 & 21 & 3 & 0.4 & 0.05 & 12 & 32 \\
\hline 164 & 23 & 3 & 0.4 & 0.05 & 5 & 22 \\
\hline 165 & 25 & 3 & 0.4 & 0.05 & 4 & 153 \\
\hline 166 & 17 & 4 & 0.4 & 0.05 & 10 & 30 \\
\hline 167 & 19 & 4 & 0.4 & 0.05 & 8 & 25 \\
\hline 168 & 21 & 4 & 0.4 & 0.05 & 6 & 21 \\
\hline 169 & 23 & 4 & 0.4 & 0.05 & 5 & 30 \\
\hline 170 & 25 & 4 & 0.4 & 0.05 & 1 & 204 \\
\hline 171 & 17 & 5 & 0.4 & 0.05 & 7 & 25 \\
\hline 172 & 19 & 5 & 0.4 & 0.05 & 6 & 22 \\
\hline 173 & 21 & 5 & 0.4 & 0.05 & 5 & 20 \\
\hline 174 & 23 & 5 & 0.4 & 0.05 & 4 & 39 \\
\hline 175 & 25 & 5 & 0.4 & 0.05 & 1 & 256 \\
\hline 176 & 17 & 6 & 0.4 & 0.05 & 6 & 25 \\
\hline 177 & 19 & 6 & 0.4 & 0.05 & 5 & 21 \\
\hline 178 & 21 & 6 & 0.4 & 0.05 & 5 & 24 \\
\hline 179 & 23 & 6 & 0.4 & 0.05 & 4 & 47 \\
\hline 180 & 25 & 6 & 0.4 & 0.05 & 1 & 308 \\
\hline 181 & 17 & 7 & 0.4 & 0.05 & 5 & 23 \\
\hline 182 & 19 & 7 & 0.4 & 0.05 & 5 & 24 \\
\hline 183 & 21 & 7 & 0.4 & 0.05 & 4 & 29 \\
\hline 184 & 23 & 7 & 0.4 & 0.05 & 4 & 55 \\
\hline 185 & 25 & 7 & 0.4 & 0.05 & 1 & 360 \\
\hline 186 & 17 & 8 & 0.4 & 0.05 & 5 & 26 \\
\hline 187 & 19 & 8 & 0.4 & 0.05 & 5 & 27 \\
\hline 188 & 21 & 8 & 0.4 & 0.05 & 4 & 33 \\
\hline 189 & 23 & 8 & 0.4 & 0.05 & 4 & 63 \\
\hline 190 & 25 & 8 & 0.4 & 0.05 & 1 & 411 \\
\hline 191 & 17 & 9 & 0.4 & 0.05 & 5 & 29 \\
\hline 192 & 19 & 9 & 0.4 & 0.05 & 4 & 25 \\
\hline 193 & 21 & 9 & 0.4 & 0.05 & 4 & 38 \\
\hline 194 & 23 & 9 & 0.4 & 0.05 & 4 & 72 \\
\hline 195 & 25 & 9 & 0.4 & 0.05 & 1 & 463 \\
\hline 196 & 17 & 10 & 0.4 & 0.05 & 4 & 25 \\
\hline 197 & 19 & 10 & 0.4 & 0.05 & 4 & 28 \\
\hline 198 & 21 & 10 & 0.4 & 0.05 & 4 & 42 \\
\hline 199 & 23 & 10 & 0.4 & 0.05 & 4 & 80 \\
\hline 200 & 25 & 10 & 0.4 & 0.05 & 1 & 515 \\
\hline 201 & 17 & 1 & 0.25 & 0.1 & 0 & 0 \\
\hline & & & & & & \\
\hline
\end{tabular}




\begin{tabular}{|c|c|c|c|c|c|c|}
\hline 202 & 19 & 1 & 0.25 & 0.1 & 0 & 0 \\
\hline 203 & 21 & 1 & 0.25 & 0.1 & 0 & 0 \\
\hline 204 & 23 & 1 & 0.25 & 0.1 & 0 & 0 \\
\hline 205 & 25 & 1 & 0.25 & 0.1 & 0 & 0 \\
\hline 206 & 17 & 2 & 0.25 & 0.1 & 200 & 66 \\
\hline 207 & 19 & 2 & 0.25 & 0.1 & 97 & 200 \\
\hline 208 & 21 & 2 & 0.25 & 0.1 & 86 & 200 \\
\hline 209 & 23 & 2 & 0.25 & 0.1 & 79 & 200 \\
\hline 210 & 25 & 2 & 0.25 & 0.1 & 75 & 200 \\
\hline 211 & 17 & 3 & 0.25 & 0.1 & 37 & 40 \\
\hline 212 & 19 & 3 & 0.25 & 0.1 & 35 & 39 \\
\hline 213 & 21 & 3 & 0.25 & 0.1 & 34 & 40 \\
\hline 214 & 23 & 3 & 0.25 & 0.1 & 32 & 38 \\
\hline 215 & 25 & 3 & 0.25 & 0.1 & 30 & 37 \\
\hline 216 & 17 & 4 & 0.25 & 0.1 & 18 & 31 \\
\hline 217 & 19 & 4 & 0.25 & 0.1 & 17 & 29 \\
\hline 218 & 21 & 4 & 0.25 & 0.1 & 17 & 30 \\
\hline 219 & 23 & 4 & 0.25 & 0.1 & 16 & 29 \\
\hline 220 & 25 & 4 & 0.25 & 0.1 & 15 & 27 \\
\hline 221 & 17 & 5 & 0.25 & 0.1 & 10 & 23 \\
\hline 222 & 19 & 5 & 0.25 & 0.1 & 10 & 23 \\
\hline 223 & 21 & 5 & 0.25 & 0.1 & 10 & 23 \\
\hline 224 & 23 & 5 & 0.25 & 0.1 & 10 & 23 \\
\hline 225 & 25 & 5 & 0.25 & 0.1 & 9 & 21 \\
\hline 226 & 17 & 6 & 0.25 & 0.1 & 8 & 23 \\
\hline 227 & 19 & 6 & 0.25 & 0.1 & 8 & 23 \\
\hline 228 & 21 & 6 & 0.25 & 0.1 & 8 & 23 \\
\hline 229 & 23 & 6 & 0.25 & 0.1 & 8 & 23 \\
\hline 230 & 25 & 6 & 0.25 & 0.1 & 8 & 23 \\
\hline 231 & 17 & 7 & 0.25 & 0.1 & 6 & 20 \\
\hline 232 & 19 & 7 & 0.25 & 0.1 & 6 & 19 \\
\hline 233 & 21 & 7 & 0.25 & 0.1 & 7 & 24 \\
\hline 234 & 23 & 7 & 0.25 & 0.1 & 7 & 24 \\
\hline 235 & 25 & 7 & 0.25 & 0.1 & 7 & 24 \\
\hline 236 & 17 & 8 & 0.25 & 0.1 & 6 & 24 \\
\hline 237 & 19 & 8 & 0.25 & 0.1 & 6 & 24 \\
\hline 238 & 21 & 8 & 0.25 & 0.1 & 6 & 23 \\
\hline 239 & 23 & 8 & 0.25 & 0.1 & 6 & 23 \\
\hline 240 & 25 & 8 & 0.25 & 0.1 & 6 & 23 \\
\hline 241 & 17 & 9 & 0.25 & 0.1 & 5 & 22 \\
\hline 242 & 19 & 9 & 0.25 & 0.1 & 5 & 21 \\
\hline 243 & 21 & 9 & 0.25 & 0.1 & 6 & 27 \\
\hline
\end{tabular}




\begin{tabular}{|l|l|l|l|l|l|l|}
\hline 244 & 23 & 9 & 0.25 & 0.1 & 6 & 27 \\
\hline 245 & 25 & 9 & 0.25 & 0.1 & 6 & 27 \\
\hline 246 & 17 & 10 & 0.25 & 0.1 & 5 & 25 \\
\hline 247 & 19 & 10 & 0.25 & 0.1 & 5 & 25 \\
\hline 248 & 21 & 10 & 0.25 & 0.1 & 5 & 24 \\
\hline 249 & 23 & 10 & 0.25 & 0.1 & 5 & 24 \\
\hline 250 & 25 & 10 & 0.25 & 0.1 & 5 & 24 \\
\hline 251 & 17 & 1 & 0.3 & 0.1 & 0 & 0 \\
\hline 252 & 19 & 1 & 0.3 & 0.1 & 0 & 0 \\
\hline 253 & 21 & 1 & 0.3 & 0.1 & 0 & 0 \\
\hline 254 & 23 & 1 & 0.3 & 0.1 & 0 & 0 \\
\hline 255 & 25 & 1 & 0.3 & 0.1 & 200 & 20 \\
\hline 256 & 17 & 2 & 0.3 & 0.1 & 69 & 200 \\
\hline 257 & 19 & 2 & 0.3 & 0.1 & 67 & 200 \\
\hline 258 & 21 & 2 & 0.3 & 0.1 & 63 & 148 \\
\hline 259 & 23 & 2 & 0.3 & 0.1 & 50 & 49 \\
\hline 260 & 25 & 2 & 0.3 & 0.1 & 47 & 48 \\
\hline 261 & 17 & 3 & 0.3 & 0.1 & 30 & 48 \\
\hline 262 & 19 & 3 & 0.3 & 0.1 & 28 & 45 \\
\hline 263 & 21 & 3 & 0.3 & 0.1 & 27 & 45 \\
\hline 264 & 23 & 3 & 0.3 & 0.1 & 25 & 43 \\
\hline 265 & 25 & 3 & 0.3 & 0.1 & 23 & 41 \\
\hline 266 & 17 & 4 & 0.3 & 0.1 & 15 & 34 \\
\hline 267 & 19 & 4 & 0.3 & 0.1 & 14 & 32 \\
\hline 268 & 21 & 4 & 0.3 & 0.1 & 13 & 30 \\
\hline 269 & 23 & 4 & 0.3 & 0.1 & 13 & 31 \\
\hline 270 & 25 & 4 & 0.3 & 0.1 & 11 & 27 \\
\hline 271 & 17 & 5 & 0.3 & 0.1 & 9 & 26 \\
\hline 272 & 19 & 5 & 0.3 & 0.1 & 9 & 26 \\
\hline 273 & 21 & 5 & 0.3 & 0.1 & 9 & 26 \\
\hline 274 & 23 & 5 & 0.3 & 0.1 & 8 & 23 \\
\hline 275 & 25 & 5 & 0.3 & 0.1 & 8 & 25 \\
\hline 276 & 17 & 6 & 0.3 & 0.1 & 7 & 24 \\
\hline 277 & 19 & 6 & 0.3 & 0.1 & 7 & 24 \\
\hline 278 & 21 & 6 & 0.3 & 0.1 & 7 & 24 \\
\hline 279 & 23 & 6 & 0.3 & 0.1 & 7 & 25 \\
\hline 280 & 25 & 6 & 0.3 & 0.1 & 6 & 21 \\
\hline 281 & 17 & 7 & 0.3 & 0.1 & 6 & 24 \\
\hline 282 & 19 & 7 & 0.3 & 0.1 & 6 & 24 \\
\hline 283 & 21 & 7 & 0.3 & 0.1 & 6 & 23 \\
\hline 284 & 23 & 7 & 0.3 & 0.1 & 6 & 24 \\
\hline 285 & 25 & 7 & 0.3 & 0.1 & 6 & 25 \\
\hline & & & & & & \\
\hline
\end{tabular}




\begin{tabular}{|l|l|l|l|l|l|l|}
\hline 286 & 17 & 8 & 0.3 & 0.1 & 6 & 28 \\
\hline 287 & 19 & 8 & 0.3 & 0.1 & 6 & 28 \\
\hline 288 & 21 & 8 & 0.3 & 0.1 & 6 & 27 \\
\hline 289 & 23 & 8 & 0.3 & 0.1 & 6 & 28 \\
\hline 290 & 25 & 8 & 0.3 & 0.1 & 5 & 23 \\
\hline 291 & 17 & 9 & 0.3 & 0.1 & 5 & 25 \\
\hline 292 & 19 & 9 & 0.3 & 0.1 & 5 & 25 \\
\hline 293 & 21 & 9 & 0.3 & 0.1 & 5 & 25 \\
\hline 294 & 23 & 9 & 0.3 & 0.1 & 5 & 25 \\
\hline 295 & 25 & 9 & 0.3 & 0.1 & 5 & 26 \\
\hline 296 & 17 & 10 & 0.3 & 0.1 & 5 & 29 \\
\hline 297 & 19 & 10 & 0.3 & 0.1 & 5 & 28 \\
\hline 298 & 21 & 10 & 0.3 & 0.1 & 5 & 28 \\
\hline 299 & 23 & 10 & 0.3 & 0.1 & 5 & 28 \\
\hline 300 & 25 & 10 & 0.3 & 0.1 & 5 & 29 \\
\hline 301 & 17 & 1 & 0.35 & 0.1 & 0 & 0 \\
\hline 302 & 19 & 1 & 0.35 & 0.1 & 0 & 0 \\
\hline 303 & 21 & 1 & 0.35 & 0.1 & 200 & 126 \\
\hline 304 & 23 & 1 & 0.35 & 0.1 & 200 & 150 \\
\hline 305 & 25 & 1 & 0.35 & 0.1 & 200 & 165 \\
\hline 306 & 17 & 2 & 0.35 & 0.1 & 47 & 65 \\
\hline 307 & 19 & 2 & 0.35 & 0.1 & 44 & 62 \\
\hline 308 & 21 & 2 & 0.35 & 0.1 & 42 & 61 \\
\hline 309 & 23 & 2 & 0.35 & 0.1 & 40 & 61 \\
\hline 310 & 25 & 2 & 0.35 & 0.1 & 36 & 60 \\
\hline 311 & 17 & 3 & 0.35 & 0.1 & 24 & 53 \\
\hline 312 & 19 & 3 & 0.35 & 0.1 & 22 & 49 \\
\hline 313 & 21 & 3 & 0.35 & 0.1 & 21 & 48 \\
\hline 314 & 23 & 3 & 0.35 & 0.1 & 18 & 43 \\
\hline 315 & 25 & 3 & 0.35 & 0.1 & 13 & 36 \\
\hline 316 & 17 & 4 & 0.35 & 0.1 & 12 & 35 \\
\hline 317 & 19 & 4 & 0.35 & 0.1 & 11 & 32 \\
\hline 318 & 21 & 4 & 0.35 & 0.1 & 11 & 33 \\
\hline 319 & 23 & 4 & 0.35 & 0.1 & 9 & 29 \\
\hline 320 & 25 & 4 & 0.35 & 0.1 & 6 & 23 \\
\hline 321 & 17 & 5 & 0.35 & 0.1 & 8 & 28 \\
\hline 322 & 19 & 5 & 0.35 & 0.1 & 8 & 28 \\
\hline 323 & 21 & 5 & 0.35 & 0.1 & 7 & 25 \\
\hline 324 & 23 & 5 & 0.35 & 0.1 & 7 & 27 \\
\hline 325 & 25 & 5 & 0.35 & 0.1 & 5 & 24 \\
\hline 326 & 17 & 6 & 0.35 & 0.1 & 7 & 29 \\
\hline 327 & 19 & 6 & 0.35 & 0.1 & 6 & 24 \\
\hline & & & & & & \\
\hline
\end{tabular}




\begin{tabular}{|c|c|c|c|c|c|c|}
\hline 328 & 21 & 6 & 0.35 & 0.1 & 6 & 25 \\
\hline 329 & 23 & 6 & 0.35 & 0.1 & 6 & 27 \\
\hline 330 & 25 & 6 & 0.35 & 0.1 & 5 & 30 \\
\hline 331 & 17 & 7 & 0.35 & 0.1 & 6 & 28 \\
\hline 332 & 19 & 7 & 0.35 & 0.1 & 6 & 28 \\
\hline 333 & 21 & 7 & 0.35 & 0.1 & 6 & 29 \\
\hline 334 & 23 & 7 & 0.35 & 0.1 & 5 & 25 \\
\hline 335 & 25 & 7 & 0.35 & 0.1 & 5 & 35 \\
\hline 336 & 17 & 8 & 0.35 & 0.1 & 5 & 26 \\
\hline 337 & 19 & 8 & 0.35 & 0.1 & 5 & 26 \\
\hline 338 & 21 & 8 & 0.35 & 0.1 & 5 & 27 \\
\hline 339 & 23 & 8 & 0.35 & 0.1 & 5 & 28 \\
\hline 340 & 25 & 8 & 0.35 & 0.1 & 5 & 41 \\
\hline 341 & 17 & 9 & 0.35 & 0.1 & 5 & 30 \\
\hline 342 & 19 & 9 & 0.35 & 0.1 & 5 & 29 \\
\hline 343 & 21 & 9 & 0.35 & 0.1 & 5 & 30 \\
\hline 344 & 23 & 9 & 0.35 & 0.1 & 5 & 32 \\
\hline 345 & 25 & 9 & 0.35 & 0.1 & 5 & 46 \\
\hline 346 & 17 & 10 & 0.35 & 0.1 & 5 & 33 \\
\hline 347 & 19 & 10 & 0.35 & 0.1 & 5 & 33 \\
\hline 348 & 21 & 10 & 0.35 & 0.1 & 5 & 33 \\
\hline 349 & 23 & 10 & 0.35 & 0.1 & 5 & 35 \\
\hline 350 & 25 & 10 & 0.35 & 0.1 & 4 & 52 \\
\hline 351 & 17 & 1 & 0.4 & 0.1 & 177 & 200 \\
\hline 352 & 19 & 1 & 0.4 & 0.1 & 98 & 105 \\
\hline 353 & 21 & 1 & 0.4 & 0.1 & 75 & 84 \\
\hline 354 & 23 & 1 & 0.4 & 0.1 & 63 & 77 \\
\hline 355 & 25 & 1 & 0.4 & 0.1 & 5 & 49 \\
\hline 356 & 17 & 2 & 0.4 & 0.1 & 39 & 78 \\
\hline 357 & 19 & 2 & 0.4 & 0.1 & 37 & 75 \\
\hline 358 & 21 & 2 & 0.4 & 0.1 & 34 & 73 \\
\hline 359 & 23 & 2 & 0.4 & 0.1 & 28 & 70 \\
\hline 360 & 25 & 2 & 0.4 & 0.1 & 4 & 101 \\
\hline 361 & 17 & 3 & 0.4 & 0.1 & 18 & 53 \\
\hline 362 & 19 & 3 & 0.4 & 0.1 & 17 & 51 \\
\hline 363 & 21 & 3 & 0.4 & 0.1 & 14 & 45 \\
\hline 364 & 23 & 3 & 0.4 & 0.1 & 6 & 26 \\
\hline 365 & 25 & 3 & 0.4 & 0.1 & 4 & 153 \\
\hline 366 & 17 & 4 & 0.4 & 0.1 & 10 & 37 \\
\hline 367 & 19 & 4 & 0.4 & 0.1 & 9 & 34 \\
\hline 368 & 21 & 4 & 0.4 & 0.1 & 8 & 33 \\
\hline 369 & 23 & 4 & 0.4 & 0.1 & 5 & 30 \\
\hline
\end{tabular}




\begin{tabular}{|c|c|c|c|c|c|c|}
\hline 370 & 25 & 4 & 0.4 & 0.1 & 1 & 204 \\
\hline 371 & 17 & 5 & 0.4 & 0.1 & 7 & 30 \\
\hline 372 & 19 & 5 & 0.4 & 0.1 & 7 & 31 \\
\hline 373 & 21 & 5 & 0.4 & 0.1 & 6 & 29 \\
\hline 374 & 23 & 5 & 0.4 & 0.1 & 4 & 39 \\
\hline 375 & 25 & 5 & 0.4 & 0.1 & 1 & 256 \\
\hline 376 & 17 & 6 & 0.4 & 0.1 & 6 & 30 \\
\hline 377 & 19 & 6 & 0.4 & 0.1 & 6 & 31 \\
\hline 378 & 21 & 6 & 0.4 & 0.1 & 5 & 28 \\
\hline 379 & 23 & 6 & 0.4 & 0.1 & 4 & 47 \\
\hline 380 & 25 & 6 & 0.4 & 0.1 & 1 & 308 \\
\hline 381 & 17 & 7 & 0.4 & 0.1 & 5 & 27 \\
\hline 382 & 19 & 7 & 0.4 & 0.1 & 5 & 28 \\
\hline 383 & 21 & 7 & 0.4 & 0.1 & 5 & 31 \\
\hline 384 & 23 & 7 & 0.4 & 0.1 & 4 & 55 \\
\hline 385 & 25 & 7 & 0.4 & 0.1 & 1 & 360 \\
\hline 386 & 17 & 8 & 0.4 & 0.1 & 5 & 31 \\
\hline 387 & 19 & 8 & 0.4 & 0.1 & 5 & 32 \\
\hline 388 & 21 & 8 & 0.4 & 0.1 & 4 & 33 \\
\hline 389 & 23 & 8 & 0.4 & 0.1 & 4 & 63 \\
\hline 390 & 25 & 8 & 0.4 & 0.1 & 1 & 411 \\
\hline 391 & 17 & 9 & 0.4 & 0.1 & 5 & 35 \\
\hline 392 & 19 & 9 & 0.4 & 0.1 & 5 & 36 \\
\hline 393 & 21 & 9 & 0.4 & 0.1 & 4 & 38 \\
\hline 394 & 23 & 9 & 0.4 & 0.1 & 4 & 72 \\
\hline 395 & 25 & 9 & 0.4 & 0.1 & 1 & 463 \\
\hline 396 & 17 & 10 & 0.4 & 0.1 & 5 & 38 \\
\hline 397 & 19 & 10 & 0.4 & 0.1 & 4 & 31 \\
\hline 398 & 21 & 10 & 0.4 & 0.1 & 4 & 42 \\
\hline 399 & 23 & 10 & 0.4 & 0.1 & 4 & 80 \\
\hline 400 & 25 & 10 & 0.4 & 0.1 & 1 & 515 \\
\hline 401 & 17 & 1 & 0.25 & 0.15 & 0 & 0 \\
\hline 402 & 19 & 1 & 0.25 & 0.15 & 0 & 0 \\
\hline 403 & 21 & 1 & 0.25 & 0.15 & 0 & 0 \\
\hline 404 & 23 & 1 & 0.25 & 0.15 & 0 & 0 \\
\hline 405 & 25 & 1 & 0.25 & 0.15 & 0 & 0 \\
\hline 406 & 17 & 2 & 0.25 & 0.15 & 200 & 33 \\
\hline 407 & 19 & 2 & 0.25 & 0.15 & 200 & 70 \\
\hline 408 & 21 & 2 & 0.25 & 0.15 & 91 & 200 \\
\hline 409 & 23 & 2 & 0.25 & 0.15 & 79 & 200 \\
\hline 410 & 25 & 2 & 0.25 & 0.15 & 73 & 200 \\
\hline 411 & 17 & 3 & 0.25 & 0.15 & 38 & 55 \\
\hline & & & & & & \\
\hline
\end{tabular}




\begin{tabular}{|l|l|l|l|l|l|l|}
\hline 412 & 19 & 3 & 0.25 & 0.15 & 36 & 53 \\
\hline 413 & 21 & 3 & 0.25 & 0.15 & 34 & 50 \\
\hline 414 & 23 & 3 & 0.25 & 0.15 & 33 & 50 \\
\hline 415 & 25 & 3 & 0.25 & 0.15 & 31 & 48 \\
\hline 416 & 17 & 4 & 0.25 & 0.15 & 19 & 42 \\
\hline 417 & 19 & 4 & 0.25 & 0.15 & 18 & 40 \\
\hline 418 & 21 & 4 & 0.25 & 0.15 & 17 & 37 \\
\hline 419 & 23 & 4 & 0.25 & 0.15 & 16 & 35 \\
\hline 420 & 25 & 4 & 0.25 & 0.15 & 16 & 36 \\
\hline 421 & 17 & 5 & 0.25 & 0.15 & 10 & 28 \\
\hline 422 & 19 & 5 & 0.25 & 0.15 & 10 & 28 \\
\hline 423 & 21 & 5 & 0.25 & 0.15 & 10 & 28 \\
\hline 424 & 23 & 5 & 0.25 & 0.15 & 10 & 28 \\
\hline 425 & 25 & 5 & 0.25 & 0.15 & 10 & 29 \\
\hline 426 & 17 & 6 & 0.25 & 0.15 & 8 & 29 \\
\hline 427 & 19 & 6 & 0.25 & 0.15 & 8 & 28 \\
\hline 428 & 21 & 6 & 0.25 & 0.15 & 8 & 28 \\
\hline 429 & 23 & 6 & 0.25 & 0.15 & 8 & 28 \\
\hline 430 & 25 & 6 & 0.25 & 0.15 & 8 & 28 \\
\hline 431 & 17 & 7 & 0.25 & 0.15 & 6 & 24 \\
\hline 432 & 19 & 7 & 0.25 & 0.15 & 7 & 30 \\
\hline 433 & 21 & 7 & 0.25 & 0.15 & 7 & 29 \\
\hline 434 & 23 & 7 & 0.25 & 0.15 & 7 & 29 \\
\hline 435 & 25 & 7 & 0.25 & 0.15 & 7 & 28 \\
\hline 436 & 17 & 8 & 0.25 & 0.15 & 6 & 30 \\
\hline 437 & 19 & 8 & 0.25 & 0.15 & 6 & 29 \\
\hline 438 & 21 & 8 & 0.25 & 0.15 & 6 & 28 \\
\hline 439 & 23 & 8 & 0.25 & 0.15 & 6 & 28 \\
\hline 440 & 25 & 8 & 0.25 & 0.15 & 6 & 27 \\
\hline 441 & 17 & 9 & 0.25 & 0.15 & 5 & 27 \\
\hline 442 & 19 & 9 & 0.25 & 0.15 & 6 & 34 \\
\hline 443 & 21 & 9 & 0.25 & 0.15 & 6 & 33 \\
\hline 444 & 23 & 9 & 0.25 & 0.15 & 6 & 32 \\
\hline 445 & 25 & 9 & 0.25 & 0.15 & 6 & 32 \\
\hline 446 & 17 & 10 & 0.25 & 0.15 & 5 & 31 \\
\hline 447 & 19 & 10 & 0.25 & 0.15 & 5 & 30 \\
\hline 448 & 21 & 10 & 0.25 & 0.15 & 5 & 29 \\
\hline 449 & 23 & 10 & 0.25 & 0.15 & 5 & 29 \\
\hline 450 & 25 & 10 & 0.25 & 0.15 & 6 & 36 \\
\hline 451 & 17 & 1 & 0.3 & 0.15 & 0 & 0 \\
\hline 452 & 19 & 1 & 0.3 & 0.15 & 0 & 0 \\
\hline 453 & 21 & 1 & 0.3 & 0.15 & 0 & 0 \\
\hline & & & & & & \\
\hline
\end{tabular}




\begin{tabular}{|c|c|c|c|c|c|c|}
\hline 454 & 23 & 1 & 0.3 & 0.15 & 0 & 0 \\
\hline 455 & 25 & 1 & 0.3 & 0.15 & 200 & 49 \\
\hline 456 & 17 & 2 & 0.3 & 0.15 & 66 & 200 \\
\hline 457 & 19 & 2 & 0.3 & 0.15 & 64 & 200 \\
\hline 458 & 21 & 2 & 0.3 & 0.15 & 63 & 200 \\
\hline 459 & 23 & 2 & 0.3 & 0.15 & 50 & 64 \\
\hline 460 & 25 & 2 & 0.3 & 0.15 & 48 & 64 \\
\hline 461 & 17 & 3 & 0.3 & 0.15 & 30 & 62 \\
\hline 462 & 19 & 3 & 0.3 & 0.15 & 29 & 60 \\
\hline 463 & 21 & 3 & 0.3 & 0.15 & 27 & 56 \\
\hline 464 & 23 & 3 & 0.3 & 0.15 & 26 & 55 \\
\hline 465 & 25 & 3 & 0.3 & 0.15 & 24 & 52 \\
\hline 466 & 17 & 4 & 0.3 & 0.15 & 15 & 43 \\
\hline 467 & 19 & 4 & 0.3 & 0.15 & 14 & 40 \\
\hline 468 & 21 & 4 & 0.3 & 0.15 & 14 & 40 \\
\hline 469 & 23 & 4 & 0.3 & 0.15 & 13 & 37 \\
\hline 470 & 25 & 4 & 0.3 & 0.15 & 12 & 35 \\
\hline 471 & 17 & 5 & 0.3 & 0.15 & 9 & 32 \\
\hline 472 & 19 & 5 & 0.3 & 0.15 & 9 & 32 \\
\hline 473 & 21 & 5 & 0.3 & 0.15 & 9 & 32 \\
\hline 474 & 23 & 5 & 0.3 & 0.15 & 9 & 32 \\
\hline 475 & 25 & 5 & 0.3 & 0.15 & 8 & 29 \\
\hline 476 & 17 & 6 & 0.3 & 0.15 & 7 & 30 \\
\hline 477 & 19 & 6 & 0.3 & 0.15 & 7 & 29 \\
\hline 478 & 21 & 6 & 0.3 & 0.15 & 7 & 29 \\
\hline 479 & 23 & 6 & 0.3 & 0.15 & 7 & 29 \\
\hline 480 & 25 & 6 & 0.3 & 0.15 & 7 & 30 \\
\hline 481 & 17 & 7 & 0.3 & 0.15 & 6 & 29 \\
\hline 482 & 19 & 7 & 0.3 & 0.15 & 6 & 28 \\
\hline 483 & 21 & 7 & 0.3 & 0.15 & 6 & 28 \\
\hline 484 & 23 & 7 & 0.3 & 0.15 & 6 & 28 \\
\hline 485 & 25 & 7 & 0.3 & 0.15 & 6 & 29 \\
\hline 486 & 17 & 8 & 0.3 & 0.15 & 6 & 35 \\
\hline 487 & 19 & 8 & 0.3 & 0.15 & 6 & 34 \\
\hline 488 & 21 & 8 & 0.3 & 0.15 & 6 & 33 \\
\hline 489 & 23 & 8 & 0.3 & 0.15 & 6 & 33 \\
\hline 490 & 25 & 8 & 0.3 & 0.15 & 6 & 34 \\
\hline 491 & 17 & 9 & 0.3 & 0.15 & 5 & 31 \\
\hline 492 & 19 & 9 & 0.3 & 0.15 & 5 & 30 \\
\hline 493 & 21 & 9 & 0.3 & 0.15 & 5 & 30 \\
\hline 494 & 23 & 9 & 0.3 & 0.15 & 5 & 30 \\
\hline 495 & 25 & 9 & 0.3 & 0.15 & 5 & 31 \\
\hline & & & & & & \\
\hline
\end{tabular}




\begin{tabular}{|c|c|c|c|c|c|c|}
\hline 496 & 17 & 10 & 0.3 & 0.15 & 5 & 36 \\
\hline 497 & 19 & 10 & 0.3 & 0.15 & 5 & 34 \\
\hline 498 & 21 & 10 & 0.3 & 0.15 & 5 & 34 \\
\hline 499 & 23 & 10 & 0.3 & 0.15 & 5 & 33 \\
\hline 500 & 25 & 10 & 0.3 & 0.15 & 5 & 34 \\
\hline 501 & 17 & 1 & 0.35 & 0.15 & 0 & 0 \\
\hline 502 & 19 & 1 & 0.35 & 0.15 & 0 & 0 \\
\hline 503 & 21 & 1 & 0.35 & 0.15 & 198 & 200 \\
\hline 504 & 23 & 1 & 0.35 & 0.15 & 185 & 200 \\
\hline 505 & 25 & 1 & 0.35 & 0.15 & 180 & 200 \\
\hline$\overline{506}$ & 17 & $\overline{2}$ & 0.35 & 0.15 & 47 & 85 \\
\hline 507 & 19 & 2 & 0.35 & 0.15 & 45 & 82 \\
\hline 508 & 21 & 2 & 0.35 & 0.15 & 43 & 80 \\
\hline 509 & 23 & 2 & 0.35 & 0.15 & 41 & 78 \\
\hline 510 & 25 & 2 & 0.35 & 0.15 & 38 & 78 \\
\hline 511 & 17 & 3 & 0.35 & 0.15 & 24 & 67 \\
\hline 512 & 19 & 3 & 0.35 & 0.15 & 23 & 65 \\
\hline 513 & 21 & 3 & 0.35 & 0.15 & 21 & 60 \\
\hline 514 & 23 & 3 & 0.35 & 0.15 & 19 & 56 \\
\hline 515 & 25 & 3 & 0.35 & 0.15 & 16 & 52 \\
\hline 516 & 17 & 4 & 0.35 & 0.15 & 12 & 44 \\
\hline 517 & 19 & 4 & 0.35 & 0.15 & 12 & 44 \\
\hline 518 & 21 & 4 & 0.35 & 0.15 & 11 & 40 \\
\hline 519 & 23 & 4 & 0.35 & 0.15 & 10 & 38 \\
\hline 520 & 25 & 4 & 0.35 & 0.15 & 8 & 35 \\
\hline 521 & 17 & 5 & 0.35 & 0.15 & 8 & 35 \\
\hline 522 & 19 & 5 & 0.35 & 0.15 & 8 & 35 \\
\hline 523 & 21 & 5 & 0.35 & 0.15 & 8 & 35 \\
\hline 524 & 23 & 5 & 0.35 & 0.15 & 7 & 32 \\
\hline 525 & 25 & 5 & 0.35 & 0.15 & 6 & 31 \\
\hline 526 & 17 & 6 & 0.35 & 0.15 & 7 & 36 \\
\hline 527 & 19 & 6 & 0.35 & 0.15 & 7 & 36 \\
\hline 528 & 21 & 6 & 0.35 & 0.15 & 7 & 36 \\
\hline 529 & 23 & 6 & 0.35 & 0.15 & 6 & 31 \\
\hline 530 & 25 & 6 & 0.35 & 0.15 & 5 & 30 \\
\hline 531 & 17 & 7 & 0.35 & 0.15 & 6 & 35 \\
\hline 532 & 19 & 7 & 0.35 & 0.15 & 6 & 35 \\
\hline 533 & 21 & 7 & 0.35 & 0.15 & 6 & 35 \\
\hline 534 & 23 & 7 & 0.35 & 0.15 & 6 & 36 \\
\hline 535 & 25 & 7 & 0.35 & 0.15 & 5 & 35 \\
\hline 536 & 17 & 8 & 0.35 & 0.15 & 5 & 32 \\
\hline 537 & 19 & 8 & 0.35 & 0.15 & 5 & 31 \\
\hline
\end{tabular}




\begin{tabular}{|c|c|c|c|c|c|c|}
\hline 538 & 21 & 8 & 0.35 & 0.15 & 5 & 32 \\
\hline 539 & 23 & 8 & 0.35 & 0.15 & 5 & 33 \\
\hline 540 & 25 & 8 & 0.35 & 0.15 & 5 & 41 \\
\hline 541 & 17 & 9 & 0.35 & 0.15 & 5 & 36 \\
\hline 542 & 19 & 9 & 0.35 & 0.15 & 5 & 36 \\
\hline 543 & 21 & 9 & 0.35 & 0.15 & 5 & 36 \\
\hline 544 & 23 & $\overline{9}$ & 0.35 & 0.15 & 5 & 37 \\
\hline 545 & 25 & 9 & 0.35 & 0.15 & 5 & 46 \\
\hline 546 & 17 & 10 & 0.35 & 0.15 & 5 & 41 \\
\hline 547 & 19 & 10 & 0.35 & 0.15 & 5 & 40 \\
\hline 548 & 21 & 10 & 0.35 & 0.15 & 5 & 40 \\
\hline 549 & 23 & $\overline{10}$ & 0.35 & 0.15 & 5 & 41 \\
\hline 550 & 25 & 10 & 0.35 & 0.15 & 5 & 52 \\
\hline 551 & 17 & 1 & 0.4 & 0.15 & 135 & 200 \\
\hline 552 & 19 & 1 & 0.4 & 0.15 & 99 & 140 \\
\hline 553 & 21 & 1 & 0.4 & 0.15 & 76 & 111 \\
\hline 554 & 23 & 1 & 0.4 & 0.15 & 65 & 102 \\
\hline 555 & 25 & 1 & 0.4 & 0.15 & 5 & 49 \\
\hline 556 & 17 & 2 & 0.4 & 0.15 & 39 & 100 \\
\hline 557 & 19 & 2 & 0.4 & 0.15 & 37 & 96 \\
\hline 558 & 21 & 2 & 0.4 & 0.15 & 35 & 93 \\
\hline 559 & 23 & 2 & 0.4 & 0.15 & 30 & 90 \\
\hline 560 & 25 & 2 & 0.4 & 0.15 & 4 & 101 \\
\hline 561 & 17 & 3 & 0.4 & 0.15 & 19 & 71 \\
\hline 562 & 19 & 3 & 0.4 & 0.15 & 18 & 67 \\
\hline 563 & 21 & 3 & 0.4 & 0.15 & 16 & 62 \\
\hline 564 & 23 & 3 & 0.4 & 0.15 & 9 & 43 \\
\hline 565 & 25 & 3 & 0.4 & 0.15 & 4 & 153 \\
\hline 566 & 17 & 4 & 0.4 & 0.15 & 10 & 46 \\
\hline 567 & 19 & 4 & 0.4 & 0.15 & 10 & 46 \\
\hline 568 & 21 & 4 & 0.4 & 0.15 & 9 & 44 \\
\hline 569 & 23 & 4 & 0.4 & 0.15 & 5 & 30 \\
\hline 570 & 25 & 4 & 0.4 & 0.15 & 1 & 204 \\
\hline 571 & 17 & 5 & 0.4 & 0.15 & 7 & 37 \\
\hline 572 & 19 & 5 & 0.4 & 0.15 & 7 & 38 \\
\hline 573 & 21 & 5 & 0.4 & 0.15 & 6 & 34 \\
\hline 574 & 23 & 5 & 0.4 & 0.15 & 5 & 39 \\
\hline 575 & 25 & 5 & 0.4 & 0.15 & 1 & 256 \\
\hline 576 & 17 & 6 & 0.4 & 0.15 & 6 & 36 \\
\hline 577 & 19 & 6 & 0.4 & 0.15 & 6 & 37 \\
\hline 578 & 21 & 6 & 0.4 & 0.15 & 5 & 32 \\
\hline 579 & 23 & 6 & 0.4 & 0.15 & 4 & 47 \\
\hline
\end{tabular}




\begin{tabular}{|c|c|c|c|c|c|c|}
\hline 580 & 25 & 6 & 0.4 & 0.15 & 1 & 308 \\
\hline 581 & 17 & 7 & 0.4 & 0.15 & 6 & 42 \\
\hline 582 & 19 & 7 & 0.4 & 0.15 & 5 & 34 \\
\hline 583 & 21 & 7 & 0.4 & 0.15 & 5 & 37 \\
\hline 584 & 23 & 7 & 0.4 & 0.15 & 4 & 55 \\
\hline 585 & 25 & 7 & 0.4 & 0.15 & 1 & 360 \\
\hline 586 & 17 & 8 & 0.4 & 0.15 & 5 & 38 \\
\hline 587 & 19 & 8 & 0.4 & 0.15 & 5 & 38 \\
\hline 588 & 21 & 8 & 0.4 & 0.15 & 5 & 41 \\
\hline 589 & 23 & 8 & 0.4 & 0.15 & 4 & 63 \\
\hline 590 & 25 & 8 & 0.4 & 0.15 & 1 & 411 \\
\hline 591 & 17 & 9 & 0.4 & 0.15 & 5 & 43 \\
\hline 592 & 19 & 9 & 0.4 & 0.15 & 5 & 43 \\
\hline 593 & 21 & 9 & 0.4 & 0.15 & 5 & 45 \\
\hline 594 & 23 & 9 & 0.4 & 0.15 & 4 & 72 \\
\hline 595 & 25 & 9 & 0.4 & 0.15 & 1 & 463 \\
\hline 596 & 17 & 10 & 0.4 & 0.15 & 5 & 47 \\
\hline 597 & 19 & 10 & 0.4 & 0.15 & 5 & 47 \\
\hline 598 & 21 & 10 & 0.4 & 0.15 & 4 & 42 \\
\hline 599 & 23 & 10 & 0.4 & 0.15 & 4 & 80 \\
\hline 600 & 25 & 10 & 0.4 & 0.15 & 1 & 515 \\
\hline 601 & 17 & 1 & 0.25 & 0.2 & 0 & 0 \\
\hline 602 & 19 & 1 & 0.25 & 0.2 & 0 & 0 \\
\hline 603 & 21 & 1 & 0.25 & 0.2 & 0 & 0 \\
\hline 604 & 23 & 1 & 0.25 & 0.2 & 0 & 0 \\
\hline 605 & 25 & 1 & 0.25 & 0.2 & 0 & 0 \\
\hline 606 & 17 & 2 & 0.25 & 0.2 & 200 & 47 \\
\hline 607 & 19 & 2 & 0.25 & 0.2 & 200 & 88 \\
\hline 608 & 21 & 2 & 0.25 & 0.2 & 95 & 200 \\
\hline 609 & 23 & 2 & 0.25 & 0.2 & 78 & 200 \\
\hline 610 & 25 & 2 & 0.25 & 0.2 & 71 & 200 \\
\hline 611 & 17 & 3 & 0.25 & 0.2 & 38 & 70 \\
\hline 612 & 19 & 3 & 0.25 & 0.2 & 36 & 67 \\
\hline 613 & 21 & 3 & 0.25 & 0.2 & 35 & 67 \\
\hline 614 & 23 & 3 & 0.25 & 0.2 & 33 & 63 \\
\hline 615 & 25 & 3 & 0.25 & 0.2 & 32 & 62 \\
\hline 616 & 17 & 4 & 0.25 & 0.2 & 19 & 53 \\
\hline 617 & 19 & 4 & 0.25 & 0.2 & 18 & 50 \\
\hline 618 & 21 & 4 & 0.25 & 0.2 & 17 & 46 \\
\hline 619 & 23 & 4 & 0.25 & 0.2 & 17 & 47 \\
\hline 620 & 25 & 4 & 0.25 & 0.2 & 16 & 44 \\
\hline 621 & 17 & 5 & 0.25 & 0.2 & 11 & 40 \\
\hline
\end{tabular}




\begin{tabular}{|l|l|l|l|l|l|l|}
\hline 622 & 19 & 5 & 0.25 & 0.2 & 10 & 35 \\
\hline 623 & 21 & 5 & 0.25 & 0.2 & 10 & 35 \\
\hline 624 & 23 & 5 & 0.25 & 0.2 & 10 & 35 \\
\hline 625 & 25 & 5 & 0.25 & 0.2 & 10 & 35 \\
\hline 626 & 17 & 6 & 0.25 & 0.2 & 8 & 36 \\
\hline 627 & 19 & 6 & 0.25 & 0.2 & 8 & 35 \\
\hline 628 & 21 & 6 & 0.25 & 0.2 & 8 & 34 \\
\hline 629 & 23 & 6 & 0.25 & 0.2 & 8 & 34 \\
\hline 630 & 25 & 6 & 0.25 & 0.2 & 8 & 33 \\
\hline 631 & 17 & 7 & 0.25 & 0.2 & 6 & 30 \\
\hline 632 & 19 & 7 & 0.25 & 0.2 & 7 & 37 \\
\hline 633 & 21 & 7 & 0.25 & 0.2 & 7 & 35 \\
\hline 634 & 23 & 7 & 0.25 & 0.2 & 7 & 35 \\
\hline 635 & 25 & 7 & 0.25 & 0.2 & 7 & 34 \\
\hline 636 & 17 & 8 & 0.25 & 0.2 & 6 & 37 \\
\hline 637 & 19 & 8 & 0.25 & 0.2 & 6 & 35 \\
\hline 638 & 21 & 8 & 0.25 & 0.2 & 6 & 34 \\
\hline 639 & 23 & 8 & 0.25 & 0.2 & 6 & 33 \\
\hline 640 & 25 & 8 & 0.25 & 0.2 & 6 & 33 \\
\hline 641 & 17 & 9 & 0.25 & 0.2 & 5 & 33 \\
\hline 642 & 19 & 9 & 0.25 & 0.2 & 6 & 42 \\
\hline 643 & 21 & 9 & 0.25 & 0.2 & 6 & 40 \\
\hline 644 & 23 & 9 & 0.25 & 0.2 & 6 & 39 \\
\hline 645 & 25 & 9 & 0.25 & 0.2 & 6 & 38 \\
\hline 646 & 17 & 10 & 0.25 & 0.2 & 5 & 38 \\
\hline 647 & 19 & 10 & 0.25 & 0.2 & 5 & 37 \\
\hline 648 & 21 & 10 & 0.25 & 0.2 & 5 & 35 \\
\hline 649 & 23 & 10 & 0.25 & 0.2 & 6 & 44 \\
\hline 650 & 25 & 10 & 0.25 & 0.2 & 6 & 43 \\
\hline 651 & 17 & 1 & 0.3 & 0.2 & 0 & 0 \\
\hline 652 & 19 & 1 & 0.3 & 0.2 & 0 & 0 \\
\hline 653 & 21 & 1 & 0.3 & 0.2 & 0 & 0 \\
\hline 654 & 23 & 1 & 0.3 & 0.2 & 0 & 0 \\
\hline 655 & 25 & 1 & 0.3 & 0.2 & 200 & 116 \\
\hline 656 & 17 & 2 & 0.3 & 0.2 & 64 & 200 \\
\hline 657 & 19 & 2 & 0.3 & 0.2 & 62 & 200 \\
\hline 658 & 21 & 2 & 0.3 & 0.2 & 60 & 200 \\
\hline 659 & 23 & 2 & 0.3 & 0.2 & 51 & 86 \\
\hline 660 & 25 & 2 & 0.3 & 0.2 & 48 & 81 \\
\hline 661 & 17 & 3 & 0.3 & 0.2 & 30 & 79 \\
\hline 662 & 19 & 3 & 0.3 & 0.2 & 29 & 77 \\
\hline 663 & 21 & 3 & 0.3 & 0.2 & 28 & 74 \\
\hline & & & & & & \\
\hline
\end{tabular}




\begin{tabular}{|l|l|l|l|l|l|l|}
\hline 664 & 23 & 3 & 0.3 & 0.2 & 26 & 69 \\
\hline 665 & 25 & 3 & 0.3 & 0.2 & 25 & 67 \\
\hline 666 & 17 & 4 & 0.3 & 0.2 & 15 & 54 \\
\hline 667 & 19 & 4 & 0.3 & 0.2 & 14 & 50 \\
\hline 668 & 21 & 4 & 0.3 & 0.2 & 14 & 50 \\
\hline 669 & 23 & 4 & 0.3 & 0.2 & 14 & 50 \\
\hline 670 & 25 & 4 & 0.3 & 0.2 & 13 & 47 \\
\hline 671 & 17 & 5 & 0.3 & 0.2 & 9 & 40 \\
\hline 672 & 19 & 5 & 0.3 & 0.2 & 9 & 39 \\
\hline 673 & 21 & 5 & 0.3 & 0.2 & 9 & 39 \\
\hline 674 & 23 & 5 & 0.3 & 0.2 & 9 & 39 \\
\hline 675 & 25 & 5 & 0.3 & 0.2 & 9 & 40 \\
\hline 676 & 17 & 6 & 0.3 & 0.2 & 7 & 37 \\
\hline 677 & 19 & 6 & 0.3 & 0.2 & 7 & 36 \\
\hline 678 & 21 & 6 & 0.3 & 0.2 & 7 & 35 \\
\hline 679 & 23 & 6 & 0.3 & 0.2 & 7 & 35 \\
\hline 680 & 25 & 6 & 0.3 & 0.2 & 7 & 36 \\
\hline 681 & 17 & 7 & 0.3 & 0.2 & 6 & 36 \\
\hline 682 & 19 & 7 & 0.3 & 0.2 & 6 & 35 \\
\hline 683 & 21 & 7 & 0.3 & 0.2 & 6 & 34 \\
\hline 684 & 23 & 7 & 0.3 & 0.2 & 6 & 34 \\
\hline 685 & 25 & 7 & 0.3 & 0.2 & 6 & 35 \\
\hline 686 & 17 & 8 & 0.3 & 0.2 & 6 & 43 \\
\hline 687 & 19 & 8 & 0.3 & 0.2 & 6 & 41 \\
\hline 688 & 21 & 8 & 0.3 & 0.2 & 6 & 40 \\
\hline 689 & 23 & 8 & 0.3 & 0.2 & 6 & 40 \\
\hline 690 & 25 & 8 & 0.3 & 0.2 & 6 & 40 \\
\hline 691 & 17 & 9 & 0.3 & 0.2 & 5 & 39 \\
\hline 692 & 19 & 9 & 0.3 & 0.2 & 5 & 37 \\
\hline 693 & 21 & 9 & 0.3 & 0.2 & 6 & 46 \\
\hline 694 & 23 & 9 & 0.3 & 0.2 & 6 & 45 \\
\hline 695 & 25 & 9 & 0.3 & 0.2 & 6 & 45 \\
\hline 696 & 17 & 10 & 0.3 & 0.2 & 5 & 44 \\
\hline 697 & 19 & 10 & 0.3 & 0.2 & 5 & 42 \\
\hline 698 & 21 & 10 & 0.3 & 0.2 & 5 & 41 \\
\hline 699 & 23 & 10 & 0.3 & 0.2 & 5 & 40 \\
\hline 700 & 25 & 10 & 0.3 & 0.2 & 5 & 40 \\
\hline 701 & 17 & 1 & 0.35 & 0.2 & 0 & 0 \\
\hline 702 & 19 & 1 & 0.35 & 0.2 & 0 & 0 \\
\hline 703 & 21 & 1 & 0.35 & 0.2 & 144 & 200 \\
\hline 704 & 23 & 1 & 0.35 & 0.2 & 141 & 200 \\
\hline 705 & 25 & 1 & 0.35 & 0.2 & 141 & 200 \\
\hline & & & & & & \\
\hline
\end{tabular}




\begin{tabular}{|c|c|c|c|c|c|c|}
\hline 706 & 17 & 2 & 0.35 & 0.2 & 47 & 111 \\
\hline 707 & 19 & 2 & 0.35 & 0.2 & 45 & 106 \\
\hline 708 & 21 & 2 & 0.35 & 0.2 & 43 & 102 \\
\hline 709 & 23 & 2 & 0.35 & 0.2 & 41 & 99 \\
\hline 710 & 25 & 2 & 0.35 & 0.2 & 39 & 99 \\
\hline 711 & 17 & 3 & 0.35 & 0.2 & 24 & 86 \\
\hline 712 & 19 & 3 & 0.35 & 0.2 & 23 & 82 \\
\hline 713 & 21 & 3 & 0.35 & 0.2 & 22 & 78 \\
\hline 714 & 23 & 3 & 0.35 & 0.2 & 20 & 72 \\
\hline 715 & 25 & 3 & 0.35 & 0.2 & 18 & 69 \\
\hline 716 & 17 & 4 & 0.35 & 0.2 & 12 & 56 \\
\hline 717 & 19 & 4 & 0.35 & 0.2 & 12 & 55 \\
\hline 718 & 21 & 4 & 0.35 & 0.2 & 12 & 55 \\
\hline 719 & 23 & 4 & 0.35 & 0.2 & 11 & 51 \\
\hline 720 & 25 & 4 & 0.35 & 0.2 & 9 & 45 \\
\hline 721 & 17 & 5 & 0.35 & 0.2 & 8 & 44 \\
\hline 722 & 19 & 5 & 0.35 & 0.2 & 8 & 43 \\
\hline 723 & 21 & 5 & 0.35 & 0.2 & 8 & 43 \\
\hline 724 & 23 & 5 & 0.35 & 0.2 & 8 & 44 \\
\hline 725 & 25 & 5 & 0.35 & 0.2 & 7 & 43 \\
\hline 726 & 17 & 6 & 0.35 & 0.2 & 7 & 45 \\
\hline 727 & 19 & 6 & 0.35 & 0.2 & 7 & 44 \\
\hline 728 & 21 & 6 & 0.35 & 0.2 & 7 & 44 \\
\hline 729 & 23 & 6 & 0.35 & 0.2 & 7 & 45 \\
\hline 730 & 25 & 6 & 0.35 & 0.2 & 6 & 42 \\
\hline 731 & 17 & 7 & 0.35 & 0.2 & 6 & 44 \\
\hline 732 & 19 & 7 & 0.35 & 0.2 & 6 & 42 \\
\hline 733 & 21 & 7 & 0.35 & 0.2 & 6 & 42 \\
\hline 734 & 23 & 7 & 0.35 & 0.2 & 6 & 43 \\
\hline 735 & 25 & 7 & 0.35 & 0.2 & 5 & 39 \\
\hline 736 & 17 & 8 & 0.35 & 0.2 & 5 & 40 \\
\hline 737 & 19 & 8 & 0.35 & 0.2 & 6 & 49 \\
\hline 738 & 21 & 8 & 0.35 & 0.2 & 6 & 48 \\
\hline 739 & 23 & 8 & 0.35 & 0.2 & 5 & 39 \\
\hline 740 & 25 & 8 & 0.35 & 0.2 & 5 & 43 \\
\hline 741 & 17 & 9 & 0.35 & 0.2 & 5 & 45 \\
\hline 742 & 19 & 9 & 0.35 & 0.2 & 5 & 43 \\
\hline 743 & 21 & 9 & 0.35 & 0.2 & 5 & 43 \\
\hline 744 & 23 & 9 & 0.35 & 0.2 & 5 & 44 \\
\hline 745 & 25 & 9 & 0.35 & 0.2 & 5 & 48 \\
\hline 746 & 17 & 10 & 0.35 & 0.2 & 5 & 51 \\
\hline 747 & 19 & 10 & 0.35 & 0.2 & 5 & 48 \\
\hline
\end{tabular}




\begin{tabular}{|c|c|c|c|c|c|c|}
\hline 748 & 21 & 10 & 0.35 & 0.2 & 5 & 48 \\
\hline 749 & 23 & 10 & 0.35 & 0.2 & 5 & 49 \\
\hline 750 & 25 & 10 & 0.35 & 0.2 & 5 & 53 \\
\hline 751 & 17 & 1 & 0.4 & 0.2 & 102 & 200 \\
\hline 752 & 19 & 1 & 0.4 & 0.2 & 99 & 184 \\
\hline 753 & 21 & 1 & 0.4 & 0.2 & 76 & 146 \\
\hline 754 & 23 & 1 & 0.4 & 0.2 & 66 & 133 \\
\hline 755 & 25 & 1 & 0.4 & 0.2 & 5 & 49 \\
\hline 756 & 17 & 2 & 0.4 & 0.2 & 39 & 130 \\
\hline 757 & 19 & 2 & 0.4 & 0.2 & 37 & 123 \\
\hline 758 & 21 & 2 & 0.4 & 0.2 & 35 & 118 \\
\hline 759 & 23 & 2 & 0.4 & 0.2 & 32 & 116 \\
\hline 760 & 25 & 2 & 0.4 & 0.2 & 4 & 101 \\
\hline 761 & 17 & 3 & 0.4 & 0.2 & 19 & 91 \\
\hline 762 & 19 & 3 & 0.4 & 0.2 & 18 & 85 \\
\hline 763 & 21 & 3 & 0.4 & 0.2 & 16 & 77 \\
\hline 764 & 23 & 3 & 0.4 & 0.2 & 12 & 66 \\
\hline 765 & 25 & 3 & 0.4 & 0.2 & 4 & 153 \\
\hline 766 & 17 & 4 & 0.4 & 0.2 & 10 & 59 \\
\hline 767 & 19 & 4 & 0.4 & 0.2 & 10 & \begin{tabular}{|l|}
58 \\
\end{tabular} \\
\hline 768 & 21 & 4 & 0.4 & 0.2 & 9 & 53 \\
\hline 769 & 23 & 4 & 0.4 & 0.2 & 6 & 42 \\
\hline 770 & 25 & 4 & 0.4 & 0.2 & 1 & 204 \\
\hline 771 & 17 & 5 & 0.4 & 0.2 & 8 & 55 \\
\hline 772 & 19 & 5 & 0.4 & 0.2 & 7 & 46 \\
\hline 773 & 21 & 5 & 0.4 & 0.2 & 7 & 48 \\
\hline 774 & 23 & 5 & 0.4 & 0.2 & 5 & 40 \\
\hline 775 & 25 & 5 & 0.4 & 0.2 & 1 & 256 \\
\hline 776 & 17 & 6 & 0.4 & 0.2 & 6 & 46 \\
\hline 777 & 19 & 6 & 0.4 & 0.2 & 6 & 45 \\
\hline 778 & 21 & 6 & 0.4 & 0.2 & 6 & 47 \\
\hline 779 & 23 & 6 & 0.4 & 0.2 & 5 & 47 \\
\hline 780 & 25 & 6 & 0.4 & 0.2 & 1 & 308 \\
\hline 781 & 17 & 7 & 0.4 & 0.2 & 6 & 53 \\
\hline 782 & 19 & 7 & 0.4 & 0.2 & 6 & 52 \\
\hline 783 & 21 & 7 & 0.4 & 0.2 & 5 & 44 \\
\hline 784 & 23 & 7 & 0.4 & 0.2 & 4 & 55 \\
\hline 785 & 25 & 7 & 0.4 & 0.2 & 1 & 360 \\
\hline 786 & 17 & 8 & 0.4 & 0.2 & 5 & 47 \\
\hline 787 & 19 & 8 & 0.4 & 0.2 & 5 & 47 \\
\hline 788 & 21 & 8 & 0.4 & 0.2 & 5 & 49 \\
\hline 789 & 23 & 8 & 0.4 & 0.2 & 4 & 63 \\
\hline
\end{tabular}




\begin{tabular}{|c|c|c|c|c|c|c|}
\hline 790 & 25 & 8 & 0.4 & 0.2 & 1 & 411 \\
\hline 791 & 17 & 9 & 0.4 & 0.2 & 5 & 53 \\
\hline 792 & 19 & 9 & 0.4 & 0.2 & 5 & 52 \\
\hline 793 & 21 & 9 & 0.4 & 0.2 & 5 & 54 \\
\hline 794 & 23 & 9 & 0.4 & 0.2 & 4 & 72 \\
\hline 795 & 25 & 9 & 0.4 & 0.2 & 1 & 463 \\
\hline 796 & 17 & 10 & 0.4 & 0.2 & 5 & 58 \\
\hline 797 & 19 & 10 & 0.4 & 0.2 & 5 & 57 \\
\hline 798 & 21 & 10 & 0.4 & 0.2 & 5 & 59 \\
\hline 799 & 23 & 10 & 0.4 & 0.2 & 4 & 80 \\
\hline 800 & 25 & 10 & 0.4 & 0.2 & 1 & 515 \\
\hline 801 & 17 & 1 & 0.25 & 0.25 & 0 & 0 \\
\hline 802 & 19 & 1 & 0.25 & 0.25 & 0 & 0 \\
\hline 803 & 21 & 1 & 0.25 & 0.25 & 0 & 0 \\
\hline 804 & 23 & 1 & 0.25 & 0.25 & 0 & 0 \\
\hline 805 & 25 & 1 & 0.25 & 0.25 & 0 & 0 \\
\hline 806 & 17 & 2 & 0.25 & 0.25 & 200 & 77 \\
\hline 807 & 19 & 2 & 0.25 & 0.25 & 200 & 127 \\
\hline 808 & 21 & 2 & 0.25 & 0.25 & 97 & 200 \\
\hline 809 & 23 & 2 & 0.25 & 0.25 & 77 & 200 \\
\hline 810 & 25 & 2 & 0.25 & 0.25 & 70 & 200 \\
\hline 811 & 17 & 3 & 0.25 & 0.25 & 38 & 91 \\
\hline 812 & 19 & 3 & 0.25 & 0.25 & 37 & 90 \\
\hline 813 & 21 & 3 & 0.25 & 0.25 & 35 & 85 \\
\hline 814 & 23 & 3 & 0.25 & 0.25 & 34 & 83 \\
\hline 815 & 25 & 3 & 0.25 & 0.25 & 32 & 78 \\
\hline 816 & 17 & 4 & 0.25 & 0.25 & 19 & 67 \\
\hline 817 & 19 & 4 & 0.25 & 0.25 & 18 & 62 \\
\hline 818 & 21 & 4 & 0.25 & 0.25 & 18 & 63 \\
\hline 819 & 23 & 4 & 0.25 & 0.25 & 17 & 58 \\
\hline 820 & 25 & 4 & 0.25 & 0.25 & 17 & 58 \\
\hline 821 & 17 & 5 & 0.25 & 0.25 & 11 & 50 \\
\hline 822 & 19 & 5 & 0.25 & 0.25 & 11 & 50 \\
\hline 823 & 21 & 5 & 0.25 & 0.25 & 11 & 49 \\
\hline 824 & 23 & 5 & 0.25 & 0.25 & 11 & 48 \\
\hline 825 & 25 & 5 & 0.25 & 0.25 & 11 & 48 \\
\hline 826 & 17 & 6 & 0.25 & 0.25 & 8 & 45 \\
\hline 827 & 19 & 6 & 0.25 & 0.25 & 8 & 43 \\
\hline 828 & 21 & 6 & 0.25 & 0.25 & 8 & 42 \\
\hline 829 & 23 & 6 & 0.25 & 0.25 & 8 & 41 \\
\hline 830 & 25 & 6 & 0.25 & 0.25 & 8 & 40 \\
\hline 831 & 17 & 7 & 0.25 & 0.25 & 6 & 37 \\
\hline & & & & & & \\
\hline
\end{tabular}




\begin{tabular}{|l|l|l|l|l|l|l|}
\hline 832 & 19 & 7 & 0.25 & 0.25 & 7 & 45 \\
\hline 833 & 21 & 7 & 0.25 & 0.25 & 7 & 44 \\
\hline 834 & 23 & 7 & 0.25 & 0.25 & 7 & 42 \\
\hline 835 & 25 & 7 & 0.25 & 0.25 & 7 & 41 \\
\hline 836 & 17 & 8 & 0.25 & 0.25 & 6 & 45 \\
\hline 837 & 19 & 8 & 0.25 & 0.25 & 6 & 44 \\
\hline 838 & 21 & 8 & 0.25 & 0.25 & 6 & 42 \\
\hline 839 & 23 & 8 & 0.25 & 0.25 & 6 & 40 \\
\hline 840 & 25 & 8 & 0.25 & 0.25 & 6 & 39 \\
\hline 841 & 17 & 9 & 0.25 & 0.25 & 5 & 41 \\
\hline 842 & 19 & 9 & 0.25 & 0.25 & 6 & 51 \\
\hline 843 & 21 & 9 & 0.25 & 0.25 & 6 & 49 \\
\hline 844 & 23 & 9 & 0.25 & 0.25 & 6 & 47 \\
\hline 845 & 25 & 9 & 0.25 & 0.25 & 6 & 45 \\
\hline 846 & 17 & 10 & 0.25 & 0.25 & 5 & 47 \\
\hline 847 & 19 & 10 & 0.25 & 0.25 & 5 & 45 \\
\hline 848 & 21 & 10 & 0.25 & 0.25 & 5 & 43 \\
\hline 849 & 23 & 10 & 0.25 & 0.25 & 6 & 54 \\
\hline 850 & 25 & 10 & 0.25 & 0.25 & 6 & 52 \\
\hline 851 & 17 & 1 & 0.3 & 0.25 & 0 & 0 \\
\hline 852 & 19 & 1 & 0.3 & 0.25 & 0 & 0 \\
\hline 853 & 21 & 1 & 0.3 & 0.25 & 0 & 0 \\
\hline 854 & 23 & 1 & 0.3 & 0.25 & 0 & 0 \\
\hline 855 & 25 & 1 & 0.3 & 0.25 & 190 & 200 \\
\hline 856 & 17 & 2 & 0.3 & 0.25 & 62 & 200 \\
\hline 857 & 19 & 2 & 0.3 & 0.25 & 60 & 200 \\
\hline 858 & 21 & 2 & 0.3 & 0.25 & 58 & 200 \\
\hline 859 & 23 & 2 & 0.3 & 0.25 & 51 & 111 \\
\hline 860 & 25 & 2 & 0.3 & 0.25 & 49 & 107 \\
\hline 861 & 17 & 3 & 0.3 & 0.25 & 30 & 101 \\
\hline 862 & 19 & 3 & 0.3 & 0.25 & 29 & 98 \\
\hline 863 & 21 & 3 & 0.3 & 0.25 & 28 & 94 \\
\hline 864 & 23 & 3 & 0.3 & 0.25 & 27 & 90 \\
\hline 865 & 25 & 3 & 0.3 & 0.25 & 25 & 84 \\
\hline 866 & 17 & 4 & 0.3 & 0.25 & 15 & 69 \\
\hline 867 & 19 & 4 & 0.3 & 0.25 & 15 & 68 \\
\hline 868 & 21 & 4 & 0.3 & 0.25 & 14 & 62 \\
\hline 869 & 23 & 4 & 0.3 & 0.25 & 14 & 62 \\
\hline 870 & 25 & 4 & 0.3 & 0.25 & 13 & 57 \\
\hline 871 & 17 & 5 & 0.3 & 0.25 & 9 & 51 \\
\hline 872 & 19 & 5 & 0.3 & 0.25 & 9 & 49 \\
\hline 873 & 21 & 5 & 0.3 & 0.25 & 9 & 48 \\
\hline & & & & & & \\
\hline
\end{tabular}




\begin{tabular}{|l|l|l|l|l|l|l|}
\hline 874 & 23 & 5 & 0.3 & 0.25 & 9 & 48 \\
\hline 875 & 25 & 5 & 0.3 & 0.25 & 9 & 48 \\
\hline 876 & 17 & 6 & 0.3 & 0.25 & 7 & 46 \\
\hline 877 & 19 & 6 & 0.3 & 0.25 & 7 & 45 \\
\hline 878 & 21 & 6 & 0.3 & 0.25 & 7 & 44 \\
\hline 879 & 23 & 6 & 0.3 & 0.25 & 8 & 51 \\
\hline 880 & 25 & 6 & 0.3 & 0.25 & 8 & 50 \\
\hline 881 & 17 & 7 & 0.3 & 0.25 & 6 & 46 \\
\hline 882 & 19 & 7 & 0.3 & 0.25 & 6 & 44 \\
\hline 883 & 21 & 7 & 0.3 & 0.25 & 6 & 42 \\
\hline 884 & 23 & 7 & 0.3 & 0.25 & 7 & 51 \\
\hline 885 & 25 & 7 & 0.3 & 0.25 & 7 & 50 \\
\hline 886 & 17 & 8 & 0.3 & 0.25 & 6 & 54 \\
\hline 887 & 19 & 8 & 0.3 & 0.25 & 6 & 51 \\
\hline 888 & 21 & 8 & 0.3 & 0.25 & 6 & 50 \\
\hline 889 & 23 & 8 & 0.3 & 0.25 & 6 & 48 \\
\hline 890 & 25 & 8 & 0.3 & 0.25 & 6 & 47 \\
\hline 891 & 17 & 9 & 0.3 & 0.25 & 5 & 48 \\
\hline 892 & 19 & 9 & 0.3 & 0.25 & 5 & 46 \\
\hline 893 & 21 & 9 & 0.3 & 0.25 & 6 & 57 \\
\hline 894 & 23 & 9 & 0.3 & 0.25 & 6 & 55 \\
\hline 895 & 25 & 9 & 0.3 & 0.25 & 6 & 54 \\
\hline 896 & 17 & 10 & 0.3 & 0.25 & 5 & 55 \\
\hline 897 & 19 & 10 & 0.3 & 0.25 & 5 & 52 \\
\hline 898 & 21 & 10 & 0.3 & 0.25 & 5 & 50 \\
\hline 899 & 23 & 10 & 0.3 & 0.25 & 5 & 48 \\
\hline 900 & 25 & 10 & 0.3 & 0.25 & 5 & 48 \\
\hline 901 & 17 & 1 & 0.35 & 0.25 & 0 & 0 \\
\hline 902 & 19 & 1 & 0.35 & 0.25 & 0 & 0 \\
\hline 903 & 21 & 1 & 0.35 & 0.25 & 109 & 200 \\
\hline 904 & 23 & 1 & 0.35 & 0.25 & 109 & 200 \\
\hline 905 & 25 & 1 & 0.35 & 0.25 & 110 & 200 \\
\hline 906 & 17 & 2 & 0.35 & 0.25 & 47 & 145 \\
\hline 907 & 19 & 2 & 0.35 & 0.25 & 45 & 138 \\
\hline 908 & 21 & 2 & 0.35 & 0.25 & 43 & 131 \\
\hline 909 & 23 & 2 & 0.35 & 0.25 & 41 & 126 \\
\hline 910 & 25 & 2 & 0.35 & 0.25 & 39 & 123 \\
\hline 911 & 17 & 3 & 0.35 & 0.25 & 24 & 111 \\
\hline 912 & 19 & 3 & 0.35 & 0.25 & 23 & 104 \\
\hline 913 & 21 & 3 & 0.35 & 0.25 & 22 & 99 \\
\hline 914 & 23 & 3 & 0.35 & 0.25 & 21 & 94 \\
\hline 915 & 25 & 3 & 0.35 & 0.25 & 19 & 89 \\
\hline & & & & & & \\
\hline
\end{tabular}




\begin{tabular}{|c|c|c|c|c|c|c|}
\hline 916 & 17 & 4 & 0.35 & 0.25 & 12 & 71 \\
\hline 917 & 19 & 4 & 0.35 & 0.25 & 12 & 70 \\
\hline 918 & 21 & 4 & 0.35 & 0.25 & 12 & 68 \\
\hline 919 & 23 & 4 & 0.35 & 0.25 & 11 & 62 \\
\hline 920 & 25 & 4 & 0.35 & 0.25 & 10 & 60 \\
\hline 921 & 17 & 5 & 0.35 & 0.25 & 8 & 56 \\
\hline 922 & 19 & 5 & 0.35 & 0.25 & 8 & 54 \\
\hline 923 & 21 & $\overline{5}$ & 0.35 & 0.25 & 8 & 53 \\
\hline 924 & 23 & 5 & 0.35 & 0.25 & 8 & 53 \\
\hline 925 & 25 & 5 & 0.35 & 0.25 & 7 & 49 \\
\hline 926 & 17 & $\overline{6}$ & 0.35 & 0.25 & 7 & 57 \\
\hline 927 & 19 & 6 & 0.35 & 0.25 & 7 & 55 \\
\hline 928 & 21 & 6 & 0.35 & 0.25 & 7 & 54 \\
\hline 929 & 23 & 6 & 0.35 & 0.25 & 7 & 54 \\
\hline 930 & 25 & 6 & 0.35 & 0.25 & 6 & 48 \\
\hline 931 & 17 & 7 & 0.35 & 0.25 & 6 & 55 \\
\hline 932 & 19 & 7 & 0.35 & 0.25 & 6 & 53 \\
\hline 933 & 21 & 7 & 0.35 & 0.25 & 6 & 51 \\
\hline 934 & 23 & 7 & 0.35 & 0.25 & 6 & 51 \\
\hline 935 & 25 & 7 & 0.35 & 0.25 & 6 & 56 \\
\hline 936 & 17 & 8 & 0.35 & 0.25 & 5 & 50 \\
\hline 937 & 19 & 8 & 0.35 & 0.25 & 6 & 61 \\
\hline 938 & 21 & 8 & 0.35 & 0.25 & 6 & 59 \\
\hline 939 & 23 & 8 & 0.35 & 0.25 & 6 & 58 \\
\hline 940 & 25 & 8 & 0.35 & 0.25 & 5 & 51 \\
\hline 941 & 17 & 9 & 0.35 & 0.25 & 5 & 57 \\
\hline 942 & 19 & 9 & 0.35 & 0.25 & 5 & 54 \\
\hline 943 & 21 & 9 & 0.35 & 0.25 & 5 & 52 \\
\hline 944 & 23 & 9 & 0.35 & 0.25 & 5 & 52 \\
\hline 945 & 25 & 9 & 0.35 & 0.25 & 5 & 56 \\
\hline 946 & 17 & 10 & 0.35 & 0.25 & 5 & 63 \\
\hline 947 & 19 & 10 & 0.35 & 0.25 & 5 & 61 \\
\hline 948 & 21 & 10 & 0.35 & 0.25 & 5 & 58 \\
\hline 949 & 23 & 10 & 0.35 & 0.25 & 5 & 58 \\
\hline 950 & 25 & 10 & 0.35 & 0.25 & 5 & 62 \\
\hline 951 & 17 & 1 & 0.4 & 0.25 & 74 & 200 \\
\hline 952 & 19 & 1 & 0.4 & 0.25 & 77 & 200 \\
\hline 953 & 21 & 1 & 0.4 & 0.25 & 76 & 190 \\
\hline 954 & 23 & 1 & 0.4 & 0.25 & 67 & 173 \\
\hline 955 & 25 & 1 & 0.4 & 0.25 & 5 & 49 \\
\hline 956 & 17 & 2 & 0.4 & 0.25 & 39 & 170 \\
\hline 957 & 19 & 2 & 0.4 & 0.25 & 37 & 159 \\
\hline
\end{tabular}




\begin{tabular}{|c|c|c|c|c|c|c|}
\hline 958 & 21 & 2 & 0.4 & 0.25 & 36 & 153 \\
\hline 959 & 23 & 2 & 0.4 & 0.25 & 33 & 148 \\
\hline 960 & 25 & 2 & 0.4 & 0.25 & 4 & 101 \\
\hline 961 & 17 & 3 & 0.4 & 0.25 & 19 & 117 \\
\hline 962 & 19 & 3 & 0.4 & 0.25 & 18 & 109 \\
\hline 963 & 21 & 3 & 0.4 & 0.25 & 17 & 102 \\
\hline 964 & 23 & 3 & 0.4 & 0.25 & 14 & 91 \\
\hline 965 & 25 & 3 & 0.4 & 0.25 & 4 & 153 \\
\hline 966 & 17 & 4 & 0.4 & 0.25 & 10 & 75 \\
\hline 967 & 19 & 4 & 0.4 & 0.25 & 10 & 73 \\
\hline 968 & 21 & 4 & 0.4 & 0.25 & 10 & 74 \\
\hline 969 & 23 & 4 & 0.4 & 0.25 & 8 & 65 \\
\hline 970 & 25 & 4 & 0.4 & 0.25 & 1 & 204 \\
\hline 971 & 17 & 5 & 0.4 & 0.25 & 8 & 71 \\
\hline 972 & 19 & 5 & 0.4 & 0.25 & 8 & 68 \\
\hline 973 & 21 & 5 & 0.4 & 0.25 & 7 & 59 \\
\hline 974 & 23 & 5 & 0.4 & 0.25 & 6 & 58 \\
\hline 975 & 25 & 5 & 0.4 & 0.25 & 1 & 256 \\
\hline 976 & 17 & 6 & 0.4 & 0.25 & 6 & 59 \\
\hline 977 & 19 & 6 & 0.4 & 0.25 & 6 & 56 \\
\hline 978 & 21 & 6 & 0.4 & 0.25 & 6 & 57 \\
\hline 979 & 23 & 6 & 0.4 & 0.25 & 5 & 54 \\
\hline 980 & 25 & 6 & 0.4 & 0.25 & 1 & 308 \\
\hline 981 & 17 & 7 & 0.4 & 0.25 & 6 & 67 \\
\hline 982 & 19 & 7 & 0.4 & 0.25 & 6 & 64 \\
\hline 983 & 21 & 7 & 0.4 & 0.25 & 6 & 65 \\
\hline 984 & 23 & 7 & 0.4 & 0.25 & 5 & 61 \\
\hline 985 & 25 & 7 & 0.4 & 0.25 & 1 & 360 \\
\hline 986 & 17 & 8 & 0.4 & 0.25 & 5 & 60 \\
\hline 987 & 19 & 8 & 0.4 & 0.25 & 5 & 58 \\
\hline 988 & 21 & 8 & 0.4 & 0.25 & 5 & 58 \\
\hline 989 & 23 & 8 & 0.4 & 0.25 & 5 & 68 \\
\hline 990 & 25 & 8 & 0.4 & 0.25 & 1 & 411 \\
\hline 991 & 17 & 9 & 0.4 & 0.25 & 5 & 67 \\
\hline 992 & 19 & 9 & 0.4 & 0.25 & 5 & 65 \\
\hline 993 & 21 & 9 & 0.4 & 0.25 & 5 & 65 \\
\hline 994 & 23 & 9 & 0.4 & 0.25 & 4 & 72 \\
\hline 995 & 25 & 9 & 0.4 & 0.25 & 1 & 463 \\
\hline 996 & 17 & 10 & 0.4 & 0.25 & 5 & 75 \\
\hline 997 & 19 & 10 & 0.4 & 0.25 & 5 & 71 \\
\hline 998 & 21 & 10 & 0.4 & 0.25 & 5 & 72 \\
\hline 999 & 23 & 10 & 0.4 & 0.25 & 4 & 80 \\
\hline & & & & & & \\
\hline
\end{tabular}




\begin{tabular}{|c|c|c|c|c|c|c|}
\hline 1000 & 25 & 10 & 0.4 & 0.25 & 1 & 515 \\
\hline 1001 & 17 & 1 & 0.25 & 0.3 & 0 & 0 \\
\hline 1002 & 19 & 1 & 0.25 & 0.3 & 0 & 0 \\
\hline 1003 & 21 & 1 & 0.25 & 0.3 & 0 & 0 \\
\hline 1004 & 23 & 1 & 0.25 & 0.3 & 0 & 0 \\
\hline 1005 & 25 & 1 & 0.25 & 0.3 & 0 & 0 \\
\hline 1006 & 17 & 2 & 0.25 & 0.3 & 200 & 123 \\
\hline 1007 & 19 & 2 & 0.25 & 0.3 & 200 & 186 \\
\hline 1008 & 21 & 2 & 0.25 & 0.3 & 96 & 200 \\
\hline 1009 & 23 & 2 & 0.25 & 0.3 & 75 & 200 \\
\hline 1010 & 25 & $\overline{2}$ & 0.25 & 0.3 & 68 & 200 \\
\hline 1011 & 17 & 3 & 0.25 & 0.3 & 39 & 122 \\
\hline 1012 & 19 & 3 & 0.25 & 0.3 & 37 & 115 \\
\hline 1013 & 21 & 3 & 0.25 & 0.3 & 35 & 108 \\
\hline 1014 & 23 & 3 & 0.25 & 0.3 & 34 & 105 \\
\hline 1015 & 25 & 3 & 0.25 & 0.3 & 32 & 98 \\
\hline 1016 & 17 & 4 & 0.25 & 0.3 & 19 & 85 \\
\hline 1017 & 19 & 4 & 0.25 & 0.3 & 18 & 79 \\
\hline 1018 & 21 & 4 & 0.25 & 0.3 & 18 & 78 \\
\hline 1019 & 23 & 4 & 0.25 & 0.3 & 17 & 73 \\
\hline 1020 & 25 & 4 & 0.25 & 0.3 & 17 & 72 \\
\hline 1021 & 17 & 5 & 0.25 & 0.3 & 11 & 64 \\
\hline 1022 & 19 & 5 & 0.25 & 0.3 & 11 & 62 \\
\hline 1023 & 21 & 5 & 0.25 & 0.3 & 11 & 61 \\
\hline 1024 & 23 & 5 & 0.25 & 0.3 & 11 & 60 \\
\hline 1025 & 25 & 5 & 0.25 & 0.3 & 11 & 59 \\
\hline 1026 & 17 & 6 & 0.25 & 0.3 & 8 & 56 \\
\hline 1027 & 19 & 6 & 0.25 & 0.3 & 8 & 54 \\
\hline 1028 & 21 & 6 & 0.25 & 0.3 & 8 & 52 \\
\hline 1029 & 23 & 6 & 0.25 & 0.3 & 8 & 51 \\
\hline 1030 & 25 & 6 & 0.25 & 0.3 & 8 & 49 \\
\hline 1031 & 17 & 7 & 0.25 & 0.3 & 6 & 47 \\
\hline 1032 & 19 & 7 & 0.25 & 0.3 & 7 & 56 \\
\hline 1033 & 21 & 7 & 0.25 & 0.3 & 7 & 54 \\
\hline 1034 & 23 & 7 & 0.25 & 0.3 & 7 & 52 \\
\hline 1035 & 25 & 7 & 0.25 & 0.3 & 7 & 50 \\
\hline 1036 & 17 & 8 & 0.25 & 0.3 & 6 & 57 \\
\hline 1037 & 19 & 8 & 0.25 & 0.3 & 6 & 54 \\
\hline 1038 & 21 & 8 & 0.25 & 0.3 & 6 & 52 \\
\hline 1039 & 23 & 8 & 0.25 & 0.3 & 6 & 50 \\
\hline 1040 & 25 & 8 & 0.25 & 0.3 & 7 & 60 \\
\hline 1041 & 17 & 9 & 0.25 & 0.3 & 5 & 51 \\
\hline
\end{tabular}




\begin{tabular}{|c|c|c|c|c|c|c|}
\hline 1042 & 19 & 9 & 0.25 & 0.3 & 6 & 64 \\
\hline 1043 & 21 & 9 & 0.25 & 0.3 & 6 & 61 \\
\hline 1044 & 23 & 9 & 0.25 & 0.3 & 6 & 58 \\
\hline 1045 & 25 & 9 & 0.25 & 0.3 & 6 & 55 \\
\hline 1046 & 17 & 10 & 0.25 & 0.3 & 5 & 59 \\
\hline 1047 & 19 & 10 & 0.25 & 0.3 & 5 & 56 \\
\hline 1048 & 21 & 10 & 0.25 & 0.3 & 5 & 53 \\
\hline 1049 & 23 & 10 & 0.25 & 0.3 & 6 & 66 \\
\hline 1050 & 25 & 10 & 0.25 & 0.3 & 6 & 63 \\
\hline 1051 & 17 & 1 & 0.3 & 0.3 & 0 & 0 \\
\hline 1052 & 19 & 1 & 0.3 & 0.3 & 0 & 0 \\
\hline 1053 & 21 & 1 & 0.3 & 0.3 & 0 & 0 \\
\hline 1054 & 23 & 1 & 0.3 & 0.3 & 0 & 0 \\
\hline 1055 & 25 & 1 & 0.3 & 0.3 & 132 & 200 \\
\hline 1056 & 17 & 2 & 0.3 & 0.3 & 60 & 200 \\
\hline 1057 & 19 & 2 & 0.3 & 0.3 & 58 & 200 \\
\hline 1058 & 21 & 2 & 0.3 & 0.3 & 56 & 200 \\
\hline 1059 & 23 & 2 & 0.3 & 0.3 & 51 & 143 \\
\hline 1060 & 25 & 2 & 0.3 & 0.3 & 49 & 136 \\
\hline 1061 & 17 & 3 & 0.3 & 0.3 & 30 & 130 \\
\hline 1062 & 19 & 3 & 0.3 & 0.3 & 29 & 125 \\
\hline 1063 & 21 & 3 & 0.3 & 0.3 & 28 & 119 \\
\hline 1064 & 23 & 3 & 0.3 & 0.3 & 27 & 114 \\
\hline 1065 & 25 & 3 & 0.3 & 0.3 & 26 & 109 \\
\hline 1066 & 17 & 4 & 0.3 & 0.3 & 15 & 88 \\
\hline 1067 & 19 & 4 & 0.3 & 0.3 & 15 & 87 \\
\hline 1068 & 21 & 4 & 0.3 & 0.3 & 14 & 78 \\
\hline 1069 & 23 & 4 & 0.3 & 0.3 & 14 & 77 \\
\hline 1070 & 25 & 4 & 0.3 & 0.3 & 14 & 77 \\
\hline 1071 & 17 & 5 & 0.3 & 0.3 & 9 & 64 \\
\hline 1072 & 19 & 5 & 0.3 & 0.3 & 9 & 62 \\
\hline 1073 & 21 & 5 & 0.3 & 0.3 & 9 & 61 \\
\hline 1074 & 23 & 5 & 0.3 & 0.3 & 9 & 59 \\
\hline 1075 & 25 & 5 & 0.3 & 0.3 & 9 & 58 \\
\hline 1076 & 17 & 6 & 0.3 & 0.3 & 7 & 59 \\
\hline 1077 & 19 & 6 & 0.3 & 0.3 & 7 & 56 \\
\hline 1078 & 21 & 6 & 0.3 & 0.3 & 7 & 54 \\
\hline 1079 & 23 & 6 & 0.3 & 0.3 & 8 & 63 \\
\hline 1080 & 25 & 6 & 0.3 & 0.3 & 8 & 61 \\
\hline 1081 & 17 & 7 & 0.3 & 0.3 & 6 & 58 \\
\hline 1082 & 19 & 7 & 0.3 & 0.3 & 6 & 55 \\
\hline 1083 & 21 & 7 & 0.3 & 0.3 & 7 & 65 \\
\hline
\end{tabular}




\begin{tabular}{|c|c|c|c|c|c|c|}
\hline 1084 & 23 & 7 & 0.3 & 0.3 & 7 & 63 \\
\hline 1085 & 25 & 7 & 0.3 & 0.3 & 7 & 61 \\
\hline 1086 & 17 & 8 & 0.3 & 0.3 & 6 & 68 \\
\hline 1087 & 19 & 8 & 0.3 & 0.3 & 6 & 65 \\
\hline 1088 & 21 & 8 & 0.3 & 0.3 & 6 & 62 \\
\hline 1089 & 23 & 8 & 0.3 & 0.3 & 6 & 59 \\
\hline 1090 & 25 & 8 & 0.3 & 0.3 & 6 & 58 \\
\hline 1091 & 17 & 9 & 0.3 & 0.3 & 5 & 61 \\
\hline 1092 & 19 & 9 & 0.3 & 0.3 & 5 & 57 \\
\hline 1093 & 21 & 9 & 0.3 & 0.3 & 6 & 71 \\
\hline 1094 & 23 & 9 & 0.3 & 0.3 & 6 & 67 \\
\hline 1095 & 25 & 9 & 0.3 & 0.3 & 6 & 66 \\
\hline 1096 & 17 & 10 & 0.3 & 0.3 & 5 & 69 \\
\hline 1097 & 19 & 10 & 0.3 & 0.3 & 5 & 65 \\
\hline 1098 & 21 & 10 & 0.3 & 0.3 & 5 & 62 \\
\hline 1099 & 23 & 10 & 0.3 & 0.3 & 5 & 59 \\
\hline 1100 & 25 & 10 & 0.3 & 0.3 & 6 & 74 \\
\hline 1101 & 17 & 1 & 0.35 & 0.3 & 0 & 0 \\
\hline 1102 & 19 & 1 & 0.35 & 0.3 & 0 & 0 \\
\hline 1103 & 21 & 1 & 0.35 & 0.3 & 83 & 200 \\
\hline 1104 & 23 & 1 & 0.35 & 0.3 & 83 & 200 \\
\hline 1105 & 25 & 1 & 0.35 & 0.3 & 84 & 200 \\
\hline 1106 & 17 & 2 & 0.35 & 0.3 & 47 & 190 \\
\hline 1107 & 19 & 2 & 0.35 & 0.3 & 45 & 179 \\
\hline 1108 & 21 & 2 & 0.35 & 0.3 & 43 & 169 \\
\hline 1109 & 23 & 2 & 0.35 & 0.3 & 41 & 161 \\
\hline 1110 & 25 & 2 & 0.35 & 0.3 & 40 & 158 \\
\hline 1111 & 17 & 3 & 0.35 & 0.3 & 24 & 143 \\
\hline 1112 & 19 & 3 & 0.35 & 0.3 & 23 & 134 \\
\hline 1113 & 21 & 3 & 0.35 & 0.3 & 22 & 126 \\
\hline 1114 & 23 & 3 & 0.35 & 0.3 & 21 & 118 \\
\hline 1115 & 25 & 3 & 0.35 & 0.3 & 20 & 115 \\
\hline 1116 & 17 & 4 & 0.35 & 0.3 & 12 & 92 \\
\hline 1117 & 19 & 4 & 0.35 & 0.3 & 12 & 89 \\
\hline 1118 & 21 & 4 & 0.35 & 0.3 & 12 & 87 \\
\hline 1119 & 23 & 4 & 0.35 & 0.3 & 12 & 85 \\
\hline 1120 & 25 & 4 & 0.35 & 0.3 & 11 & 80 \\
\hline 1121 & 17 & 5 & 0.35 & 0.3 & 8 & 72 \\
\hline 1122 & 19 & 5 & 0.35 & 0.3 & 8 & 69 \\
\hline 1123 & 21 & 5 & 0.35 & 0.3 & 9 & 77 \\
\hline 1124 & 23 & 5 & 0.35 & 0.3 & 8 & 66 \\
\hline 1125 & 25 & 5 & 0.35 & 0.3 & 8 & 68 \\
\hline
\end{tabular}




\begin{tabular}{|c|c|c|c|c|c|c|}
\hline 1126 & 17 & 6 & 0.35 & 0.3 & 7 & 74 \\
\hline 1127 & 19 & 6 & 0.35 & 0.3 & 7 & 70 \\
\hline 1128 & 21 & 6 & 0.35 & 0.3 & 7 & 68 \\
\hline 1129 & 23 & 6 & 0.35 & 0.3 & 7 & 66 \\
\hline 1130 & 25 & 6 & 0.35 & 0.3 & 7 & 69 \\
\hline 1131 & 17 & 7 & 0.35 & 0.3 & 6 & 71 \\
\hline 1132 & 19 & 7 & 0.35 & 0.3 & 6 & 67 \\
\hline 1133 & 21 & 7 & 0.35 & 0.3 & 6 & 64 \\
\hline 1134 & 23 & 7 & 0.35 & 0.3 & 6 & 63 \\
\hline 1135 & 25 & 7 & 0.35 & 0.3 & 6 & 66 \\
\hline 1136 & 17 & 8 & 0.35 & 0.3 & 5 & 64 \\
\hline 1137 & 19 & 8 & 0.35 & 0.3 & 6 & 77 \\
\hline 1138 & 21 & 8 & 0.35 & 0.3 & 6 & 74 \\
\hline 1139 & 23 & 8 & 0.35 & 0.3 & 6 & 72 \\
\hline 1140 & 25 & 8 & 0.35 & 0.3 & 5 & 60 \\
\hline 1141 & 17 & 9 & 0.35 & 0.3 & 5 & 72 \\
\hline 1142 & 19 & 9 & 0.35 & 0.3 & 5 & 68 \\
\hline 1143 & 21 & 9 & 0.35 & 0.3 & 5 & 65 \\
\hline 1144 & 23 & 9 & 0.35 & 0.3 & 5 & 64 \\
\hline 1145 & 25 & 9 & 0.35 & 0.3 & 5 & 67 \\
\hline 1146 & 17 & 10 & 0.35 & 0.3 & 5 & 81 \\
\hline 1147 & 19 & 10 & 0.35 & 0.3 & 5 & 77 \\
\hline 1148 & 21 & 10 & 0.35 & 0.3 & 5 & 73 \\
\hline 1149 & 23 & 10 & 0.35 & 0.3 & 5 & 71 \\
\hline 1150 & 25 & 10 & 0.35 & 0.3 & 5 & 74 \\
\hline 1151 & 17 & 1 & 0.4 & 0.3 & 51 & 200 \\
\hline 1152 & 19 & 1 & 0.4 & 0.3 & 52 & 200 \\
\hline 1153 & 21 & 1 & 0.4 & 0.3 & 54 & 200 \\
\hline 1154 & 23 & 1 & 0.4 & 0.3 & 56 & 200 \\
\hline 1155 & 25 & 1 & 0.4 & 0.3 & 35 & 200 \\
\hline 1156 & 17 & 2 & 0.4 & 0.3 & 34 & 200 \\
\hline 1157 & 19 & 2 & 0.4 & 0.3 & 35 & 200 \\
\hline 1158 & 21 & 2 & 0.4 & 0.3 & 36 & 199 \\
\hline 1159 & 23 & 2 & 0.4 & 0.3 & 33 & 187 \\
\hline 1160 & 25 & 2 & 0.4 & 0.3 & 5 & 101 \\
\hline 1161 & 17 & 3 & 0.4 & 0.3 & 19 & 154 \\
\hline 1162 & 19 & 3 & 0.4 & 0.3 & 18 & 141 \\
\hline 1163 & 21 & 3 & 0.4 & 0.3 & 17 & 130 \\
\hline 1164 & 23 & 3 & 0.4 & 0.3 & 15 & 120 \\
\hline 1165 & 25 & 3 & 0.4 & 0.3 & 4 & 153 \\
\hline 1166 & 17 & 4 & 0.4 & 0.3 & 11 & 110 \\
\hline 1167 & 19 & 4 & 0.4 & 0.3 & 10 & 95 \\
\hline
\end{tabular}




\begin{tabular}{|c|c|c|c|c|c|c|}
\hline 1168 & 21 & 4 & 0.4 & 0.3 & 10 & 93 \\
\hline 1169 & 23 & 4 & 0.4 & 0.3 & 9 & 89 \\
\hline 1170 & 25 & 4 & 0.4 & 0.3 & 1 & 204 \\
\hline 1171 & 17 & 5 & 0.4 & 0.3 & 8 & 92 \\
\hline 1172 & 19 & 5 & 0.4 & 0.3 & 8 & 88 \\
\hline 1173 & 21 & 5 & 0.4 & 0.3 & 8 & 86 \\
\hline 1174 & 23 & 5 & 0.4 & 0.3 & 7 & 81 \\
\hline 1175 & 25 & 5 & 0.4 & 0.3 & 1 & 256 \\
\hline 1176 & 17 & 6 & 0.4 & 0.3 & 6 & 76 \\
\hline 1177 & 19 & 6 & 0.4 & 0.3 & 7 & 88 \\
\hline 1178 & 21 & 6 & 0.4 & 0.3 & 6 & 71 \\
\hline 1179 & 23 & 6 & 0.4 & 0.3 & 6 & 79 \\
\hline 1180 & 25 & 6 & 0.4 & 0.3 & 1 & 308 \\
\hline 1181 & 17 & 7 & 0.4 & 0.3 & 6 & 87 \\
\hline 1182 & 19 & 7 & 0.4 & 0.3 & 6 & 83 \\
\hline 1183 & 21 & 7 & 0.4 & 0.3 & 6 & 81 \\
\hline 1184 & 23 & 7 & 0.4 & 0.3 & 5 & 72 \\
\hline 1185 & 25 & 7 & 0.4 & 0.3 & 1 & 360 \\
\hline 1186 & 17 & 8 & 0.4 & 0.3 & 5 & 78 \\
\hline 1187 & 19 & 8 & 0.4 & 0.3 & 5 & 74 \\
\hline 1188 & 21 & 8 & 0.4 & 0.3 & 5 & 73 \\
\hline 1189 & 23 & 8 & 0.4 & 0.3 & 5 & 80 \\
\hline 1190 & 25 & 8 & 0.4 & 0.3 & 1 & 411 \\
\hline 1191 & 17 & 9 & 0.4 & 0.3 & 5 & 88 \\
\hline 1192 & 19 & 9 & 0.4 & 0.3 & 5 & 83 \\
\hline 1193 & 21 & 9 & 0.4 & 0.3 & 5 & 81 \\
\hline 1194 & 23 & 9 & 0.4 & 0.3 & 5 & 89 \\
\hline 1195 & 25 & 9 & 0.4 & 0.3 & 1 & 463 \\
\hline 1196 & 17 & 10 & 0.4 & 0.3 & 5 & 97 \\
\hline 1197 & 19 & 10 & 0.4 & 0.3 & 5 & 91 \\
\hline 1198 & 21 & 10 & 0.4 & 0.3 & 5 & 89 \\
\hline 1199 & 23 & 10 & 0.4 & 0.3 & 5 & 97 \\
\hline 1200 & 25 & 10 & 0.4 & 0.3 & 1 & 515 \\
\hline 1201 & 17 & 1 & 0.25 & 0.35 & 0 & 0 \\
\hline 1202 & 19 & 1 & 0.25 & 0.35 & 0 & 0 \\
\hline 1203 & 21 & 1 & 0.25 & 0.35 & 0 & 0 \\
\hline 1204 & 23 & 1 & 0.25 & 0.35 & 0 & 0 \\
\hline 1205 & 25 & 1 & 0.25 & 0.35 & 0 & 0 \\
\hline 1206 & 17 & 2 & 0.25 & 0.35 & 200 & 191 \\
\hline 1207 & 19 & 2 & 0.25 & 0.35 & 101 & 200 \\
\hline 1208 & 21 & 2 & 0.25 & 0.35 & 87 & 200 \\
\hline 1209 & 23 & 2 & 0.25 & 0.35 & 73 & 200 \\
\hline
\end{tabular}




\begin{tabular}{|c|c|c|c|c|c|c|}
\hline 1210 & 25 & 2 & 0.25 & 0.35 & 66 & 200 \\
\hline 1211 & 17 & 3 & 0.25 & 0.35 & 39 & 158 \\
\hline 1212 & 19 & 3 & 0.25 & 0.35 & 37 & 147 \\
\hline 1213 & 21 & 3 & 0.25 & 0.35 & 35 & 137 \\
\hline 1214 & 23 & 3 & 0.25 & 0.35 & 34 & 133 \\
\hline 1215 & 25 & 3 & 0.25 & 0.35 & 32 & 123 \\
\hline 1216 & 17 & 4 & 0.25 & 0.35 & 19 & 108 \\
\hline 1217 & 19 & 4 & 0.25 & 0.35 & 18 & 100 \\
\hline 1218 & 21 & 4 & 0.25 & 0.35 & 18 & 99 \\
\hline 1219 & 23 & 4 & 0.25 & 0.35 & 17 & 91 \\
\hline 1220 & 25 & 4 & 0.25 & 0.35 & 17 & 90 \\
\hline 1221 & 17 & 5 & 0.25 & 0.35 & 11 & 80 \\
\hline 1222 & 19 & 5 & 0.25 & 0.35 & 11 & 78 \\
\hline 1223 & 21 & 5 & 0.25 & 0.35 & 11 & 76 \\
\hline 1224 & 23 & 5 & 0.25 & 0.35 & 11 & 74 \\
\hline 1225 & 25 & 5 & 0.25 & 0.35 & 11 & 73 \\
\hline 1226 & 17 & 6 & 0.25 & 0.35 & 8 & 71 \\
\hline 1227 & 19 & 6 & 0.25 & 0.35 & 8 & 68 \\
\hline 1228 & 21 & 6 & 0.25 & 0.35 & 8 & 65 \\
\hline 1229 & 23 & 6 & 0.25 & 0.35 & 8 & 63 \\
\hline 1230 & 25 & 6 & 0.25 & 0.35 & 8 & 61 \\
\hline 1231 & 17 & 7 & 0.25 & 0.35 & 6 & 59 \\
\hline 1232 & 19 & 7 & 0.25 & 0.35 & 7 & 71 \\
\hline 1233 & 21 & 7 & 0.25 & 0.35 & 7 & 67 \\
\hline 1234 & 23 & 7 & 0.25 & 0.35 & 7 & 64 \\
\hline 1235 & 25 & 7 & 0.25 & 0.35 & 7 & 62 \\
\hline 1236 & 17 & 8 & 0.25 & 0.35 & 6 & 71 \\
\hline 1237 & 19 & 8 & 0.25 & 0.35 & 6 & 68 \\
\hline 1238 & 21 & 8 & 0.25 & 0.35 & 6 & 64 \\
\hline 1239 & 23 & 8 & 0.25 & 0.35 & 6 & 61 \\
\hline 1240 & 25 & 8 & 0.25 & 0.35 & 7 & 74 \\
\hline 1241 & 17 & 9 & 0.25 & 0.35 & 5 & 64 \\
\hline 1242 & 19 & 9 & 0.25 & 0.35 & 6 & 80 \\
\hline 1243 & 21 & 9 & 0.25 & 0.35 & 6 & 75 \\
\hline 1244 & 23 & 9 & 0.25 & 0.35 & 6 & 71 \\
\hline 1245 & 25 & 9 & 0.25 & 0.35 & 6 & 68 \\
\hline 1246 & 17 & 10 & 0.25 & 0.35 & 5 & 73 \\
\hline 1247 & 19 & 10 & 0.25 & 0.35 & 5 & 69 \\
\hline 1248 & 21 & 10 & 0.25 & 0.35 & 5 & 66 \\
\hline 1249 & 23 & 10 & 0.25 & 0.35 & 6 & 82 \\
\hline 1250 & 25 & 10 & 0.25 & 0.35 & 6 & 78 \\
\hline 1251 & 17 & 1 & 0.3 & 0.35 & 0 & 0 \\
\hline
\end{tabular}




\begin{tabular}{|c|c|c|c|c|c|c|}
\hline 1252 & 19 & 1 & 0.3 & 0.35 & 0 & 0 \\
\hline 1253 & 21 & 1 & 0.3 & 0.35 & 0 & 0 \\
\hline 1254 & 23 & 1 & 0.3 & 0.35 & 0 & 0 \\
\hline 1255 & 25 & 1 & 0.3 & 0.35 & 99 & 200 \\
\hline 1256 & 17 & 2 & 0.3 & 0.35 & 57 & 200 \\
\hline 1257 & 19 & 2 & 0.3 & 0.35 & 55 & 200 \\
\hline 1258 & 21 & 2 & 0.3 & 0.35 & 54 & 200 \\
\hline 1259 & 23 & 2 & 0.3 & 0.35 & 51 & 184 \\
\hline 1260 & 25 & 2 & 0.3 & 0.35 & 49 & 174 \\
\hline 1261 & 17 & 3 & 0.3 & 0.35 & 30 & 168 \\
\hline 1262 & 19 & 3 & 0.3 & 0.35 & 29 & 160 \\
\hline 1263 & 21 & 3 & 0.3 & 0.35 & 28 & 152 \\
\hline 1264 & 23 & 3 & 0.3 & 0.35 & 27 & 144 \\
\hline 1265 & 25 & 3 & 0.3 & 0.35 & 26 & 136 \\
\hline 1266 & 17 & 4 & 0.3 & 0.35 & 15 & 113 \\
\hline 1267 & 19 & 4 & 0.3 & 0.35 & 15 & 111 \\
\hline 1268 & 21 & 4 & 0.3 & 0.35 & 14 & 99 \\
\hline 1269 & 23 & 4 & 0.3 & 0.35 & 14 & 97 \\
\hline 1270 & 25 & 4 & 0.3 & 0.35 & 14 & 95 \\
\hline 1271 & 17 & 5 & 0.3 & 0.35 & 9 & 83 \\
\hline 1272 & 19 & 5 & 0.3 & 0.35 & 9 & 80 \\
\hline 1273 & 21 & 5 & 0.3 & 0.35 & 9 & 77 \\
\hline 1274 & 23 & 5 & 0.3 & 0.35 & 10 & 84 \\
\hline 1275 & 25 & 5 & 0.3 & 0.35 & 10 & 82 \\
\hline 1276 & 17 & 6 & 0.3 & 0.35 & 7 & 75 \\
\hline 1277 & 19 & 6 & 0.3 & 0.35 & 7 & 72 \\
\hline 1278 & 21 & 6 & 0.3 & 0.35 & 8 & 82 \\
\hline 1279 & 23 & 6 & 0.3 & 0.35 & 8 & 78 \\
\hline 1280 & 25 & 6 & 0.3 & 0.35 & 8 & 76 \\
\hline 1281 & 17 & 7 & 0.3 & 0.35 & 6 & 74 \\
\hline 1282 & 19 & 7 & 0.3 & 0.35 & 6 & 70 \\
\hline 1283 & 21 & 7 & 0.3 & 0.35 & 7 & 82 \\
\hline 1284 & 23 & 7 & 0.3 & 0.35 & 7 & 78 \\
\hline 1285 & 25 & 7 & 0.3 & 0.35 & 7 & 75 \\
\hline 1286 & 17 & 8 & 0.3 & 0.35 & 6 & 87 \\
\hline 1287 & 19 & 8 & 0.3 & 0.35 & 6 & 82 \\
\hline 1288 & 21 & 8 & 0.3 & 0.35 & 6 & 77 \\
\hline 1289 & 23 & 8 & 0.3 & 0.35 & 6 & 74 \\
\hline 1290 & 25 & 8 & 0.3 & 0.35 & 6 & 70 \\
\hline 1291 & 17 & 9 & 0.3 & 0.35 & 5 & 77 \\
\hline 1292 & 19 & 9 & 0.3 & 0.35 & 5 & 73 \\
\hline 1293 & 21 & 9 & 0.3 & 0.35 & 6 & 89 \\
\hline
\end{tabular}




\begin{tabular}{|c|c|c|c|c|c|c|}
\hline 1294 & 23 & 9 & 0.3 & 0.35 & 6 & 84 \\
\hline 1295 & 25 & 9 & 0.3 & 0.35 & 6 & 80 \\
\hline 1296 & 17 & 10 & 0.3 & 0.35 & 5 & 88 \\
\hline 1297 & 19 & 10 & 0.3 & 0.35 & 5 & 82 \\
\hline 1298 & 21 & 10 & 0.3 & 0.35 & 5 & 77 \\
\hline 1299 & 23 & 10 & 0.3 & 0.35 & 5 & 73 \\
\hline 1300 & 25 & 10 & 0.3 & 0.35 & 6 & 90 \\
\hline 1301 & 17 & 1 & 0.35 & 0.35 & 0 & 0 \\
\hline 1302 & 19 & 1 & 0.35 & 0.35 & 0 & 0 \\
\hline 1303 & 21 & 1 & 0.35 & 0.35 & 61 & 200 \\
\hline 1304 & 23 & 1 & 0.35 & 0.35 & 62 & 200 \\
\hline 1305 & 25 & 1 & 0.35 & 0.35 & 62 & 200 \\
\hline 1306 & 17 & 2 & 0.35 & 0.35 & 37 & 200 \\
\hline 1307 & 19 & 2 & 0.35 & 0.35 & 38 & 200 \\
\hline 1308 & 21 & 2 & 0.35 & 0.35 & 39 & 200 \\
\hline 1309 & 23 & 2 & 0.35 & 0.35 & 40 & 200 \\
\hline 1310 & 25 & 2 & 0.35 & 0.35 & 40 & 199 \\
\hline 1311 & 17 & 3 & 0.35 & 0.35 & 24 & 188 \\
\hline 1312 & 19 & 3 & 0.35 & 0.35 & 23 & 175 \\
\hline 1313 & 21 & 3 & 0.35 & 0.35 & 22 & 162 \\
\hline 1314 & 23 & 3 & 0.35 & 0.35 & 21 & 151 \\
\hline 1315 & 25 & 3 & 0.35 & 0.35 & 20 & 143 \\
\hline 1316 & 17 & 4 & 0.35 & 0.35 & 12 & 120 \\
\hline 1317 & 19 & 4 & 0.35 & 0.35 & 12 & 115 \\
\hline 1318 & 21 & 4 & 0.35 & 0.35 & 12 & 111 \\
\hline 1319 & 23 & 4 & 0.35 & 0.35 & 12 & 108 \\
\hline 1320 & 25 & 4 & 0.35 & 0.35 & 11 & 98 \\
\hline 1321 & 17 & 5 & 0.35 & 0.35 & 8 & 94 \\
\hline 1322 & 19 & 5 & 0.35 & 0.35 & 8 & 89 \\
\hline 1323 & 21 & 5 & 0.35 & 0.35 & 9 & 98 \\
\hline 1324 & 23 & 5 & 0.35 & 0.35 & 9 & 95 \\
\hline 1325 & 25 & 5 & 0.35 & 0.35 & 8 & 83 \\
\hline 1326 & 17 & 6 & 0.35 & 0.35 & 7 & 96 \\
\hline 1327 & 19 & 6 & 0.35 & 0.35 & 7 & 91 \\
\hline 1328 & 21 & 6 & 0.35 & 0.35 & 7 & 86 \\
\hline 1329 & 23 & 6 & 0.35 & 0.35 & 7 & 82 \\
\hline 1330 & 25 & 6 & 0.35 & 0.35 & 7 & 83 \\
\hline 1331 & 17 & 7 & 0.35 & 0.35 & 6 & 92 \\
\hline 1332 & 19 & 7 & 0.35 & 0.35 & 6 & 87 \\
\hline 1333 & 21 & 7 & 0.35 & 0.35 & 6 & 82 \\
\hline 1334 & 23 & 7 & 0.35 & 0.35 & 6 & 78 \\
\hline 1335 & 25 & 7 & 0.35 & 0.35 & 6 & 79 \\
\hline
\end{tabular}




\begin{tabular}{|c|c|c|c|c|c|c|}
\hline 1336 & 17 & 8 & 0.35 & 0.35 & 5 & 83 \\
\hline 1337 & 19 & 8 & 0.35 & 0.35 & 6 & 99 \\
\hline 1338 & 21 & 8 & 0.35 & 0.35 & 6 & 94 \\
\hline 1339 & 23 & 8 & 0.35 & 0.35 & 6 & 89 \\
\hline 1340 & 25 & 8 & 0.35 & 0.35 & 6 & 90 \\
\hline 1341 & 17 & 9 & 0.35 & 0.35 & 5 & 94 \\
\hline 1342 & 19 & $\overline{9}$ & 0.35 & 0.35 & 5 & 88 \\
\hline 1343 & 21 & $\overline{9}$ & 0.35 & 0.35 & 5 & 83 \\
\hline 1344 & 23 & 9 & 0.35 & 0.35 & 6 & 100 \\
\hline 1345 & 25 & 9 & 0.35 & 0.35 & 5 & 80 \\
\hline 1346 & 17 & 10 & 0.35 & 0.35 & 5 & 106 \\
\hline 1347 & 19 & $\overline{10}$ & 0.35 & 0.35 & 5 & 98 \\
\hline 1348 & 21 & 10 & 0.35 & 0.35 & 5 & 92 \\
\hline 1349 & 23 & 10 & 0.35 & 0.35 & 5 & 88 \\
\hline 1350 & 25 & 10 & 0.35 & 0.35 & 5 & 89 \\
\hline 1351 & 17 & 1 & 0.4 & 0.35 & 35 & 200 \\
\hline 1352 & 19 & 1 & 0.4 & 0.35 & 36 & 200 \\
\hline 1353 & 21 & 1 & 0.4 & 0.35 & 37 & 200 \\
\hline 1354 & 23 & 1 & 0.4 & 0.35 & 37 & 200 \\
\hline 1355 & 25 & 1 & 0.4 & 0.35 & 27 & 200 \\
\hline 1356 & 17 & 2 & 0.4 & 0.35 & 25 & 200 \\
\hline 1357 & 19 & 2 & 0.4 & 0.35 & 26 & 200 \\
\hline 1358 & 21 & 2 & 0.4 & 0.35 & 27 & 200 \\
\hline 1359 & 23 & 2 & 0.4 & 0.35 & 27 & 200 \\
\hline 1360 & 25 & 2 & 0.4 & 0.35 & 5 & 101 \\
\hline 1361 & 17 & 3 & 0.4 & 0.35 & 19 & 200 \\
\hline 1362 & 19 & 3 & 0.4 & 0.35 & 18 & 187 \\
\hline 1363 & 21 & 3 & 0.4 & 0.35 & 17 & 170 \\
\hline 1364 & 23 & 3 & 0.4 & 0.35 & 16 & 161 \\
\hline 1365 & 25 & 3 & 0.4 & 0.35 & 4 & 153 \\
\hline 1366 & 17 & 4 & 0.4 & 0.35 & 11 & 147 \\
\hline 1367 & 19 & 4 & 0.4 & 0.35 & 10 & 125 \\
\hline 1368 & 21 & 4 & 0.4 & 0.35 & 10 & 120 \\
\hline 1369 & 23 & 4 & 0.4 & 0.35 & 10 & 122 \\
\hline 1370 & 25 & 4 & 0.4 & 0.35 & 1 & 204 \\
\hline 1371 & 17 & 5 & 0.4 & 0.35 & 8 & 124 \\
\hline 1372 & 19 & 5 & 0.4 & 0.35 & 8 & 116 \\
\hline 1373 & 21 & 5 & 0.4 & 0.35 & 8 & 111 \\
\hline 1374 & 23 & 5 & 0.4 & 0.35 & 7 & 98 \\
\hline 1375 & 25 & 5 & 0.4 & 0.35 & 1 & 256 \\
\hline 1376 & 17 & 6 & 0.4 & 0.35 & 6 & 102 \\
\hline 1377 & 19 & 6 & 0.4 & 0.35 & 7 & 115 \\
\hline
\end{tabular}




\begin{tabular}{|c|c|c|c|c|c|c|}
\hline 1378 & 21 & 6 & 0.4 & 0.35 & 7 & 109 \\
\hline 1379 & 23 & 6 & 0.4 & 0.35 & 6 & 96 \\
\hline 1380 & 25 & 6 & 0.4 & 0.35 & 1 & 308 \\
\hline 1381 & 17 & 7 & 0.4 & 0.35 & 6 & 117 \\
\hline 1382 & 19 & 7 & 0.4 & 0.35 & 6 & 109 \\
\hline 1383 & 21 & 7 & 0.4 & 0.35 & 6 & 103 \\
\hline 1384 & 23 & 7 & 0.4 & 0.35 & 5 & 88 \\
\hline 1385 & 25 & 7 & 0.4 & 0.35 & 1 & 360 \\
\hline 1386 & 17 & 8 & 0.4 & 0.35 & 5 & 105 \\
\hline 1387 & 19 & 8 & 0.4 & 0.35 & 5 & 97 \\
\hline 1388 & 21 & 8 & 0.4 & 0.35 & 6 & 116 \\
\hline 1389 & 23 & 8 & 0.4 & 0.35 & 5 & 98 \\
\hline 1390 & 25 & 8 & 0.4 & 0.35 & 1 & 411 \\
\hline 1391 & 17 & 9 & 0.4 & 0.35 & 5 & 117 \\
\hline 1392 & 19 & 9 & 0.4 & 0.35 & 5 & 109 \\
\hline 1393 & 21 & 9 & 0.4 & 0.35 & 5 & 102 \\
\hline 1394 & 23 & 9 & 0.4 & 0.35 & 5 & 108 \\
\hline 1395 & 25 & 9 & 0.4 & 0.35 & 1 & 463 \\
\hline 1396 & 17 & 10 & 0.4 & 0.35 & 5 & 130 \\
\hline 1397 & 19 & 10 & 0.4 & 0.35 & 5 & 120 \\
\hline 1398 & 21 & 10 & 0.4 & 0.35 & 5 & 113 \\
\hline 1399 & 23 & 10 & 0.4 & 0.35 & 5 & 119 \\
\hline 1400 & 25 & 10 & 0.4 & 0.35 & 1 & 515 \\
\hline & & & & & & \\
\hline
\end{tabular}




\section{RESULT OF SIMULATION FOR NORMAL SPREADING LOAD}

\begin{tabular}{|c|c|c|c|c|c|c|}
\hline $\begin{array}{c}\text { No of } \\
\text { simulation }\end{array}$ & $\begin{array}{l}\text { Angle of } \\
\text { friction }\end{array}$ & Cohesion & $\begin{array}{l}\text { Coefficient } \\
\text { of earth } \\
\text { pressure } \\
\text { at rest }\end{array}$ & $\begin{array}{l}\text { coefficient } \\
\text { of residual } \\
\text { friction }\end{array}$ & $\begin{array}{l}\text { Number } \\
\text { of } \\
\text { elements }\end{array}$ & $\begin{array}{l}\text { Final } \\
\text { Load }\end{array}$ \\
\hline & $\phi^{\prime}$ & $c^{\prime}$ & $K_{0}$ & $K_{r}$ & No. & $\mathrm{P}$ \\
\hline & $\circ$ & $\mathrm{kPa}$ & & & & $\%$ \\
\hline 1 & 17 & 1 & 0.25 & 0.05 & 0 & 0 \\
\hline 2 & 19 & 1 & 0.25 & 0.05 & 0 & 0 \\
\hline 3 & 21 & 1 & 0.25 & 0.05 & 0 & 0 \\
\hline 4 & 23 & 1 & 0.25 & 0.05 & 0 & 0 \\
\hline 5 & 25 & 1 & 0.25 & 0.05 & 0 & 0 \\
\hline 6 & 17 & 2 & 0.25 & 0.05 & 200 & 2 \\
\hline 7 & 19 & 2 & 0.25 & 0.05 & 200 & 2 \\
\hline 8 & 21 & 2 & 0.25 & 0.05 & 200 & 3 \\
\hline 9 & 23 & 2 & 0.25 & 0.05 & 200 & 4 \\
\hline 10 & 25 & 2 & 0.25 & 0.05 & 200 & 7 \\
\hline 11 & 17 & 3 & 0.25 & 0.05 & 200 & 101 \\
\hline 12 & 19 & 3 & 0.25 & 0.05 & 168 & 200 \\
\hline 13 & 21 & 3 & 0.25 & 0.05 & 143 & 200 \\
\hline 14 & 23 & 3 & 0.25 & 0.05 & 132 & 200 \\
\hline 15 & 25 & 3 & 0.25 & 0.05 & 126 & 200 \\
\hline 16 & 17 & 4 & 0.25 & 0.05 & 99 & 200 \\
\hline 17 & 19 & 4 & 0.25 & 0.05 & 98 & 200 \\
\hline 18 & 21 & 4 & 0.25 & 0.05 & 98 & 200 \\
\hline 19 & 23 & 4 & 0.25 & 0.05 & 97 & 200 \\
\hline 20 & 25 & 4 & 0.25 & 0.05 & 93 & 200 \\
\hline 21 & 17 & 5 & 0.25 & 0.05 & 83 & 200 \\
\hline 22 & 19 & 5 & 0.25 & 0.05 & 82 & 200 \\
\hline 23 & 21 & 5 & 0.25 & 0.05 & 81 & 200 \\
\hline 24 & 23 & 5 & 0.25 & 0.05 & 81 & 200 \\
\hline 25 & 25 & 5 & 0.25 & 0.05 & 80 & 200 \\
\hline 26 & 17 & 6 & 0.25 & 0.05 & 76 & 200 \\
\hline 27 & 19 & 6 & 0.25 & 0.05 & 74 & 200 \\
\hline 28 & 21 & 6 & 0.25 & 0.05 & 71 & 200 \\
\hline 29 & 23 & 6 & 0.25 & 0.05 & 69 & 200 \\
\hline 30 & 25 & 6 & 0.25 & 0.05 & 67 & 200 \\
\hline 31 & 17 & 7 & 0.25 & 0.05 & 64 & 200 \\
\hline 32 & 19 & 7 & 0.25 & 0.05 & 63 & 200 \\
\hline
\end{tabular}




\begin{tabular}{|c|c|c|c|c|c|c|}
\hline 33 & 21 & 7 & 0.25 & 0.05 & 62 & 200 \\
\hline 34 & 23 & 7 & 0.25 & 0.05 & 60 & 200 \\
\hline 35 & 25 & 7 & 0.25 & 0.05 & 60 & 200 \\
\hline 36 & 17 & 8 & 0.25 & 0.05 & 59 & 200 \\
\hline 37 & 19 & 8 & 0.25 & 0.05 & 58 & 200 \\
\hline 38 & 21 & 8 & 0.25 & 0.05 & 56 & 200 \\
\hline 39 & 23 & 8 & 0.25 & 0.05 & 55 & 200 \\
\hline 40 & 25 & 8 & 0.25 & 0.05 & 54 & 200 \\
\hline 41 & 17 & 9 & 0.25 & 0.05 & 54 & 200 \\
\hline 42 & 19 & 9 & 0.25 & 0.05 & 52 & 200 \\
\hline 43 & 21 & 9 & 0.25 & 0.05 & 52 & 200 \\
\hline 44 & 23 & 9 & 0.25 & 0.05 & 51 & 200 \\
\hline 45 & 25 & 9 & 0.25 & 0.05 & 50 & 200 \\
\hline 46 & 17 & 10 & 0.25 & 0.05 & 50 & 200 \\
\hline 47 & 19 & 10 & 0.25 & 0.05 & 49 & 200 \\
\hline 48 & 21 & 10 & 0.25 & 0.05 & 48 & 200 \\
\hline 49 & 23 & 10 & 0.25 & 0.05 & 48 & 200 \\
\hline 50 & 25 & 10 & 0.25 & 0.05 & 47 & 200 \\
\hline 51 & 17 & 1 & 0.3 & 0.05 & 0 & 0 \\
\hline 52 & 19 & 1 & 0.3 & 0.05 & 0 & 0 \\
\hline 53 & 21 & 1 & 0.3 & 0.05 & 0 & 0 \\
\hline 54 & 23 & 1 & 0.3 & 0.05 & 0 & 0 \\
\hline 55 & 25 & 1 & 0.3 & 0.05 & 200 & 3 \\
\hline 56 & 17 & 2 & 0.3 & 0.05 & 200 & 8 \\
\hline 57 & 19 & 2 & 0.3 & 0.05 & 200 & 19 \\
\hline 58 & 21 & 2 & 0.3 & 0.05 & 200 & 38 \\
\hline 59 & 23 & 2 & 0.3 & 0.05 & 200 & 70 \\
\hline 60 & 25 & 2 & 0.3 & 0.05 & 200 & 123 \\
\hline 61 & 17 & 3 & 0.3 & 0.05 & 117 & 200 \\
\hline 62 & 19 & 3 & 0.3 & 0.05 & 109 & 200 \\
\hline 63 & 21 & 3 & 0.3 & 0.05 & 102 & 200 \\
\hline 64 & 23 & 3 & 0.3 & 0.05 & 97 & 200 \\
\hline 65 & 25 & 3 & 0.3 & 0.05 & 92 & 200 \\
\hline 66 & 17 & 4 & 0.3 & 0.05 & 83 & 200 \\
\hline 67 & 19 & 4 & 0.3 & 0.05 & 81 & 200 \\
\hline 68 & 21 & 4 & 0.3 & 0.05 & 79 & 200 \\
\hline 69 & 23 & 4 & 0.3 & 0.05 & 73 & 200 \\
\hline 70 & 25 & 4 & 0.3 & 0.05 & 69 & 200 \\
\hline 71 & 17 & 5 & 0.3 & 0.05 & 67 & 200 \\
\hline 72 & 19 & 5 & 0.3 & 0.05 & 64 & 200 \\
\hline 73 & 21 & 5 & 0.3 & 0.05 & 62 & 200 \\
\hline 74 & 23 & 5 & 0.3 & 0.05 & 60 & 200 \\
\hline 75 & 25 & 5 & 0.3 & 0.05 & 58 & 200 \\
\hline
\end{tabular}




\begin{tabular}{|c|c|c|c|c|c|c|}
\hline 76 & 17 & 6 & 0.3 & 0.05 & 58 & 200 \\
\hline 77 & 19 & 6 & 0.3 & 0.05 & 56 & 200 \\
\hline 78 & 21 & 6 & 0.3 & 0.05 & 54 & 200 \\
\hline 79 & 23 & 6 & 0.3 & 0.05 & 52 & 200 \\
\hline 80 & 25 & 6 & 0.3 & 0.05 & 50 & 200 \\
\hline 81 & 17 & 7 & 0.3 & 0.05 & 52 & 200 \\
\hline 82 & 19 & 7 & 0.3 & 0.05 & 50 & 200 \\
\hline 83 & 21 & 7 & 0.3 & 0.05 & 49 & 200 \\
\hline 84 & 23 & 7 & 0.3 & 0.05 & 48 & 200 \\
\hline 85 & 25 & 7 & 0.3 & 0.05 & 46 & 200 \\
\hline 86 & 17 & 8 & 0.3 & 0.05 & 48 & 200 \\
\hline 87 & 19 & 8 & 0.3 & 0.05 & 47 & 200 \\
\hline 88 & 21 & 8 & 0.3 & 0.05 & 46 & 200 \\
\hline 89 & 23 & 8 & 0.3 & 0.05 & 45 & 200 \\
\hline 90 & 25 & 8 & 0.3 & 0.05 & 43 & 200 \\
\hline 91 & 17 & 9 & 0.3 & 0.05 & 45 & 200 \\
\hline 92 & 19 & 9 & 0.3 & 0.05 & 44 & 200 \\
\hline 93 & 21 & 9 & 0.3 & 0.05 & 43 & 200 \\
\hline 94 & 23 & 9 & 0.3 & 0.05 & 42 & 200 \\
\hline 95 & 25 & 9 & 0.3 & 0.05 & 41 & 200 \\
\hline 96 & 17 & 10 & 0.3 & 0.05 & 43 & 200 \\
\hline 97 & 19 & 10 & 0.3 & 0.05 & 42 & 200 \\
\hline 98 & 21 & 10 & 0.3 & 0.05 & 41 & 200 \\
\hline 99 & 23 & 10 & 0.3 & 0.05 & 41 & 200 \\
\hline 100 & 25 & 10 & 0.3 & 0.05 & 37 & 200 \\
\hline 101 & 17 & 1 & 0.35 & 0.05 & 0 & 0 \\
\hline 102 & 19 & 1 & 0.35 & 0.05 & 0 & 0 \\
\hline 103 & 21 & 1 & 0.35 & 0.05 & 200 & 68 \\
\hline 104 & 23 & 1 & 0.35 & 0.05 & 200 & 196 \\
\hline 105 & 25 & 1 & 0.35 & 0.05 & 111 & 200 \\
\hline 106 & 17 & 2 & 0.35 & 0.05 & 98 & 200 \\
\hline 107 & 19 & 2 & 0.35 & 0.05 & 87 & 200 \\
\hline 108 & 21 & 2 & 0.35 & 0.05 & 76 & 200 \\
\hline 109 & 23 & 2 & 0.35 & 0.05 & 64 & 200 \\
\hline 110 & 25 & 2 & 0.35 & 0.05 & 54 & 200 \\
\hline 111 & 17 & 3 & 0.35 & 0.05 & 64 & 200 \\
\hline 112 & 19 & 3 & 0.35 & 0.05 & \begin{tabular}{|l|}
58 \\
\end{tabular} & 200 \\
\hline 113 & 21 & 3 & 0.35 & 0.05 & 53 & 200 \\
\hline 114 & 23 & 3 & 0.35 & 0.05 & 47 & 200 \\
\hline 115 & 25 & 3 & 0.35 & 0.05 & 40 & 200 \\
\hline 116 & 17 & 4 & 0.35 & 0.05 & 51 & 200 \\
\hline 117 & 19 & 4 & 0.35 & 0.05 & 48 & 200 \\
\hline 118 & 21 & 4 & 0.35 & 0.05 & 44 & 200 \\
\hline
\end{tabular}




\begin{tabular}{|c|c|c|c|c|c|c|}
\hline 119 & 23 & 4 & 0.35 & 0.05 & 40 & 200 \\
\hline 120 & 25 & 4 & 0.35 & 0.05 & 35 & 200 \\
\hline 121 & 17 & 5 & 0.35 & 0.05 & 46 & 200 \\
\hline 122 & 19 & 5 & 0.35 & 0.05 & 42 & 200 \\
\hline 123 & 21 & 5 & 0.35 & 0.05 & 37 & 200 \\
\hline 124 & 23 & 5 & 0.35 & 0.05 & 35 & 200 \\
\hline 125 & 25 & 5 & 0.35 & 0.05 & 32 & 200 \\
\hline 126 & 17 & 6 & 0.35 & 0.05 & 41 & 200 \\
\hline 127 & 19 & 6 & 0.35 & 0.05 & 37 & 200 \\
\hline 128 & 21 & 6 & 0.35 & 0.05 & 35 & 200 \\
\hline 129 & 23 & 6 & 0.35 & 0.05 & 32 & 200 \\
\hline 130 & 25 & 6 & 0.35 & 0.05 & 26 & 200 \\
\hline 131 & 17 & 7 & 0.35 & 0.05 & 37 & 200 \\
\hline 132 & 19 & 7 & 0.35 & 0.05 & 35 & 200 \\
\hline 133 & 21 & 7 & 0.35 & 0.05 & 33 & 200 \\
\hline 134 & 23 & 7 & 0.35 & 0.05 & 30 & 200 \\
\hline 135 & 25 & 7 & 0.35 & 0.05 & 26 & 200 \\
\hline 136 & 17 & 8 & 0.35 & 0.05 & 35 & 200 \\
\hline 137 & 19 & 8 & 0.35 & 0.05 & 33 & 200 \\
\hline 138 & 21 & 8 & 0.35 & 0.05 & 32 & 200 \\
\hline 139 & 23 & 8 & 0.35 & 0.05 & 26 & 200 \\
\hline 140 & 25 & 8 & 0.35 & 0.05 & 21 & 200 \\
\hline 141 & 17 & 9 & 0.35 & 0.05 & 33 & 200 \\
\hline 142 & 19 & 9 & 0.35 & 0.05 & 32 & 200 \\
\hline 143 & 21 & 9 & 0.35 & 0.05 & 30 & 200 \\
\hline 144 & 23 & 9 & 0.35 & 0.05 & 26 & 200 \\
\hline 145 & 25 & 9 & 0.35 & 0.05 & 21 & 200 \\
\hline 146 & 17 & 10 & 0.35 & 0.05 & 32 & 200 \\
\hline 147 & 19 & 10 & 0.35 & 0.05 & 30 & 200 \\
\hline 148 & 21 & 10 & 0.35 & 0.05 & 26 & 200 \\
\hline 149 & 23 & 10 & 0.35 & 0.05 & 25 & 200 \\
\hline 150 & 25 & 10 & 0.35 & 0.05 & 8 & 200 \\
\hline 151 & 17 & 1 & 0.4 & 0.05 & 5 & 200 \\
\hline 152 & 19 & 1 & 0.4 & 0.05 & 5 & 200 \\
\hline 153 & 21 & 1 & 0.4 & 0.05 & 4 & 200 \\
\hline 154 & 23 & 1 & 0.4 & 0.05 & 1 & 200 \\
\hline 155 & 25 & 1 & 0.4 & 0.05 & 1 & 200 \\
\hline 156 & 17 & 2 & 0.4 & 0.05 & 5 & 200 \\
\hline 157 & 19 & 2 & 0.4 & 0.05 & 4 & 200 \\
\hline 158 & 21 & 2 & 0.4 & 0.05 & 4 & 200 \\
\hline 159 & 23 & 2 & 0.4 & 0.05 & 1 & 200 \\
\hline 160 & 25 & 2 & 0.4 & 0.05 & 1 & 205 \\
\hline 161 & 17 & 3 & 0.4 & 0.05 & 5 & 200 \\
\hline
\end{tabular}




\begin{tabular}{|c|c|c|c|c|c|c|}
\hline 162 & 19 & 3 & 0.4 & 0.05 & 4 & 200 \\
\hline 163 & 21 & 3 & 0.4 & 0.05 & 4 & 200 \\
\hline 164 & 23 & 3 & 0.4 & 0.05 & 1 & 200 \\
\hline 165 & 25 & 3 & 0.4 & 0.05 & 1 & 310 \\
\hline 166 & 17 & 4 & 0.4 & 0.05 & 5 & 200 \\
\hline 167 & 19 & 4 & 0.4 & 0.05 & 4 & 200 \\
\hline 168 & 21 & 4 & 0.4 & 0.05 & 4 & 200 \\
\hline 169 & 23 & 4 & 0.4 & 0.05 & 1 & 200 \\
\hline 170 & 25 & 4 & 0.4 & 0.05 & 1 & 415 \\
\hline 171 & 17 & 5 & 0.4 & 0.05 & 5 & 200 \\
\hline 172 & 19 & 5 & 0.4 & 0.05 & 4 & 200 \\
\hline 173 & 21 & 5 & 0.4 & 0.05 & 4 & 200 \\
\hline 174 & 23 & 5 & 0.4 & 0.05 & 1 & 200 \\
\hline 175 & 25 & 5 & 0.4 & 0.05 & 1 & 520 \\
\hline 176 & 17 & 6 & 0.4 & 0.05 & 5 & 200 \\
\hline 177 & 19 & 6 & 0.4 & 0.05 & 4 & 200 \\
\hline 178 & 21 & 6 & 0.4 & 0.05 & 4 & 200 \\
\hline 179 & 23 & 6 & 0.4 & 0.05 & 1 & 200 \\
\hline 180 & 25 & 6 & 0.4 & 0.05 & 1 & 625 \\
\hline 181 & 17 & 7 & 0.4 & 0.05 & 4 & 200 \\
\hline 182 & 19 & 7 & 0.4 & 0.05 & 4 & 200 \\
\hline 183 & 21 & 7 & 0.4 & 0.05 & 4 & 200 \\
\hline 184 & 23 & 7 & 0.4 & 0.05 & 1 & 200 \\
\hline 185 & 25 & 7 & 0.4 & 0.05 & 1 & 730 \\
\hline 186 & 17 & 8 & 0.4 & 0.05 & 4 & 200 \\
\hline 187 & 19 & 8 & 0.4 & 0.05 & 4 & 200 \\
\hline 188 & 21 & 8 & 0.4 & 0.05 & 4 & 200 \\
\hline 189 & 23 & 8 & 0.4 & 0.05 & 1 & 200 \\
\hline 190 & 25 & 8 & 0.4 & 0.05 & 1 & 835 \\
\hline 191 & 17 & 9 & 0.4 & 0.05 & 4 & 200 \\
\hline 192 & 19 & 9 & 0.4 & 0.05 & 4 & 200 \\
\hline 193 & 21 & 9 & 0.4 & 0.05 & 4 & 200 \\
\hline 194 & 23 & 9 & 0.4 & 0.05 & 1 & 200 \\
\hline 195 & 25 & 9 & 0.4 & 0.05 & 1 & 940 \\
\hline 196 & 17 & 10 & 0.4 & 0.05 & 4 & 200 \\
\hline 197 & 19 & 10 & 0.4 & 0.05 & 4 & 200 \\
\hline 198 & 21 & 10 & 0.4 & 0.05 & 4 & 200 \\
\hline 199 & 23 & 10 & 0.4 & 0.05 & 1 & 200 \\
\hline 200 & 25 & 10 & 0.4 & 0.05 & 1 & 1045 \\
\hline 201 & 17 & 1 & 0.25 & 0.1 & 0 & 0 \\
\hline 202 & 19 & 1 & 0.25 & 0.1 & 0 & 0 \\
\hline 203 & 21 & 1 & 0.25 & 0.1 & 0 & 0 \\
\hline 204 & 23 & 1 & 0.25 & 0.1 & 0 & 0 \\
\hline
\end{tabular}




\begin{tabular}{|c|c|c|c|c|c|c|}
\hline 205 & 25 & 1 & 0.25 & 0.1 & 0 & 0 \\
\hline 206 & 17 & 2 & 0.25 & 0.1 & 200 & 2 \\
\hline 207 & 19 & 2 & 0.25 & 0.1 & 200 & 2 \\
\hline 208 & 21 & 2 & 0.25 & 0.1 & 200 & 3 \\
\hline 209 & 23 & 2 & 0.25 & 0.1 & 200 & 4 \\
\hline 210 & 25 & 2 & 0.25 & 0.1 & 200 & 6 \\
\hline 211 & 17 & 3 & 0.25 & 0.1 & 200 & 44 \\
\hline 212 & 19 & 3 & 0.25 & 0.1 & 200 & 72 \\
\hline 213 & 21 & 3 & 0.25 & 0.1 & 200 & 117 \\
\hline 214 & 23 & 3 & 0.25 & 0.1 & 200 & 198 \\
\hline 215 & 25 & 3 & 0.25 & 0.1 & 146 & 200 \\
\hline 216 & 17 & 4 & 0.25 & 0.1 & 101 & 200 \\
\hline 217 & 19 & 4 & 0.25 & 0.1 & 98 & 200 \\
\hline 218 & 21 & 4 & 0.25 & 0.1 & 95 & 200 \\
\hline 219 & 23 & 4 & 0.25 & 0.1 & 93 & 200 \\
\hline 220 & 25 & 4 & 0.25 & 0.1 & 91 & 200 \\
\hline 221 & 17 & 5 & 0.25 & 0.1 & 83 & 200 \\
\hline 222 & 19 & 5 & 0.25 & 0.1 & 82 & 200 \\
\hline 223 & 21 & 5 & 0.25 & 0.1 & 81 & 200 \\
\hline 224 & 23 & 5 & 0.25 & 0.1 & 79 & 200 \\
\hline 225 & 25 & 5 & 0.25 & 0.1 & 77 & 200 \\
\hline 226 & 17 & 6 & 0.25 & 0.1 & 73 & 200 \\
\hline 227 & 19 & 6 & 0.25 & 0.1 & 69 & 200 \\
\hline 228 & 21 & 6 & 0.25 & 0.1 & 67 & 200 \\
\hline 229 & 23 & 6 & 0.25 & 0.1 & 64 & 200 \\
\hline 230 & 25 & 6 & 0.25 & 0.1 & 63 & 200 \\
\hline 231 & 17 & 7 & 0.25 & 0.1 & 62 & 200 \\
\hline 232 & 19 & 7 & 0.25 & 0.1 & 60 & 200 \\
\hline 233 & 21 & 7 & 0.25 & 0.1 & 59 & 200 \\
\hline 234 & 23 & 7 & 0.25 & 0.1 & 58 & 200 \\
\hline 235 & 25 & 7 & 0.25 & 0.1 & 56 & 200 \\
\hline 236 & 17 & 8 & 0.25 & 0.1 & 57 & 200 \\
\hline 237 & 19 & 8 & 0.25 & 0.1 & 55 & 200 \\
\hline 238 & 21 & 8 & 0.25 & 0.1 & 54 & 200 \\
\hline 239 & 23 & 8 & 0.25 & 0.1 & 52 & 200 \\
\hline 240 & 25 & 8 & 0.25 & 0.1 & 51 & 200 \\
\hline 241 & 17 & 9 & 0.25 & 0.1 & 52 & 200 \\
\hline 242 & 19 & 9 & 0.25 & 0.1 & 51 & 200 \\
\hline 243 & 21 & 9 & 0.25 & 0.1 & 50 & 200 \\
\hline 244 & 23 & 9 & 0.25 & 0.1 & 49 & 200 \\
\hline 245 & 25 & 9 & 0.25 & 0.1 & 48 & 200 \\
\hline 246 & 17 & 10 & 0.25 & 0.1 & 49 & 200 \\
\hline 247 & 19 & 10 & 0.25 & 0.1 & 48 & 200 \\
\hline
\end{tabular}




\begin{tabular}{|c|c|c|c|c|c|c|}
\hline 248 & 21 & 10 & 0.25 & 0.1 & 47 & 200 \\
\hline 249 & 23 & 10 & 0.25 & 0.1 & 46 & 200 \\
\hline 250 & 25 & 10 & 0.25 & 0.1 & 46 & 200 \\
\hline 251 & 17 & 1 & 0.3 & 0.1 & 0 & 0 \\
\hline 252 & 19 & 1 & 0.3 & 0.1 & 0 & 0 \\
\hline 253 & 21 & 1 & 0.3 & 0.1 & 0 & 0 \\
\hline 254 & 23 & 1 & 0.3 & 0.1 & 0 & 0 \\
\hline 255 & 25 & 1 & 0.3 & 0.1 & 200 & 3 \\
\hline 256 & 17 & 2 & 0.3 & 0.1 & 200 & 15 \\
\hline 257 & 19 & 2 & 0.3 & 0.1 & 200 & 38 \\
\hline 258 & 21 & 2 & 0.3 & 0.1 & 200 & 82 \\
\hline 259 & 23 & 2 & 0.3 & 0.1 & 200 & 153 \\
\hline 260 & 25 & 2 & 0.3 & 0.1 & 141 & 200 \\
\hline 261 & 17 & 3 & 0.3 & 0.1 & 100 & 200 \\
\hline 262 & 19 & 3 & 0.3 & 0.1 & 94 & 200 \\
\hline 263 & 21 & 3 & 0.3 & 0.1 & 89 & 200 \\
\hline 264 & 23 & 3 & 0.3 & 0.1 & 84 & 200 \\
\hline 265 & 25 & 3 & 0.3 & 0.1 & 80 & 200 \\
\hline 266 & 17 & 4 & 0.3 & 0.1 & 79 & 200 \\
\hline 267 & 19 & 4 & 0.3 & 0.1 & 71 & 200 \\
\hline 268 & 21 & 4 & 0.3 & 0.1 & 66 & 200 \\
\hline 269 & 23 & 4 & 0.3 & 0.1 & 62 & 200 \\
\hline 270 & 25 & 4 & 0.3 & 0.1 & 59 & 200 \\
\hline 271 & 17 & 5 & 0.3 & 0.1 & 61 & 200 \\
\hline 272 & 19 & 5 & 0.3 & 0.1 & 58 & 200 \\
\hline 273 & 21 & 5 & 0.3 & 0.1 & 55 & 200 \\
\hline 274 & 23 & 5 & 0.3 & 0.1 & 53 & 200 \\
\hline 275 & 25 & 5 & 0.3 & 0.1 & 50 & 200 \\
\hline 276 & 17 & 6 & 0.3 & 0.1 & 53 & 200 \\
\hline 277 & 19 & 6 & 0.3 & 0.1 & 51 & 200 \\
\hline 278 & 21 & 6 & 0.3 & 0.1 & 49 & 200 \\
\hline 279 & 23 & 6 & 0.3 & 0.1 & 47 & 200 \\
\hline 280 & 25 & 6 & 0.3 & 0.1 & 44 & 200 \\
\hline 281 & 17 & 7 & 0.3 & 0.1 & 49 & 200 \\
\hline 282 & 19 & 7 & 0.3 & 0.1 & 47 & 200 \\
\hline 283 & 21 & 7 & 0.3 & 0.1 & 45 & 200 \\
\hline 284 & 23 & 7 & 0.3 & 0.1 & 43 & 200 \\
\hline 285 & 25 & 7 & 0.3 & 0.1 & 42 & 200 \\
\hline 286 & 17 & 8 & 0.3 & 0.1 & 46 & 200 \\
\hline 287 & 19 & 8 & 0.3 & 0.1 & 43 & 200 \\
\hline 288 & 21 & 8 & 0.3 & 0.1 & 42 & 200 \\
\hline 289 & 23 & 8 & 0.3 & 0.1 & 40 & 200 \\
\hline 290 & 25 & 8 & 0.3 & 0.1 & 37 & 200 \\
\hline
\end{tabular}




\begin{tabular}{|c|c|c|c|c|c|c|}
\hline 291 & 17 & 9 & 0.3 & 0.1 & 42 & 200 \\
\hline 292 & 19 & 9 & 0.3 & 0.1 & 41 & 200 \\
\hline 293 & 21 & 9 & 0.3 & 0.1 & 40 & 200 \\
\hline 294 & 23 & 9 & 0.3 & 0.1 & 37 & 200 \\
\hline 295 & 25 & 9 & 0.3 & 0.1 & 35 & 200 \\
\hline 296 & 17 & 10 & 0.3 & 0.1 & 40 & 200 \\
\hline 297 & 19 & 10 & 0.3 & 0.1 & 39 & 200 \\
\hline 298 & 21 & 10 & 0.3 & 0.1 & 36 & 200 \\
\hline 299 & 23 & 10 & 0.3 & 0.1 & 35 & 200 \\
\hline 300 & 25 & 10 & 0.3 & 0.1 & 33 & 200 \\
\hline 301 & 17 & 1 & 0.35 & 0.1 & 0 & 0 \\
\hline 302 & 19 & 1 & 0.35 & 0.1 & 0 & 0 \\
\hline 303 & 21 & 1 & 0.35 & 0.1 & 84 & 200 \\
\hline 304 & 23 & 1 & 0.35 & 0.1 & 47 & 200 \\
\hline 305 & 25 & 1 & 0.35 & 0.1 & 6 & 200 \\
\hline 306 & 17 & 2 & 0.35 & 0.1 & 67 & 200 \\
\hline 307 & 19 & 2 & 0.35 & 0.1 & 56 & 200 \\
\hline 308 & 21 & 2 & 0.35 & 0.1 & 45 & 200 \\
\hline 309 & 23 & 2 & 0.35 & 0.1 & 26 & 200 \\
\hline 310 & 25 & 2 & 0.35 & 0.1 & 6 & 200 \\
\hline 311 & 17 & 3 & 0.35 & 0.1 & 49 & 200 \\
\hline 312 & 19 & 3 & 0.35 & 0.1 & 43 & 200 \\
\hline 313 & 21 & 3 & 0.35 & 0.1 & 34 & 200 \\
\hline 314 & 23 & 3 & 0.35 & 0.1 & 8 & 200 \\
\hline 315 & 25 & 3 & 0.35 & 0.1 & 5 & 200 \\
\hline 316 & 17 & 4 & 0.35 & 0.1 & 41 & 200 \\
\hline 317 & 19 & 4 & 0.35 & 0.1 & 36 & 200 \\
\hline 318 & 21 & 4 & 0.35 & 0.1 & 31 & 200 \\
\hline 319 & 23 & 4 & 0.35 & 0.1 & 8 & 200 \\
\hline 320 & 25 & 4 & 0.35 & 0.1 & 5 & 200 \\
\hline 321 & 17 & 5 & 0.35 & 0.1 & 36 & 200 \\
\hline 322 & 19 & 5 & 0.35 & 0.1 & 31 & 200 \\
\hline 323 & 21 & 5 & 0.35 & 0.1 & 26 & 200 \\
\hline 324 & 23 & 5 & 0.35 & 0.1 & 6 & 200 \\
\hline 325 & 25 & 5 & 0.35 & 0.1 & 5 & 200 \\
\hline 326 & 17 & 6 & 0.35 & 0.1 & 33 & 200 \\
\hline 327 & 19 & 6 & 0.35 & 0.1 & 30 & 200 \\
\hline 328 & 21 & 6 & 0.35 & 0.1 & 25 & 200 \\
\hline 329 & 23 & 6 & 0.35 & 0.1 & 6 & 200 \\
\hline 330 & 25 & 6 & 0.35 & 0.1 & 5 & 200 \\
\hline 331 & 17 & 7 & 0.35 & 0.1 & 31 & 200 \\
\hline 332 & 19 & 7 & 0.35 & 0.1 & 26 & 200 \\
\hline 333 & 21 & 7 & 0.35 & 0.1 & 19 & 200 \\
\hline
\end{tabular}




\begin{tabular}{|c|c|c|c|c|c|c|}
\hline 334 & 23 & 7 & 0.35 & 0.1 & 6 & 200 \\
\hline 335 & 25 & 7 & 0.35 & 0.1 & 1 & 200 \\
\hline 336 & 17 & 8 & 0.35 & 0.1 & 30 & 200 \\
\hline 337 & 19 & 8 & 0.35 & 0.1 & 25 & 200 \\
\hline 338 & 21 & 8 & 0.35 & 0.1 & 19 & 200 \\
\hline 339 & 23 & 8 & 0.35 & 0.1 & 5 & 200 \\
\hline 340 & 25 & 8 & 0.35 & 0.1 & 1 & 200 \\
\hline 341 & 17 & 9 & 0.35 & 0.1 & 26 & 200 \\
\hline 342 & 19 & 9 & 0.35 & 0.1 & 23 & 200 \\
\hline 343 & 21 & 9 & 0.35 & 0.1 & 13 & 200 \\
\hline 344 & 23 & 9 & 0.35 & 0.1 & 5 & 200 \\
\hline 345 & 25 & 9 & 0.35 & 0.1 & 1 & 200 \\
\hline 346 & 17 & 10 & 0.35 & 0.1 & 25 & 200 \\
\hline 347 & 19 & 10 & 0.35 & 0.1 & 21 & 200 \\
\hline 348 & 21 & 10 & 0.35 & 0.1 & 8 & 200 \\
\hline 349 & 23 & 10 & 0.35 & 0.1 & 5 & 200 \\
\hline 350 & 25 & 10 & 0.35 & 0.1 & 1 & 200 \\
\hline 351 & 17 & 1 & 0.4 & 0.1 & 4 & 200 \\
\hline 352 & 19 & 1 & 0.4 & 0.1 & 3 & 200 \\
\hline 353 & 21 & 1 & 0.4 & 0.1 & 3 & 200 \\
\hline 354 & 23 & 1 & 0.4 & 0.1 & 1 & 200 \\
\hline 355 & 25 & 1 & 0.4 & 0.1 & 1 & 200 \\
\hline 356 & 17 & 2 & 0.4 & 0.1 & 4 & 200 \\
\hline 357 & 19 & 2 & 0.4 & 0.1 & 3 & 200 \\
\hline 358 & 21 & 2 & 0.4 & 0.1 & 3 & 200 \\
\hline 359 & 23 & 2 & 0.4 & 0.1 & 1 & 200 \\
\hline 360 & 25 & 2 & 0.4 & 0.1 & 1 & 205 \\
\hline 361 & 17 & 3 & 0.4 & 0.1 & 4 & 200 \\
\hline 362 & 19 & 3 & 0.4 & 0.1 & 3 & 200 \\
\hline 363 & 21 & 3 & 0.4 & 0.1 & 3 & 200 \\
\hline 364 & 23 & 3 & 0.4 & 0.1 & 1 & 200 \\
\hline 365 & 25 & 3 & 0.4 & 0.1 & 1 & 310 \\
\hline 366 & 17 & 4 & 0.4 & 0.1 & 3 & 200 \\
\hline 367 & 19 & 4 & 0.4 & 0.1 & 3 & 200 \\
\hline 368 & 21 & 4 & 0.4 & 0.1 & 3 & 200 \\
\hline 369 & 23 & 4 & 0.4 & 0.1 & 1 & 200 \\
\hline 370 & 25 & 4 & 0.4 & 0.1 & 1 & 415 \\
\hline 371 & 17 & 5 & 0.4 & 0.1 & 3 & 200 \\
\hline 372 & 19 & 5 & 0.4 & 0.1 & 3 & 200 \\
\hline 373 & 21 & 5 & 0.4 & 0.1 & 3 & 200 \\
\hline 374 & 23 & 5 & 0.4 & 0.1 & 1 & 200 \\
\hline 375 & 25 & 5 & 0.4 & 0.1 & 1 & 520 \\
\hline 376 & 17 & 6 & 0.4 & 0.1 & 3 & 200 \\
\hline
\end{tabular}




\begin{tabular}{|c|c|c|c|c|c|c|}
\hline 377 & 19 & 6 & 0.4 & 0.1 & 3 & 200 \\
\hline 378 & 21 & 6 & 0.4 & 0.1 & 3 & 200 \\
\hline 379 & 23 & 6 & 0.4 & 0.1 & 1 & 200 \\
\hline 380 & 25 & 6 & 0.4 & 0.1 & 1 & 625 \\
\hline 381 & 17 & 7 & 0.4 & 0.1 & 3 & 200 \\
\hline 382 & 19 & 7 & 0.4 & 0.1 & 3 & 200 \\
\hline 383 & 21 & 7 & 0.4 & 0.1 & 3 & 200 \\
\hline 384 & 23 & 7 & 0.4 & 0.1 & 1 & 200 \\
\hline 385 & 25 & 7 & 0.4 & 0.1 & 1 & 730 \\
\hline 386 & 17 & 8 & 0.4 & 0.1 & 3 & 200 \\
\hline 387 & 19 & 8 & 0.4 & 0.1 & 3 & 200 \\
\hline 388 & 21 & 8 & 0.4 & 0.1 & 1 & 200 \\
\hline 389 & 23 & 8 & 0.4 & 0.1 & 1 & 200 \\
\hline 390 & 25 & 8 & 0.4 & 0.1 & 1 & 835 \\
\hline 391 & 17 & 9 & 0.4 & 0.1 & 3 & 200 \\
\hline 392 & 19 & 9 & 0.4 & 0.1 & 3 & 200 \\
\hline 393 & 21 & 9 & 0.4 & 0.1 & 1 & 200 \\
\hline 394 & 23 & 9 & 0.4 & 0.1 & 1 & 200 \\
\hline 395 & 25 & 9 & 0.4 & 0.1 & 1 & 940 \\
\hline 396 & 17 & 10 & 0.4 & 0.1 & 3 & 200 \\
\hline 397 & 19 & 10 & 0.4 & 0.1 & 3 & 200 \\
\hline 398 & 21 & 10 & 0.4 & 0.1 & 1 & 200 \\
\hline 399 & 23 & 10 & 0.4 & 0.1 & 1 & 200 \\
\hline 400 & 25 & 10 & 0.4 & 0.1 & 1 & 1045 \\
\hline 401 & 17 & 1 & 0.25 & 0.15 & 0 & 0 \\
\hline 402 & 19 & 1 & 0.25 & 0.15 & 0 & 0 \\
\hline 403 & 21 & 1 & 0.25 & 0.15 & 0 & 0 \\
\hline 404 & 23 & 1 & 0.25 & 0.15 & 0 & 0 \\
\hline 405 & 25 & 1 & 0.25 & 0.15 & 0 & 0 \\
\hline 406 & 17 & 2 & 0.25 & 0.15 & 200 & 2 \\
\hline 407 & 19 & 2 & 0.25 & 0.15 & 200 & 2 \\
\hline 408 & 21 & 2 & 0.25 & 0.15 & 200 & 3 \\
\hline 409 & 23 & 2 & 0.25 & 0.15 & 200 & 4 \\
\hline 410 & 25 & 2 & 0.25 & 0.15 & 200 & 7 \\
\hline 411 & 17 & 3 & 0.25 & 0.15 & 200 & 39 \\
\hline 412 & 19 & 3 & 0.25 & 0.15 & 200 & 69 \\
\hline 413 & 21 & 3 & 0.25 & 0.15 & 200 & 114 \\
\hline 414 & 23 & 3 & 0.25 & 0.15 & 200 & 180 \\
\hline 415 & 25 & 3 & 0.25 & 0.15 & 135 & 200 \\
\hline 416 & 17 & 4 & 0.25 & 0.15 & 98 & 200 \\
\hline 417 & 19 & 4 & 0.25 & 0.15 & 94 & 200 \\
\hline 418 & 21 & 4 & 0.25 & 0.15 & 91 & 200 \\
\hline 419 & 23 & 4 & 0.25 & 0.15 & 89 & 200 \\
\hline
\end{tabular}




\begin{tabular}{|c|c|c|c|c|c|c|}
\hline 420 & 25 & 4 & 0.25 & 0.15 & 86 & 200 \\
\hline 421 & 17 & 5 & 0.25 & 0.15 & 82 & 200 \\
\hline 422 & 19 & 5 & 0.25 & 0.15 & 80 & 200 \\
\hline 423 & 21 & 5 & 0.25 & 0.15 & 79 & 200 \\
\hline 424 & 23 & 5 & 0.25 & 0.15 & 73 & 200 \\
\hline 425 & 25 & 5 & 0.25 & 0.15 & 69 & 200 \\
\hline 426 & 17 & 6 & 0.25 & 0.15 & 68 & 200 \\
\hline 427 & 19 & 6 & 0.25 & 0.15 & 65 & 200 \\
\hline 428 & 21 & 6 & 0.25 & 0.15 & 63 & 200 \\
\hline 429 & 23 & 6 & 0.25 & 0.15 & 61 & 200 \\
\hline 430 & 25 & 6 & 0.25 & 0.15 & 59 & 200 \\
\hline 431 & 17 & 7 & 0.25 & 0.15 & 60 & 200 \\
\hline 432 & 19 & 7 & 0.25 & 0.15 & 58 & 200 \\
\hline 433 & 21 & 7 & 0.25 & 0.15 & 56 & 200 \\
\hline 434 & 23 & 7 & 0.25 & 0.15 & 54 & 200 \\
\hline 435 & 25 & 7 & 0.25 & 0.15 & 53 & 200 \\
\hline 436 & 17 & 8 & 0.25 & 0.15 & 54 & 200 \\
\hline 437 & 19 & 8 & 0.25 & 0.15 & 53 & 200 \\
\hline 438 & 21 & 8 & 0.25 & 0.15 & 51 & 200 \\
\hline 439 & 23 & 8 & 0.25 & 0.15 & 50 & 200 \\
\hline 440 & 25 & 8 & 0.25 & 0.15 & 49 & 200 \\
\hline 441 & 17 & 9 & 0.25 & 0.15 & 50 & 200 \\
\hline 442 & 19 & 9 & 0.25 & 0.15 & 49 & 200 \\
\hline 443 & 21 & 9 & 0.25 & 0.15 & 48 & 200 \\
\hline 444 & 23 & 9 & 0.25 & 0.15 & 47 & 200 \\
\hline 445 & 25 & 9 & 0.25 & 0.15 & 46 & 200 \\
\hline 446 & 17 & 10 & 0.25 & 0.15 & 47 & 200 \\
\hline 447 & 19 & 10 & 0.25 & 0.15 & 46 & 200 \\
\hline 448 & 21 & 10 & 0.25 & 0.15 & 46 & 200 \\
\hline 449 & 23 & 10 & 0.25 & 0.15 & 44 & 200 \\
\hline 450 & 25 & 10 & 0.25 & 0.15 & 43 & 200 \\
\hline 451 & 17 & 1 & 0.3 & 0.15 & 0 & 0 \\
\hline 452 & 19 & 1 & 0.3 & 0.15 & 0 & 0 \\
\hline 453 & 21 & 1 & 0.3 & 0.15 & 0 & 0 \\
\hline 454 & 23 & 1 & 0.3 & 0.15 & 0 & 0 \\
\hline 455 & 25 & 1 & 0.3 & 0.15 & 200 & 22 \\
\hline 456 & 17 & 2 & 0.3 & 0.15 & 200 & 58 \\
\hline 457 & 19 & 2 & 0.3 & 0.15 & 200 & 134 \\
\hline 458 & 21 & 2 & 0.3 & 0.15 & 127 & 200 \\
\hline 459 & 23 & 2 & 0.3 & 0.15 & 102 & 200 \\
\hline 460 & 25 & 2 & 0.3 & 0.15 & 89 & 200 \\
\hline 461 & 17 & 3 & 0.3 & 0.15 & 87 & 200 \\
\hline 462 & 19 & 3 & 0.3 & 0.15 & 82 & 200 \\
\hline
\end{tabular}




\begin{tabular}{|c|c|c|c|c|c|c|}
\hline 463 & 21 & 3 & 0.3 & 0.15 & 72 & 200 \\
\hline 464 & 23 & 3 & 0.3 & 0.15 & 65 & 200 \\
\hline 465 & 25 & 3 & 0.3 & 0.15 & 58 & 200 \\
\hline 466 & 17 & 4 & 0.3 & 0.15 & 64 & 200 \\
\hline 467 & 19 & 4 & 0.3 & 0.15 & 61 & 200 \\
\hline 468 & 21 & 4 & 0.3 & 0.15 & 56 & 200 \\
\hline 469 & 23 & 4 & 0.3 & 0.15 & 52 & 200 \\
\hline 470 & 25 & 4 & 0.3 & 0.15 & 48 & 200 \\
\hline 471 & 17 & 5 & 0.3 & 0.15 & 54 & 200 \\
\hline 472 & 19 & 5 & 0.3 & 0.15 & 51 & 200 \\
\hline 473 & 21 & 5 & 0.3 & 0.15 & 48 & 200 \\
\hline 474 & 23 & 5 & 0.3 & 0.15 & 45 & 200 \\
\hline 475 & 25 & 5 & 0.3 & 0.15 & 41 & 200 \\
\hline 476 & 17 & 6 & 0.3 & 0.15 & 48 & 200 \\
\hline 477 & 19 & 6 & 0.3 & 0.15 & 47 & 200 \\
\hline 478 & 21 & 6 & 0.3 & 0.15 & 44 & 200 \\
\hline 479 & 23 & 6 & 0.3 & 0.15 & 41 & 200 \\
\hline 480 & 25 & 6 & 0.3 & 0.15 & 37 & 200 \\
\hline 481 & 17 & 7 & 0.3 & 0.15 & 44 & 200 \\
\hline 482 & 19 & 7 & 0.3 & 0.15 & 43 & 200 \\
\hline 483 & 21 & 7 & 0.3 & 0.15 & 40 & 200 \\
\hline 484 & 23 & 7 & 0.3 & 0.15 & 37 & 200 \\
\hline 485 & 25 & 7 & 0.3 & 0.15 & 34 & 200 \\
\hline 486 & 17 & 8 & 0.3 & 0.15 & 42 & 200 \\
\hline 487 & 19 & 8 & 0.3 & 0.15 & 40 & 200 \\
\hline 488 & 21 & 8 & 0.3 & 0.15 & 37 & 200 \\
\hline 489 & 23 & 8 & 0.3 & 0.15 & 34 & 200 \\
\hline 490 & 25 & 8 & 0.3 & 0.15 & 33 & 200 \\
\hline 491 & 17 & 9 & 0.3 & 0.15 & 40 & 200 \\
\hline 492 & 19 & 9 & 0.3 & 0.15 & 37 & 200 \\
\hline 493 & 21 & 9 & 0.3 & 0.15 & 34 & 200 \\
\hline 494 & 23 & 9 & 0.3 & 0.15 & 33 & 200 \\
\hline 495 & 25 & 9 & 0.3 & 0.15 & 31 & 200 \\
\hline 496 & 17 & 10 & 0.3 & 0.15 & 37 & 200 \\
\hline 497 & 19 & 10 & 0.3 & 0.15 & 34 & 200 \\
\hline 498 & 21 & 10 & 0.3 & 0.15 & 33 & 200 \\
\hline 499 & 23 & 10 & 0.3 & 0.15 & 31 & 200 \\
\hline 500 & 25 & 10 & 0.3 & 0.15 & 30 & 200 \\
\hline 501 & 17 & 1 & 0.35 & 0.15 & 0 & 0 \\
\hline 502 & 19 & 1 & 0.35 & 0.15 & 0 & 0 \\
\hline 503 & 21 & 1 & 0.35 & 0.15 & 5 & 200 \\
\hline 504 & 23 & 1 & 0.35 & 0.15 & 4 & 200 \\
\hline 505 & 25 & 1 & 0.35 & 0.15 & 1 & 200 \\
\hline
\end{tabular}




\begin{tabular}{|c|c|c|c|c|c|c|}
\hline 506 & 17 & 2 & 0.35 & 0.15 & 39 & 200 \\
\hline 507 & 19 & 2 & 0.35 & 0.15 & 13 & 200 \\
\hline 508 & 21 & 2 & 0.35 & 0.15 & 5 & 200 \\
\hline 509 & 23 & 2 & 0.35 & 0.15 & 4 & 200 \\
\hline 510 & 25 & 2 & 0.35 & 0.15 & 1 & 200 \\
\hline 511 & 17 & 3 & 0.35 & 0.15 & 32 & 200 \\
\hline 512 & 19 & 3 & 0.35 & 0.15 & 7 & 200 \\
\hline 513 & 21 & 3 & 0.35 & 0.15 & 5 & 200 \\
\hline 514 & 23 & 3 & 0.35 & 0.15 & 4 & 200 \\
\hline 515 & 25 & 3 & 0.35 & 0.15 & 1 & 200 \\
\hline 516 & 17 & 4 & 0.35 & 0.15 & 27 & 200 \\
\hline 517 & 19 & 4 & 0.35 & 0.15 & 6 & 200 \\
\hline 518 & 21 & 4 & 0.35 & 0.15 & 5 & 200 \\
\hline 519 & 23 & 4 & 0.35 & 0.15 & 4 & 200 \\
\hline 520 & 25 & 4 & 0.35 & 0.15 & 1 & 200 \\
\hline 521 & 17 & 5 & 0.35 & 0.15 & 26 & 200 \\
\hline 522 & 19 & 5 & 0.35 & 0.15 & 5 & 200 \\
\hline 523 & 21 & 5 & 0.35 & 0.15 & 4 & 200 \\
\hline 524 & 23 & 5 & 0.35 & 0.15 & 4 & 200 \\
\hline 525 & 25 & 5 & 0.35 & 0.15 & 1 & 200 \\
\hline 526 & 17 & 6 & 0.35 & 0.15 & 22 & 200 \\
\hline 527 & 19 & 6 & 0.35 & 0.15 & 5 & 200 \\
\hline 528 & 21 & 6 & 0.35 & 0.15 & 4 & 200 \\
\hline 529 & 23 & 6 & 0.35 & 0.15 & 4 & 200 \\
\hline 530 & 25 & 6 & 0.35 & 0.15 & 1 & 200 \\
\hline 531 & 17 & 7 & 0.35 & 0.15 & 17 & 200 \\
\hline 532 & 19 & 7 & 0.35 & 0.15 & 5 & 200 \\
\hline 533 & 21 & 7 & 0.35 & 0.15 & 4 & 200 \\
\hline 534 & 23 & 7 & 0.35 & 0.15 & 4 & 200 \\
\hline 535 & 25 & 7 & 0.35 & 0.15 & 1 & 200 \\
\hline 536 & 17 & 8 & 0.35 & 0.15 & 16 & 200 \\
\hline 537 & 19 & 8 & 0.35 & 0.15 & 5 & 200 \\
\hline 538 & 21 & 8 & 0.35 & 0.15 & 4 & 200 \\
\hline 539 & 23 & 8 & 0.35 & 0.15 & 4 & 200 \\
\hline 540 & 25 & 8 & 0.35 & 0.15 & 1 & 200 \\
\hline 541 & 17 & 9 & 0.35 & 0.15 & 12 & 200 \\
\hline 542 & 19 & 9 & 0.35 & 0.15 & 5 & 200 \\
\hline 543 & 21 & 9 & 0.35 & 0.15 & 4 & 200 \\
\hline 544 & 23 & 9 & 0.35 & 0.15 & 4 & 200 \\
\hline 545 & 25 & 9 & 0.35 & 0.15 & 1 & 200 \\
\hline 546 & 17 & 10 & 0.35 & 0.15 & 7 & 200 \\
\hline 547 & 19 & 10 & 0.35 & 0.15 & 5 & 200 \\
\hline 548 & 21 & 10 & 0.35 & 0.15 & 4 & 200 \\
\hline
\end{tabular}




\begin{tabular}{|c|c|c|c|c|c|c|}
\hline 549 & 23 & 10 & 0.35 & 0.15 & 3 & 200 \\
\hline 550 & 25 & 10 & 0.35 & 0.15 & 1 & 200 \\
\hline 551 & 17 & 1 & 0.4 & 0.15 & 3 & 200 \\
\hline 552 & 19 & 1 & 0.4 & 0.15 & 3 & 200 \\
\hline 553 & 21 & 1 & 0.4 & 0.15 & 1 & 200 \\
\hline 554 & 23 & 1 & 0.4 & 0.15 & 1 & 200 \\
\hline 555 & 25 & 1 & 0.4 & 0.15 & 1 & 200 \\
\hline 556 & 17 & 2 & 0.4 & 0.15 & 3 & 200 \\
\hline 557 & 19 & 2 & 0.4 & 0.15 & 2 & 200 \\
\hline 558 & 21 & 2 & 0.4 & 0.15 & 1 & 200 \\
\hline 559 & 23 & 2 & 0.4 & 0.15 & 1 & 200 \\
\hline 560 & 25 & 2 & 0.4 & 0.15 & 1 & 205 \\
\hline 561 & 17 & 3 & 0.4 & 0.15 & 3 & 200 \\
\hline 562 & 19 & 3 & 0.4 & 0.15 & 2 & 200 \\
\hline 563 & 21 & 3 & 0.4 & 0.15 & 1 & 200 \\
\hline 564 & 23 & 3 & 0.4 & 0.15 & 1 & 200 \\
\hline 565 & 25 & 3 & 0.4 & 0.15 & 1 & 310 \\
\hline 566 & 17 & 4 & 0.4 & 0.15 & 3 & 200 \\
\hline 567 & 19 & 4 & 0.4 & 0.15 & 2 & 200 \\
\hline 568 & 21 & 4 & 0.4 & 0.15 & 1 & 200 \\
\hline 569 & 23 & 4 & 0.4 & 0.15 & 1 & 200 \\
\hline 570 & 25 & 4 & 0.4 & 0.15 & 1 & 415 \\
\hline 571 & 17 & 5 & 0.4 & 0.15 & 3 & 200 \\
\hline 572 & 19 & 5 & 0.4 & 0.15 & 2 & 200 \\
\hline 573 & 21 & 5 & 0.4 & 0.15 & 1 & 200 \\
\hline 574 & 23 & 5 & 0.4 & 0.15 & 1 & 200 \\
\hline 575 & 25 & 5 & 0.4 & 0.15 & 1 & 520 \\
\hline 576 & 17 & 6 & 0.4 & 0.15 & 3 & 200 \\
\hline 577 & 19 & 6 & 0.4 & 0.15 & 2 & 200 \\
\hline 578 & 21 & 6 & 0.4 & 0.15 & 1 & 200 \\
\hline 579 & 23 & 6 & 0.4 & 0.15 & 1 & 200 \\
\hline 580 & 25 & 6 & 0.4 & 0.15 & 1 & 625 \\
\hline 581 & 17 & 7 & 0.4 & 0.15 & 3 & 200 \\
\hline 582 & 19 & 7 & 0.4 & 0.15 & 2 & 200 \\
\hline 583 & 21 & 7 & 0.4 & 0.15 & 1 & 200 \\
\hline 584 & 23 & 7 & 0.4 & 0.15 & 1 & 200 \\
\hline 585 & 25 & 7 & 0.4 & 0.15 & 1 & 730 \\
\hline 586 & 17 & 8 & 0.4 & 0.15 & 3 & 200 \\
\hline 587 & 19 & 8 & 0.4 & 0.15 & 2 & 200 \\
\hline 588 & 21 & 8 & 0.4 & 0.15 & 1 & 200 \\
\hline 589 & 23 & 8 & 0.4 & 0.15 & 1 & 200 \\
\hline 590 & 25 & 8 & 0.4 & 0.15 & 1 & 835 \\
\hline 591 & 17 & 9 & 0.4 & 0.15 & 3 & 200 \\
\hline
\end{tabular}




\begin{tabular}{|c|c|c|c|c|c|c|}
\hline 592 & 19 & 9 & 0.4 & 0.15 & 2 & 200 \\
\hline 593 & 21 & 9 & 0.4 & 0.15 & 1 & 200 \\
\hline 594 & 23 & 9 & 0.4 & 0.15 & 1 & 200 \\
\hline 595 & 25 & 9 & 0.4 & 0.15 & 1 & 940 \\
\hline 596 & 17 & 10 & 0.4 & 0.15 & 2 & 200 \\
\hline 597 & 19 & 10 & 0.4 & 0.15 & 2 & 200 \\
\hline 598 & 21 & 10 & 0.4 & 0.15 & 1 & 200 \\
\hline 599 & 23 & 10 & 0.4 & 0.15 & 1 & 200 \\
\hline 600 & 25 & 10 & 0.4 & 0.15 & 1 & 1045 \\
\hline 601 & 17 & 1 & 0.25 & 0.2 & 0 & 0 \\
\hline 602 & 19 & 1 & 0.25 & 0.2 & 0 & 0 \\
\hline 603 & 21 & 1 & 0.25 & 0.2 & 0 & 0 \\
\hline 604 & 23 & 1 & 0.25 & 0.2 & 0 & 0 \\
\hline 605 & 25 & 1 & 0.25 & 0.2 & 0 & 0 \\
\hline 606 & 17 & 2 & 0.25 & 0.2 & 200 & 2 \\
\hline 607 & 19 & 2 & 0.25 & 0.2 & 200 & 2 \\
\hline 608 & 21 & 2 & 0.25 & 0.2 & 200 & 3 \\
\hline 609 & 23 & 2 & 0.25 & 0.2 & 200 & 4 \\
\hline 610 & 25 & 2 & 0.25 & 0.2 & 200 & 14 \\
\hline 611 & 17 & 3 & 0.25 & 0.2 & 200 & 54 \\
\hline 612 & 19 & 3 & 0.25 & 0.2 & 200 & 102 \\
\hline 613 & 21 & 3 & 0.25 & 0.2 & 200 & 172 \\
\hline 614 & 23 & 3 & 0.25 & 0.2 & 124 & 200 \\
\hline 615 & 25 & 3 & 0.25 & 0.2 & 109 & 200 \\
\hline 616 & 17 & 4 & 0.25 & 0.2 & 93 & 200 \\
\hline 617 & 19 & 4 & 0.25 & 0.2 & 89 & 200 \\
\hline 618 & 21 & 4 & 0.25 & 0.2 & 86 & 200 \\
\hline 619 & 23 & 4 & 0.25 & 0.2 & 84 & 200 \\
\hline 620 & 25 & 4 & 0.25 & 0.2 & 81 & 200 \\
\hline 621 & 17 & 5 & 0.25 & 0.2 & 81 & 200 \\
\hline 622 & 19 & 5 & 0.25 & 0.2 & 73 & 200 \\
\hline 623 & 21 & 5 & 0.25 & 0.2 & 68 & 200 \\
\hline 624 & 23 & 5 & 0.25 & 0.2 & 65 & 200 \\
\hline 625 & 25 & 5 & 0.25 & 0.2 & 62 & 200 \\
\hline 626 & 17 & 6 & 0.25 & 0.2 & 63 & 200 \\
\hline 627 & 19 & 6 & 0.25 & 0.2 & 62 & 200 \\
\hline 628 & 21 & 6 & 0.25 & 0.2 & $\begin{array}{l}59 \\
\end{array}$ & 200 \\
\hline 629 & 23 & 6 & 0.25 & 0.2 & 56 & 200 \\
\hline 630 & 25 & 6 & 0.25 & 0.2 & 54 & 200 \\
\hline 631 & 17 & 7 & 0.25 & 0.2 & 56 & 200 \\
\hline 632 & 19 & 7 & 0.25 & 0.2 & 54 & 200 \\
\hline 633 & 21 & 7 & 0.25 & 0.2 & 52 & 200 \\
\hline 634 & 23 & 7 & 0.25 & 0.2 & 51 & 200 \\
\hline
\end{tabular}




\begin{tabular}{|c|c|c|c|c|c|c|}
\hline 635 & 25 & 7 & 0.25 & 0.2 & 49 & 200 \\
\hline 636 & 17 & 8 & 0.25 & 0.2 & 51 & 200 \\
\hline 637 & 19 & 8 & 0.25 & 0.2 & 50 & 200 \\
\hline 638 & 21 & 8 & 0.25 & 0.2 & 48 & 200 \\
\hline 639 & 23 & 8 & 0.25 & 0.2 & 47 & 200 \\
\hline 640 & 25 & 8 & 0.25 & 0.2 & 45 & 200 \\
\hline 641 & 17 & 9 & 0.25 & 0.2 & 48 & 200 \\
\hline 642 & 19 & 9 & 0.25 & 0.2 & 47 & 200 \\
\hline 643 & 21 & 9 & 0.25 & 0.2 & 45 & 200 \\
\hline 644 & 23 & 9 & 0.25 & 0.2 & 44 & 200 \\
\hline 645 & 25 & 9 & 0.25 & 0.2 & 43 & 200 \\
\hline 646 & 17 & 10 & 0.25 & 0.2 & 46 & 200 \\
\hline 647 & 19 & 10 & 0.25 & 0.2 & 44 & 200 \\
\hline 648 & 21 & 10 & 0.25 & 0.2 & 43 & 200 \\
\hline 649 & 23 & 10 & 0.25 & 0.2 & 42 & 200 \\
\hline 650 & 25 & 10 & 0.25 & 0.2 & 41 & 200 \\
\hline 651 & 17 & 1 & 0.3 & 0.2 & 0 & 0 \\
\hline 652 & 19 & 1 & 0.3 & 0.2 & 0 & 0 \\
\hline 653 & 21 & 1 & 0.3 & 0.2 & 0 & 0 \\
\hline 654 & 23 & 1 & 0.3 & 0.2 & 0 & 0 \\
\hline 655 & 25 & 1 & 0.3 & 0.2 & 124 & 200 \\
\hline 656 & 17 & 2 & 0.3 & 0.2 & 116 & 200 \\
\hline 657 & 19 & 2 & 0.3 & 0.2 & 95 & 200 \\
\hline 658 & 21 & 2 & 0.3 & 0.2 & 84 & 200 \\
\hline 659 & 23 & 2 & 0.3 & 0.2 & 67 & 200 \\
\hline 660 & 25 & 2 & 0.3 & 0.2 & 55 & 200 \\
\hline 661 & 17 & 3 & 0.3 & 0.2 & 69 & 200 \\
\hline 662 & 19 & 3 & 0.3 & 0.2 & 62 & 200 \\
\hline 663 & 21 & 3 & 0.3 & 0.2 & 55 & 200 \\
\hline 664 & 23 & 3 & 0.3 & 0.2 & 49 & 200 \\
\hline 665 & 25 & 3 & 0.3 & 0.2 & 42 & 200 \\
\hline 666 & 17 & 4 & 0.3 & 0.2 & 54 & 200 \\
\hline 667 & 19 & 4 & 0.3 & 0.2 & 50 & 200 \\
\hline 668 & 21 & 4 & 0.3 & 0.2 & 46 & 200 \\
\hline 669 & 23 & 4 & 0.3 & 0.2 & 41 & 200 \\
\hline 670 & 25 & 4 & 0.3 & 0.2 & 35 & 200 \\
\hline 671 & 17 & 5 & 0.3 & 0.2 & 48 & 200 \\
\hline 672 & 19 & 5 & 0.3 & 0.2 & 44 & 200 \\
\hline 673 & 21 & 5 & 0.3 & 0.2 & 41 & 200 \\
\hline 674 & 23 & 5 & 0.3 & 0.2 & 35 & 200 \\
\hline 675 & 25 & 5 & 0.3 & 0.2 & 32 & 200 \\
\hline 676 & 17 & 6 & 0.3 & 0.2 & 43 & 200 \\
\hline 677 & 19 & 6 & 0.3 & 0.2 & 41 & 200 \\
\hline
\end{tabular}




\begin{tabular}{|c|c|c|c|c|c|c|}
\hline 678 & 21 & 6 & 0.3 & 0.2 & 37 & 200 \\
\hline 679 & 23 & 6 & 0.3 & 0.2 & 32 & 200 \\
\hline 680 & 25 & 6 & 0.3 & 0.2 & 27 & 200 \\
\hline 681 & 17 & 7 & 0.3 & 0.2 & 41 & 200 \\
\hline 682 & 19 & 7 & 0.3 & 0.2 & 37 & 200 \\
\hline 683 & 21 & 7 & 0.3 & 0.2 & 34 & 200 \\
\hline 684 & 23 & 7 & 0.3 & 0.2 & 31 & 200 \\
\hline 685 & 25 & 7 & 0.3 & 0.2 & 27 & 200 \\
\hline 686 & 17 & 8 & 0.3 & 0.2 & 37 & 200 \\
\hline 687 & 19 & 8 & 0.3 & 0.2 & 34 & 200 \\
\hline 688 & 21 & 8 & 0.3 & 0.2 & 32 & 200 \\
\hline 689 & 23 & 8 & 0.3 & 0.2 & 29 & 200 \\
\hline 690 & 25 & 8 & 0.3 & 0.2 & 22 & 200 \\
\hline 691 & 17 & 9 & 0.3 & 0.2 & 34 & 200 \\
\hline 692 & 19 & 9 & 0.3 & 0.2 & 32 & 200 \\
\hline 693 & 21 & 9 & 0.3 & 0.2 & 31 & 200 \\
\hline 694 & 23 & 9 & 0.3 & 0.2 & 27 & 200 \\
\hline 695 & 25 & 9 & 0.3 & 0.2 & 22 & 200 \\
\hline 696 & 17 & 10 & 0.3 & 0.2 & 33 & 200 \\
\hline 697 & 19 & 10 & 0.3 & 0.2 & 31 & 200 \\
\hline 698 & 21 & 10 & 0.3 & 0.2 & 29 & 200 \\
\hline 699 & 23 & 10 & 0.3 & 0.2 & 26 & 200 \\
\hline 700 & 25 & 10 & 0.3 & 0.2 & 21 & 200 \\
\hline 701 & 17 & 1 & 0.35 & 0.2 & 0 & 0 \\
\hline 702 & 19 & 1 & 0.35 & 0.2 & 0 & 0 \\
\hline 703 & 21 & 1 & 0.35 & 0.2 & 3 & 200 \\
\hline 704 & 23 & 1 & 0.35 & 0.2 & 3 & 200 \\
\hline 705 & 25 & 1 & 0.35 & 0.2 & 1 & 200 \\
\hline 706 & 17 & 2 & 0.35 & 0.2 & 4 & 200 \\
\hline 707 & 19 & 2 & 0.35 & 0.2 & 4 & 200 \\
\hline 708 & 21 & 2 & 0.35 & 0.2 & 3 & 200 \\
\hline 709 & 23 & 2 & 0.35 & 0.2 & 3 & 200 \\
\hline 710 & 25 & 2 & 0.35 & 0.2 & 1 & 200 \\
\hline 711 & 17 & 3 & 0.35 & 0.2 & 4 & 200 \\
\hline 712 & 19 & 3 & 0.35 & 0.2 & 4 & 200 \\
\hline 713 & 21 & 3 & 0.35 & 0.2 & 3 & 200 \\
\hline 714 & 23 & 3 & 0.35 & 0.2 & 3 & 200 \\
\hline 715 & 25 & 3 & 0.35 & 0.2 & 1 & 200 \\
\hline 716 & 17 & 4 & 0.35 & 0.2 & 4 & 200 \\
\hline 717 & 19 & 4 & 0.35 & 0.2 & 4 & 200 \\
\hline 718 & 21 & 4 & 0.35 & 0.2 & 3 & 200 \\
\hline 719 & 23 & 4 & 0.35 & 0.2 & 3 & 200 \\
\hline 720 & 25 & 4 & 0.35 & 0.2 & 1 & 200 \\
\hline
\end{tabular}




\begin{tabular}{|c|c|c|c|c|c|c|}
\hline 721 & 17 & 5 & 0.35 & 0.2 & 4 & 200 \\
\hline 722 & 19 & 5 & 0.35 & 0.2 & 4 & 200 \\
\hline 723 & 21 & 5 & 0.35 & 0.2 & 3 & 200 \\
\hline 724 & 23 & 5 & 0.35 & 0.2 & 3 & 200 \\
\hline 725 & 25 & 5 & 0.35 & 0.2 & 1 & 200 \\
\hline 726 & 17 & 6 & 0.35 & 0.2 & 4 & 200 \\
\hline 727 & 19 & 6 & 0.35 & 0.2 & 3 & 200 \\
\hline 728 & 21 & 6 & 0.35 & 0.2 & 3 & 200 \\
\hline 729 & 23 & 6 & 0.35 & 0.2 & 3 & 200 \\
\hline 730 & 25 & 6 & 0.35 & 0.2 & 1 & 200 \\
\hline 731 & 17 & 7 & 0.35 & 0.2 & 4 & 200 \\
\hline 732 & 19 & 7 & 0.35 & 0.2 & 3 & 200 \\
\hline 733 & 21 & 7 & 0.35 & 0.2 & 3 & 200 \\
\hline 734 & 23 & 7 & 0.35 & 0.2 & 2 & 200 \\
\hline 735 & 25 & 7 & 0.35 & 0.2 & 1 & 200 \\
\hline 736 & 17 & 8 & 0.35 & 0.2 & 4 & 200 \\
\hline 737 & 19 & 8 & 0.35 & 0.2 & 3 & 200 \\
\hline 738 & 21 & 8 & 0.35 & 0.2 & 3 & 200 \\
\hline 739 & 23 & 8 & 0.35 & 0.2 & 2 & 200 \\
\hline 740 & 25 & 8 & 0.35 & 0.2 & 1 & 200 \\
\hline 741 & 17 & 9 & 0.35 & 0.2 & 4 & 200 \\
\hline 742 & 19 & 9 & 0.35 & 0.2 & 3 & 200 \\
\hline 743 & 21 & 9 & 0.35 & 0.2 & 3 & 200 \\
\hline 744 & 23 & 9 & 0.35 & 0.2 & 1 & 200 \\
\hline 745 & 25 & 9 & 0.35 & 0.2 & 1 & 200 \\
\hline 746 & 17 & 10 & 0.35 & 0.2 & 4 & 200 \\
\hline 747 & 19 & 10 & 0.35 & 0.2 & 3 & 200 \\
\hline 748 & 21 & 10 & 0.35 & 0.2 & 3 & 200 \\
\hline 749 & 23 & 10 & 0.35 & 0.2 & 1 & 200 \\
\hline 750 & 25 & 10 & 0.35 & 0.2 & 1 & 200 \\
\hline 751 & 17 & 1 & 0.4 & 0.2 & 2 & 200 \\
\hline 752 & 19 & 1 & 0.4 & 0.2 & 2 & 200 \\
\hline 753 & 21 & 1 & 0.4 & 0.2 & 1 & 200 \\
\hline 754 & 23 & 1 & 0.4 & 0.2 & 1 & 200 \\
\hline 755 & 25 & 1 & 0.4 & 0.2 & 1 & 200 \\
\hline 756 & 17 & 2 & 0.4 & 0.2 & 2 & 200 \\
\hline 757 & 19 & 2 & 0.4 & 0.2 & 2 & 200 \\
\hline 758 & 21 & 2 & 0.4 & 0.2 & 1 & 200 \\
\hline 759 & 23 & 2 & 0.4 & 0.2 & 1 & 200 \\
\hline 760 & 25 & 2 & 0.4 & 0.2 & 1 & 205 \\
\hline 761 & 17 & 3 & 0.4 & 0.2 & 2 & 200 \\
\hline 762 & 19 & 3 & 0.4 & 0.2 & 2 & 200 \\
\hline 763 & 21 & 3 & 0.4 & 0.2 & 1 & 200 \\
\hline
\end{tabular}




\begin{tabular}{|c|c|c|c|c|c|c|}
\hline 764 & 23 & 3 & 0.4 & 0.2 & 1 & 200 \\
\hline 765 & 25 & 3 & 0.4 & 0.2 & 1 & 310 \\
\hline 766 & 17 & 4 & 0.4 & 0.2 & 2 & 200 \\
\hline 767 & 19 & 4 & 0.4 & 0.2 & 2 & 200 \\
\hline 768 & 21 & 4 & 0.4 & 0.2 & 1 & 200 \\
\hline 769 & 23 & 4 & 0.4 & 0.2 & 1 & 200 \\
\hline 770 & 25 & 4 & 0.4 & 0.2 & 1 & 415 \\
\hline 771 & 17 & 5 & 0.4 & 0.2 & 2 & 200 \\
\hline 772 & 19 & 5 & 0.4 & 0.2 & 2 & 200 \\
\hline 773 & 21 & 5 & 0.4 & 0.2 & 1 & 200 \\
\hline 774 & 23 & 5 & 0.4 & 0.2 & 1 & 200 \\
\hline 775 & 25 & 5 & 0.4 & 0.2 & 1 & 520 \\
\hline 776 & 17 & 6 & 0.4 & 0.2 & 2 & 200 \\
\hline 777 & 19 & 6 & 0.4 & 0.2 & 2 & 200 \\
\hline 778 & 21 & 6 & 0.4 & 0.2 & 1 & 200 \\
\hline 779 & 23 & 6 & 0.4 & 0.2 & 1 & 200 \\
\hline 780 & 25 & 6 & 0.4 & 0.2 & 1 & 625 \\
\hline 781 & 17 & 7 & 0.4 & 0.2 & 2 & 200 \\
\hline 782 & 19 & 7 & 0.4 & 0.2 & 2 & 200 \\
\hline 783 & 21 & 7 & 0.4 & 0.2 & 1 & 200 \\
\hline 784 & 23 & 7 & 0.4 & 0.2 & 1 & 200 \\
\hline 785 & 25 & 7 & 0.4 & 0.2 & 1 & 730 \\
\hline 786 & 17 & 8 & 0.4 & 0.2 & 2 & 200 \\
\hline 787 & 19 & 8 & 0.4 & 0.2 & 1 & 200 \\
\hline 788 & 21 & 8 & 0.4 & 0.2 & 1 & 200 \\
\hline 789 & 23 & 8 & 0.4 & 0.2 & 1 & 200 \\
\hline 790 & 25 & 8 & 0.4 & 0.2 & 1 & 835 \\
\hline 791 & 17 & 9 & 0.4 & 0.2 & 2 & 200 \\
\hline 792 & 19 & 9 & 0.4 & 0.2 & 1 & 200 \\
\hline 793 & 21 & 9 & 0.4 & 0.2 & 1 & 200 \\
\hline 794 & 23 & 9 & 0.4 & 0.2 & 1 & 200 \\
\hline 795 & 25 & 9 & 0.4 & 0.2 & 1 & 940 \\
\hline 796 & 17 & 10 & 0.4 & 0.2 & 2 & 200 \\
\hline 797 & 19 & 10 & 0.4 & 0.2 & 1 & 200 \\
\hline 798 & 21 & 10 & 0.4 & 0.2 & 1 & 200 \\
\hline 799 & 23 & 10 & 0.4 & 0.2 & 1 & 200 \\
\hline 800 & 25 & 10 & 0.4 & 0.2 & 1 & 1045 \\
\hline 801 & 17 & 1 & 0.25 & 0.25 & 0 & 0 \\
\hline 802 & 19 & 1 & 0.25 & 0.25 & 0 & 0 \\
\hline 803 & 21 & 1 & 0.25 & 0.25 & 0 & 0 \\
\hline 804 & 23 & 1 & 0.25 & 0.25 & 0 & 0 \\
\hline 805 & 25 & 1 & 0.25 & 0.25 & 0 & 0 \\
\hline 806 & 17 & 2 & 0.25 & 0.25 & 200 & 2 \\
\hline
\end{tabular}




\begin{tabular}{|c|c|c|c|c|c|c|}
\hline 807 & 19 & 2 & 0.25 & 0.25 & 200 & 3 \\
\hline 808 & 21 & 2 & 0.25 & 0.25 & 200 & 3 \\
\hline 809 & 23 & 2 & 0.25 & 0.25 & 200 & 18 \\
\hline 810 & 25 & 2 & 0.25 & 0.25 & 200 & 56 \\
\hline 811 & 17 & 3 & 0.25 & 0.25 & 200 & 113 \\
\hline 812 & 19 & 3 & 0.25 & 0.25 & 140 & 200 \\
\hline 813 & 21 & 3 & 0.25 & 0.25 & 108 & 200 \\
\hline 814 & 23 & 3 & 0.25 & 0.25 & 97 & 200 \\
\hline 815 & 25 & 3 & 0.25 & 0.25 & 90 & 200 \\
\hline 816 & 17 & 4 & 0.25 & 0.25 & 87 & 200 \\
\hline 817 & 19 & 4 & 0.25 & 0.25 & 85 & 200 \\
\hline 818 & 21 & 4 & 0.25 & 0.25 & 79 & 200 \\
\hline 819 & 23 & 4 & 0.25 & 0.25 & 71 & 200 \\
\hline 820 & 25 & 4 & 0.25 & 0.25 & 66 & 200 \\
\hline 821 & 17 & 5 & 0.25 & 0.25 & 69 & 200 \\
\hline 822 & 19 & 5 & 0.25 & 0.25 & 65 & 200 \\
\hline 823 & 21 & 5 & 0.25 & 0.25 & 62 & 200 \\
\hline 824 & 23 & 5 & 0.25 & 0.25 & 58 & 200 \\
\hline 825 & 25 & 5 & 0.25 & 0.25 & 55 & 200 \\
\hline 826 & 17 & 6 & 0.25 & 0.25 & 59 & 200 \\
\hline 827 & 19 & 6 & 0.25 & 0.25 & 56 & 200 \\
\hline 828 & 21 & 6 & 0.25 & 0.25 & 53 & 200 \\
\hline 829 & 23 & 6 & 0.25 & 0.25 & 51 & 200 \\
\hline 830 & 25 & 6 & 0.25 & 0.25 & 49 & 200 \\
\hline 831 & 17 & 7 & 0.25 & 0.25 & 52 & 200 \\
\hline 832 & 19 & 7 & 0.25 & 0.25 & 51 & 200 \\
\hline 833 & 21 & 7 & 0.25 & 0.25 & 49 & 200 \\
\hline 834 & 23 & 7 & 0.25 & 0.25 & 47 & 200 \\
\hline 835 & 25 & 7 & 0.25 & 0.25 & 45 & 200 \\
\hline 836 & 17 & 8 & 0.25 & 0.25 & 49 & 200 \\
\hline 837 & 19 & 8 & 0.25 & 0.25 & 47 & 200 \\
\hline 838 & 21 & 8 & 0.25 & 0.25 & 45 & 200 \\
\hline 839 & 23 & 8 & 0.25 & 0.25 & 44 & 200 \\
\hline 840 & 25 & 8 & 0.25 & 0.25 & 42 & 200 \\
\hline 841 & 17 & 9 & 0.25 & 0.25 & 46 & 200 \\
\hline 842 & 19 & 9 & 0.25 & 0.25 & 44 & 200 \\
\hline 843 & 21 & 9 & 0.25 & 0.25 & 43 & 200 \\
\hline 844 & 23 & 9 & 0.25 & 0.25 & 41 & 200 \\
\hline 845 & 25 & 9 & 0.25 & 0.25 & 39 & 200 \\
\hline 846 & 17 & 10 & 0.25 & 0.25 & 44 & 200 \\
\hline 847 & 19 & 10 & 0.25 & 0.25 & 42 & 200 \\
\hline 848 & 21 & 10 & 0.25 & 0.25 & 41 & 200 \\
\hline 849 & 23 & 10 & 0.25 & 0.25 & 38 & 200 \\
\hline
\end{tabular}




\begin{tabular}{|c|c|c|c|c|c|c|}
\hline 850 & 25 & 10 & 0.25 & 0.25 & 37 & 200 \\
\hline 851 & 17 & 1 & 0.3 & 0.25 & 0 & 0 \\
\hline 852 & 19 & 1 & 0.3 & 0.25 & 0 & 0 \\
\hline 853 & 21 & 1 & 0.3 & 0.25 & 0 & 0 \\
\hline 854 & 23 & 1 & 0.3 & 0.25 & 0 & 0 \\
\hline 855 & 25 & 1 & 0.3 & 0.25 & 7 & 200 \\
\hline 856 & 17 & 2 & 0.3 & 0.25 & 78 & 200 \\
\hline 857 & 19 & 2 & 0.3 & 0.25 & 62 & 200 \\
\hline 858 & 21 & 2 & 0.3 & 0.25 & 51 & 200 \\
\hline 859 & 23 & 2 & 0.3 & 0.25 & 39 & 200 \\
\hline 860 & 25 & 2 & 0.3 & 0.25 & 6 & 200 \\
\hline 861 & 17 & 3 & 0.3 & 0.25 & 53 & 200 \\
\hline 862 & 19 & 3 & 0.3 & 0.25 & 47 & 200 \\
\hline 863 & 21 & 3 & 0.3 & 0.25 & 39 & 200 \\
\hline 864 & 23 & 3 & 0.3 & 0.25 & 32 & 200 \\
\hline 865 & 25 & 3 & 0.3 & 0.25 & 5 & 200 \\
\hline 866 & 17 & 4 & 0.3 & 0.25 & 45 & 200 \\
\hline 867 & 19 & 4 & 0.3 & 0.25 & 40 & 200 \\
\hline 868 & 21 & 4 & 0.3 & 0.25 & 35 & 200 \\
\hline 869 & 23 & 4 & 0.3 & 0.25 & 25 & 200 \\
\hline 870 & 25 & 4 & 0.3 & 0.25 & 5 & 200 \\
\hline 871 & 17 & 5 & 0.3 & 0.25 & 40 & 200 \\
\hline 872 & 19 & 5 & 0.3 & 0.25 & 35 & 200 \\
\hline 873 & 21 & 5 & 0.3 & 0.25 & 32 & 200 \\
\hline 874 & 23 & 5 & 0.3 & 0.25 & 20 & 200 \\
\hline 875 & 25 & 5 & 0.3 & 0.25 & 5 & 200 \\
\hline 876 & 17 & 6 & 0.3 & 0.25 & 36 & 200 \\
\hline 877 & 19 & 6 & 0.3 & 0.25 & 32 & 200 \\
\hline 878 & 21 & 6 & 0.3 & 0.25 & 27 & 200 \\
\hline 879 & 23 & 6 & 0.3 & 0.25 & 19 & 200 \\
\hline 880 & 25 & 6 & 0.3 & 0.25 & 5 & 200 \\
\hline 881 & 17 & 7 & 0.3 & 0.25 & 33 & 200 \\
\hline 882 & 19 & 7 & 0.3 & 0.25 & 30 & 200 \\
\hline 883 & 21 & 7 & 0.3 & 0.25 & 25 & 200 \\
\hline 884 & 23 & 7 & 0.3 & 0.25 & 7 & 200 \\
\hline 885 & 25 & 7 & 0.3 & 0.25 & 5 & 200 \\
\hline 886 & 17 & 8 & 0.3 & 0.25 & 32 & 200 \\
\hline 887 & 19 & 8 & 0.3 & 0.25 & 28 & 200 \\
\hline 888 & 21 & 8 & 0.3 & 0.25 & 22 & 200 \\
\hline 889 & 23 & 8 & 0.3 & 0.25 & 6 & 200 \\
\hline 890 & 25 & 8 & 0.3 & 0.25 & 4 & 200 \\
\hline 891 & 17 & 9 & 0.3 & 0.25 & 30 & 200 \\
\hline 892 & 19 & 9 & 0.3 & 0.25 & 25 & 200 \\
\hline
\end{tabular}




\begin{tabular}{|c|c|c|c|c|c|c|}
\hline 893 & 21 & 9 & 0.3 & 0.25 & 21 & 200 \\
\hline 894 & 23 & 9 & 0.3 & 0.25 & 5 & 200 \\
\hline 895 & 25 & 9 & 0.3 & 0.25 & 4 & 200 \\
\hline 896 & 17 & 10 & 0.3 & 0.25 & 28 & 200 \\
\hline 897 & 19 & 10 & 0.3 & 0.25 & 24 & 200 \\
\hline 898 & 21 & 10 & 0.3 & 0.25 & 19 & 200 \\
\hline 899 & 23 & 10 & 0.3 & 0.25 & 5 & 200 \\
\hline 900 & 25 & 10 & 0.3 & 0.25 & 4 & 200 \\
\hline 901 & 17 & 1 & 0.35 & 0.25 & 0 & 0 \\
\hline 902 & 19 & 1 & 0.35 & 0.25 & 0 & 0 \\
\hline 903 & 21 & 1 & 0.35 & 0.25 & 2 & 200 \\
\hline 904 & 23 & 1 & 0.35 & 0.25 & 2 & 200 \\
\hline 905 & 25 & 1 & 0.35 & 0.25 & 1 & 200 \\
\hline 906 & 17 & 2 & 0.35 & 0.25 & 3 & 200 \\
\hline 907 & 19 & 2 & 0.35 & 0.25 & 3 & 200 \\
\hline 908 & 21 & 2 & 0.35 & 0.25 & 2 & 200 \\
\hline 909 & 23 & 2 & 0.35 & 0.25 & 1 & 200 \\
\hline 910 & 25 & 2 & 0.35 & 0.25 & 1 & 200 \\
\hline 911 & 17 & 3 & 0.35 & 0.25 & 3 & 200 \\
\hline 912 & 19 & 3 & 0.35 & 0.25 & 3 & 200 \\
\hline 913 & 21 & 3 & 0.35 & 0.25 & 2 & 200 \\
\hline 914 & 23 & 3 & 0.35 & 0.25 & 1 & 200 \\
\hline 915 & 25 & 3 & 0.35 & 0.25 & 1 & 200 \\
\hline 916 & 17 & 4 & 0.35 & 0.25 & 3 & 200 \\
\hline 917 & 19 & 4 & 0.35 & 0.25 & 3 & 200 \\
\hline 918 & 21 & 4 & 0.35 & 0.25 & 2 & 200 \\
\hline 919 & 23 & 4 & 0.35 & 0.25 & 1 & 200 \\
\hline 920 & 25 & 4 & 0.35 & 0.25 & 1 & 200 \\
\hline 921 & 17 & 5 & 0.35 & 0.25 & 3 & 200 \\
\hline 922 & 19 & 5 & 0.35 & 0.25 & 3 & 200 \\
\hline 923 & 21 & 5 & 0.35 & 0.25 & 2 & 200 \\
\hline 924 & 23 & 5 & 0.35 & 0.25 & 1 & 200 \\
\hline 925 & 25 & 5 & 0.35 & 0.25 & 1 & 200 \\
\hline 926 & 17 & 6 & 0.35 & 0.25 & 3 & 200 \\
\hline 927 & 19 & 6 & 0.35 & 0.25 & 3 & 200 \\
\hline 928 & 21 & 6 & 0.35 & 0.25 & 2 & 200 \\
\hline 929 & 23 & 6 & 0.35 & 0.25 & 1 & 200 \\
\hline 930 & 25 & 6 & 0.35 & 0.25 & 1 & 200 \\
\hline 931 & 17 & 7 & 0.35 & 0.25 & 3 & 200 \\
\hline 932 & 19 & 7 & 0.35 & 0.25 & 3 & 200 \\
\hline 933 & 21 & 7 & 0.35 & 0.25 & 2 & 200 \\
\hline 934 & 23 & 7 & 0.35 & 0.25 & 1 & 200 \\
\hline 935 & 25 & 7 & 0.35 & 0.25 & 1 & 200 \\
\hline
\end{tabular}




\begin{tabular}{|c|c|c|c|c|c|c|}
\hline 936 & 17 & 8 & 0.35 & 0.25 & 3 & 200 \\
\hline 937 & 19 & 8 & 0.35 & 0.25 & 3 & 200 \\
\hline 938 & 21 & 8 & 0.35 & 0.25 & 2 & 200 \\
\hline 939 & 23 & 8 & 0.35 & 0.25 & 1 & 200 \\
\hline 940 & 25 & 8 & 0.35 & 0.25 & 1 & 200 \\
\hline 941 & 17 & 9 & 0.35 & 0.25 & 3 & 200 \\
\hline 942 & 19 & 9 & 0.35 & 0.25 & 2 & 200 \\
\hline 943 & 21 & 9 & 0.35 & 0.25 & 2 & 200 \\
\hline 944 & 23 & 9 & 0.35 & 0.25 & 1 & 200 \\
\hline 945 & 25 & 9 & 0.35 & 0.25 & 1 & 200 \\
\hline 946 & 17 & 10 & 0.35 & 0.25 & 3 & 200 \\
\hline 947 & 19 & 10 & 0.35 & 0.25 & 2 & 200 \\
\hline 948 & 21 & 10 & 0.35 & 0.25 & 2 & 200 \\
\hline 949 & 23 & 10 & 0.35 & 0.25 & 1 & 200 \\
\hline 950 & 25 & 10 & 0.35 & 0.25 & 1 & 200 \\
\hline 951 & 17 & 1 & 0.4 & 0.25 & 2 & 200 \\
\hline 952 & 19 & 1 & 0.4 & 0.25 & 1 & 200 \\
\hline 953 & 21 & 1 & 0.4 & 0.25 & 1 & 200 \\
\hline 954 & 23 & 1 & 0.4 & 0.25 & 1 & 200 \\
\hline 955 & 25 & 1 & 0.4 & 0.25 & 1 & 200 \\
\hline 956 & 17 & 2 & 0.4 & 0.25 & 2 & 200 \\
\hline 957 & 19 & 2 & 0.4 & 0.25 & 1 & 200 \\
\hline 958 & 21 & 2 & 0.4 & 0.25 & 1 & 200 \\
\hline 959 & 23 & 2 & 0.4 & 0.25 & 1 & 200 \\
\hline 960 & 25 & 2 & 0.4 & 0.25 & 1 & 205 \\
\hline 961 & 17 & 3 & 0.4 & 0.25 & 2 & 200 \\
\hline 962 & 19 & 3 & 0.4 & 0.25 & 1 & 200 \\
\hline 963 & 21 & 3 & 0.4 & 0.25 & 1 & 200 \\
\hline 964 & 23 & 3 & 0.4 & 0.25 & 1 & 200 \\
\hline 965 & 25 & 3 & 0.4 & 0.25 & 1 & 310 \\
\hline 966 & 17 & 4 & 0.4 & 0.25 & 2 & 200 \\
\hline 967 & 19 & 4 & 0.4 & 0.25 & 1 & 200 \\
\hline 968 & 21 & 4 & 0.4 & 0.25 & 1 & 200 \\
\hline 969 & 23 & 4 & 0.4 & 0.25 & 1 & 200 \\
\hline 970 & 25 & 4 & 0.4 & 0.25 & 1 & 415 \\
\hline 971 & 17 & 5 & 0.4 & 0.25 & 2 & 200 \\
\hline 972 & 19 & 5 & 0.4 & 0.25 & 1 & 200 \\
\hline 973 & 21 & 5 & 0.4 & 0.25 & 1 & 200 \\
\hline 974 & 23 & 5 & 0.4 & 0.25 & 1 & 200 \\
\hline 975 & 25 & 5 & 0.4 & 0.25 & 1 & 520 \\
\hline 976 & 17 & 6 & 0.4 & 0.25 & 2 & 200 \\
\hline 977 & 19 & 6 & 0.4 & 0.25 & 1 & 200 \\
\hline 978 & 21 & 6 & 0.4 & 0.25 & 1 & 200 \\
\hline
\end{tabular}




\begin{tabular}{|c|c|c|c|c|c|c|}
\hline 979 & 23 & 6 & 0.4 & 0.25 & 1 & 200 \\
\hline 980 & 25 & 6 & 0.4 & 0.25 & 1 & 625 \\
\hline 981 & 17 & 7 & 0.4 & 0.25 & 2 & 200 \\
\hline 982 & 19 & 7 & 0.4 & 0.25 & 1 & 200 \\
\hline 983 & 21 & 7 & 0.4 & 0.25 & 1 & 200 \\
\hline 984 & 23 & 7 & 0.4 & 0.25 & 1 & 200 \\
\hline 985 & 25 & 7 & 0.4 & 0.25 & 1 & 730 \\
\hline 986 & 17 & 8 & 0.4 & 0.25 & 2 & 200 \\
\hline 987 & 19 & 8 & 0.4 & 0.25 & 1 & 200 \\
\hline 988 & 21 & 8 & 0.4 & 0.25 & 1 & 200 \\
\hline 989 & 23 & 8 & 0.4 & 0.25 & 1 & 200 \\
\hline 990 & 25 & 8 & 0.4 & 0.25 & 1 & 835 \\
\hline 991 & 17 & 9 & 0.4 & 0.25 & 2 & 200 \\
\hline 992 & 19 & 9 & 0.4 & 0.25 & 1 & 200 \\
\hline 993 & 21 & 9 & 0.4 & 0.25 & 1 & 200 \\
\hline 994 & 23 & 9 & 0.4 & 0.25 & 1 & 200 \\
\hline 995 & 25 & 9 & 0.4 & 0.25 & 1 & 940 \\
\hline 996 & 17 & 10 & 0.4 & 0.25 & 2 & 200 \\
\hline 997 & 19 & 10 & 0.4 & 0.25 & 1 & 200 \\
\hline 998 & 21 & 10 & 0.4 & 0.25 & 1 & 200 \\
\hline 999 & 23 & 10 & 0.4 & 0.25 & 1 & 200 \\
\hline 1000 & 25 & 10 & 0.4 & 0.25 & 1 & 1045 \\
\hline 1001 & 17 & 1 & 0.25 & 0.3 & 0 & 0 \\
\hline 1002 & 19 & 1 & 0.25 & 0.3 & 0 & 0 \\
\hline 1003 & 21 & 1 & 0.25 & 0.3 & 0 & 0 \\
\hline 1004 & 23 & 1 & 0.25 & 0.3 & 0 & 0 \\
\hline 1005 & 25 & 1 & 0.25 & 0.3 & 0 & 0 \\
\hline 1006 & 17 & 2 & 0.25 & 0.3 & 200 & 3 \\
\hline 1007 & 19 & 2 & 0.25 & 0.3 & 200 & 4 \\
\hline 1008 & 21 & 2 & 0.25 & 0.3 & 200 & 33 \\
\hline 1009 & 23 & 2 & 0.25 & 0.3 & 200 & 101 \\
\hline 1010 & 25 & 2 & 0.25 & 0.3 & 131 & 200 \\
\hline 1011 & 17 & 3 & 0.25 & 0.3 & 109 & 200 \\
\hline 1012 & 19 & 3 & 0.25 & 0.3 & 97 & 200 \\
\hline 1013 & 21 & 3 & 0.25 & 0.3 & 90 & 200 \\
\hline 1014 & 23 & 3 & 0.25 & 0.3 & 85 & 200 \\
\hline 1015 & 25 & 3 & 0.25 & 0.3 & 70 & 200 \\
\hline 1016 & 17 & 4 & 0.25 & 0.3 & 84 & 200 \\
\hline 1017 & 19 & 4 & 0.25 & 0.3 & 71 & 200 \\
\hline 1018 & 21 & 4 & 0.25 & 0.3 & 65 & 200 \\
\hline 1019 & 23 & 4 & 0.25 & 0.3 & 59 & 200 \\
\hline 1020 & 25 & 4 & 0.25 & 0.3 & 55 & 200 \\
\hline 1021 & 17 & 5 & 0.25 & 0.3 & 63 & 200 \\
\hline
\end{tabular}




\begin{tabular}{|c|c|c|c|c|c|c|}
\hline 1022 & 19 & 5 & 0.25 & 0.3 & 57 & 200 \\
\hline 1023 & 21 & 5 & 0.25 & 0.3 & 54 & 200 \\
\hline 1024 & 23 & 5 & 0.25 & 0.3 & 51 & 200 \\
\hline 1025 & 25 & 5 & 0.25 & 0.3 & 49 & 200 \\
\hline 1026 & 17 & 6 & 0.25 & 0.3 & 53 & 200 \\
\hline 1027 & 19 & 6 & 0.25 & 0.3 & 51 & 200 \\
\hline 1028 & 21 & 6 & 0.25 & 0.3 & 49 & 200 \\
\hline 1029 & 23 & 6 & 0.25 & 0.3 & 46 & 200 \\
\hline 1030 & 25 & 6 & 0.25 & 0.3 & 43 & 200 \\
\hline 1031 & 17 & 7 & 0.25 & 0.3 & 49 & 200 \\
\hline 1032 & 19 & 7 & 0.25 & 0.3 & 47 & 200 \\
\hline 1033 & 21 & 7 & 0.25 & 0.3 & 45 & 200 \\
\hline 1034 & 23 & 7 & 0.25 & 0.3 & 43 & 200 \\
\hline 1035 & 25 & 7 & 0.25 & 0.3 & 39 & 200 \\
\hline 1036 & 17 & 8 & 0.25 & 0.3 & 46 & 200 \\
\hline 1037 & 19 & 8 & 0.25 & 0.3 & 44 & 200 \\
\hline 1038 & 21 & 8 & 0.25 & 0.3 & 42 & 200 \\
\hline 1039 & 23 & 8 & 0.25 & 0.3 & 39 & 200 \\
\hline 1040 & 25 & 8 & 0.25 & 0.3 & 37 & 200 \\
\hline 1041 & 17 & 9 & 0.25 & 0.3 & 43 & 200 \\
\hline 1042 & 19 & 9 & 0.25 & 0.3 & 42 & 200 \\
\hline 1043 & 21 & 9 & 0.25 & 0.3 & 39 & 200 \\
\hline 1044 & 23 & 9 & 0.25 & 0.3 & 37 & 200 \\
\hline 1045 & 25 & 9 & 0.25 & 0.3 & 35 & 200 \\
\hline 1046 & 17 & 10 & 0.25 & 0.3 & 41 & 200 \\
\hline 1047 & 19 & 10 & 0.25 & 0.3 & 39 & 200 \\
\hline 1048 & 21 & 10 & 0.25 & 0.3 & 37 & 200 \\
\hline 1049 & 23 & 10 & 0.25 & 0.3 & 35 & 200 \\
\hline 1050 & 25 & 10 & 0.25 & 0.3 & 33 & 200 \\
\hline 1051 & 17 & 1 & 0.3 & 0.3 & 0 & 0 \\
\hline 1052 & 19 & 1 & 0.3 & 0.3 & 0 & 0 \\
\hline 1053 & 21 & 1 & 0.3 & 0.3 & 0 & 0 \\
\hline 1054 & 23 & 1 & 0.3 & 0.3 & 0 & 0 \\
\hline 1055 & 25 & 1 & 0.3 & 0.3 & 3 & 200 \\
\hline 1056 & 17 & 2 & 0.3 & 0.3 & 49 & 200 \\
\hline 1057 & 19 & 2 & 0.3 & 0.3 & 37 & 200 \\
\hline 1058 & 21 & 2 & 0.3 & 0.3 & 6 & 200 \\
\hline 1059 & 23 & 2 & 0.3 & 0.3 & 4 & 200 \\
\hline 1060 & 25 & 2 & 0.3 & 0.3 & 3 & 200 \\
\hline 1061 & 17 & 3 & 0.3 & 0.3 & 39 & 200 \\
\hline 1062 & 19 & 3 & 0.3 & 0.3 & 30 & 200 \\
\hline 1063 & 21 & 3 & 0.3 & 0.3 & 5 & 200 \\
\hline 1064 & 23 & 3 & 0.3 & 0.3 & 4 & 200 \\
\hline
\end{tabular}




\begin{tabular}{|c|c|c|c|c|c|c|}
\hline 1065 & 25 & 3 & 0.3 & 0.3 & 3 & 200 \\
\hline 1066 & 17 & 4 & 0.3 & 0.3 & 33 & 200 \\
\hline 1067 & 19 & 4 & 0.3 & 0.3 & 27 & 200 \\
\hline 1068 & 21 & 4 & 0.3 & 0.3 & 5 & 200 \\
\hline 1069 & 23 & 4 & 0.3 & 0.3 & 4 & 200 \\
\hline 1070 & 25 & 4 & 0.3 & 0.3 & 3 & 200 \\
\hline 1071 & 17 & 5 & 0.3 & 0.3 & 30 & 200 \\
\hline 1072 & 19 & 5 & 0.3 & 0.3 & 22 & 200 \\
\hline 1073 & 21 & 5 & 0.3 & 0.3 & 5 & 200 \\
\hline 1074 & 23 & 5 & 0.3 & 0.3 & 4 & 200 \\
\hline 1075 & 25 & 5 & 0.3 & 0.3 & 3 & 200 \\
\hline 1076 & 17 & 6 & 0.3 & 0.3 & 27 & 200 \\
\hline 1077 & 19 & 6 & 0.3 & 0.3 & 18 & 200 \\
\hline 1078 & 21 & 6 & 0.3 & 0.3 & 4 & 200 \\
\hline 1079 & 23 & 6 & 0.3 & 0.3 & 4 & 200 \\
\hline 1080 & 25 & 6 & 0.3 & 0.3 & 3 & 200 \\
\hline 1081 & 17 & 7 & 0.3 & 0.3 & 25 & 200 \\
\hline 1082 & 19 & 7 & 0.3 & 0.3 & 15 & 200 \\
\hline 1083 & 21 & 7 & 0.3 & 0.3 & 4 & 200 \\
\hline 1084 & 23 & 7 & 0.3 & 0.3 & 3 & 200 \\
\hline 1085 & 25 & 7 & 0.3 & 0.3 & 3 & 200 \\
\hline 1086 & 17 & 8 & 0.3 & 0.3 & 23 & 200 \\
\hline 1087 & 19 & 8 & 0.3 & 0.3 & 7 & 200 \\
\hline 1088 & 21 & 8 & 0.3 & 0.3 & 4 & 200 \\
\hline 1089 & 23 & 8 & 0.3 & 0.3 & 3 & 200 \\
\hline 1090 & 25 & 8 & 0.3 & 0.3 & 3 & 200 \\
\hline 1091 & 17 & 9 & 0.3 & 0.3 & 22 & 200 \\
\hline 1092 & 19 & 9 & 0.3 & 0.3 & 6 & 200 \\
\hline 1093 & 21 & 9 & 0.3 & 0.3 & 4 & 200 \\
\hline 1094 & 23 & 9 & 0.3 & 0.3 & 3 & 200 \\
\hline 1095 & 25 & 9 & 0.3 & 0.3 & 3 & 200 \\
\hline 1096 & 17 & 10 & 0.3 & 0.3 & 20 & 200 \\
\hline 1097 & 19 & 10 & 0.3 & 0.3 & 5 & 200 \\
\hline 1098 & 21 & 10 & 0.3 & 0.3 & 4 & 200 \\
\hline 1099 & 23 & 10 & 0.3 & 0.3 & 3 & 200 \\
\hline 1100 & 25 & 10 & 0.3 & 0.3 & 3 & 200 \\
\hline 1101 & 17 & 1 & 0.35 & 0.3 & 0 & 0 \\
\hline 1102 & 19 & 1 & 0.35 & 0.3 & 0 & 0 \\
\hline 1103 & 21 & 1 & 0.35 & 0.3 & 2 & 200 \\
\hline 1104 & 23 & 1 & 0.35 & 0.3 & 1 & 200 \\
\hline 1105 & 25 & 1 & 0.35 & 0.3 & 1 & 200 \\
\hline 1106 & 17 & 2 & 0.35 & 0.3 & 3 & 200 \\
\hline 1107 & 19 & 2 & 0.35 & 0.3 & 2 & 200 \\
\hline & & & & & & \\
\hline
\end{tabular}




\begin{tabular}{|c|c|c|c|c|c|c|}
\hline 1108 & 21 & 2 & 0.35 & 0.3 & 2 & 200 \\
\hline 1109 & 23 & 2 & 0.35 & 0.3 & 1 & 200 \\
\hline 1110 & 25 & 2 & 0.35 & 0.3 & 1 & 200 \\
\hline 1111 & 17 & 3 & 0.35 & 0.3 & 2 & 200 \\
\hline 1112 & 19 & 3 & 0.35 & 0.3 & 2 & 200 \\
\hline 1113 & 21 & 3 & 0.35 & 0.3 & 2 & 200 \\
\hline 1114 & 23 & 3 & 0.35 & 0.3 & 1 & 200 \\
\hline 1115 & 25 & 3 & 0.35 & 0.3 & 1 & 200 \\
\hline 1116 & 17 & 4 & 0.35 & 0.3 & 2 & 200 \\
\hline 1117 & 19 & 4 & 0.35 & 0.3 & 2 & 200 \\
\hline 1118 & 21 & 4 & 0.35 & 0.3 & 2 & 200 \\
\hline 1119 & 23 & 4 & 0.35 & 0.3 & 1 & 200 \\
\hline 1120 & 25 & 4 & 0.35 & 0.3 & 1 & 200 \\
\hline 1121 & 17 & 5 & 0.35 & 0.3 & 2 & 200 \\
\hline 1122 & 19 & 5 & 0.35 & 0.3 & 2 & 200 \\
\hline 1123 & 21 & 5 & 0.35 & 0.3 & 2 & 200 \\
\hline 1124 & 23 & 5 & 0.35 & 0.3 & 1 & 200 \\
\hline 1125 & 25 & 5 & 0.35 & 0.3 & 1 & 200 \\
\hline 1126 & 17 & 6 & 0.35 & 0.3 & 2 & 200 \\
\hline 1127 & 19 & 6 & 0.35 & 0.3 & 2 & 200 \\
\hline 1128 & 21 & 6 & 0.35 & 0.3 & 2 & 200 \\
\hline 1129 & 23 & 6 & 0.35 & 0.3 & 1 & 200 \\
\hline 1130 & 25 & 6 & 0.35 & 0.3 & 1 & 200 \\
\hline 1131 & 17 & 7 & 0.35 & 0.3 & 2 & 200 \\
\hline 1132 & 19 & 7 & 0.35 & 0.3 & 2 & 200 \\
\hline 1133 & 21 & 7 & 0.35 & 0.3 & 2 & 200 \\
\hline 1134 & 23 & 7 & 0.35 & 0.3 & 1 & 200 \\
\hline 1135 & 25 & 7 & 0.35 & 0.3 & 1 & 200 \\
\hline 1136 & 17 & 8 & 0.35 & 0.3 & 2 & 200 \\
\hline 1137 & 19 & 8 & 0.35 & 0.3 & 2 & 200 \\
\hline 1138 & 21 & 8 & 0.35 & 0.3 & 2 & 200 \\
\hline 1139 & 23 & 8 & 0.35 & 0.3 & 1 & 200 \\
\hline 1140 & 25 & 8 & 0.35 & 0.3 & 1 & 200 \\
\hline 1141 & 17 & 9 & 0.35 & 0.3 & 2 & 200 \\
\hline 1142 & 19 & 9 & 0.35 & 0.3 & 2 & 200 \\
\hline 1143 & 21 & 9 & 0.35 & 0.3 & 1 & 200 \\
\hline 1144 & 23 & 9 & 0.35 & 0.3 & 1 & 200 \\
\hline 1145 & 25 & 9 & 0.35 & 0.3 & 1 & 200 \\
\hline 1146 & 17 & 10 & 0.35 & 0.3 & 2 & 200 \\
\hline 1147 & 19 & 10 & 0.35 & 0.3 & 2 & 200 \\
\hline 1148 & 21 & 10 & 0.35 & 0.3 & 1 & 200 \\
\hline 1149 & 23 & 10 & 0.35 & 0.3 & 1 & 200 \\
\hline 1150 & 25 & 10 & 0.35 & 0.3 & 1 & 200 \\
\hline
\end{tabular}




\begin{tabular}{|l|l|l|l|l|l|l|}
\hline 1151 & 17 & 1 & 0.4 & 0.3 & 2 & 200 \\
\hline 1152 & 19 & 1 & 0.4 & 0.3 & 1 & 200 \\
\hline 1153 & 21 & 1 & 0.4 & 0.3 & 1 & 200 \\
\hline 1154 & 23 & 1 & 0.4 & 0.3 & 1 & 200 \\
\hline 1155 & 25 & 1 & 0.4 & 0.3 & 1 & 200 \\
\hline 1156 & 17 & 2 & 0.4 & 0.3 & 2 & 200 \\
\hline 1157 & 19 & 2 & 0.4 & 0.3 & 1 & 200 \\
\hline 1158 & 21 & 2 & 0.4 & 0.3 & 1 & 200 \\
\hline 1159 & 23 & 2 & 0.4 & 0.3 & 1 & 200 \\
\hline 1160 & 25 & 2 & 0.4 & 0.3 & 1 & 205 \\
\hline 1161 & 17 & 3 & 0.4 & 0.3 & 2 & 200 \\
\hline 1162 & 19 & 3 & 0.4 & 0.3 & 1 & 200 \\
\hline 1163 & 21 & 3 & 0.4 & 0.3 & 1 & 200 \\
\hline 1164 & 23 & 3 & 0.4 & 0.3 & 1 & 200 \\
\hline 1165 & 25 & 3 & 0.4 & 0.3 & 1 & 310 \\
\hline 1166 & 17 & 4 & 0.4 & 0.3 & 2 & 200 \\
\hline 1167 & 19 & 4 & 0.4 & 0.3 & 1 & 200 \\
\hline 1168 & 21 & 4 & 0.4 & 0.3 & 1 & 200 \\
\hline 1169 & 23 & 4 & 0.4 & 0.3 & 1 & 200 \\
\hline 1170 & 25 & 4 & 0.4 & 0.3 & 1 & 415 \\
\hline 1171 & 17 & 5 & 0.4 & 0.3 & 2 & 200 \\
\hline 1172 & 19 & 5 & 0.4 & 0.3 & 1 & 200 \\
\hline 1173 & 21 & 5 & 0.4 & 0.3 & 1 & 200 \\
\hline 1174 & 23 & 5 & 0.4 & 0.3 & 1 & 200 \\
\hline 1175 & 25 & 5 & 0.4 & 0.3 & 1 & 520 \\
\hline 1176 & 17 & 6 & 0.4 & 0.3 & 1 & 200 \\
\hline 1177 & 19 & 6 & 0.4 & 0.3 & 1 & 200 \\
\hline 1178 & 21 & 6 & 0.4 & 0.3 & 1 & 200 \\
\hline 1179 & 23 & 6 & 0.4 & 0.3 & 1 & 200 \\
\hline 1180 & 25 & 6 & 0.4 & 0.3 & 1 & 625 \\
\hline 1181 & 17 & 7 & 0.4 & 0.3 & 1 & 200 \\
\hline 1182 & 19 & 7 & 0.4 & 0.3 & 1 & 200 \\
\hline 1183 & 21 & 7 & 0.4 & 0.3 & 1 & 200 \\
\hline 1184 & 23 & 7 & 0.4 & 0.3 & 1 & 200 \\
\hline 1185 & 25 & 7 & 0.4 & 0.3 & 1 & 730 \\
\hline 1186 & 17 & 8 & 0.4 & 0.3 & 1 & 200 \\
\hline 1187 & 19 & 8 & 0.4 & 0.3 & 1 & 200 \\
\hline 1188 & 21 & 8 & 0.4 & 0.3 & 1 & 200 \\
\hline 1189 & 23 & 8 & 0.4 & 0.3 & 1 & 200 \\
\hline 1190 & 25 & 8 & 0.4 & 0.3 & 1 & 835 \\
\hline 1191 & 17 & 9 & 0.4 & 0.3 & 1 & 200 \\
\hline 1192 & 19 & 9 & 0.4 & 0.3 & 1 & 200 \\
\hline 1193 & 21 & 9 & 0.4 & 0.3 & 1 & 200 \\
\hline & & & & & & \\
\hline
\end{tabular}




\begin{tabular}{|c|c|c|c|c|c|c|}
\hline 1194 & 23 & 9 & \begin{tabular}{ll|}
0.4 \\
\end{tabular} & 0.3 & 1 & 200 \\
\hline 1195 & 25 & 9 & 0.4 & 0.3 & 1 & 940 \\
\hline 1196 & 17 & 10 & 0.4 & 0.3 & 1 & 200 \\
\hline 1197 & 19 & 10 & 0.4 & 0.3 & 1 & 200 \\
\hline 1198 & 21 & 10 & 0.4 & 0.3 & 1 & 200 \\
\hline 1199 & 23 & 10 & 0.4 & 0.3 & 1 & 200 \\
\hline 1200 & 25 & 10 & 0.4 & 0.3 & 1 & 1045 \\
\hline 1201 & 17 & 1 & 0.25 & 0.35 & 0 & 0 \\
\hline 1202 & 19 & 1 & 0.25 & 0.35 & 0 & 0 \\
\hline 1203 & 21 & 1 & 0.25 & 0.35 & 0 & 0 \\
\hline 1204 & 23 & 1 & 0.25 & 0.35 & 0 & 0 \\
\hline 1205 & 25 & 1 & 0.25 & 0.35 & 0 & 0 \\
\hline 1206 & 17 & 2 & 0.25 & 0.35 & 200 & 5 \\
\hline 1207 & 19 & 2 & 0.25 & 0.35 & 200 & 67 \\
\hline 1208 & 21 & 2 & 0.25 & 0.35 & 138 & 200 \\
\hline 1209 & 23 & 2 & 0.25 & 0.35 & 98 & 200 \\
\hline 1210 & 25 & 2 & 0.25 & 0.35 & 80 & 200 \\
\hline 1211 & 17 & 3 & 0.25 & 0.35 & 92 & 200 \\
\hline 1212 & 19 & 3 & 0.25 & 0.35 & 87 & 200 \\
\hline 1213 & 21 & 3 & 0.25 & 0.35 & 70 & 200 \\
\hline 1214 & 23 & 3 & 0.25 & 0.35 & 61 & 200 \\
\hline 1215 & 25 & 3 & 0.25 & 0.35 & 54 & 200 \\
\hline 1216 & 17 & 4 & 0.25 & 0.35 & 66 & 200 \\
\hline 1217 & 19 & 4 & 0.25 & 0.35 & 59 & 200 \\
\hline 1218 & 21 & 4 & 0.25 & 0.35 & 54 & 200 \\
\hline 1219 & 23 & 4 & 0.25 & 0.35 & 50 & 200 \\
\hline 1220 & 25 & 4 & 0.25 & 0.35 & 46 & 200 \\
\hline 1221 & 17 & 5 & 0.25 & 0.35 & 54 & 200 \\
\hline 1222 & 19 & 5 & 0.25 & 0.35 & 51 & 200 \\
\hline 1223 & 21 & 5 & 0.25 & 0.35 & 48 & 200 \\
\hline 1224 & 23 & 5 & 0.25 & 0.35 & 44 & 200 \\
\hline 1225 & 25 & 5 & 0.25 & 0.35 & 40 & 200 \\
\hline 1226 & 17 & 6 & 0.25 & 0.35 & 49 & 200 \\
\hline 1227 & 19 & 6 & 0.25 & 0.35 & 46 & 200 \\
\hline 1228 & 21 & 6 & 0.25 & 0.35 & 44 & 200 \\
\hline 1229 & 23 & 6 & 0.25 & 0.35 & 40 & 200 \\
\hline 1230 & 25 & 6 & 0.25 & 0.35 & 36 & 200 \\
\hline 1231 & 17 & 7 & 0.25 & 0.35 & 45 & 200 \\
\hline 1232 & 19 & 7 & 0.25 & 0.35 & 43 & 200 \\
\hline 1233 & 21 & 7 & 0.25 & 0.35 & 40 & 200 \\
\hline 1234 & 23 & 7 & 0.25 & 0.35 & 37 & 200 \\
\hline 1235 & 25 & 7 & 0.25 & 0.35 & 33 & 200 \\
\hline 1236 & 17 & 8 & 0.25 & 0.35 & 43 & 200 \\
\hline
\end{tabular}




\begin{tabular}{|c|c|c|c|c|c|c|}
\hline 1237 & 19 & 8 & 0.25 & 0.35 & 40 & 200 \\
\hline 1238 & 21 & 8 & 0.25 & 0.35 & 37 & 200 \\
\hline 1239 & 23 & 8 & 0.25 & 0.35 & 34 & 200 \\
\hline 1240 & 25 & 8 & 0.25 & 0.35 & 31 & 200 \\
\hline 1241 & 17 & 9 & 0.25 & 0.35 & 40 & 200 \\
\hline 1242 & 19 & 9 & 0.25 & 0.35 & 37 & 200 \\
\hline 1243 & 21 & 9 & 0.25 & 0.35 & 35 & 200 \\
\hline 1244 & 23 & 9 & 0.25 & 0.35 & 33 & 200 \\
\hline 1245 & 25 & 9 & 0.25 & 0.35 & 30 & 200 \\
\hline 1246 & 17 & 10 & 0.25 & 0.35 & 38 & 200 \\
\hline 1247 & 19 & 10 & 0.25 & 0.35 & 36 & 200 \\
\hline 1248 & 21 & 10 & 0.25 & 0.35 & 33 & 200 \\
\hline 1249 & 23 & 10 & 0.25 & 0.35 & 30 & 200 \\
\hline 1250 & 25 & 10 & 0.25 & 0.35 & 28 & 200 \\
\hline 1251 & 17 & 1 & 0.3 & 0.35 & 0 & 0 \\
\hline 1252 & 19 & 1 & 0.3 & 0.35 & 0 & 0 \\
\hline 1253 & 21 & 1 & 0.3 & 0.35 & 0 & 0 \\
\hline 1254 & 23 & 1 & 0.3 & 0.35 & 0 & 0 \\
\hline 1255 & 25 & 1 & 0.3 & 0.35 & 2 & 200 \\
\hline 1256 & 17 & 2 & 0.3 & 0.35 & 20 & 200 \\
\hline 1257 & 19 & 2 & 0.3 & 0.35 & 4 & 200 \\
\hline 1258 & 21 & 2 & 0.3 & 0.35 & 3 & 200 \\
\hline 1259 & 23 & 2 & 0.3 & 0.35 & 3 & 200 \\
\hline 1260 & 25 & 2 & 0.3 & 0.35 & 2 & 200 \\
\hline 1261 & 17 & 3 & 0.3 & 0.35 & 8 & 200 \\
\hline 1262 & 19 & 3 & 0.3 & 0.35 & 4 & 200 \\
\hline 1263 & 21 & 3 & 0.3 & 0.35 & 3 & 200 \\
\hline 1264 & 23 & 3 & 0.3 & 0.35 & 3 & 200 \\
\hline 1265 & 25 & 3 & 0.3 & 0.35 & 2 & 200 \\
\hline 1266 & 17 & 4 & 0.3 & 0.35 & 6 & 200 \\
\hline 1267 & 19 & 4 & 0.3 & 0.35 & 4 & 200 \\
\hline 1268 & 21 & 4 & 0.3 & 0.35 & 3 & 200 \\
\hline 1269 & 23 & 4 & 0.3 & 0.35 & 3 & 200 \\
\hline 1270 & 25 & 4 & 0.3 & 0.35 & 2 & 200 \\
\hline 1271 & 17 & 5 & 0.3 & 0.35 & 5 & 200 \\
\hline 1272 & 19 & 5 & 0.3 & 0.35 & 4 & 200 \\
\hline 1273 & 21 & 5 & 0.3 & 0.35 & 3 & 200 \\
\hline 1274 & 23 & 5 & 0.3 & 0.35 & 3 & 200 \\
\hline 1275 & 25 & 5 & 0.3 & 0.35 & 2 & 200 \\
\hline 1276 & 17 & 6 & 0.3 & 0.35 & 5 & 200 \\
\hline 1277 & 19 & 6 & 0.3 & 0.35 & 4 & 200 \\
\hline 1278 & 21 & 6 & 0.3 & 0.35 & 3 & 200 \\
\hline 1279 & 23 & 6 & 0.3 & 0.35 & 3 & 200 \\
\hline & & & & & & \\
\hline
\end{tabular}




\begin{tabular}{|c|c|c|c|c|c|c|}
\hline 1280 & 25 & 6 & 0.3 & 0.35 & 2 & 200 \\
\hline 1281 & 17 & 7 & 0.3 & 0.35 & 4 & 200 \\
\hline 1282 & 19 & 7 & 0.3 & 0.35 & 3 & 200 \\
\hline 1283 & 21 & 7 & 0.3 & 0.35 & 3 & 200 \\
\hline 1284 & 23 & 7 & 0.3 & 0.35 & 2 & 200 \\
\hline 1285 & 25 & 7 & 0.3 & 0.35 & 2 & 200 \\
\hline 1286 & 17 & 8 & 0.3 & 0.35 & 4 & 200 \\
\hline 1287 & 19 & 8 & 0.3 & 0.35 & 3 & 200 \\
\hline 1288 & 21 & 8 & 0.3 & 0.35 & 3 & 200 \\
\hline 1289 & 23 & 8 & 0.3 & 0.35 & 2 & 200 \\
\hline 1290 & 25 & 8 & 0.3 & 0.35 & 1 & 200 \\
\hline 1291 & 17 & 9 & 0.3 & 0.35 & 4 & 200 \\
\hline 1292 & 19 & 9 & 0.3 & 0.35 & 3 & 200 \\
\hline 1293 & 21 & 9 & 0.3 & 0.35 & 3 & 200 \\
\hline 1294 & 23 & 9 & 0.3 & 0.35 & 2 & 200 \\
\hline 1295 & 25 & 9 & 0.3 & 0.35 & 1 & 200 \\
\hline 1296 & 17 & 10 & 0.3 & 0.35 & 4 & 200 \\
\hline 1297 & 19 & 10 & 0.3 & 0.35 & 3 & 200 \\
\hline 1298 & 21 & 10 & 0.3 & 0.35 & 3 & 200 \\
\hline 1299 & 23 & 10 & 0.3 & 0.35 & 2 & 200 \\
\hline 1300 & 25 & 10 & 0.3 & 0.35 & 1 & 200 \\
\hline 1301 & 17 & 1 & 0.35 & 0.35 & 0 & 0 \\
\hline 1302 & 19 & 1 & 0.35 & 0.35 & 0 & 0 \\
\hline 1303 & 21 & 1 & 0.35 & 0.35 & 2 & 200 \\
\hline 1304 & 23 & 1 & 0.35 & 0.35 & 1 & 200 \\
\hline 1305 & 25 & 1 & 0.35 & 0.35 & 1 & 200 \\
\hline 1306 & 17 & 2 & 0.35 & 0.35 & 2 & 200 \\
\hline 1307 & 19 & 2 & 0.35 & 0.35 & 2 & 200 \\
\hline 1308 & 21 & 2 & 0.35 & 0.35 & 1 & 200 \\
\hline 1309 & 23 & 2 & 0.35 & 0.35 & 1 & 200 \\
\hline 1310 & 25 & 2 & 0.35 & 0.35 & 1 & 200 \\
\hline 1311 & 17 & 3 & 0.35 & 0.35 & 2 & 200 \\
\hline 1312 & 19 & 3 & 0.35 & 0.35 & 2 & 200 \\
\hline 1313 & 21 & 3 & 0.35 & 0.35 & 1 & 200 \\
\hline 1314 & 23 & 3 & 0.35 & 0.35 & 1 & 200 \\
\hline 1315 & 25 & 3 & 0.35 & 0.35 & 1 & 200 \\
\hline 1316 & 17 & 4 & 0.35 & 0.35 & 2 & 200 \\
\hline 1317 & 19 & 4 & 0.35 & 0.35 & 2 & 200 \\
\hline 1318 & 21 & 4 & 0.35 & 0.35 & 1 & 200 \\
\hline 1319 & 23 & 4 & 0.35 & 0.35 & 1 & 200 \\
\hline 1320 & 25 & 4 & 0.35 & 0.35 & 1 & 200 \\
\hline 1321 & 17 & 5 & 0.35 & 0.35 & 2 & 200 \\
\hline 1322 & 19 & 5 & 0.35 & 0.35 & 2 & 200 \\
\hline
\end{tabular}




\begin{tabular}{|c|c|c|c|c|c|c|}
\hline 1323 & 21 & 5 & 0.35 & 0.35 & 1 & 200 \\
\hline 1324 & 23 & 5 & 0.35 & 0.35 & 1 & 200 \\
\hline 1325 & 25 & 5 & 0.35 & 0.35 & 1 & 200 \\
\hline 1326 & 17 & 6 & 0.35 & 0.35 & 2 & 200 \\
\hline 1327 & 19 & 6 & 0.35 & 0.35 & 2 & 200 \\
\hline 1328 & 21 & 6 & 0.35 & 0.35 & 1 & 200 \\
\hline 1329 & 23 & 6 & 0.35 & 0.35 & 1 & 200 \\
\hline 1330 & 25 & 6 & 0.35 & 0.35 & 1 & 200 \\
\hline 1331 & 17 & 7 & 0.35 & 0.35 & 2 & 200 \\
\hline 1332 & 19 & 7 & 0.35 & 0.35 & 2 & 200 \\
\hline 1333 & 21 & 7 & 0.35 & 0.35 & 1 & 200 \\
\hline 1334 & 23 & 7 & 0.35 & 0.35 & 1 & 200 \\
\hline 1335 & 25 & 7 & 0.35 & 0.35 & 1 & 200 \\
\hline 1336 & 17 & 8 & 0.35 & 0.35 & 2 & 200 \\
\hline 1337 & 19 & 8 & 0.35 & 0.35 & 2 & 200 \\
\hline 1338 & 21 & 8 & 0.35 & 0.35 & 1 & 200 \\
\hline 1339 & 23 & 8 & 0.35 & 0.35 & 1 & 200 \\
\hline 1340 & 25 & 8 & 0.35 & 0.35 & 1 & 200 \\
\hline 1341 & 17 & 9 & 0.35 & 0.35 & 2 & 200 \\
\hline 1342 & 19 & 9 & 0.35 & 0.35 & 2 & 200 \\
\hline 1343 & 21 & 9 & 0.35 & 0.35 & 1 & 200 \\
\hline 1344 & 23 & 9 & 0.35 & 0.35 & 1 & 200 \\
\hline 1345 & 25 & 9 & 0.35 & 0.35 & 1 & 200 \\
\hline 1346 & 17 & 10 & 0.35 & 0.35 & 2 & 200 \\
\hline 1347 & 19 & 10 & 0.35 & 0.35 & 2 & 200 \\
\hline 1348 & 21 & 10 & 0.35 & 0.35 & 1 & 200 \\
\hline 1349 & 23 & 10 & 0.35 & 0.35 & 1 & 200 \\
\hline 1350 & 25 & 10 & 0.35 & 0.35 & 1 & 200 \\
\hline 1351 & 17 & 1 & 0.4 & 0.35 & 1 & 200 \\
\hline 1352 & 19 & 1 & 0.4 & 0.35 & 1 & 200 \\
\hline 1353 & 21 & 1 & 0.4 & 0.35 & 1 & 200 \\
\hline 1354 & 23 & 1 & 0.4 & 0.35 & 1 & 200 \\
\hline 1355 & 25 & 1 & 0.4 & 0.35 & 1 & 200 \\
\hline 1356 & 17 & 2 & 0.4 & 0.35 & 1 & 200 \\
\hline 1357 & 19 & 2 & 0.4 & 0.35 & 1 & 200 \\
\hline 1358 & 21 & 2 & 0.4 & 0.35 & 1 & 200 \\
\hline 1359 & 23 & 2 & 0.4 & 0.35 & 1 & 200 \\
\hline 1360 & 25 & 2 & 0.4 & 0.35 & 1 & 205 \\
\hline 1361 & 17 & 3 & 0.4 & 0.35 & 1 & 200 \\
\hline 1362 & 19 & 3 & 0.4 & 0.35 & 1 & 200 \\
\hline 1363 & 21 & 3 & 0.4 & 0.35 & 1 & 200 \\
\hline 1364 & 23 & 3 & 0.4 & 0.35 & 1 & 200 \\
\hline 1365 & 25 & 3 & 0.4 & 0.35 & 1 & 310 \\
\hline
\end{tabular}




\begin{tabular}{|l|l|l|l|l|l|l|}
\hline 1366 & 17 & 4 & 0.4 & 0.35 & 1 & 200 \\
\hline 1367 & 19 & 4 & 0.4 & 0.35 & 1 & 200 \\
\hline 1368 & 21 & 4 & 0.4 & 0.35 & 1 & 200 \\
\hline 1369 & 23 & 4 & 0.4 & 0.35 & 1 & 200 \\
\hline 1370 & 25 & 4 & 0.4 & 0.35 & 1 & 415 \\
\hline 1371 & 17 & 5 & 0.4 & 0.35 & 1 & 200 \\
\hline 1372 & 19 & 5 & 0.4 & 0.35 & 1 & 200 \\
\hline 1373 & 21 & 5 & 0.4 & 0.35 & 1 & 200 \\
\hline 1374 & 23 & 5 & 0.4 & 0.35 & 1 & 200 \\
\hline 1375 & 25 & 5 & 0.4 & 0.35 & 1 & 520 \\
\hline 1376 & 17 & 6 & 0.4 & 0.35 & 1 & 200 \\
\hline 1377 & 19 & 6 & 0.4 & 0.35 & 1 & 200 \\
\hline 1378 & 21 & 6 & 0.4 & 0.35 & 1 & 200 \\
\hline 1379 & 23 & 6 & 0.4 & 0.35 & 1 & 200 \\
\hline 1380 & 25 & 6 & 0.4 & 0.35 & 1 & 625 \\
\hline 1381 & 17 & 7 & 0.4 & 0.35 & 1 & 200 \\
\hline 1382 & 19 & 7 & 0.4 & 0.35 & 1 & 200 \\
\hline 1383 & 21 & 7 & 0.4 & 0.35 & 1 & 200 \\
\hline 1384 & 23 & 7 & 0.4 & 0.35 & 1 & 200 \\
\hline 1385 & 25 & 7 & 0.4 & 0.35 & 1 & 730 \\
\hline 1386 & 17 & 8 & 0.4 & 0.35 & 1 & 200 \\
\hline 1387 & 19 & 8 & 0.4 & 0.35 & 1 & 200 \\
\hline 1388 & 21 & 8 & 0.4 & 0.35 & 1 & 200 \\
\hline 1389 & 23 & 8 & 0.4 & 0.35 & 1 & 200 \\
\hline 1390 & 25 & 8 & 0.4 & 0.35 & 1 & 835 \\
\hline 1391 & 17 & 9 & 0.4 & 0.35 & 1 & 200 \\
\hline 1392 & 19 & 9 & 0.4 & 0.35 & 1 & 200 \\
\hline 1393 & 21 & 9 & 0.4 & 0.35 & 1 & 200 \\
\hline 1394 & 23 & 9 & 0.4 & 0.35 & 1 & 200 \\
\hline 1395 & 25 & 9 & 0.4 & 0.35 & 1 & 940 \\
\hline 1396 & 17 & 10 & 0.4 & 0.35 & 1 & 200 \\
\hline 1397 & 19 & 10 & 0.4 & 0.35 & 1 & 200 \\
\hline 1398 & 21 & 10 & 0.4 & 0.35 & 1 & 200 \\
\hline 1399 & 23 & 10 & 0.4 & 0.35 & 1 & 200 \\
\hline 1400 & 25 & 10 & 0.4 & 0.35 & 1 & 1045 \\
\hline & & & & & & \\
\hline
\end{tabular}

